University of Tennessee Health Science Center

UTHSC Digital Commons

\title{
Skeletal and Dental Components of Class II Division 1 Correction with the MARA Compared to the Standard Edgewise Appliance
}

Zachary Paul Pitcher

University of Tennessee Health Science Center

Follow this and additional works at: https://dc.uthsc.edu/dissertations

Part of the Orthodontics and Orthodontology Commons

\section{Recommended Citation}

Pitcher, Zachary Paul , "Skeletal and Dental Components of Class II Division 1 Correction with the MARA Compared to the Standard Edgewise Appliance" (2012). Theses and Dissertations (ETD). Paper 199. http://dx.doi.org/10.21007/etd.cghs.2012.0246. 


\title{
Skeletal and Dental Components of Class II Division 1 Correction with the MARA Compared to the Standard Edgewise Appliance
}

\begin{abstract}
Many tools are available to correct Class II dental relationships. A functional orthopedic appliance is a popular type of Class II corrector that is thought to correct Class II dental relationships both dentally and skeletally by enhancing mandibular growth. The purpose of the study was to quantify differences in the amounts of skeletodental change based on treatment (MARA and Standard Edgewise) in Class II Division 1 patients. The sample consisted of 2 groups of Class II Division 1 patients: 51 patients treated with the MARA followed by an Edgewise appliance and another group of 51 patients treated with the Standard Edgewise appliance. Cephaloprams were measured at the start and end of active treatment. Johnston's Pitchfork analysis was used to compare the two treatment groups.
\end{abstract}

\section{Document Type}

Thesis

\section{Degree Name}

Master of Dental Science (MDS)

\section{Research Advisor}

Edward F. Harris, Ph.D.

\section{Keywords}

MARA

\section{Subject Categories}

Dentistry | Medicine and Health Sciences | Orthodontics and Orthodontology 


\title{
SKELETAL AND DENTAL COMPONENTS OF CLASS II DIVISION 1 CORRECTION WITH THE MARA COMPARED TO THE STANDARD EDGEWISE APPLIANCE
}

\author{
A Thesis \\ Presented for \\ The Graduate Studies Council \\ The University of Tennessee \\ Health Science Center
}

\author{
In Partial Fulfillment \\ Of the Requirements for the Degree \\ Master of Dental Science \\ From The University of Tennessee
}

By

Zachary Paul Pitcher, D.M.D.

May 2012 
Copyright (C 2012 by Zachary Paul Pitcher. All rights reserved. 


\section{ACKNOWLEDGEMENTS}

Because of his guiding hand in my thesis completion, I owe a great deal of gratitude and thanks to Dr. Edward Harris. He was integral in my academic advancement and training while at the University of Tennessee. I also want to express appreciation to the support and insights I gained from my committee members, Dr. Joseph Wasson and Dr. Jere Yates.

Finally, I could not be at this point in my life without my kind and loving wife Melanie. Thank you for your continued support during my academic pursuits. Some day this will all be worth it! 


\begin{abstract}
Many tools are available to correct Class II dental relationships. A functional orthopedic appliance is a popular type of Class II corrector that is thought to correct Class II dental relationships both dentally and skeletally by enhancing mandibular growth. The purpose of the study was to quantify differences in the amounts of skeletodental change based on treatment (MARA and Standard Edgewise) in Class II Division 1 patients. The sample consisted of two groups of Class II Division 1 patients: 51 patients treated with the MARA, followed by an Edgewise appliance and another group of 51 patients treated with the Standard Edgewise appliance. Cephalograms were measured at the start and end of active treatment. Johnston's Pitchfork analysis was used to compare the two treatment groups.
\end{abstract}


CHAPTER 1. INTRODUCTION AND RATIONALE ............................................1

CHAPTER 2. REVIEW OF THE LITERATURE ...........................................................

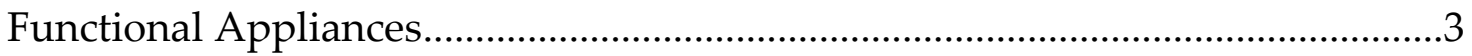

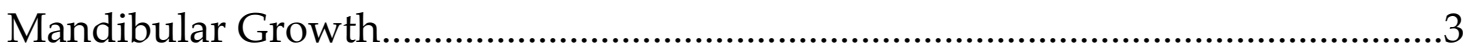

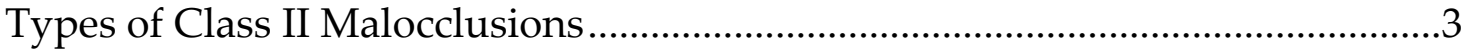

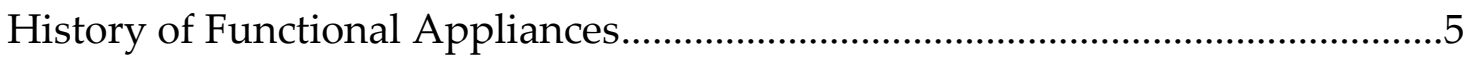

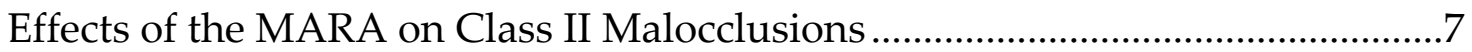

Effects of the MARA on the Lower Anterior Teeth ................................................

Outcome of Functional Appliances ..................................................................10

CHAPTER 3. MATERIALS AND METHODS ...........................................................12

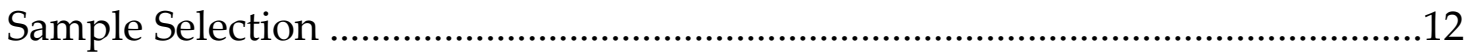

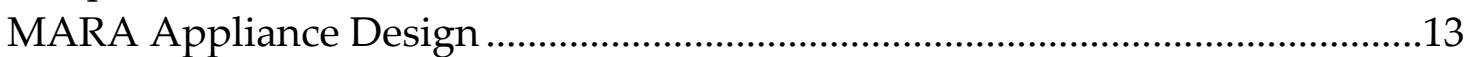

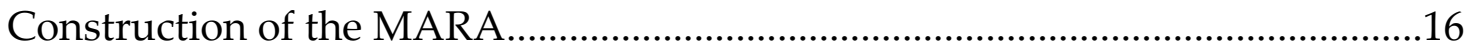

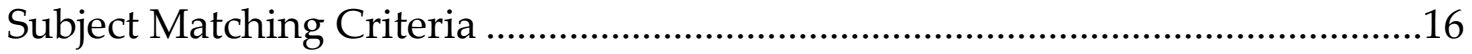

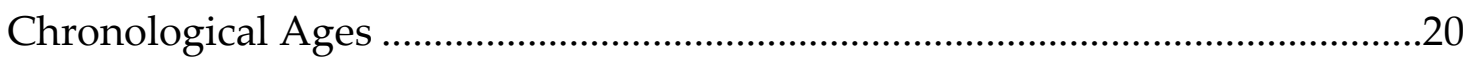

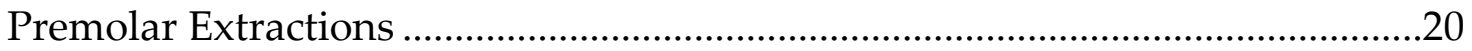

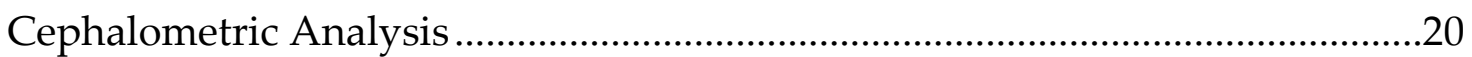

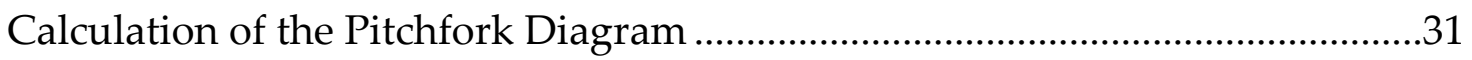

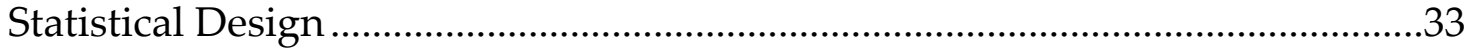

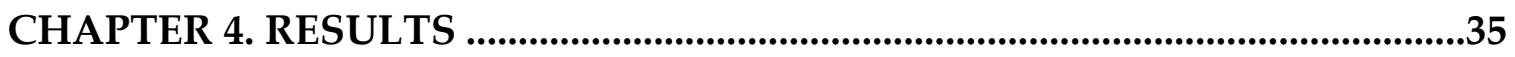

Matching Subjects between Treatments .................................................................35

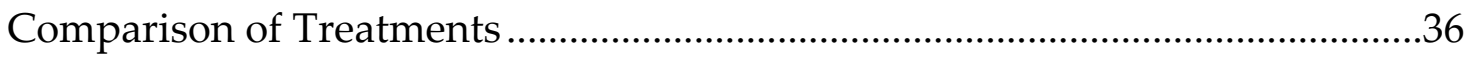

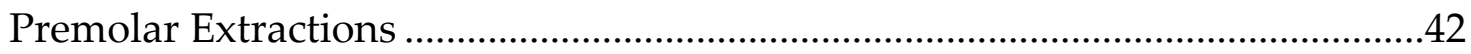

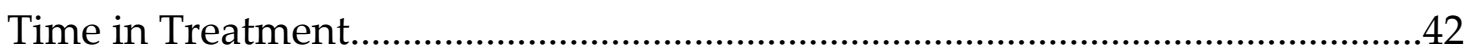

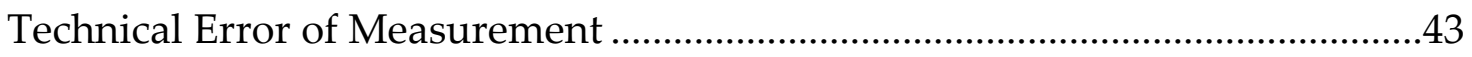

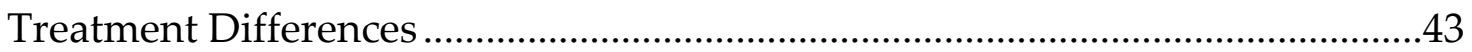

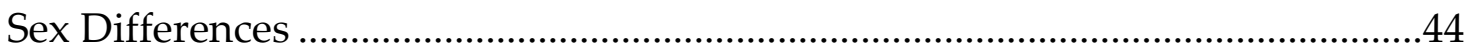

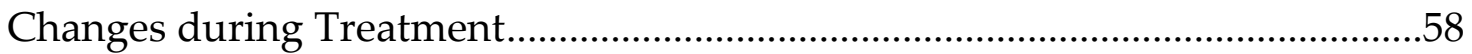

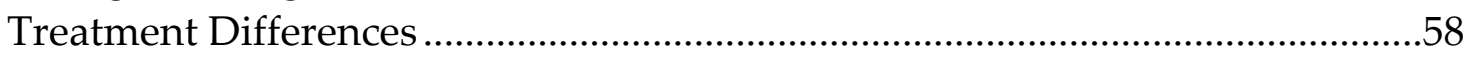

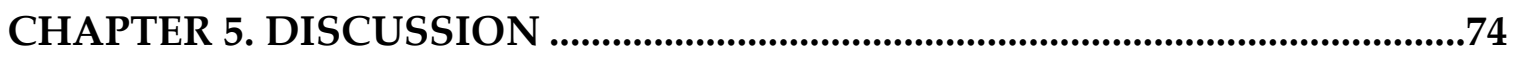

CHAPTER 6. CONCLUSIONS.......................................................................................77 


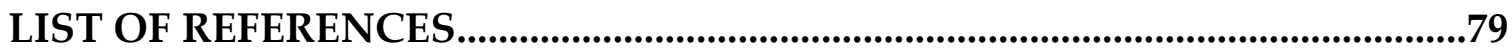

APPENDIX A. RESULTS OF THE TECHNICAL ERROR OF

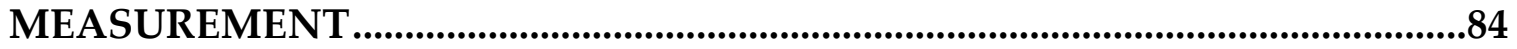

APPENDIX B. DESCRIPTIVE STATISTICS BY TREATMENT GROUP,

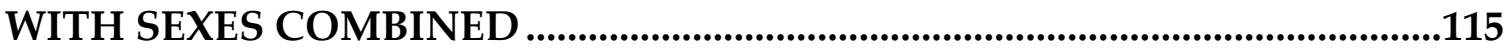

APPENDIX C. DESCRIPTIVE STATISTICS BY TREATMENT GROUP

AND SEX …….....................................................................................................................131

APPENDIX D. ANOVA RESULTS FOR DIFFERENCES BETWEEN TREATMENTS, CONTROLLING FOR SEX AND INITIAL AGE.....................147

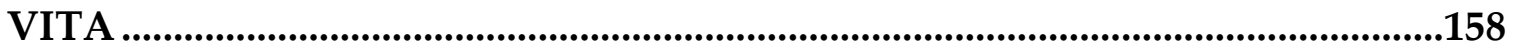




\section{LIST OF TABLES}

Table 1. Descriptive statistics for ages of the patients in the two, matched treatment groups.

Table 2. Results of mixed-model analysis of variance tests to evaluate the comparability of the matched samples at the start of treatment.........35

Table 3. Results of a pairing design t-test assessing the results of matching patients for NAP....................................................................................37

Table 4. Results of a pairing design t-test assessing the results of matching

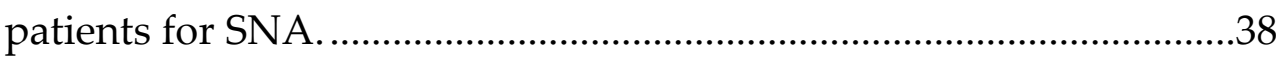

Table 5. Results of a pairing design t-test assessing the results of matching patients for SNB.

Table 6. Results of a pairing design t-test assessing the results of matching patients for ANB.

Table 7. Results of a pairing design t-test assessing the results of matching patients for FMA. 


\section{LIST OF FIGURES}

Figure 1. Drawings of Emile Herbst's original appliance......................................6

Figure 2. Frontal view of the MARA. ................................................................13

Figure 3. Maxillary occlusal view of the MARA.....................................................14

Figure 4. Mandibular occlusal view of the MARA with a lower lingual

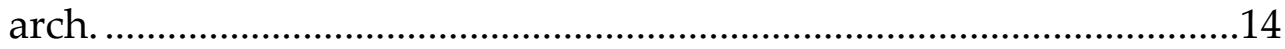

Figure 5. Left lateral view of the MARA............................................................15

Figure 6. Left lateral close-up view of the MARA.................................................15

Figure 7. Schematized buccal view and description of the MARA.....................17

Figure 8. Schematized frontal view and description of the MARA....................18

Figure 9. Patient profile photographs before and after MARA insertion. .........19

Figure 10. Facsimile of Johnston's (1986) pitchfork diagram used to characterize the skeletal and dental contributions to the correction of a Class II malocclusion.

Figure 11. Diagram of Johnston's (2006) pitchfork diagram that includes incisor changes

Figure 12. Diagram of U6 showing the posterior-superior angle measured at the pre- and posttreatment examination to calculate the change in molar angulation.

Figure 13. Diagram of U6 before and after treatment showing the change in position.

Figure 14. Diagrams of U6 before and after treatment showing the change in position.

Figure 15. Changes in the straight-line distances of point $\mathrm{D}$ to point $\mathrm{D}^{\prime}$ and horizontal and vertical changes during orthodontics, by sex and treatment. 
Figure 16. Diagram of a maxillary cephalographic superimposition showing the forward growth of the maxillary complex (parallel lines) that detracts from correction of a Class II malocclusion.

Figure 17. Diagrams of the maxillary incisors before and after treatment showing the change in incisal edges (measured parallel with the MFOP)

Figure 18. Bland-Altman plot for NAP between the Edgewise and MARA matches at the start of treatment.

Figure 19. Bland-Altman plot for SNA between the Edgewise and MARA matches at the start of treatment.

Figure 20. Bland-Altman plot for SNB between the Edgewise and MARA matches at the start of treatment.

Figure 21. Bland-Altman plot for ANB between the Edgewise and MARA matches at the start of treatment.

Figure 22. Bland-Altman plot for FMA between the Edgewise and MARA matches at the start of treatment

Figure 23. Barchart of the mean values for the L6 angle at the posttreatment examination, by treatment and sex

Figure 24. Barchart showing the sexual dimorphism in the treatment change in the angle of L6.

Figure 25. Barchart of the average values for treatment changes in D-D'.

Figure 26. Barchart of the treatment change of the horizontal component of

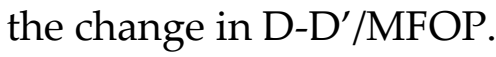

Figure 27. Barchart of the average treatment changes of the vertical (D$\mathrm{D}^{\prime} / \mathrm{MFOP}$ ) between treatments and sexes. . .50

Figure 28. Barchart of the pretreatment distance between L6 and D. .51

Figure 29. Barchart of the average distances of L6 to D at the posttreatment examination.

Figure 30. Barchart of total molar correction by treatment and sex. .54 
Figure 31. Barchart of the average changes in the apical base $(\mathrm{ABCH})$, by treatment and sex.

Figure 32. Barchart of the mean angulation of $\mathrm{U} 1$ at the end of treatment, showing a statistically significantly greater angle in boys....................56

Figure 33. Barchart of the mean treatment change in $\mathrm{U} 1$ by treatment and sex.

Figure 34. Barchart of the average amounts of overjet at the posttreatment examination.

Figure 35. Barchart of the maxillary translative growth in the two treatments.

Figure 36. Barchart of average mandibular translative growth showing the significantly larger treatment effect in the Edgewise-only group $(\mathrm{P}=0.0317)$

Figure 37. Barchart of the treatment effects for U6 M-D movement relative to the MFOP.....

Figure 38. Barchart of the treatment difference in L6 M-D movement/MFOP...64

Figure 39. Barchart showing mean sizes for the L6-D distance at the start of treatment

Figure 40. Barchart of the treatment differences in the amount of SE growth....66

Figure 41. Barchart of the means of $\mathrm{U} 1$ angle at the end of treatment, by treatment sample $(\mathrm{P}<0.0001)$.

Figure 42. Barchart showing the average treatment changes in $\mathrm{U} 1$ between groups.

Figure 43. Barchart of the U1 movement parallel to the MFOP in the two treatment groups. .70

Figure 44. Barchart of the millimeters of overjet at the start of treatment. . .71

Figure 45. Barchart of the millimeters of overjet at the end of treatment. . .72

Figure 46. Barchart of the average in-treatment changes in overjet. .73 


\section{CHAPTER 1. INTRODUCTION AND RATIONALE}

Population studies show that about one-third of youths in the United States have a Class II malocclusion (Brunelle et al. 1996; Cozza et al. 2006). A frequent finding of a Class II skeletal malocclusion is deficient mandibular length rather than excessive maxillary size (Moyers et al. 1980; Graber et al. 2005). Treatment of Class II malocclusion in adolescence can be broken down into 4 categories as described by Proffit: (1) growth modification with the use of either extraoral headgears or functional orthopedic appliances; (2) distalization of maxillary molars; (3) retraction of maxillary anterior teeth into extraction spaces of premolars; and (4) a combination of distalization of maxillary teeth and protraction of mandibular teeth (Proffit 2007). All but the first category involves dental movements.

Functional jaw orthopedic appliances are those that use muscle forces from mastication, speaking and swallowing to encourage orthopedic correction of the Class II mandibular deficiency. These forces also affect the dentition, resulting in tooth movement as well as bony changes. Functional appliances can be divided into two broad categories, fixed and removable (Proffit 2007). While both types generally act by placing distally-directed forces on the maxillary dentition and mesially-directed forces on the mandibular dentition, fixed appliances require less patient compliance than removable appliances. Also, fixed functional appliances tend to be less bulky and more esthetic. Two popular rigid fixed functional appliances are the Herbst appliance and the Mandibular Anterior Repositioning Appliance (MARA). The Herbst is currently the most popular and one of the oldest fixed functional appliances used today (English et al. 2009). The MARA offers several advantages over the Herbst appliance. The MARA is less bulky than the Herbst, can easily be used simultaneously with full Edgewise appliances, and can be activated incrementally and unilaterally as needed. The MARA works by translating the patient's mandible forward into a protracted position. This is accomplished by designing buccally placed occlusal interferences that guide the patient's mandible forward in order to close completely. Developed in 1991 by Douglas Toll of Germany, the MARA is a tooth-borne functional appliance aimed at Class II skeletal correction by enhancing mandibular growth (Pangrazio-Kulbersh et al. 2003; Siara-Olds et al. 2010).

While studies have analyzed the MARA, they have used traditional cephalometric methods to compare skeletal and dental changes during treatment 
(e.g., Pangrazio-Kulbersh et al. 2003; Siara-Olds et al. 2010). The purpose of the present study was to compare patients who received MARA therapy with patients that only used Standard Edgewise fixed appliances to correct their Class II Division 1 malocclusion. Differences were evaluated using Johnston's Pitchfork diagram (Johnston 1986, 1996).

The pitchfork analysis is a cephalometric analysis that accounts for molar and overjet relations algebraically as the sum of facial skeletal growth and tooth movement relative to the basal bone. The pitchfork analysis is not a duplication of what can be measured with traditional cephalometry. The purpose of the pitchfork analysis is to account for the sources of the parasagittal molar correction by measuring molar movement relative to basal bone and the movement of the jaws, both with respect to the cranial base and to each other. This overall change is called apical base change (ABCH) (Johnston 1996). 


\section{CHAPTER 2. REVIEW OF THE LITERATURE}

\section{Functional Appliances}

Although various forms of functional appliances exist, they are based on a common principle of changing the posture of the mandible. Proffit (2007) defined functional appliances as appliances that guide the mandible forward, holding the patient open or open and forward.

\section{Mandibular Growth}

English anatomist, John Hunter, was the first to document that the mandible grows mostly in the posterior direction and not by elongation at the chin (Enlow and Harris 1964). Hunter found that the ramus grows in a posterior direction through the addition of new bone on the posterior border along with some removal from the anterior side of the ramus. Later, Humphry experimentally confirmed Hunter's concept by inserting small metal rings on the posterior and anterior border of the ramus in a growing pig. The rings on the posterior surface of the ramus became increasingly embedded whereas the rings on the anterior were released from the ramus with continued growth.

Charles (1925) and Brodie (1941) argued that the mandibular condyle is an important site of growth of the mandible that brings about forward and downward growth of the mandible. The rate of growth is proportional to the increase of cortical bone along the posterior border of the ramus and to the growth of alveolar bone on the body of the mandible (Enlow and Harris 1964). According to Enlow and Harris (1964:29), "structural remodeling is a companion process to growth and functions to maintain the constant shape of the mandible as it continues to increase in size."

\section{Types of Class II Malocclusions}

Class II malocclusions can be subdivided into Class II Division 1 and Class II Division 2 malocclusions. Class II Division 1 malocclusions are defined by orthognathic maxillae. retrognathic mandibles, and protrusive maxillary incisors. Class II Divisions 2 malocclusions are defined by orthognathic maxillae, 
retrognathic mandible, and retroclined maxillary incisors (Feldmann et al. 1999:33).

Moyers et al. (1980) studied 697 lateral cephalograms of North American white children who had either undergone treatment for an Angle Class II malocclusion by an orthodontist or were a part of an untreated control group. The study found some general characteristics of Class II malocclusions. Many of their linear measurements are smaller than the mean values in the normative data base (as determined from the Michigan Growth Study; Riolo et al. 1976) and, as a rule, Class II patients have smaller faces. Six subgroups (Types A, B, C, $\mathrm{D}$, and $\mathrm{E})$, based on horizontal variables, were identified and among them four (Types B, C, D, and E) are true syndromic types with different skeletal and dental features.

Type A is characterized as having a normal skeletal pattern and normal occlusal plane. The mandibular dentition is in a normative position on its base with the maxillary dentition located in a protracted relationship, thus causing the Class II molar relationship with a larger than normal overjet and overbite. Type $\mathrm{B}$ has a Class II skeletal pattern with a prognathic maxilla and a mandible in a normal relationship anteroposteriorly. Type $\mathrm{C}$ has a severe Class II skeletal pattern with a short mandible and maxilla. The lower incisors are tipped labially with the upper incisors either upright or labially inclined.

Type D has a retrognathic skeletal profile due to a small mandible and a maxilla that is normal or slightly diminished. The mandibular incisors are either lingually inclined or upright and the maxillary incisors are labially inclined. Type E displays a severe Class II profile because of a prognathic midface and a normal mandible. Maxillary and mandibular dentitions tend to be positioned forward of their base with the incisors being inclined labially. Type F has the mildest Class II tendency and can be considered as a milder nonsyndromic form of Type B, C, D, or E. This large subgroup is not well defined but displays some skeletal Class II characteristics with the mandible and midface being small. In Types C, D, and F extraoral traction to the maxilla is avoided and the main focus is placed on enhancing mandibular growth.

Moyers et al. (1980) identified five vertical subgroups of the Class II malocclusion (Types 1 through 5), but these vertical types are not as clearly differentiated as the horizontal types discussed previously. Type 1 has a higher than normal mandibular plane angle, a steep functional occlusal plane and the palate is tipped downward. The anterior facial height is greater than the 
posterior facial height, leaving these patients to be referred to as "long face syndrome" by oral surgeons and "high angles" by orthodontists. Type 2 has a mandibular plane, functional occlusal plane and palatal plane that is flatter than normal. The incisors tend to be upright with excessive overbite. Type 3 is characterized by an upward and anteriorly positioned palatal plane resulting in a tendency towards open bite. If the mandibular plane angle is higher than normal a skeletal open bite is inevitable.

Type 4, on the other hand, has a mandibular plane, functional occlusal plane, and palatal plane that are tipped significantly downward resulting in a gummy appearance. The maxillary incisors are tipped labially and the mandibular incisors are tipped lingually. This subgroup is the rarest and most severe of the vertical types. Type 5 is similar to Type 2 with a normal mandibular and functional occlusal plane. The palatal plane is tipped downward in the front resulting in a skeletal deep bite. The mandibular incisors are labially inclined and the maxillary incisors are nearly upright.

In a study conducted by McNamara (1981), lateral cephalometrics were reviewed of 277 Class II children with an average age of 9.0 years and the following results were obtained. The position of the maxilla is normal in the majority of the Class II individuals. If the position of the maxilla is abnormal, it tends to be retrusive rather than protrusive. When a child exhibits a long anterior lower facial height with a steep Frankfort Mandibular Plane Angle (FMA), both the maxilla and mandible are in a retrusive position in relation to the cranial base structures. Almost half of Class II individuals have normally positioned upper incisors, but approximately $30 \%$ are retruded and $60 \%$ of these patients exhibited mandibular skeletal retrusion (McNamara 1981).

\section{History of Functional Appliances}

The history of functional appliances began in 1879 when Norman W. Kingsley introduced the first "bite jumping" device. The vulcanite device was designed as a removable bite plane with molar clasps. Kingsley explained that the goal of the bite jumping device was not to protrude the lower teeth but to change or "jump" the bite in cases of mandibular retrognathism (Kingsley 1880). Kingsley's bite jumping device is believed by many to be the first functional appliance (Wahl 2006). 
Edward $\mathrm{H}$. Angle also designed a repositioning device that consisted of pairs of interlocking rings. The rings were soldered to molar bands creating occlusal interferences that forced the patient to posture the mandible forward, similar to today's MARA (Wahl 2006). The Oliver guide plane is another functional appliance that is similar in action to Angle's device and to the MARA (Wahl 2006). Pierre Robin of France made adaptations to Kingsley's device, adapting his appliance for neonates with deficient mandibles. The resulting, plastic tissue-borne monobloc was a passive positioning device used to treat glossoptosis in infants with severely malformed mandibles (Graber et al. 2005).

Viggo Andresen of Norway used a modified Hawley-type retainer and added a lingual horseshoe flange that protracted the mandible 3 to 4 millimeters forward. Andresen fabricated the first device as a retainer for his daughter to use while she was away for three months on vacation. On returning home, Andresen had found that her Class II occlusion had been corrected. He also reported that the correction was stable (Graber et al. 2005; Wahl 2006).

At the International Dental Congress of 1909 in Berlin, Emil Herbst presented his fixed bite-jumping appliance called Scharnier or "joint." Introduced in 1905, Herbst's appliance (Figure 1) was the first functional device that did not require patient compliance (McNamara and Brudon 1993). The device postures the patient's mandible forward at all times. The typical Herbst

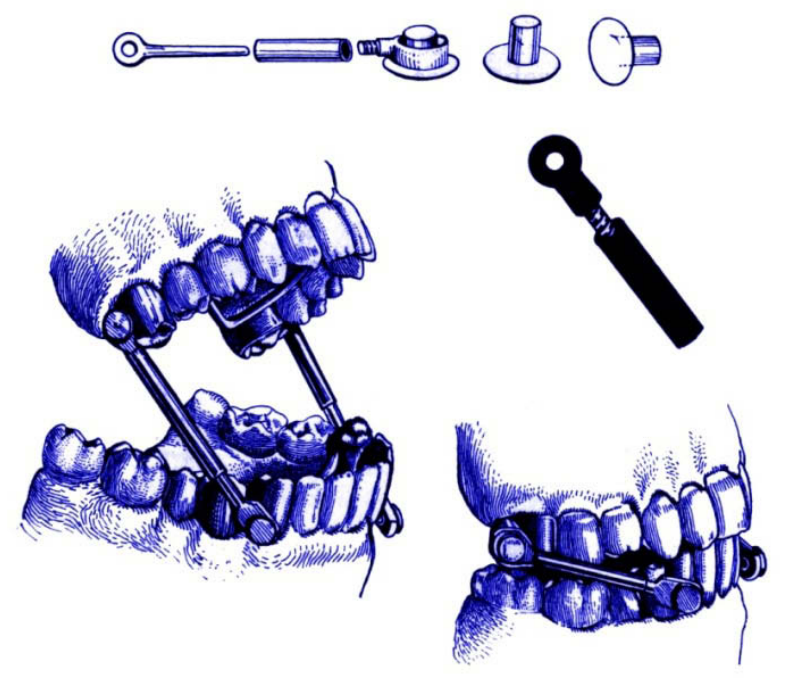

Figure 1. Drawings of Emile Herbst's original appliance. 
consists of a telescoping tube and plunger assembly that is generally connected to maxillary first molars and mandibular first premolars (Graber et al. 2005; Wahl 2006). Although Herbst developed the appliance in the early 1900s, it was Hans Pancherz who reintroduced the device in 1979, ultimately leading to its present today. Pancherz recognized its potential for mandibular growth stimulation, publishing several papers in support of his theory (e.g., Pancherz 1979, 2003).

Wilhelm Roux is recognized as being one of the first to relate function with form in relation to natural forces (Wahl 2006). Today's general and dental functional appliance principles are based on observations made by Roux in the nineteenth century. Karl Häupl later built on the principles that Roux described by using them to explain functional appliance and their connection to the activation of the appliances with orofacial muscles (Wahl 2006). Alfred P. Rogers, the "first to implicate the facial muscles for the growth, development, and form of the stomatognathic system" (Wahl 2006, p. 829) has become widely known as the father of myofunctional therapy.

\section{Effects of the MARA on Class II Malocclusions}

Currently very few published studies exist on the effects of the MARA. A study by Pangrazio-Kulbersh et al. (2003) examined the MARA's skeletal and dental effects on 30 patients with Class II malocclusion. Twelve boys and 18 girls were treated with the MARA for an average of 11 months. Lateral cephalograms were taken 2 weeks prior to treatment and 6 weeks after the MARA was removed. These cases were compared to 21 untreated Class II control subjects (13 girls, 8 boys). Cephalometric records of the controls were from the Michigan Elementary and Secondary School Growth Study, and longitudinal cephalograms were available for the age ranges studied. The MARA patients were also compared to Fränkel and Herbst groups that had been reported previously (Pangrazio-Kulbersh et al. 2003).

Pangrazio-Kulbersh et al. (2003) reported that the MARA produced significant changes both skeletally and dentally compared to the control group. The MARA group had an average $1.1 \mathrm{~mm}$ distalization of maxillary molars, while the control group had an average mesial molar movement $1.3 \mathrm{~mm}$. Differences in mandibular molars and incisors were as follows: the MARA groups had 1.2 and $0.6 \mathrm{~mm}$ anterior movement, respectively, while the control group had an average of 0.5 and $-0.4 \mathrm{~mm}$ change. Mandibular incisors were found to proclinate, with a $3.9^{\circ}$ increase per year of the IMPA with MARA 
therapy but only increased $0.3^{\circ}$ per year in the control group. Mandibular length (Condylion to Gnathion) increased annually $4.8 \mathrm{~mm}$ in the MARA patients but only $2.1 \mathrm{~mm}$ in the control group. Chin point (Pogonion to Nasionperpendicular) changed $2.3 \mathrm{~mm}$ in the anterior direction in the MARA group, whereas the control group's change was only $0.3 \mathrm{~mm}$ on average. ANB decreased $-1.4 \mathrm{~mm}$ in the MARA group, but $-0.1 \mathrm{~mm}$ in the control group. The authors also reported that the mandibular anterior facial height increased $2.5 \mathrm{~mm}$ per year on average in the MARA group, but only $1.0 \mathrm{~mm}$ in the control group. They also reported an increase of $4.0 \mathrm{~mm}$ in posterior facial height (how they measured it) in the MARA group and only a $1.3 \mathrm{~mm}$ increase in the control. There was no change in the mandibular plane angle during treatment with the MARA (Pangrazio-Kulbersh et al. 2003).

Pangrazio-Kulbersh et al. (2003) explain that there is no maxillary skeletal change with MARA patients, only $-1.1 \mathrm{~mm}$ movement of maxillary molars in a posterior direction. They attribute the Class II correction to a combination of changes, both skeletal and dental. The distalization of maxillary molars contributed greatly to the Class II correction. The MARA was also reported to increase mandibular length by $2.7 \mathrm{~mm}$, thus decreasing SNB by $1.0^{\circ}$, and decreasing ANB by $1.3^{\circ}$. Pogonion moved in an anterior direction by $2.0 \mathrm{~mm}$. The lower anterior facial height (ANS-Me) of the MARA group increased about $2.5 \mathrm{~mm}$ per year, and the posterior facial height (Cd-Go) increased approximately $4.0 \mathrm{~mm}$ per year. The authors attributed these increases in facial height to the stainless steel crowns on maxillary and mandibular molars causing the condyle to be positioned in a more inferior position in the glenoid fossa, stimulating condylar growth in a more superior and posterior direction. These reported changes suggest that the MARA can be used to correct Class II malocclusion in growing patients by increasing mandibular length and distalizing maxillary molars. The MARA was not shown to have an orthopedic effect on the maxilla (Pangrazio-Kulbersh et al. 2003).

A more recent study compared the MARA with other popular removable functional appliances (Siara-Olds et al. 2010). After identifying a sample of 80 Class II patients with similar skeletal characteristics, patients were equally divided among Bionator, removable acrylic Herbst, Twin Block, and MARA functional appliance groups. Lateral cephalograms were taken for the treated groups at the time of initial records (T1), the completion of functional therapy (T2), and at the completion of fixed appliance therapy (T3). The untreated control group consisted of 21 children from the Michigan and Denver Growth Study samples. The selection criteria for the control group were similar to the 
treatment groups. Control group lateral cephalograms were also matched to the treated groups at T1, T2, and T3 by CVM (Franchi et al. 2000, Baccetti et al. 2002), and comparisons were made (Siara-Olds et al. 2010).

At the pretreatment time interval T1, no significant differences were found between the treatment and control groups. A comparison of the different treatment groups with the control group depicted very few statistically significant differences when compared from T1 to T3. Interestingly, when statistically significant differences were found between groups from T1 to T2, most of these differences dissipated long term. Overjet, overbite, and Wits analysis were the only measurements that demonstrated significant differences at the end of treatment (T3) (Siara-Olds et al. 2010).

When comparing the treatment groups among themselves, the Herbst appliance, followed by the MARA, demonstrated a significant effect on restricted maxillary growth and produced a steeper occlusal plane. The twin block was most effective in controlling the mandibular plane angle and had the greatest long-term effect on the proclination of the mandibular incisors (Siara-Olds et al. 2010).

Ghislanzoni et al. (2011) have also recently completed a study that assessed clinical outcomes of a group of patients that were treated with the MARA appliance. The study consisted of two groups, a sample of 23 consecutively-treated MARA patients and a control group of 17 untreated Class II subjects selected from the University of Michigan and Denver Child Growth Studies (Stahl et al. 2008). Results show a decrease in ANB of $-1.8^{\circ}$, a decrease in $\mathrm{AOBO}$ of $-2.1 \mathrm{~mm}$ and a decrease in overjet of $-3.3 \mathrm{~mm}$. Additionally, the authors found that a "headgear effect" was observed in the maxilla (A to Nasion perpendicular of $-1.4 \mathrm{~mm}$ ), while total mandibular length (Co-Gn) increased significantly more in cases than in the controls (2.0mm) (Ghislanzoni et al. 2011).

\section{Effects of the MARA on the Lower Anterior Teeth}

Gönner et al. (2007) compared mandibular incisor position after Class II treatment with the MARA. Cases $(\mathrm{n}=90)$ with skeletal and dental Class II malocclusion were treated with the MARA and multi-bracket appliances to achieve anterior mandibular repositioning. These cases were divided into three groups: children $(n=36)$, adolescents $(n=28)$, and adults $(n=26)$. The children group had a mean age of 11 years, the adolescent group a mean age of 15 years, 
and the adult group a mean age of 34 years. Lateral cephalograms were taken at three times for comparison: at the onset of MARA treatment (T1), on removal of the MARA (T2), and one year post-removal of the MARA (T3) (Gönner et al. 2007).

The authors reported the lower anterior teeth moving forward an average of $0.4 \mathrm{~mm}$ between $\mathrm{T} 1$ and $\mathrm{T} 2$ in group 1 , followed by $0.2 \mathrm{~mm}$ posterior movement between T2 and T3. Group 2 had an initial $1.0 \mathrm{~mm}$ anterior movement between $\mathrm{T} 1$ and $\mathrm{T} 2$ and a latter posterior movement of $0.7 \mathrm{~mm}$. In group 3 there was a $1.7 \mathrm{~mm}$ anterior movement between $\mathrm{T} 1$ and $\mathrm{T} 2$ and a posterior movement of $0.2 \mathrm{~mm}$ from T2 to T3. As would be expected, there appears to be an association between more lingually inclined lower incisors and increased anterior movement of mandibular incisors (Gönner et al. 2007).

The authors suggested that they believe there is a neuromuscular reprogramming process that occurs via a biofeedback pathway affecting the masticatory system. They also suggested that the mandibular molars show more bodily movement than tipping movement because the MARA is situated near the molar's center of resistance. In addition, because the force in mainly on the molars, Cozza et al. (2006) suggest that the supporting bone is mainly cortical, thereby providing the best anchorage. The MARA is effective in correcting dental and skeletal Class II malocclusions in various age groups, but in the adult patient there are greater dentoaloveolar effects on the mandibular anterior teeth than in children. The study also suggests that the mandibular anterior proclination can be controlled with the use of a multi-bracket appliance on the lower incisors (Gönner et al. 2007).

\section{Outcome of Functional Appliances}

In a systematic review by Cozza et al. (2006), mandibular changes were evaluated in studies that used functional appliances to correct a Class II malocclusion. The review covered studies published between 1966 and 2005. The search ultimately was narrowed to 22 articles. The authors defined clinical significance as a difference greater than $2.0 \mathrm{~mm}$ between experimental and control groups (Cozza et al. 2006).

Functional appliances produced statistically significant elongation in 23 of 33 samples for mandibular length, in 12 of 17 samples for ramus height, and in 8 of 23 samples for mandibular length. SNB did not increase significantly in any 
study except the article by Tumer and Gultan (1999) who found an annual SNB angle increase of $2.2^{\circ}$. When considering the overall treatment change, 20 of the 33 samples found clinically significant supplemental mandibular growth compared with untreated groups (Cozza et al. 2006).

Franchi and Baccetti (2006) have addressed the prediction of mandibular changes using various functional appliances in Class II patients. Patients were divided into three groups (24 females, 27 males) and assigned to one of three functional appliances for first-phase therapy, either the twin block, a stainless steel crown Herbst, or an acrylic splint Herbst. All patients started functional therapy during cervical vertebrae maturation stage 3. Franchi and Baccetti (2006) found that when functional treatment is carried out during peak mandibular growth, a "good responder" can have a biannual increase in Condylion-Gnathion length up to $5.3 \mathrm{~mm}$ (2006). Also, the Co-Go-Me angle was found to provide a reliable differentiator between good and bad Class II responders to functional appliances (Franchi and Baccetti 2006). They also found that a patient with a CoGo-Me angle smaller than $125.5^{\circ}$ would be expected to respond favorably to functional appliance treatment, whereas a patient with a Co-Go-Me angle greater than $125.5^{\circ}$ would be expected to respond poorly to functional appliance therapy. The authors attribute the skeletal component of Class II correction to an alteration in the direction of condylar growth (Franchi and Baccetti 2006). 


\section{CHAPTER 3. MATERIALS AND METHODS}

\section{Sample Selection}

The present study was a retrospective analysis of lateral cephalograms taken on 51 subjects with Class II, Division 1 malocclusions at the beginning comprehensive orthodontic treatment. The 51 MARA patients received treatment with a MARA followed by or coinciding with full fixed Edgewise appliance treatment. Lateral cephalograms were taken pre- and post-treatment. These records were acquired from the office of Joe L. Wasson, D.D.S, M.S., Memphis, Tennessee, who treated all of these cases. The comparison group consisted of a matched sample of 51 subjects with Class II division 1 malocclusions treated with a single phase of full fixed Standard Edgewise appliances at The University of Tennessee, Department of Orthodontics in Memphis, Tennessee.

Dr. Wasson uses a three-tier treatment approach for his treatment of Class II malocclusions. Patients who fall within the first tier usually are in the early mixed dentition stage, with high mandibular plane angles (FMA), openbite tendencies, and deleterious oral habits (e.g., tongue thrusts, digit habits). These patients usually have excessive overjet with constricted or underdeveloped dental arches due to habits and/or poor lip competence. A patient's treatment typically consists of Fränkel II (FR-2) wear for approximately 22 hours a day for 1 year followed by a retention phase consisting of wearing the appliance for 8 to 12 hours a day. Upon eruption of all of the permanent teeth, full fixed Edgewise appliances are used to finish treatment.

The second tier of treatment is aimed at patients exhibiting Class II division 2 malocclusions. These hypodivergent patients have low mandibular plane angles (FMA), deepbite tendencies and a forward growth pattern. These patients are older, 9 to 11 years of age, as compared to the Tier 1 patients but still remain in the mixed dentition. First, the Class II division 2 malocclusion is converted to a Class II division 1 by partially bonding the maxillary arch (maxillary first molars banded and maxillary incisors bonded). The patient then wears a Bionator full time for 9 to 12 months with 6-to 8-week appointment intervals to assess their progress. Once correction is achieved, the appliance is worn only at night for retention while the rest of the permanent dentition erupts. Next, full fixed Edgewise appliances are used to detail and finish the case. 
The third treatment strategy is aimed at Class II patients in the early permanent dentition (11 to 14 years of age). This group of patients often is treated with fixed functional appliances such as the Herbst appliance or the MARA. These patients can have brackets placed on the upper four incisors and bands on the upper first molars to aid in aligning the incisors. Alternatively, full brackets and bands can be placed concomitantly to expedite treatment.

\section{MARA Appliance Design}

The MARA belongs to the group of permanent intermaxillary functional appliance connections (Gönner et al. 2007:399). The design of the MARA does not require patient compliance and it is a simple treatment solution for the older child with a Class II malocclusion. The typical patient selected for the MARA is still growing, with most of the permanent dentition present, with the maxilla in a favorable position, and the mandible in a retrognathic position. Even if the patient has ceased growing, the MARA will produce upper and lower dentoalveolar changes (Wasson, personal communication, 3/14/2010). Figures 2 through 6 are views of the MARA.

The standard MARA design is composed of four stainless steel crowns, one cemented on each permanent first molar. Both maxillary and mandibular crowns have tubes soldered to them to enable the use of upper and lower arch wires during MARA use. Large rectangular tubes are also soldered to the maxillary crowns for the insertion and ligation of stainless steel elbows. The mandibular crowns have lower fixed elbows soldered permanently to the lower

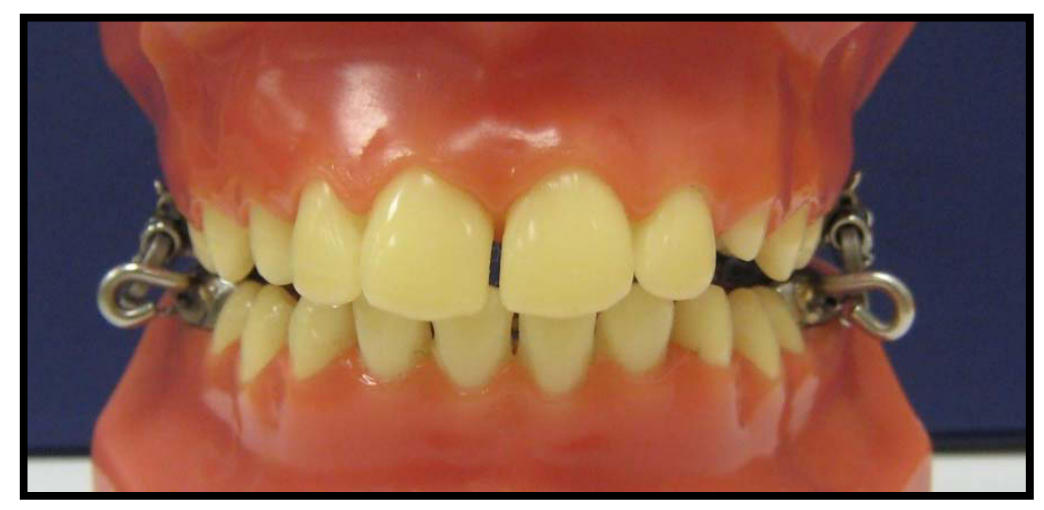

Figure 2. Frontal view of the MARA. 


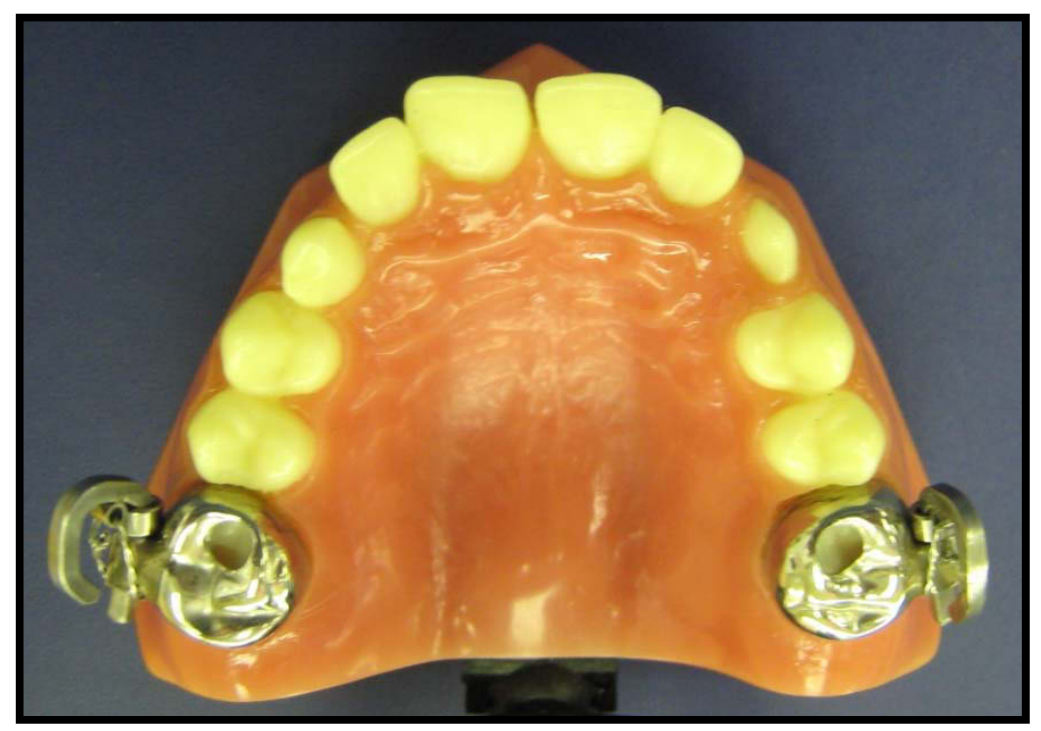

Figure 3. Maxillary occlusal view of the MARA.

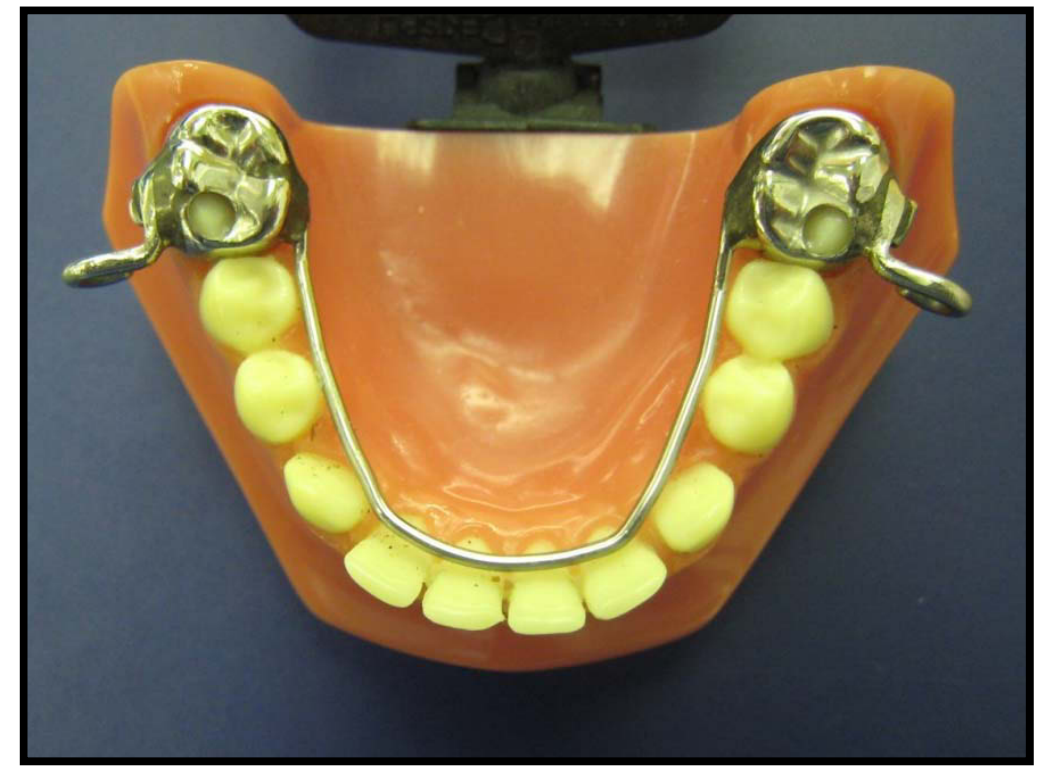

Figure 4. Mandibular occlusal view of the MARA with a lower lingual arch. 


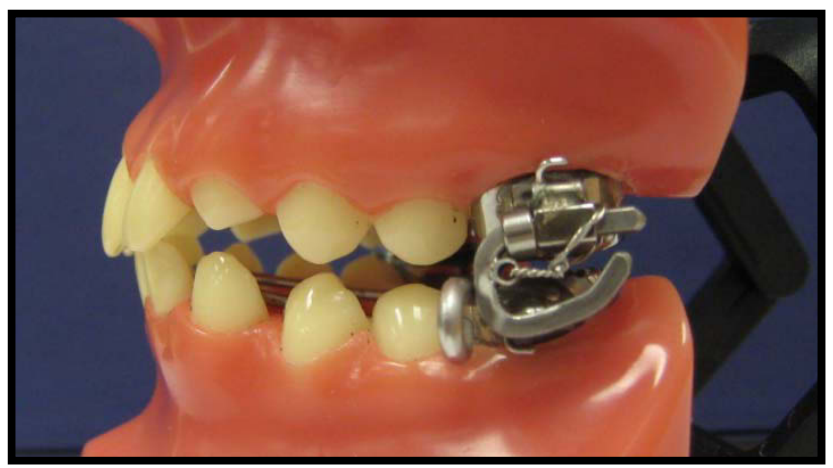

Figure 5. Left lateral view of the MARA.

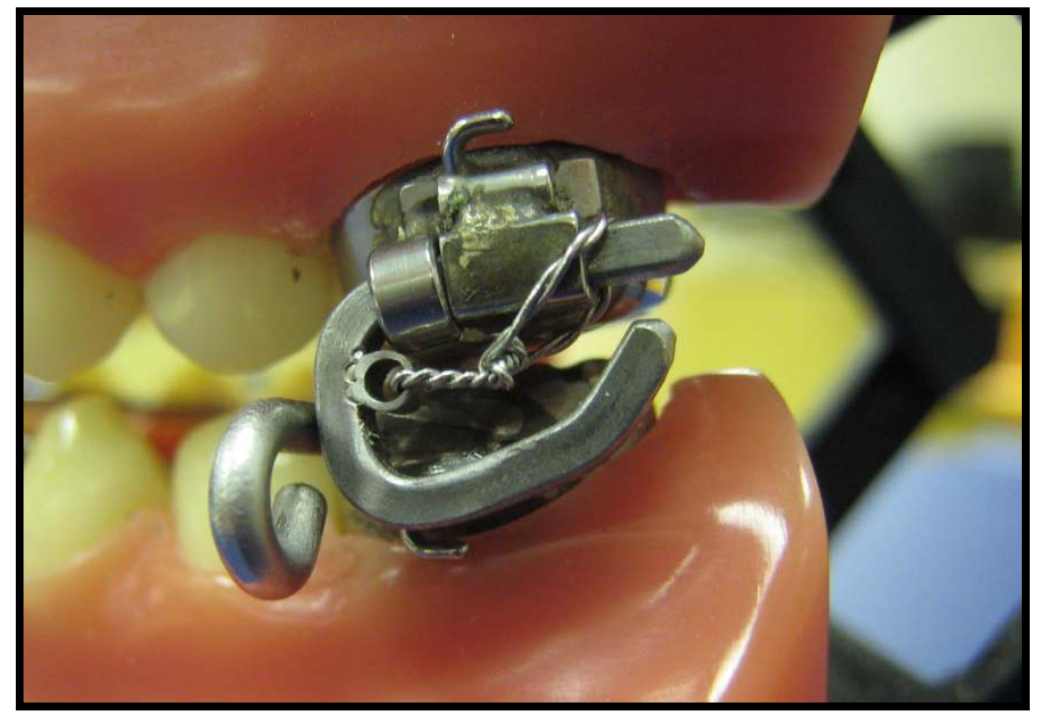

Figure 6. Left lateral close-up view of the MARA. 
crowns. Shims or spacers are available to adjust the amount of activation of the upper elbow, thus increasing or decreasing the amount of anterior displacement of the appliance. The lower arch is usually reinforced with a lower lingual arch (not touching the lower anterior teeth) to help control tipping of the lower incisors and to prevent the tendency of the upper elbows to rotate and tip the lower molars. As an additional option, a maxillary expander can be added to the upper part of the appliance for expansion if needed.

When the patient closes, the fixed lower arm of the MARA contacts with the upper elbow, the patient is therefore forced to posture the mandible anteriorly, into a Class I or super-Class I relationship to achieve intermaxillary occlusion (Figures 7,8 ). Patients generally adjust to the appliance in days to weeks and experience minimal discomfort (Gönner et al. 2007:400).

\section{Construction of the MARA}

A maxillary and mandibular alginate impression free of voids and bubbles is poured in dental stone. The casts and prescription sheet are sent to Allessee Orthodontic Association (AOA) or another orthodontic laboratory. A bite registration is not necessary when fabricating a MARA but can be used if desired. If the overjet is 4 to $5 \mathrm{~mm}$, the MARA can be advanced to an end-to-end incisor relationship. If the overjet is 8 to $9 \mathrm{~mm}$, then the MARA is advanced half of this total distance to prevent excessive strain on the temporomandibular joint (TMJ). The appliance is then advanced the remainder of the distance over several months. To facilitate cementation, separators may be placed one to two weeks prior to insertion of the MARA.

Upon cementation of the stainless steel crown and insertion of the upper elbows, an immediate change in profile will be seen (Figure 9).

\section{Subject Matching Criteria}

MARA subjects in the sample $(n=51)$ were matched case-by-case to 51 conventional fixed Standard Edgewise appliance cases based on five cephalometric criteria: Sella-Nasion to Point A angle (SNA), Sella-Nasion to Point $B$ angle (SNB), ANB angle, A Point to Nasion to Pogonion angle (NAP), and the Frankfort-Mandibular Plane angle (FMA). 


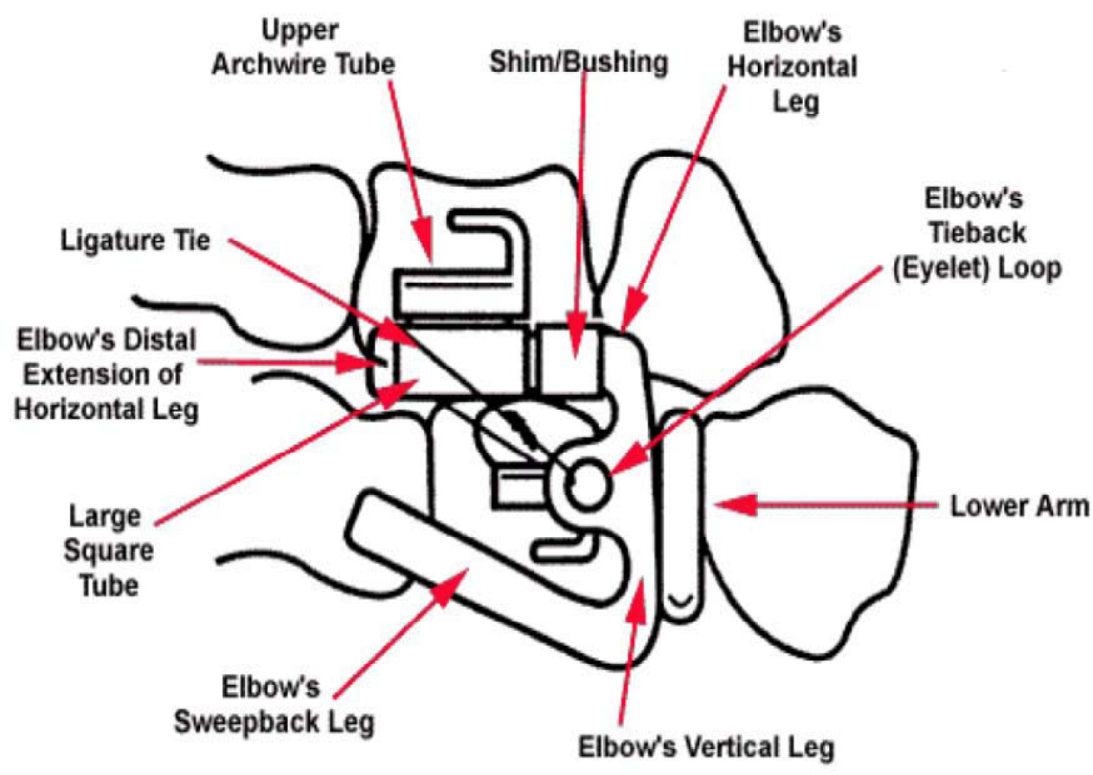

Figure 7. Schematized buccal view and description of the MARA.

Modified with permission. Allen-Noble PS. A manual for orthodontists and staff: Clinical management of the MARA. http://www.ormco.com/index/cmsfilesystem-action?file=AOALab-Education-PDF/clinicalmanagementmara2002manuals.pdf. February 2002. Accessed 10/19/2009. 


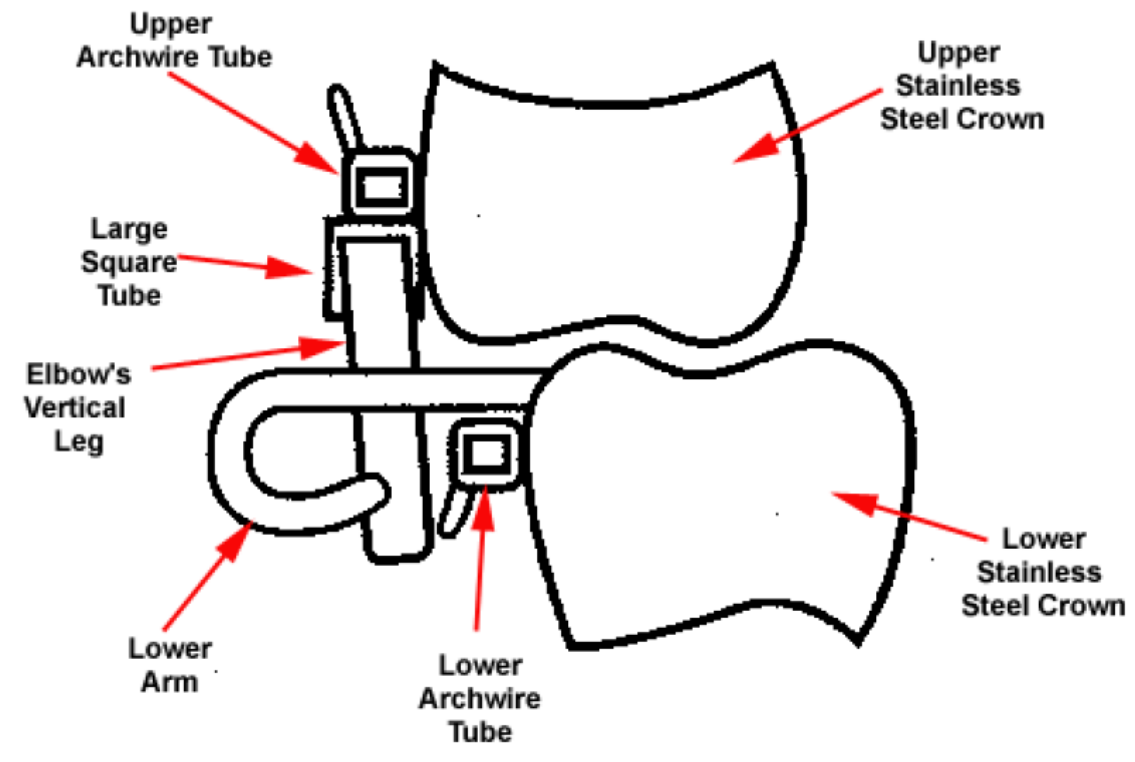

Figure 8. Schematized frontal view and description of the MARA. Modified with permission. Allen-Noble PS. A manual for orthodontists and staff: Clinical management of the MARA. http://www.ormco.com/index/cmsfilesystem-action?file=AOALab-Education-PDF/clinicalmanagementmara2002manuals.pdf. February 2002. Accessed 10/19/2009. 


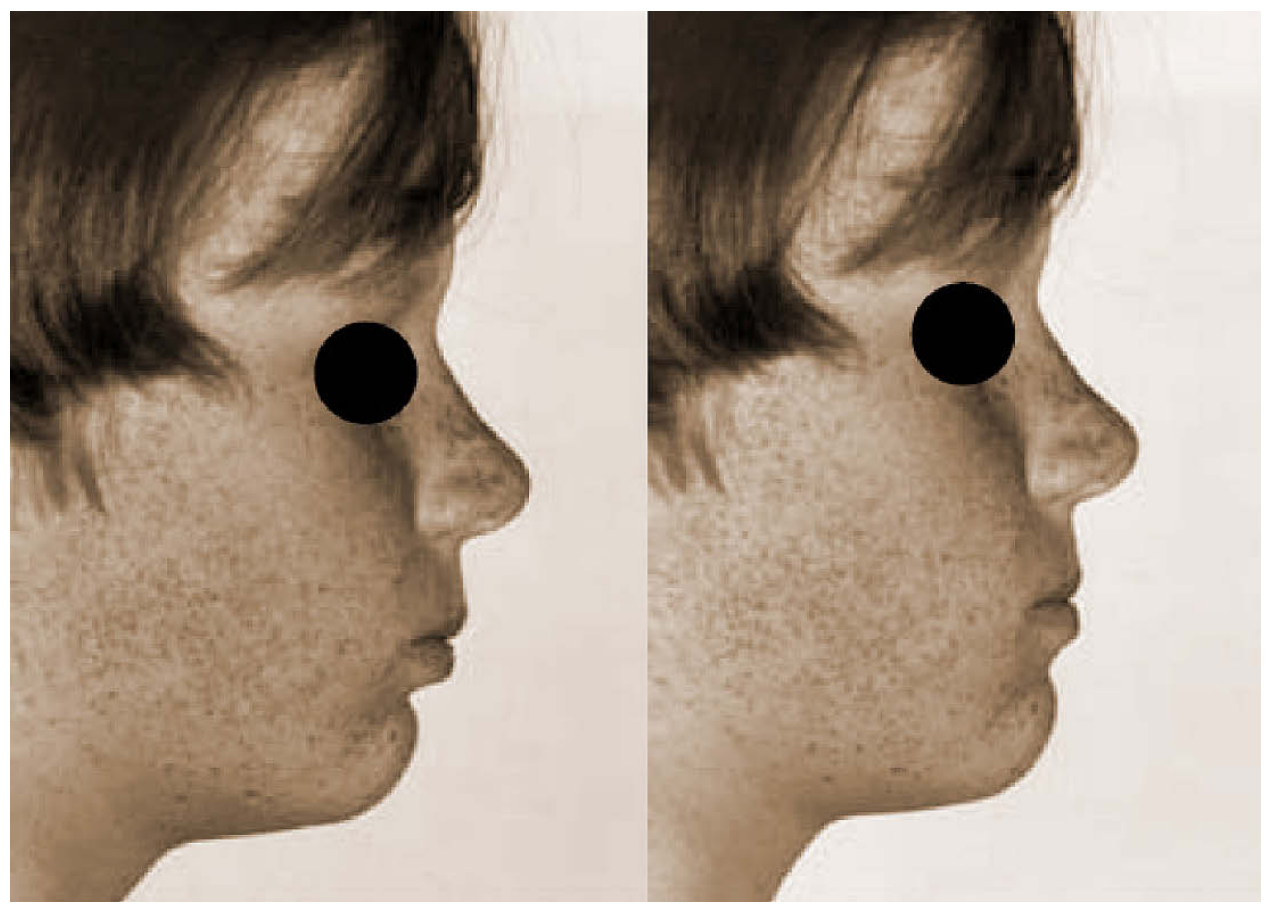

Figure 9. Patient profile photographs before and after MARA insertion. (Left) Patient with a typical Class II profile. (Right) Patient with lower jaw positioned forward to an incisor edge-to-edge relationship with the MARA. Modified with permission. Allen-Noble PS. A manual for orthodontists and staff: Clinical management of the MARA. http://www.ormco.com/index/cmsfilesystem-action?file=AOALab-Education-PDF/clinicalmanagementmara2002manuals.pdf. February 2002. Accessed 10/19/2009. 


\section{Chronological Ages}

Because facial growth is age- and sex-dependent, it is important to match the ages and sexes between the MARA and the Edgewise groups at the start of treatment. After matching the cases based on cephalometric values and sex, ages were compared to ensure that both groups were statistically similar. The Edgewise group's average age at the beginning of treatment was 13.2 and the MARA group's average age was 12.6 years old. Although there is about 6 month average difference in the beginning age of the two groups, this difference was found to not be statistically significant (Table 1). Average age at the start of treatment was about 13 years of age in both groups $(\mathrm{P}=0.06)$. Also, while not matched, results show that the two groups were also comparable at the end of treatment, at about $15 \frac{1}{2}$ years $(P=0.15)$.

With comparable starting and ending ages, it is predictable that the durations of treatment are very similar statistically $(\mathrm{P}=0.54)$. Average time in treatment was 2.77 years for the total sample. Treatment time was slightly longer in the MARA cases (2.8 vs. 2.7 years). The bulk of Edgewise cases were treated with premolar extractions which could account for some of the difference in treatment time. These frequencies are so different that a statistical test seemed unnecessary, but by chi-square with Yate's correction the statistic is a whopping $50.4(1 \mathrm{df})$, so extractions are far more common with Edgewise treatment $(\mathrm{P}<$ $0.0001)$.

\section{Premolar Extractions}

A significant difference in the amount of premolar extractions was found to exist between the two treatment groups. In the MARA treatment group, only 2 of the 51 cases (4\%) were treated with extractions. Conversely, 38 out of 51 Edgewise patients $(75 \%)$ were treated with extractions.

\section{Cephalometric Analysis}

The pitchfork analysis, formulated by Lysle E. Johnston Jr. (1986), was used to assess skeletal and dentoalveolar changes that contribute to the Class II correction. This analysis uses lateral cephalometric superimposition to measure the movement of mandibular and maxillary molars and incisors relative to their skeletal bases. It determines changes that occur during orthodontic treatment by 
Table 1. Descriptive statistics for ages of the patients in the two, matched treatment groups.

\begin{tabular}{|c|c|c|c|c|c|c|c|c|c|}
\hline \multirow[b]{2}{*}{ Time $\bar{x}$} & \multicolumn{3}{|c|}{ MARA-Edgewise } & \multicolumn{3}{|c|}{ Edgewise-Alone } & \multicolumn{3}{|c|}{ Paired t-Tests } \\
\hline & sd & sem & t-test & sd & sem & t-test & t-test & $\mathrm{df}$ & P-value \\
\hline Start Age & 12.58 & 1.08 & 0.15 & 13.17 & 2.07 & 0.29 & 1.93 & 50 & 0.0597 \\
\hline End Age & 15.41 & 1.05 & 0.15 & 15.87 & 1.95 & 0.27 & 1.44 & 50 & 0.1548 \\
\hline Treatment Duration & 2.83 & 0.90 & 0.13 & 2.70 & 0.96 & 0.13 & -0.62 & 50 & 0.5389 \\
\hline
\end{tabular}

Descriptive statistics are provided for each treatment, and the paired $t$-tests assessed whether the treatment ages differed statistically. 
identifying the dental and skeletal components of the change (Figure 10). All cephalometric radiographs in this study were evaluated in norma lateralis, so Frankfort Horizontal is oriented horizontally. Two lateral cephalograms were obtained from each MARA case, a pre-treatment and post-treatment radiograph. The Edgewise group, treated with full fixed appliance, also had two lateral cephalograms, namely from the start of treatment and the end of treatment.

The pitchfork analysis is useful as it separate movements of the dentoskeletal elements into dental movements and skeletal movements (Figures 10, 11). Also, dental movements are separated into tipping and bodily movements (Figure 11).

The initial and posttreatment films of each patient were placed side-byside and traced at the same sitting (Johnston 1986). The following structures were traced on both pre- and post-treatment films: SE point (intersection of the averaged greater wings and planum of the sphenoid), the first molars, the functional occlusal plane (first molars and premolars), the outline of the key ridge, the PTM outline (pterygomaxillary fissure) and the palatal and mandibular symphyseal trabecular architecture common to both films. The maxillae were then superimposed using the palatal plane (ANS-PNS) and the lingual palatal curvature. In superimposing the maxillae, the PTM fissure of the posttreatment film must be at or posterior to the fissure of the pretreatment film and the anterior borders of the key ridges must also be aligned in the anteroposterior direction.

Next, the pretreatment and posttreatment functional occusal planes were averaged to find the mean functional occlusal plane (MFOP). This MFOP was then recorded on each tracing to serve as the base for measurement of change. Lastly, D point (center of mandibular symphysis by inspection) was marked on one film and transferred to the other film by superimposition on the bony architecture of the symphysis.

All linear measurements were recorded using a vernier digital caliper, calibrated to $0.005 \mathrm{~mm}$ precision. All angular measurements were handmeasured with a standard orthodontic protractor made in France by OrmcoSybron dental company, calibrated to 0.5 degrees precision. The data were recorded into Excel 2007 spreadsheets (Microsoft Corporation, Redmond, WA). 


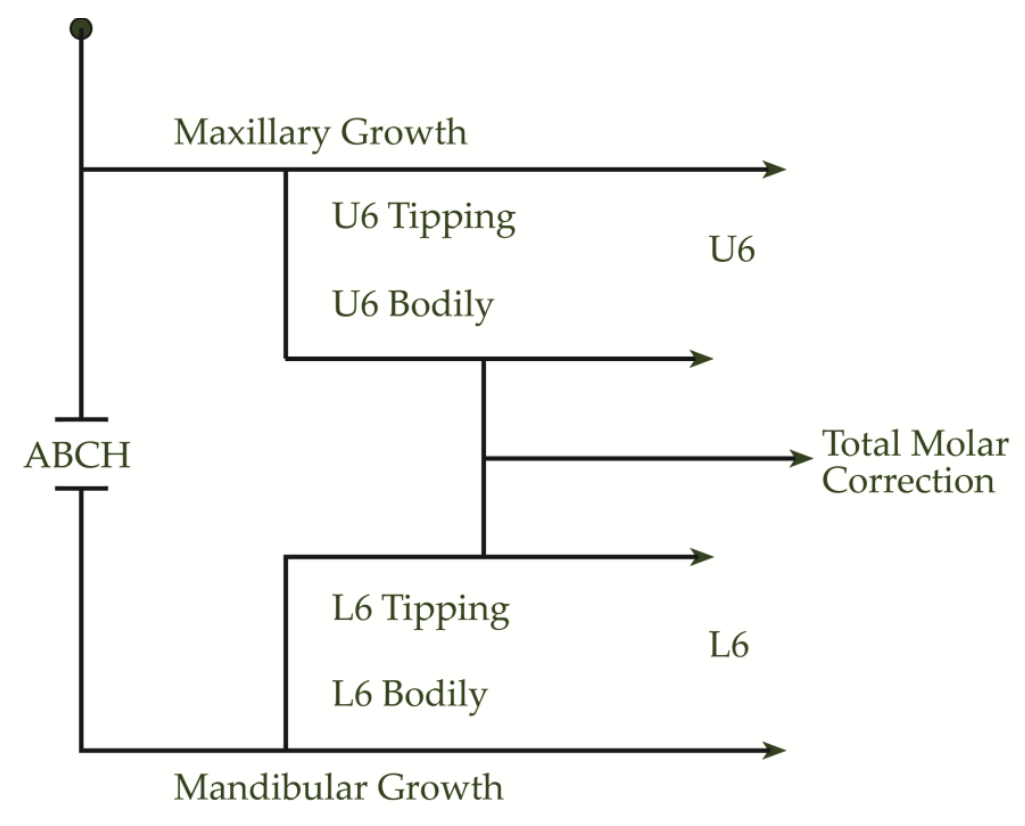

Figure 10. Facsimile of Johnston's (1986) pitchfork diagram used to characterize the skeletal and dental contributions to the correction of a Class II malocclusion. 


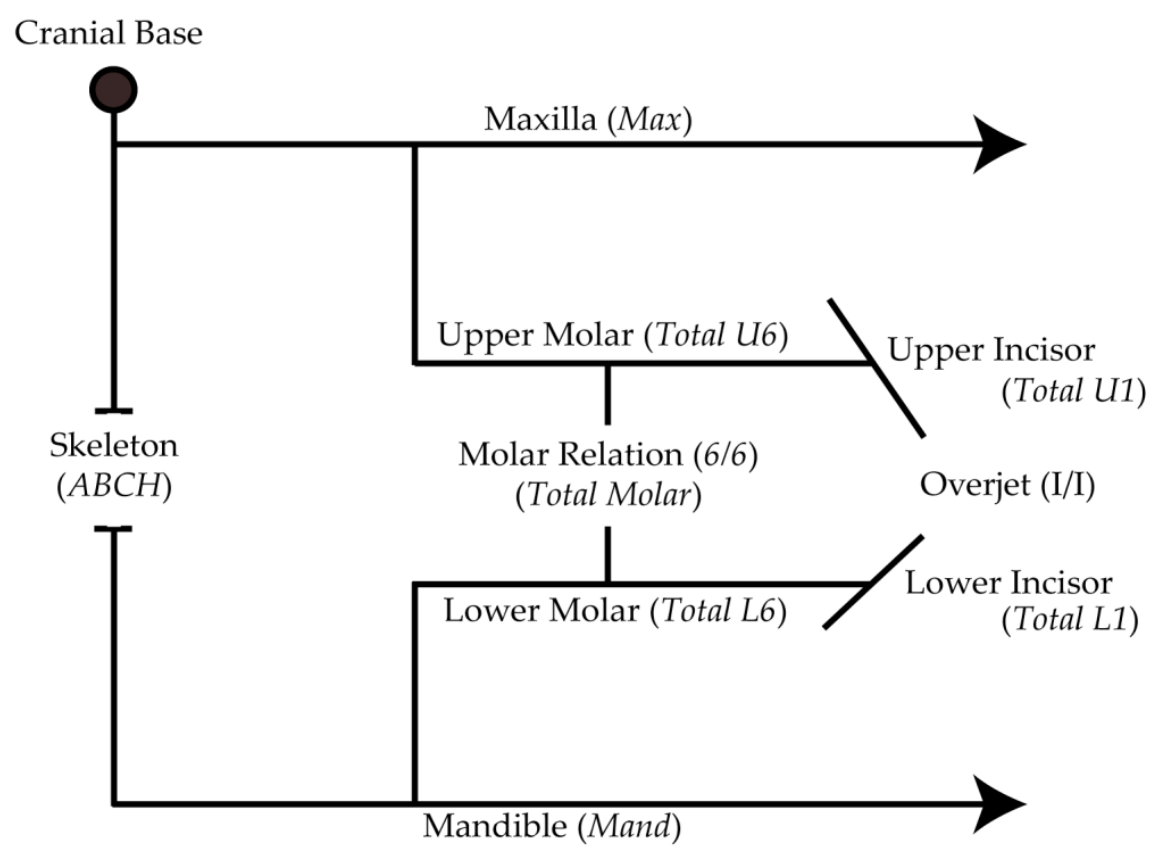

Figure 11. Diagram of Johnston's (2006) pitchfork diagram that includes incisor changes. 
The following is a listing of the measurements and the information they provide for the Pitchfork analysis (McKinney 2001).

1. Pretreatment occlusal plane slope. This is the slope of the functional occlusal plane relative to the orientation of the acetate tracing and the digitizing table in degrees. The functional plane in this study is defined as the occlusal plane passing through the posterior teeth in maximum intercuspation.

2. Posttreatment occlusal plane slope. This is the slope, in degrees, of the functional occlusal plane on the posttreatment cephalogram relative to the same frame of reference on the digitizing table used for pretreatment functional occlusal plane.

3. Change in occlusal plane slope. This is the change in the occlusal plane slope from pre- to posttreatment. Therefore if the occlusal plane becomes steeper during treatment, the change will be recorded as a negative value.

4. Mean functional occlusal plane (MFOP). This measurement is calculated as the arithmetic average of the pre- and posttreatment values. The majority of the Pitchfork values are measured in relation to the MFOP.

5. U6 angulation pretreatment. The angle of the maxillary first molar relative to the MFOP. The long axis of the tooth is drawn on the tracing and the posterosuperior angle is measured (Figure 12).

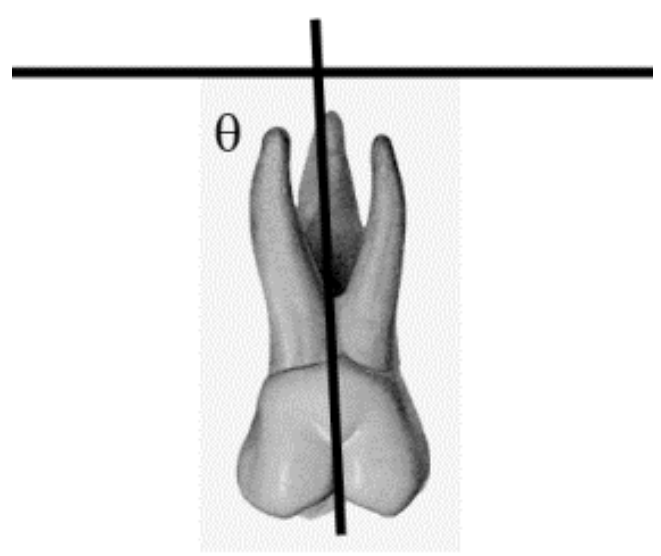

Figure 12. Diagram of U6 showing the posterior-superior angle measured at the pre- and posttreatment examination to calculate the change in molar angulation. 
6. U6 angulation posttreatment. This angle of the maxillary first molar relative to MFOP. The long axis of the tooth is drawn on the tracing and the posterosuperior angle is measured.

7. Change in U6 angulation. This is the mathmatical difference in the maxillary first molar angulation, posttreatment minus pretreatment. Therefore mesial tipping of the maxillary molar will result in a negative value, reflecting the worsening of the Class II molar relationship.

8. Linear conversion of $\mathrm{U} 6$ tipping. The change in $\mathrm{U} 6$ angulation recorded above in item 7 , is converted to a linear distance in millimeters using the formula:

$$
\bar{x}=(13.2 \sin (\theta+24))-5.5
$$

where $\theta$ is the change in $\mathrm{U} 6$ angulation and $(\bar{x})$ is the linear conversion in millimeters. In fact, this formula makes no sense, though it was presented by Johnston (1986) without comment. For example, if there is no angular change, this equation results still indicates $5.5 \mathrm{~mm}$ of mesial U6 movement, which seems inappropriate unless there is an error with the parentheses. We have agreed with other recent publications (Pangrazio-Kulbersh et al. 2003, Ghislanzoni et al. 2011) that present total U6 and L6 movement will be used without trying to partition between bodily and tipping movements.

9. U6 Mesiodistal Movement/MFOP. This measurement constitutes the mesiodistal movement of the distal anatomic contact of the maxillary first molar from pre- to posttreatment parallel to the MFOP. The pretreatment value is subtracted from the posttreatment value (Figure 13).

10. L6 angulation pretreatment. This measurement is the same for the maxillary molar (item 5), except that the angle measured here is the posteroinferior angle formed by the intersection of the long axis of the lower molar and MFOP.

11. L6 angulation posttreatment. Same measurement as in item 11 above, measured on the posttreatment cephalogram.

12. Change in L6 angulation. This change is calculated by subtracting the pretreatment angle from the posttreatment angle. Therefore, if the angle is decreased during treatment, a positive value will reflect tipping that will aid in Class II correction. 


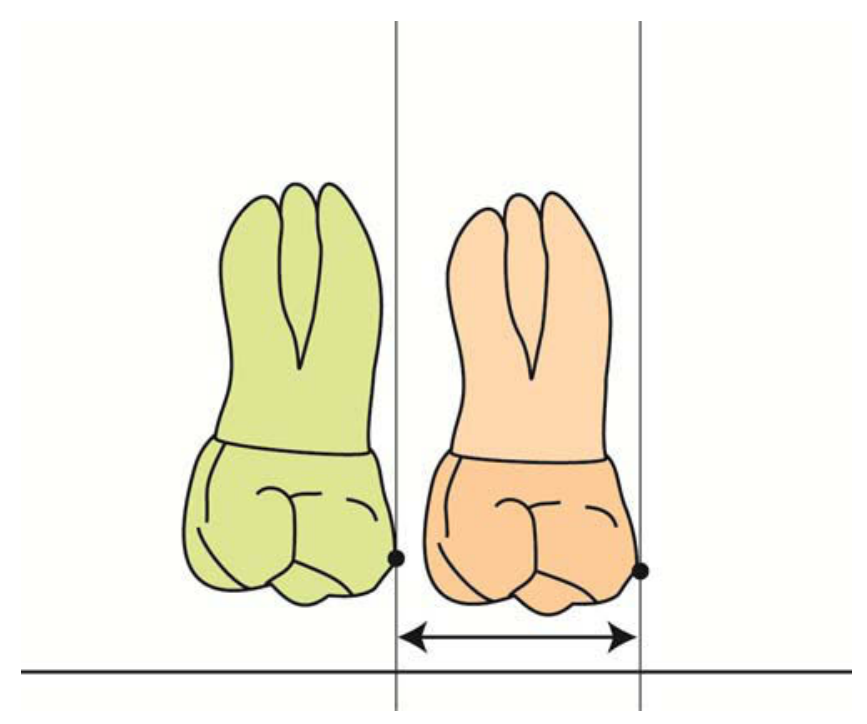

Figure 13. Diagram of U6 before and after treatment showing the change in position.

Measurements were taken at the crowns' height of contour. This molar distance is U6 Mesiodistal Movement parallel with the MFOP.

13. Linear conversion of L6 tipping. Similar to the maxillary molar, it is necessary to convert the degree change in angulation to a linear millemetric measurement. The same formula as was used for upper molars is used for mandibular molar conversion. (Again, we omit this formula in the present study.)

14. L6 mesiodistal movement/MFOP. This measurement is the linear distance the molar moves during treatment parallel to the MFOP. This measurement is affected by both tooth movement as well as any mandibular translative growth relative to the maxilla. The measurement is calculated by subtracting the posttreatment value from the pretreatment value. Once again, a positive value reflects positive, mesial movement, aiding in Class II correction (Figure 14).

15. Linear (diagonal) change from $\mathrm{D}$ to $\mathrm{D}^{\prime}$. Point $\mathrm{D}$ is the center of the mandibular symphysis as viewed on a lateral cephalogram. The pretreatment $\mathrm{D}$ point was located visually and transferred to the posttreatment film by aligning mandibular bony architecture and labeled as $\mathrm{D}^{\prime}$. The linear change from $\mathrm{D}$ to $\mathrm{D}^{\prime}$ was calculated using the Pythagorean theorem. Positive values reflect anterior movement of the 


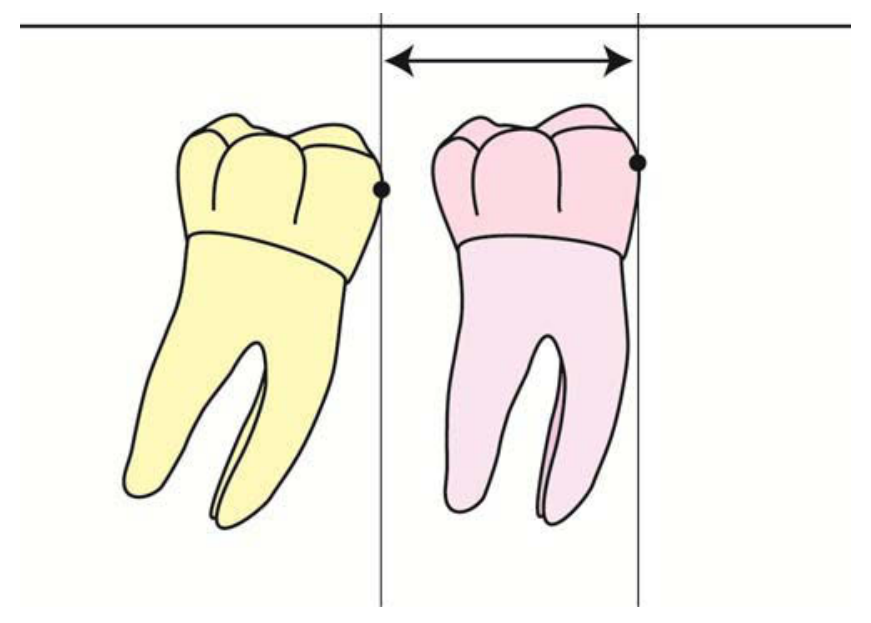

Figure 14. Diagrams of U6 before and after treatment showing the change in position.

Measurements were taken at the crowns' height of contour measured parallel with MFOP.

mandible during treatment. Therefore, the pretreatment position of $\mathrm{D}$ is subtracted from $\mathrm{D}^{\prime}$.

16. Horizontal change from $\mathrm{D}$ to $\mathrm{D}^{\prime}$. Similar to the measurement from item 15 above, but this change is measured parallel to the MFOP. The result is a positive value reflecting forward movement of the mandible during treatment (Figure 15).

17. Vertical change from $\mathrm{D}$ to $\mathrm{D}^{\prime}$. Similar to items 15 and 16 above, but the change is measured perpendicular to the MFOP. A positive value indicated a depressed mandible during treatment (i.e., increased hyperdivergence). Pretreatment vertical distance is subtracted from posttreatment distance perpendicular to the MFOP.

18. L6 Mesiodistal movement/D. This measurement constitutes the total mesiodistal movement of the mandibular first molars relative to the apical base (point $\mathrm{D}$ ). The linear distance in millimeters is measured from point $\mathrm{D}$ to the mesial anatomic contact point of the lower molar parallel to the MFOP on the pretreatment tracing. The same measurement is repeated on the posttreatment tracing using $\mathrm{D}^{\prime}$. The posttreatment value is subtracted from the pretreatment value; thus, a positive value indicates mesial movement of the lower molar relative to the apical base. 

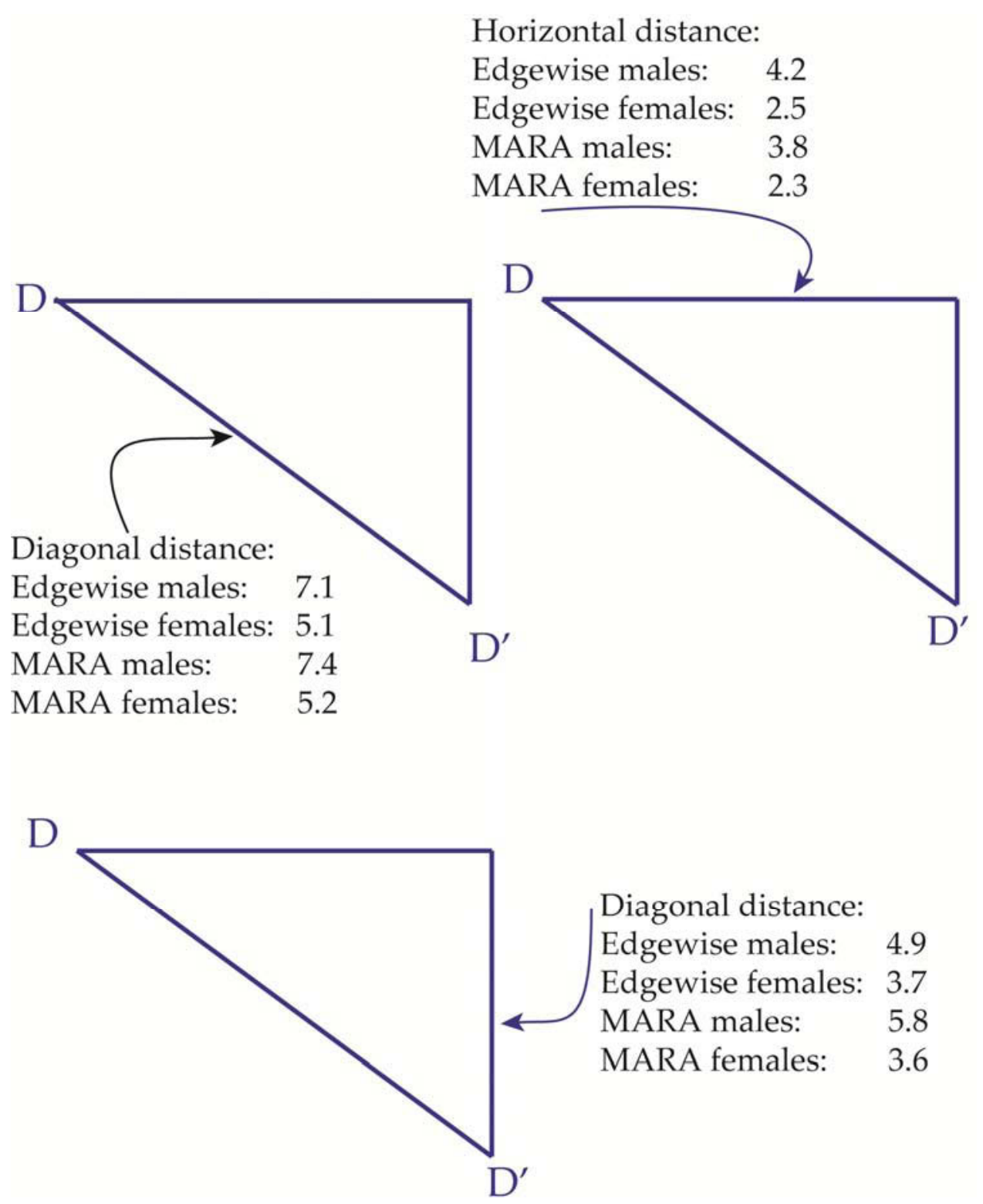

Figure 15. Changes in the straight-line distances of point $D$ to point $D^{\prime}$ and horizontal and vertical changes during orthodontics, by sex and treatment. 
19. SE change. The SE change is the change in location of the SE point parallel to the MFOP from pre- to posttreatment. This change is the maxillary anteroposterior change relative to the cranial base. Anterior movement of the SE point is given a negative value to reflect its worsening of the Class II condition (Figure 16).

20. Total molar correction. This is the change in distance between the anatomic contact points of maxillary and mandibular first molars from pre- to posttreament measured parallel to the MFOP.

21. Apical base change $(\mathrm{ABCH})$. This measure represents the horizontal change in position of the mandible as recorded by $\mathrm{D}$ point relative to the superimposed maxillae parallel to the MFOP.

22. Maxillary translational growth. Maxillary growth is measured relative to the cranial base as the change in SE point from the superimposed maxillae parallel to the MFOP. Maxillary translation is negative because anterior maxillary growth worsens the Class II molar relationship.

23. Mandibular translational growth. Mandibular growth is the sum of the maxillary growth (negative value) relative to the cranial base plus mandibular displacement measured relative to the maxilla. Represented algebraically as:

$$
\text { Mand }=\mathrm{ABCH}-\mathrm{Max}
$$

24. Change in $\mathrm{U} 1$ angulation. This value represents the change in angulation of the maxillary incisors. The posterosuperior angles of the

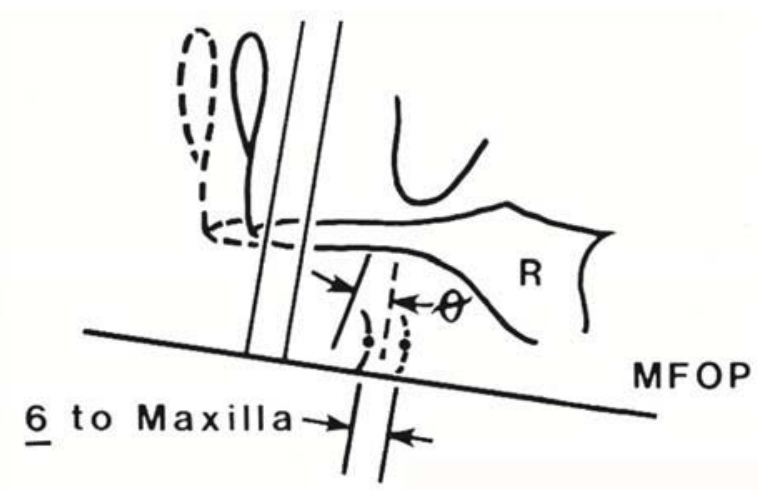

Figure 16. Diagram of a maxillary cephalographic superimposition showing the forward growth of the maxillary complex (parallel lines) that detracts from correction of a Class II malocclusion. 
intersection of the line through the long axis of the maxillary incisors and the MFOP are measured on both pre- and posttreatment films. Pretreatment values are subtracted from posttreatment values; therefore flaring of upper incisors during treatment would result in a negative value.

25. U1 movement. Lines are drawn perpendicular to the MFOP through incision superius (Is) to the MFOP on both pre- and posttreatment films. The distance between these two points parallel to the MFOP is U1 movement. A negative sign indicates anterior movement of the incisor (Figure 17).

\section{Calculation of the Pitchfork Diagram}

In assessing the sagittal changes that affect molar correction, the component parts can be distinguished. A "pitchfork" diagram (Johnston 1986) is used to differentiate the dental and skeletal movements. A cranial base superimposition method is useful in describing the change in mandibular displacement relative to the cranial base, but it is not informative as to how the mandible relates to the maxilla. Likewise, a cranial base superimposition does not account for the changes of the maxilla as it relates to the mandible. The pitchfork analysis accounts for this change and is recorded as $\mathrm{ABCH}$.

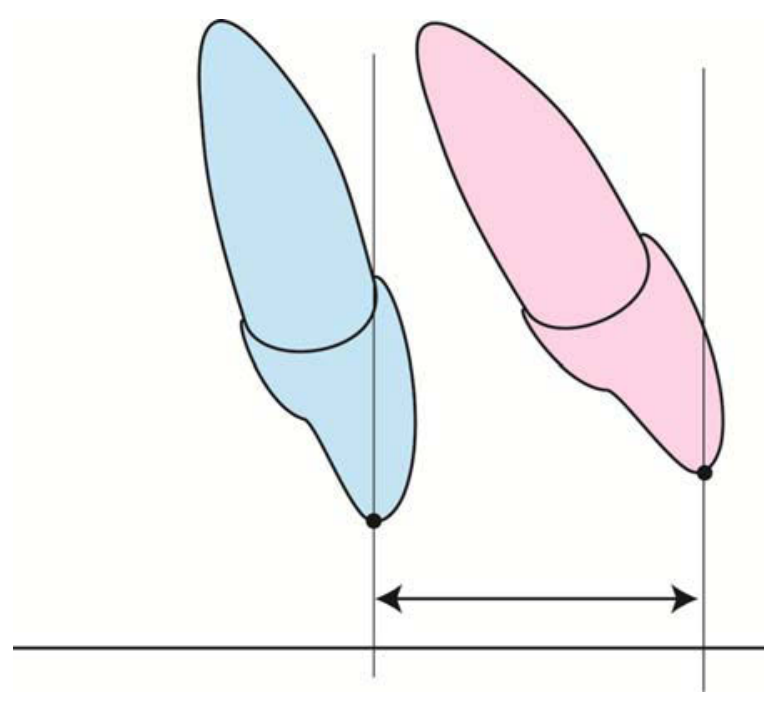

Figure 17. Diagrams of the maxillary incisors before and after treatment showing the change in incisal edges (measured parallel with the MFOP). 
As stated, all sagittal measurements are measured along the MFOP. Mandibular translation relative to the maxilla is termed Apical Base Change $(\mathrm{ABCH})$ and is measured as the horizontal change of $\mathrm{D}$ to $\mathrm{D}^{\prime}$. Mandibular translation relative to the cranial base is the sum of the absolute value of the maxillary translation plus $\mathrm{ABCH}$,

$$
\text { Mandibular translation }=\text { maxillary translation }+\mathrm{ABCH} \text {. }
$$

This can be rewritten as:

$$
\mathrm{ABCH}=\text { mandibular translation }+ \text { maxillary translation } .
$$

Overall movement of the maxillary first molar (U6) is the value U6 M-D Movement/MFOP. The amount of linear movement caused by tipping was recorded as U6 linear conversion and the remainder as bodily movement. Overall movement of the mandibular first molar (L6) relative to the mandible is L6 Movement/MFOP, and the linear movement caused by tipping was recorded as L6 Linear Conversion. The remainder of the movement is bodily displacement:

$$
\text { Tipping + bodily }=\text { total movement }
$$

Total molar correction (U6/L6) is the sum of $\mathrm{ABCH}$, maxillary first molar movement (U6), mandibular molar movement (L6):

$$
\mathrm{U} 6 / \mathrm{L} 6=\mathrm{ABCH}+\mathrm{U} 6+\mathrm{L} 6
$$

The components of molar correction in each sample can then be determined. The amount of correction attributable to skeletal growth is $\mathrm{ABCH}$, and the amount due to dental movement is assessed as changes in first molar positions relative to one another (U6/L6).

Apical base change $(\mathrm{ABCH})$ is the amount of forward growth of the mandible, specifically the horizontal component of the $\mathrm{D}$ to $\mathrm{D}^{\prime}$ change. This will be positive unless there is a severe down and back, or clockwise rotation of the mandible. The $\mathrm{ABCH}$ value is the maxillomandibular differential, or the movement of the mandible relative to the maxilla. A positive value indicates that the mandible grew more than the maxilla, and a negative value means that the maxilla outgrew the mandible. 
"Mandibular" growth is the net change between the mesial displacements of the maxilla and mandible. It is not the amount of mesial mandibular growth (which is termed apical base change); instead, mandibular growth is the $\mathrm{ABCH}$ minus maxillary growth. Note that, since maxillary growth normally is negative, subtraction of a negative value is the same as addition. So, for example, if maxillary growth is $-1.0 \mathrm{~mm}$ and $\mathrm{ABCH}$ is $2.0 \mathrm{~mm}$, then mandibular growth is

$$
\text { 2.0-(-1.0), which is }+3.0 \mathrm{~mm} \text {. }
$$

As an aside, remember that the two cephalometric tracings are superimposed on the lingual palatal outlines. Consequently, mandibular growth is exaggerated to the extent that the maxilla is moved between examinations. The amount of exaggeration is "SE growth", so "SE growth" must be subtracted from the $\mathrm{ABCH}$ value to obtain the true amount of mandibular growth. Notice, then, that $\mathrm{ABCH}$ is the amount the mandible grows forward relative to the maxilla, but the maxilla is also moving forward.

Total molar correction is the net mesiodistal change of the maxillary and mandibular first molars measured along the MFOP. Orthodontic correction should decrease the difference between the mesial margins of the upper and lower first molars, so the change should be positive.

After all cephalograms were traced, measured and the data recorded, a wash-out period of 3 months was taken. After the wash-out period, all radiographs were re-traced, re-measured and re-recorded to account for tracing and measurement error.

\section{Statistical Design}

Data were collated into an Excel 2007 spreadsheet (Microsoft Corporation, Redmond, WA) then transferred to the JMP statistical package version 9 (SAS Institute Inc., Cary, NC). Exploratory data analysis (Tukey 1977) was performed, searching for outliers; those due to technical errors were corrected. Conventional descriptive statistics (e.g., Sokal and Rohlf 1995) were calculated; these (and their abbreviations) are sample size (n, taken as counts of individuals, not sides), the arithmetic mean $(\bar{x})$, the standard deviation (sd), and the standard error of the mean (sem, calculated as $\mathrm{sd} / \mathrm{V}_{\mathrm{n}}$ ). The conventional alpha level of 0.05 was used throughout, and all of the tests were two-tail. No correction was made for 
multiple comparisons. Salient results of the analysis were graphed using Delta Graph $^{\circledR} 6.5$ for Windows (Red Rock Software, Inc., Salt Lake City, Utah). 


\section{CHAPTER 4. RESULTS}

Comparability of the two samples at the start of treatment is highly desirable. As noted earlier, the MARA and Standard Edgewise samples were matched based on six criteria, specifically (1) the patient's sex, (2) SNA, (3) SNB, (4) ANB, (5) NAP, and (6) FMA. The strategy was to match the two groups on a case-by-case basis using the subject's sex and these cephalometric criteria specifically directed at the anteroposterior relationship of the maxilla and mandible.

\section{Matching Subjects between Treatments}

It is key that the patients treated with the MARA-plus-Edgewise appliance were cephalometrically comparable to the Edgewise-only patients at the start of treatment. The time-intensive effort of matching was found to be successful (Table 2) in that the probabilities (P values) of all five cephalometric variables were far from statistical significance.

To confirm the efficacy of the matching process, which was quit timeconsuming, we used two statistics. One approach was to calculate pairing design t-tests (e.g., Woolf 1968) along with Bland-Altman plots (e.g., Bland and Altman 1996a,b) to test for a systematic difference between the matches. The

Table 2. Results of mixed-model analysis of variance tests to evaluate the comparability of the matched samples at the start of treatment.

\begin{tabular}{lcccccccc}
\hline & \multicolumn{2}{c}{ Sex } & & \multicolumn{2}{c}{ Treatment } & & \multicolumn{2}{c}{ Interaction } \\
\cline { 2 - 3 } \cline { 8 - 9 } Variable & $\mathrm{F}$ & $\mathrm{P}$ & & $\mathrm{F}$ & $\mathrm{P}$ & & $\mathrm{F}$ & $\mathrm{P}$ \\
\hline NAP & 0.09 & 0.7708 & & 0.14 & 0.7096 & & 0.02 & 0.8753 \\
SNA & 0.09 & 0.5425 & & 0.37 & 0.5419 & & 0.13 & 0.7177 \\
SNB & 0.00 & 0.9954 & & 0.17 & 0.6787 & & 0.07 & 0.7894 \\
ANB & 1.58 & 02114 & & 0.26 & 0.6127 & & 0.04 & 0.8488 \\
FMA & 0.05 & 0.8307 & & 2.25 & 0.1365 & & 0.62 & 0.4316 \\
\hline
\end{tabular}

These are group comparison tests from ANOVA. 
other approach was to calculate the regression correlation (regressing Edgewise cases on MARA cases) to test the correlation and difference between means.

Figure 18 plots the differences against mean size for NAP. The average difference for NAP was less than a millimeter, though individual differences ranged to roughly $10^{\circ}$. As with all five matching variables, the Bland-Altman regression coefficient (regressing difference on size) was far from statistical significance. There was no significant difference between groups $(P=0.2041)$, and the correlation was 0.65 (Table 3).

The matching process for SNA (Figure 19) was successful $(\mathrm{t}=0.02 ; \mathrm{P}=$ 0.9871). Nearly all of the matches differed by less than $5^{\circ}$ (Table 4 ). The correlation coefficient between matches was 0.76 .

For $\mathrm{SNB}$, the dispersion was fairly tight (with $+6^{\circ}$ ), and there was no suggestion of a slope between size and difference (Figure 20). The correlation was 0.81 (Table 5).

The matching effort for the ANB angle also was successful (Figure 21); all of the pairs were within $0.22^{\circ}$ of one another. The correlation between the matches was 0.58 for ANB (Table 6).

Matching for FMA averaged less than one degree $\left(0.68^{\circ}\right)$ between subjects in the two treatment groups (Figure 22). The pairing design test was low $(\mathrm{t}=$ 1.50; $\mathrm{P}=0.1402$ ) as listed in Table 7. The correlation for the matches was 0.79 .

In sum, a total of five cephalometric variables were used for matching. These primarily tested for comparable degrees of maxillary and mandible protrusion, which seemed important in this comparison of treatments to obtain an orthognathic final facial profile.

\section{Comparison of Treatments}

Conventional fixed orthodontic appliances do not simply move teeth and teeth only. Instead, it has been shown that orthopedic corrections can be achieved insomuch that the American Journal of Orthodontics was changed to include "Dentofacial Orthopedics". In this sense, dental and orthopedic changes can occur during active treatment. Several mechanical devices, such as intermaxillary elastics, headgear and orthodontic mini-implants (otherwise 


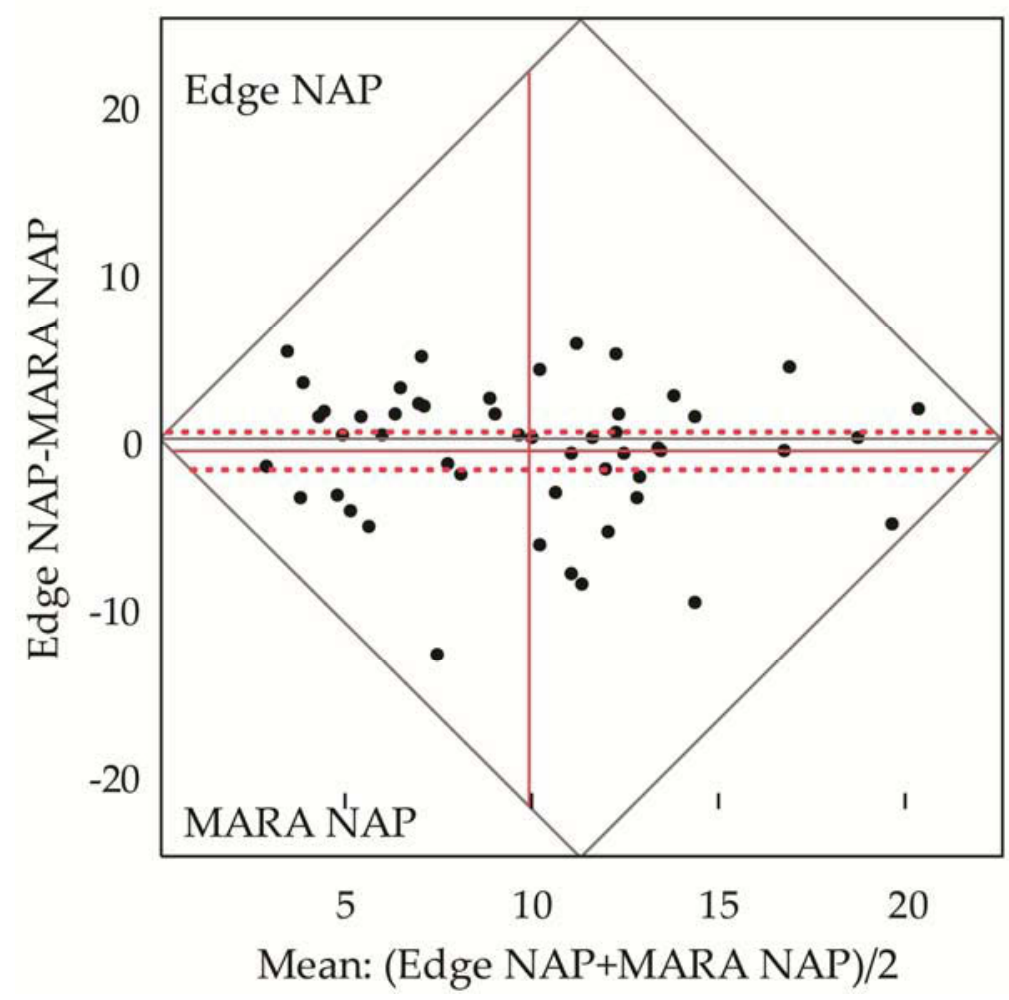

Figure 18. Bland-Altman plot for NAP between the Edgewise and MARA matches at the start of treatment.

Table 3. Results of a pairing design t-test assessing the results of matching patients for NAP.

\begin{tabular}{lrll}
\hline Statistic Value & $\mathrm{t}$-Test & \multicolumn{1}{c}{ Value } & Statistic \\
\hline Edge NAP & 9.52 & $\mathrm{t}$-Ratio & -1.29 \\
MARA NAP & 10.24 & $\mathrm{df}$ & 50 \\
Mean Difference & -0.72 & Probability $>|\mathrm{t}|$ & 0.2041 \\
Standard Error & 0.56 & Probability $>\mathrm{t}$ & 0.8979 \\
Upper 95\% & 0.40 & Probability $<\mathrm{t}$ & 0.1021 \\
Lower 95\% & -1.84 & & \\
Sample size & 51 & & \\
Correlation & 0.65 & & \\
\hline
\end{tabular}




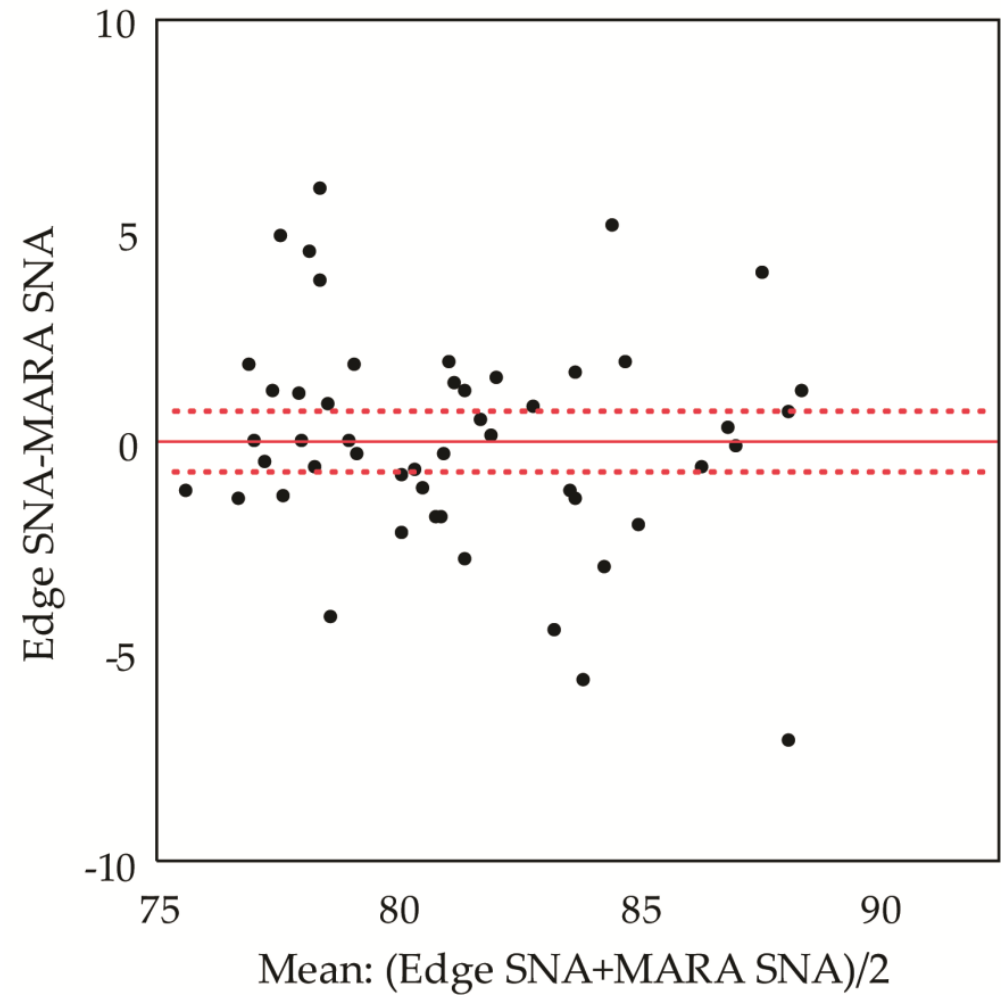

Figure 19. Bland-Altman plot for SNA between the Edgewise and MARA matches at the start of treatment.

Table 4. Results of a pairing design t-test assessing the results of matching patients for SNA.

\begin{tabular}{lclc}
\hline Statistic Value & $\mathrm{t}$-Test & Value & Statistic \\
\hline Edge SNA & 81.25 & t-Ratio & 0.02 \\
MARA SNA & 81.25 & Degrees freedom & 50 \\
Mean Difference & 0.01 & Probability $>|\mathrm{t}|$ & 0.9871 \\
Standard Error & 0.36 & Probability $>\mathrm{t}$ & 0.4935 \\
Upper 95\% & 0.73 & Probability $<\mathrm{t}$ & 0.5065 \\
Lower 95\% & -0.72 & & \\
Sample size & 51 & & \\
Correlation & 0.76 & & \\
\hline
\end{tabular}




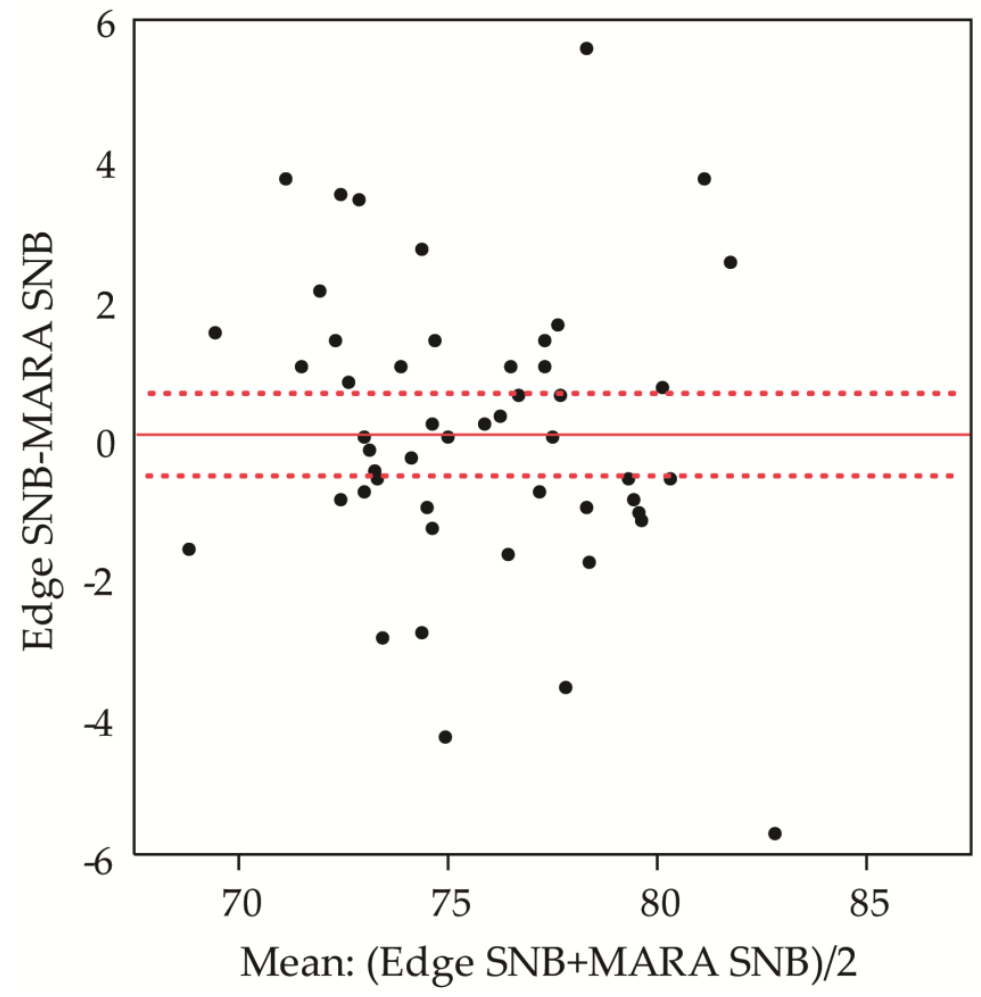

Figure 20. Bland-Altman plot for SNB between the Edgewise and MARA matches at the start of treatment.

Table 5. Results of a pairing design t-test assessing the results of matching patients for SNB.

\begin{tabular}{lclc}
\hline Statistic Value & t-Test & Value & Statistic \\
\hline Edge SNB & 75.73 & t-Ratio & 0.19 \\
MARA SNB & 75.68 & Degrees freedom & 50 \\
Mean Difference & 0.05 & Probability $>|\mathrm{t}|$ & 0.8532 \\
Standard Error & 0.30 & Probability $>\mathrm{t}$ & 0.426 \\
Upper 95\% & 0.65 & Probability $<\mathrm{t}$ & 0.5734 \\
Lower 95\% & -0.54 & & \\
Sample size & 51 & & \\
Correlation & 0.81 & & \\
\hline
\end{tabular}




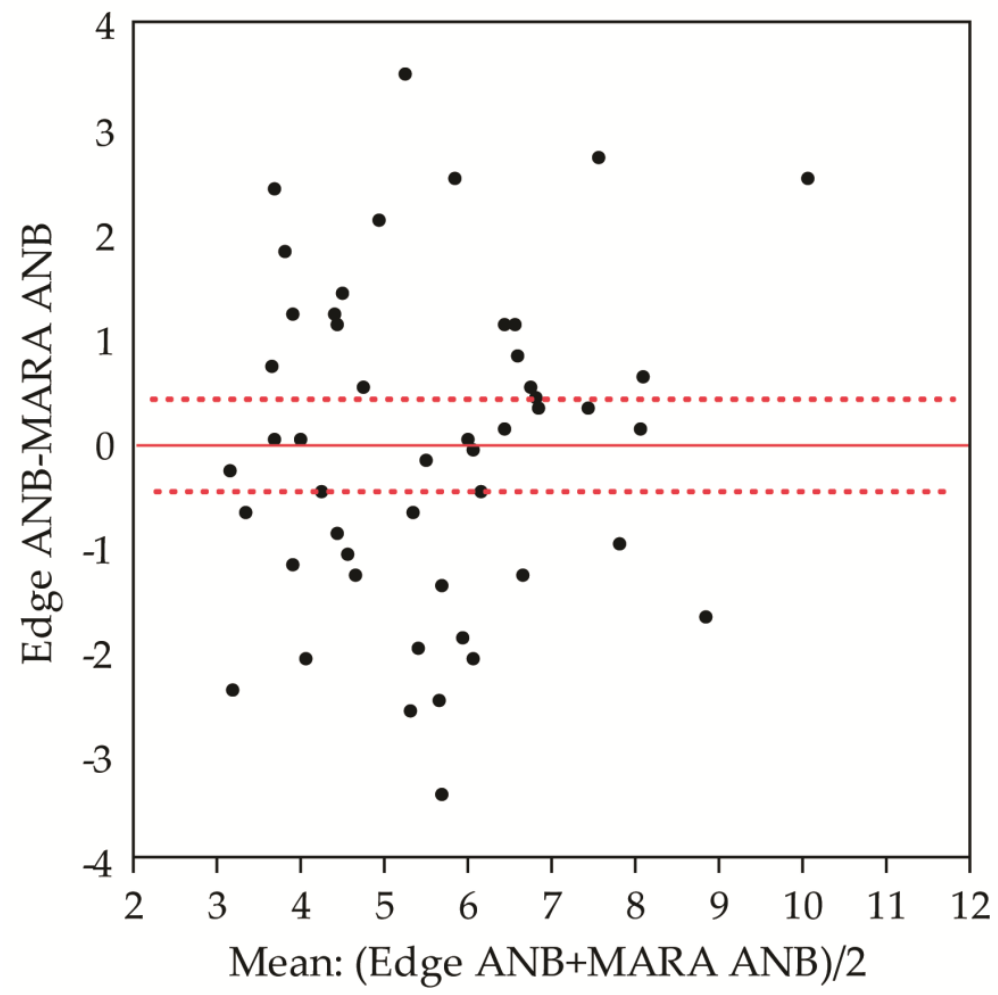

Figure 21. Bland-Altman plot for ANB between the Edgewise and MARA matches at the start of treatment.

Table 6. Results of a pairing design t-test assessing the results of matching patients for ANB.

\begin{tabular}{lclc}
\hline Statistic Value & t-Test & Value & Statistic \\
\hline Edge ANB & 5.52 & t-Ratio & -0.20 \\
MARA ANB & 5.57 & Degrees freedom & 50 \\
Mean Difference & -0.05 & Probability $>|\mathrm{t}|$ & 0.8385 \\
Standard Error & 0.22 & Probability $>\mathrm{t}$ & 0.5807 \\
Upper 95\% & 0.40 & Probability $<\mathrm{t}$ & 0.4193 \\
Lower 95\% & -0.49 & & \\
Sample size & 51 & & \\
Correlation & 0.58 & & \\
\hline
\end{tabular}




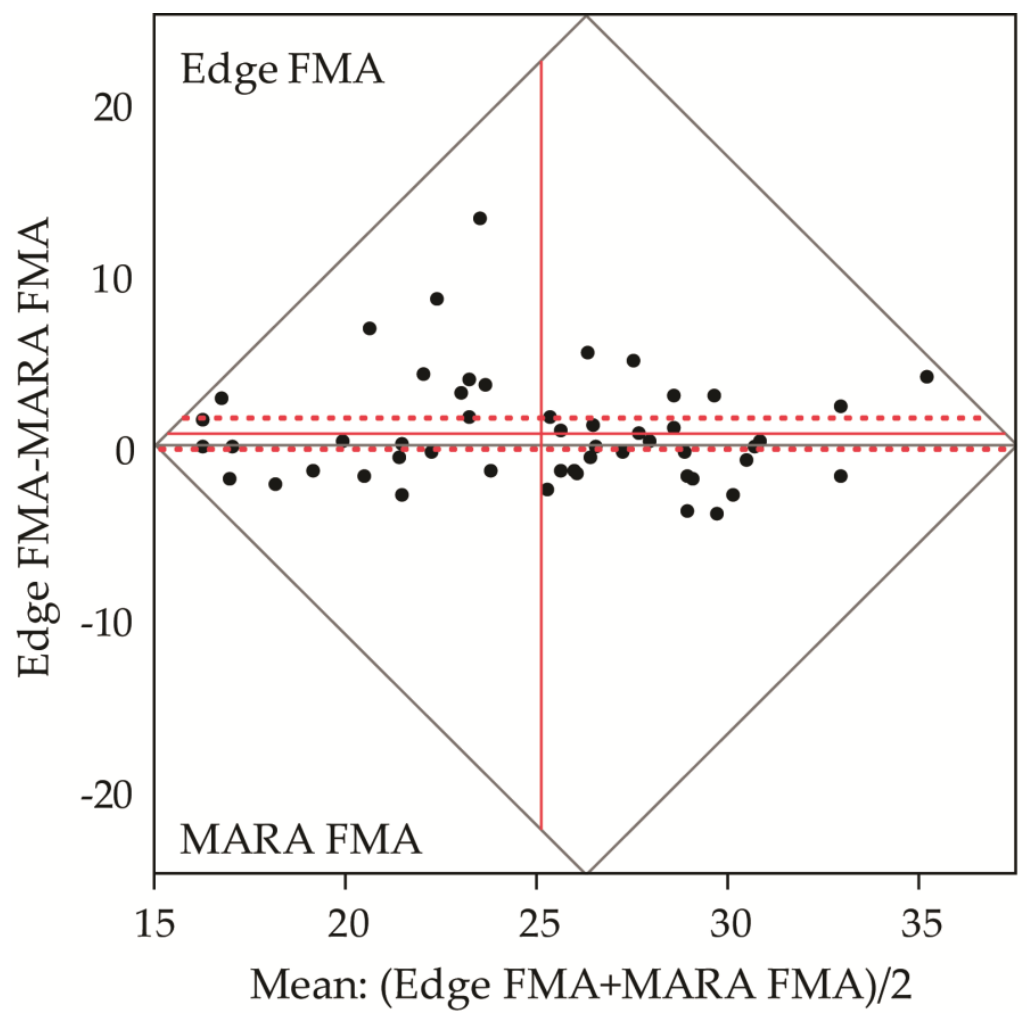

Figure 22. Bland-Altman plot for FMA between the Edgewise and MARA matches at the start of treatment.

Table 7. Results of a pairing design t-test assessing the results of matching patients for FMA.

\begin{tabular}{lclc}
\hline Statistic Value & $\mathrm{t}$-Test & \multicolumn{1}{c}{ Value } & Statistic \\
\hline Edge FMA & 25.41 & t-Ratio & 1.50 \\
MARA FMA & 24.73 & Degrees freedom & 50 \\
Mean Difference & 0.68 & Probability $>|\mathrm{t}|$ & 0.1402 \\
Standard Error & 0.45 & Probability $>\mathrm{t}$ & 0.0701 \\
Upper 95\% & 1.58 & Probability $<\mathrm{t}$ & 0.9299 \\
Lower 95\% & -0.23 & & \\
Sample size & 51 & & \\
Correlation & 0.79 & & \\
\hline
\end{tabular}


termed temporary anchorage devices, or, simply, TADs), are capable of altering bone growth as well as accomplishing dental movement.

It is easy to conceptualize that a restraining force can reduce growth. It is not so clear based on current literature whether propulsive/tensile forces can predictably enhance bone growth. Meikle (2007) states that while there is strong evidence for growth enhancement in animal models, there remains much controversy in humans (Collet 2000; Cozza et al. 2006).

The purpose of the present study was to test the hypothesis that the use of the mandibular anterior repositioning appliance or MARA results in an improved bony facial profile compared to that of a group of standard Edgewise patients. As detailed above, this retrospective study measured the skeletal and dental changes during treatment in a cohort treated with a MARA and Edgewise appliance compared to a matched sample of patients treated with Standard Edgewise appliances alone. The remainder of this chapter describes the treatment changes in these two groups.

\section{Premolar Extractions}

The extraction of teeth for orthodontic treatment is often indicated. In this study, extractions as part of orthodontic treatment were far more common in the Standard Edgewise group than in the MARA group. In the present study, 38 out of $51(75 \%)$ of the Standard Edgewise patients had premolars extracted while only 2 out of 51 (4\%) of MARA patients had teeth extracted. By chi-square analysis ( $1 \mathrm{df})$, these proportions are hugely different statistically $(\chi 2=53.3$; $\mathrm{P}<$ $0.0001)$.

\section{Time in Treatment}

Treatment time of the MARA group was slightly longer than the Standard Edgewise group. The MARA group had an average treatment time of 2.8 years and the Standard Edgewise group's average treatment time was 2.7 years (Table 7). The average age to begin treatment for the MARA group was 12.6 years while the average age to start treatment for the Standard Edgewise group was 13.2 years (Table 7$)$. This difference in treatment time of 0.1 years was statistically insignificant $(\mathrm{P}=0.53)$. 


\section{Technical Error of Measurement}

It is essential to measure the accuracy of measurements, particularly with the Johnston method where the dimensions are fairly small. Johnston is noted for the remark that orthodontics is a "5-mm science" (Johnston 1987). Repeating measurements is the only known method of gauging accuracy (Houston 1984; Harris and Smith 2009). In the present study, all measurements were made independently by the author on two separate occasions. The data files were merged and, for each variable, the difference between the repeated observations was calculated as were the mean difference of the two observations. The sets of values were used to assess intraobserver accuracy using the method of Bland and Altman (1986, 2007). Bland-Altman plots (Braždžionytė and Macas 2007) were made (regressing the differences on mean size), and simple linear regression was used to test for a significant slope of the best-fit line-which would show whether size of the differences are dependent on trait size. These plots are complemented by regressing the differences on mean size; in the absence of a size dependence, the regression line will not differ from zero. Calculations and graphs were made using SPSS version 19, which does not have Bland-Altman plots as an option, but the procedure is easily adapted to the program (e.g., Braždžionytė and Macas 2007).

For these analyses, we did not distinguish between groups (Edgewise treatment, with or without a MARA) or between sexes, so sample size was 102 cases (there were no missing values).

The results of the regression analysis are shown Appendix A (Tables A-1 through A-30 and Figures A-1 through A-30). These are the consequence of performing all of the analyses twice--tthe first time (not shown) to check the results, then the outliers were examined and corrected, then the analyses (shown in Appendix A) were recalculated. No specific value was used to identify outliers; the graphs were inspected, and the obvious errors were flagged and corrected.

\section{Treatment Differences}

The primary question in the present study is if the use of the MARA in Class II patients yields a significantly different result compared to Class II patients treated with the standard Edgewise appliance. This chapter describes the results of statistical analysis directed at detecting treatment effects in a two 
samples of Class II, division 1 orthodontic patients. The analyses are based on the results of the Johnston analysis as described in the prior chapter. Two different orthodontic appliance were used - the MARA appliance and the standard Edgewise appliance-each with proportionate samples of males and females.

Within each section, two broad issues are addressed. One is whether a given variable changed systematically during treatment. That is, if a measurement was not affected by treatment not by growth during treatment, then its average change would not differ significantly from zero. Likewise, if a change occurred but was random, so the variable increased in some cases and decreased in others, then the mean change also would not differ systematically from zero. The following presentation of results includes one-sample t-tests that assess whether each variable actually changed in a patterned fashion during the course of treatment. The descriptive statistics for both treatment groups is found in Appendix B (Tables B-1 through B-30). In many instances, it is as important to recognize whether treatment affected a variable in a systematic fashion as it is to test for differences among groups.

The second issue was to compare whether a given variable differed significantly between groups. These groups were divided by sex and treatment type, as described below. In the present study, two-sample t-tests were used to assess whether a given variable differed significantly between two groups.

\section{Sex Differences}

Several sex differences occurred between the treatments, which is intriguing because they suggest that the structure and response to treatment differ between boys and girls. The descriptive statistics separated by treatment group and sex are found in Appendix C (Tables C-1 through C-30). This sex difference is unanticipated since the conventional view is that, while adolescent girls may be a bit smaller than their male counterparts, they should respond to treatment in parallel. An ANOVA was also performed to find significant differences between treatments, controlling for sex and initial age. The ANOVA results are found in Appendix D (Tables D-1 through D-29). There are 12 significant sex differences from among the variables studied, and these are reviewed here en bloc. 
Radiographic examination found that boys and girls differed statistically in posttreatment L6 angles (Figure 23). Boys in the MARA group had a mean posttreatment L6 angle of $86.39^{\circ}$ and boys in the Edgewise-only group had a mean L6 angle of $85.8^{\circ}$. Girls in the MARA and Edgweise-only group had L6 postreatment angles of $83.9^{\circ}$ and $84.7^{\circ}$ respectively. A larger L6 angle suggests that boys have on average, a greater distal crown tip of the mandibular molars at the end of treatment. Interestingly, there was not a significant difference in pretreatment L6 angles, therefore, boys and girls mandibular molars responded differently to treatment, independent of treatment type.

As would be expected because pretreatment L6 molar angulation was similar but posttreatment L6 angulation was different between sexes, it was found that boy's L6 molars experienced a greater distal crown tip during treatment (Figure 24). This sex dependent molar tip was greater in boys than girls and was independent of the type of treatment (Figure 24). The change is assigned a negative value because distal mandibular molar crown tip would move the molars into a worse Class II relationship.

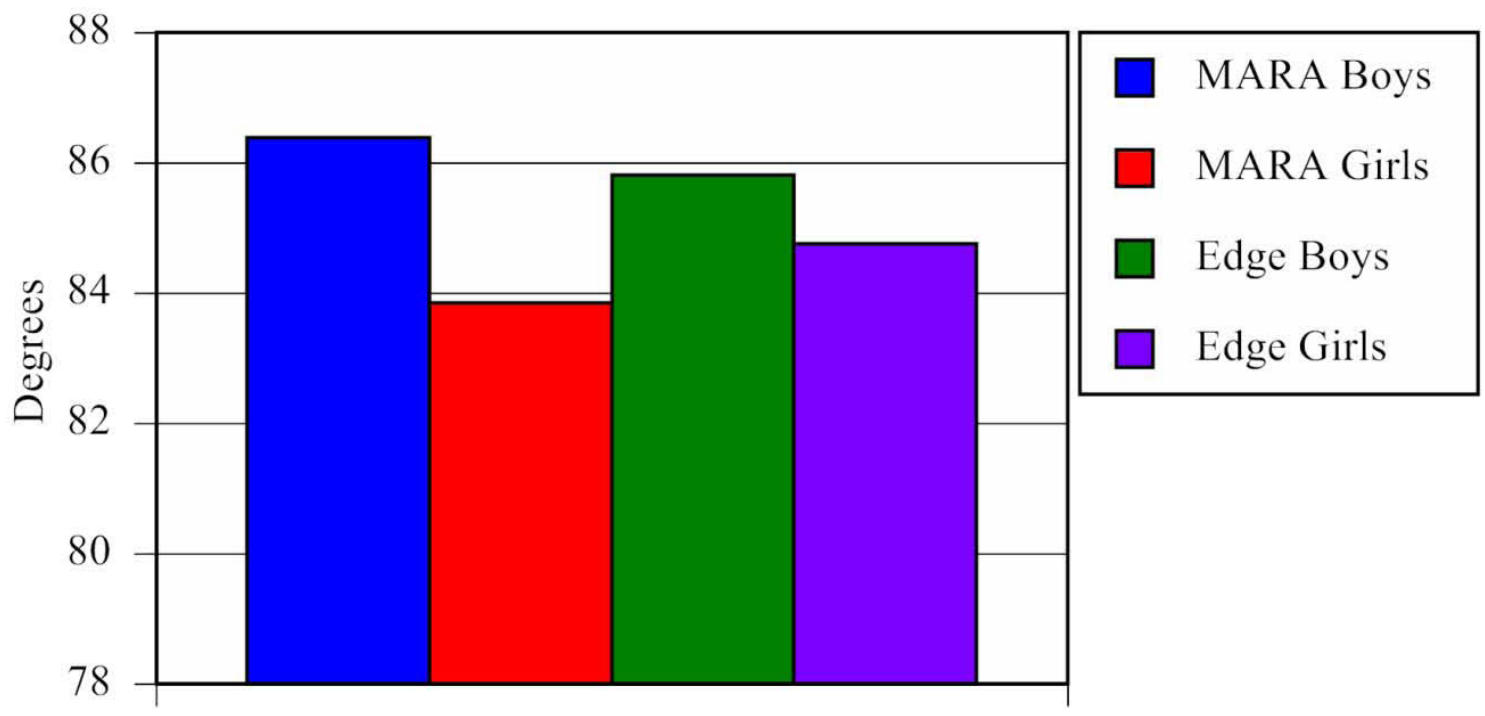

Figure 23. Barchart of the mean values for the L6 angle at the posttreatment examination, by treatment and sex.

Girls have significantly smaller angles than boys at the end of treatment $(\mathrm{P}=$ 0.0314), but not at the start $(\mathrm{P}=0.9982)$. 


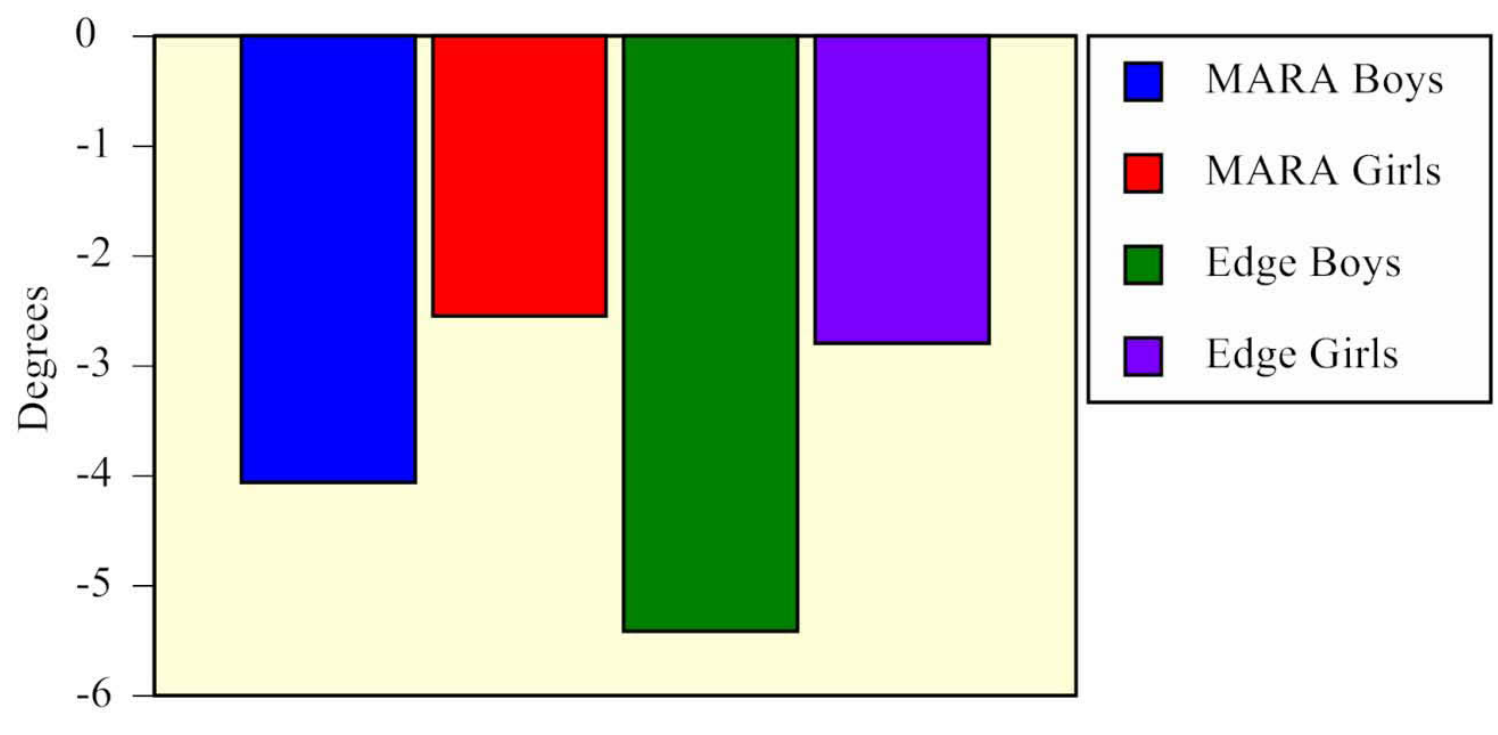

Figure 24. Barchart showing the sexual dimorphism in the treatment change in the angle of L6.

While not strictly significant at an alpha of $0.05(\mathrm{P}=0.0557)$, it is suggestive that boys experienced a greater treatment change in this mandibular tooth during treatment. 
As would be expected, changes in D point were shown to be statistically greater in boys than girls (Figure 25). This illustrates this sex difference for the linear change in $\mathrm{D}$ point. Boys on average had $7.4 \mathrm{~mm}$ of change in $\mathrm{D}$ point in the MARA group and $7.1 \mathrm{~mm}$ of $\mathrm{D}$ point change in the Edgewise-only group. Girls however, were found to have on average $5.2 \mathrm{~mm}$ of D point change in the MARA group and $5.1 \mathrm{~mm}$ of $\mathrm{D}$ point change in the Edgewise-only group. This difference is expected between sexes because boys grow on average appreciably more than girls.

If one breaks down the linear change in $\mathrm{D}$ point into horizontal and vertical vectors, boys were found to have greater horizontal growth, independent of the appliance (Figure 26). Boys in the MARA group were found to have on average $3.7 \mathrm{~mm}$ of horizontal change in D point and boys in the Edgewise-only group had $4.2 \mathrm{~mm}$ of horizontal change. Girls had less horizontal change in D point averaging $2.3 \mathrm{~mm}$ in the MARA group and $2.5 \mathrm{~mm}$ in the Edgewise-only group. This plot illustrates the significant sexual dimorphism in horizontal (relative to MFOP) mandibular growth (Figure 26).

The vertical change in $\mathrm{D}$ point was also found to vary significantly dependent on the subject's sex (Figure 27). Boys were found to have on average $5.8 \mathrm{~mm}$ of vertical change in D point in the MARA group and $4.9 \mathrm{~mm}$ in the Edgewise-only group. Girls, being smaller, had on average $3.6 \mathrm{~mm}$ of vertical change in D point in the MARA group and $3.7 \mathrm{~mm}$ in the Edgewise-only group. This difference is expected and shows the sexual dimorphism of facial growth.

The pretreatment distance L6-D was found to be significantly different between sexes (Figure 28). This difference shows that on average, in early adolescence, boys have greater arch length than females. Boys in the MARA group were found to have on average a L6-D pretreatment distance of $16.9 \mathrm{~mm}$ and boys in the Edgewise-only group had an average pretreatment L6-D distance of $18.3 \mathrm{~mm}$. Girls however, had on average $16.6 \mathrm{~mm}$ in the MARA group and $16.9 \mathrm{~mm}$ in the Edgewise-only group (Figure 28).

Figure 29 illustrates the sexual dimorphism present for the L6 - D distance at posttreatment. As mentioned earlier, this demonstrates the tendency for boys' to have larger mandibles. Compared to the early adolescent, males grow at a greater rate and hence have greater L6-D distance at posttreatment then do females. On average, the posttreatment L6-D for boys in the MARA group was $15.99 \mathrm{~mm}$ and $16.46 \mathrm{~mm}$ for boys in the Edgewise-only group. Girls were found 


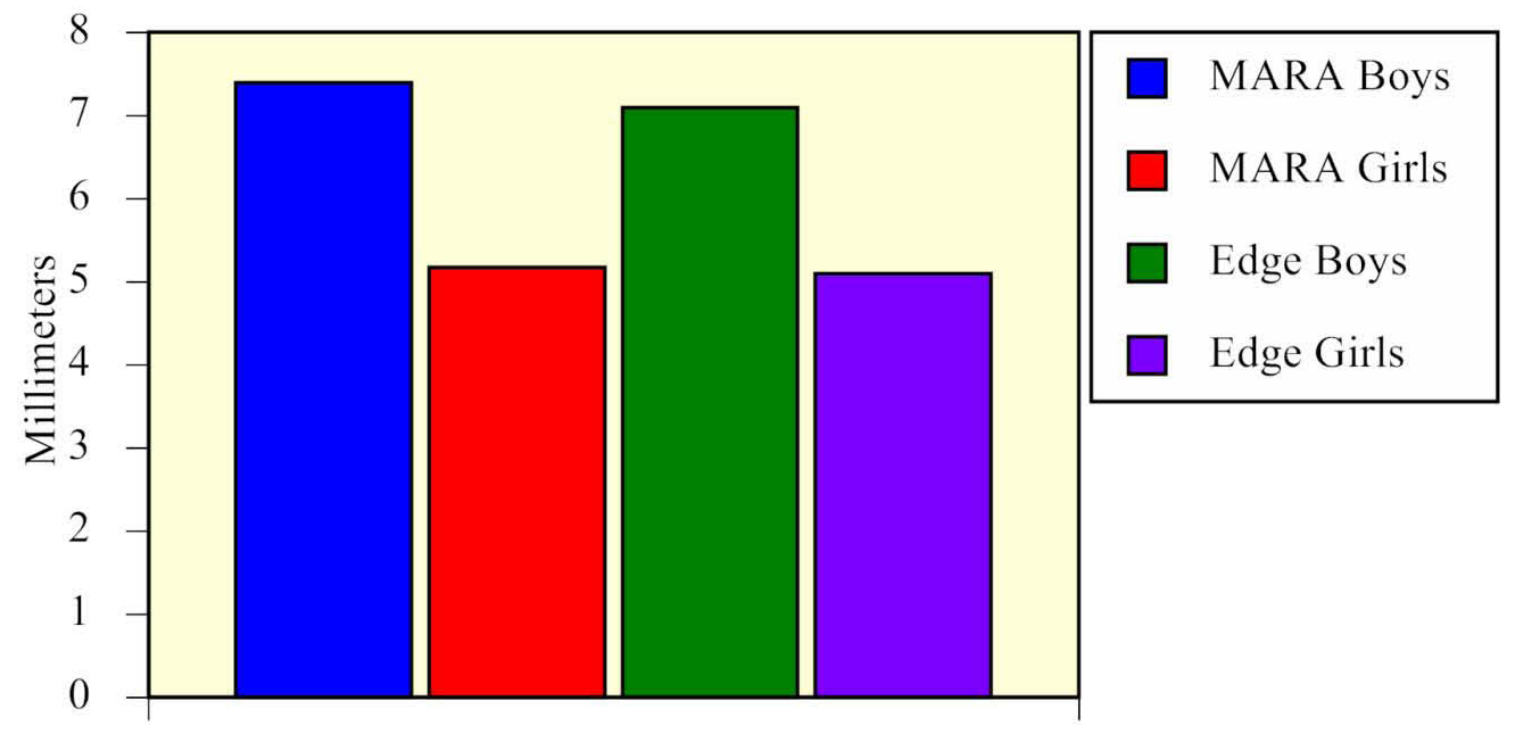

Figure 25. Barchart of the average values for treatment changes in D-D'. The plot shows the nature of the significant sexual dimorphism in the amount of mandibular growth (D-D'), where, on average, boys grow appreciably more than girls. 


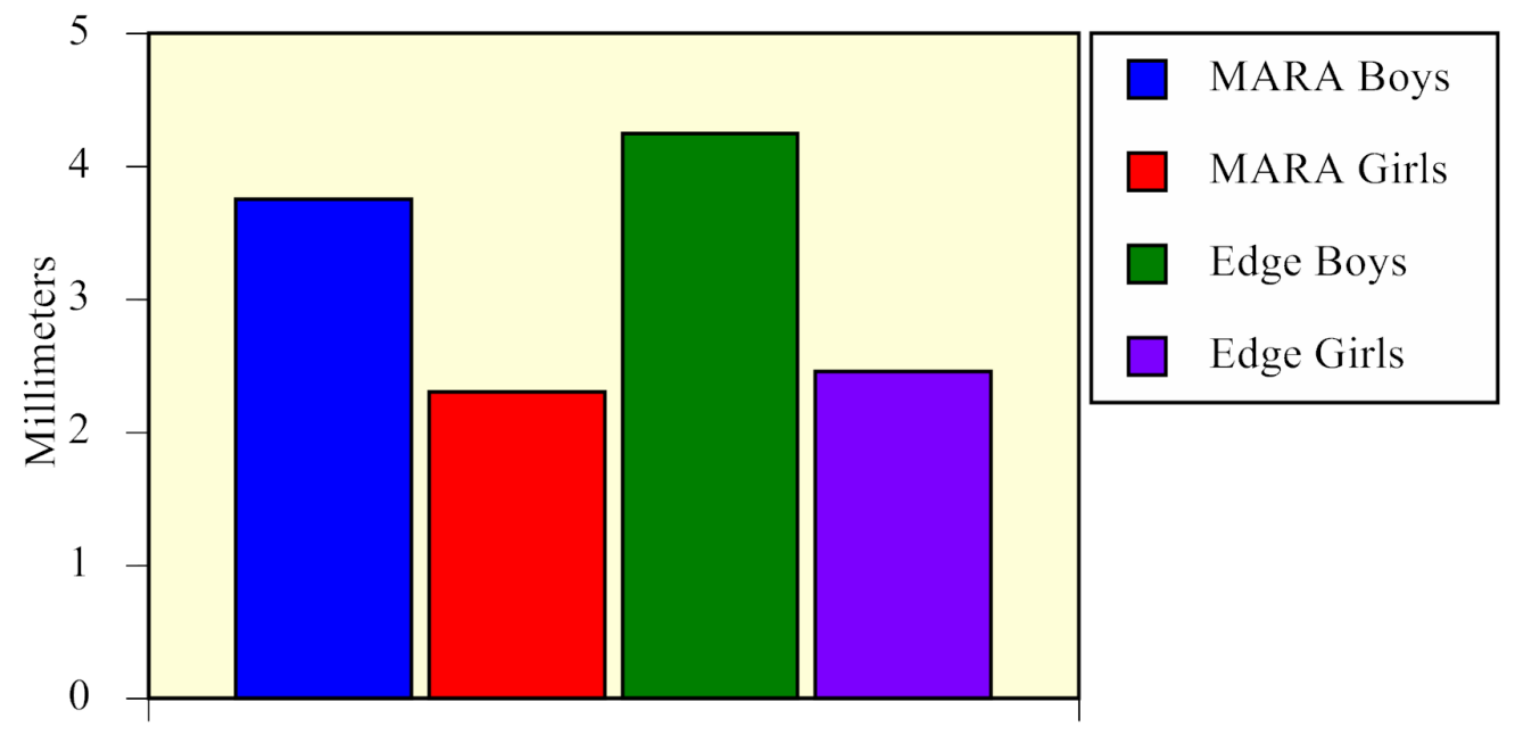

Figure 26. Barchart of the treatment change of the horizontal component of the change in D-D'/MFOP.

As with overall $\mathrm{D}-\mathrm{D}^{\prime}$ growth, the horizontal piece is significantly larger in boys $(\mathrm{P}=0.0061)$. Visually, growth is about twice as large in boys (ca. $4 \mathrm{~mm})$ than girls (ca. $2 \mathrm{~mm}$ ). 


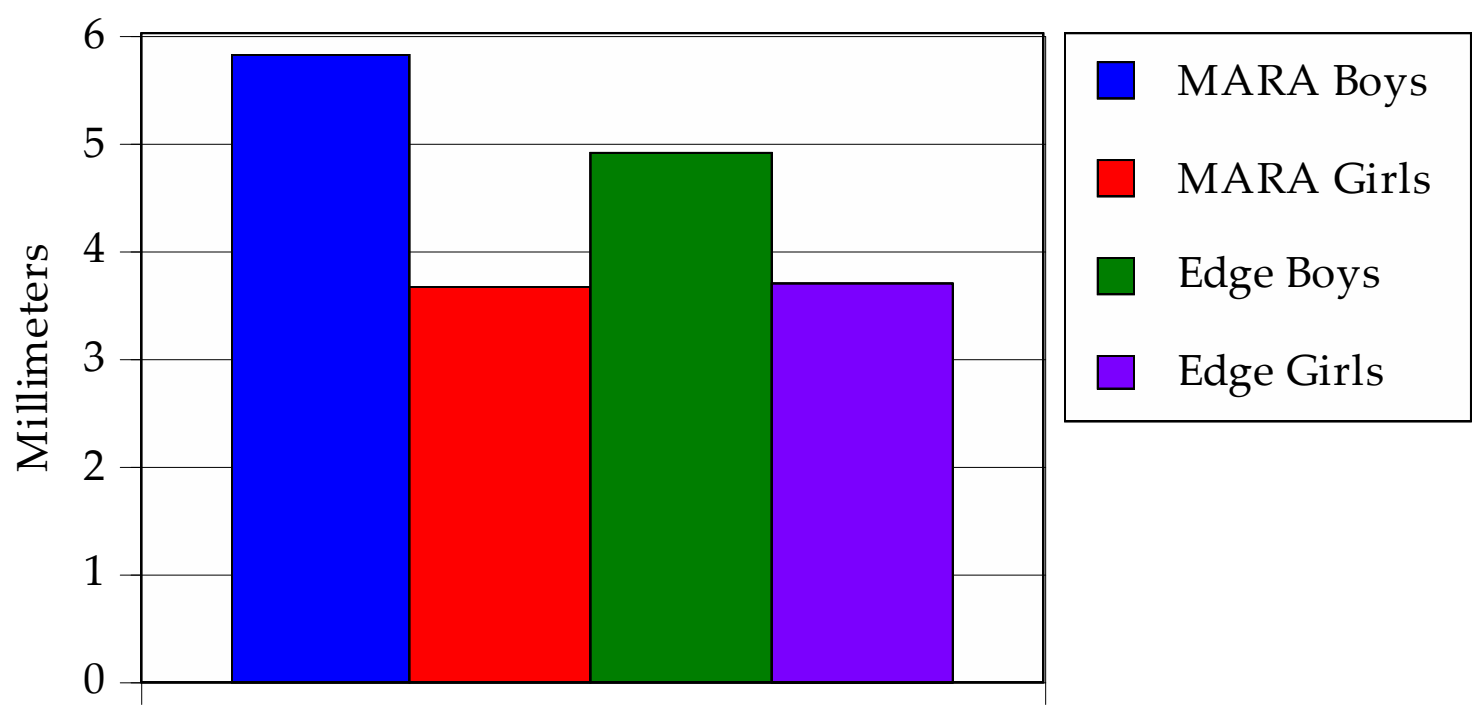

Figure 27. Barchart of the average treatment changes of the vertical (D$\left.\mathrm{D}^{\prime} / \mathrm{MFOP}\right)$ between treatments and sexes.

Growth is significantly greater in boys than girls, especially in the MARA sample. Of course, much of this change is attributable to normative growth, not just treatment. 


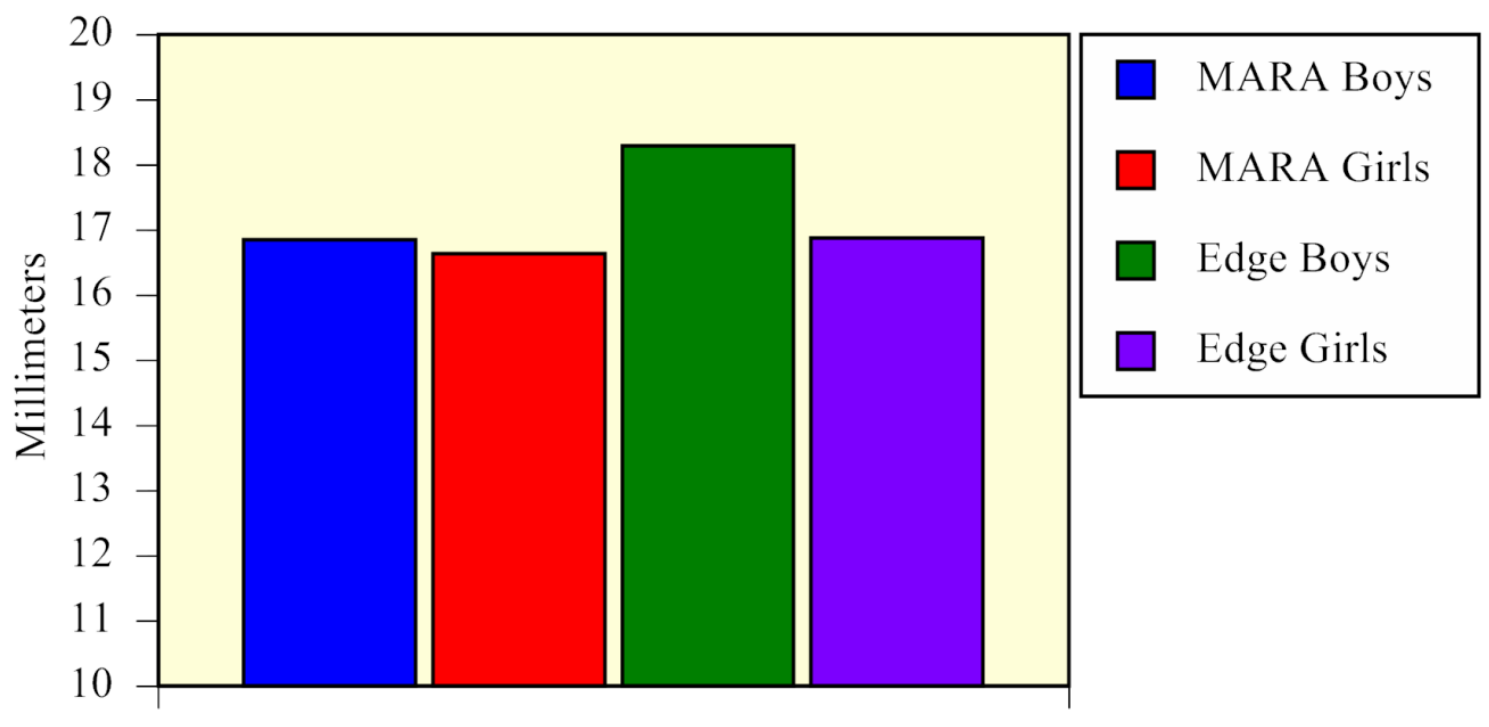

Figure 28. Barchart of the pretreatment distance between L6 and D.

The figure shows that, by early teenage years, boys' mandibles are larger than in girls $(\mathrm{P}=00588)$. While not strictly significant, the statistical difference is small enough to warrant mention. 


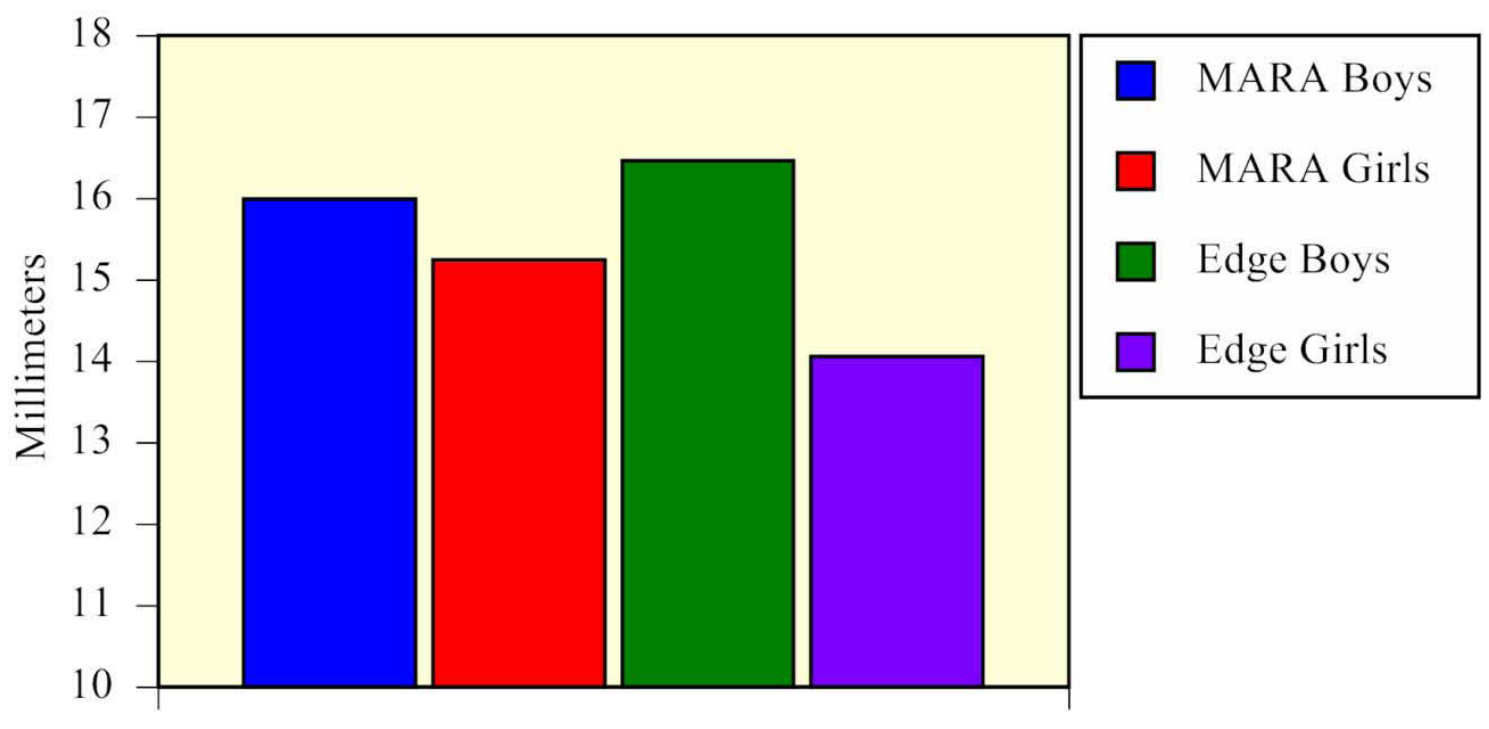

Figure 29. Barchart of the average distances of $L 6$ to $D$ at the posttreatment examination.

Just as in the prior graph, this shows that by the teenage years, boys tend to have a longer mandibular arch length (L6-D) than girls (P 0.0289). Here, in the latter part of adolescence, the sex difference in more apparent than when the subjects were younger. 
to have on average $15.2 \mathrm{~mm}$ in the MARA group and $14.1 \mathrm{~mm}$ in the Edgewiseonly group (Table C-15).

Total molar correction is the net mesiodistal change of the maxillary and mandibular first molars measured along the MFOP. Boys were found to have significantly greater total molar correction compared to girls (Figure 30). Boys had on average $6.6 \mathrm{~mm}$ of total molar correction in the MARA group, $7.6 \mathrm{~mm}$ of total molar correction in the Edgewise-only group. Girls on average were found to have a total molar correction of $4.7 \mathrm{~mm}$ in the MARA group and $4.4 \mathrm{~mm}$ in the Edgewise-only group (Table C-20).

The $\mathrm{ABCH}$ value is the maxillomandibular differential, or the movement of the mandible relative to the maxilla. This will be positive unless there is a severe down and back, or clockwise rotation of the mandible. Since boys on average experience greater growth, it is expected to have a greater $\mathrm{ABCH}$ in males as shown in Figure 31. Boys on average had $3.7 \mathrm{~mm} \mathrm{ABCH}$ in the MARA group and $4.3 \mathrm{~mm} \mathrm{ABCH}$ in the Edgewise-only group. Girls, however, on average had $2.3 \mathrm{~mm} \mathrm{ABCH}$ in the MARA group and $2.5 \mathrm{~mm} \mathrm{ABCH}$ in the Edgewise-only group (Table C-21).

Maxillary incisor angulation and movement also was found to have differences dependant on the sex of the subjects. Posttreatment radiograph comparison shows significant difference in the $\mathrm{U} 1$ angulation (Figure 32). The larger the $\mathrm{U} 1$ angle, the more upright or retrusive the maxillary incisor. Females had a significantly larger posttreatment $\mathrm{U} 1$ angle compared to males. Boys had on average, an $\mathrm{U} 1$ posttreatment angle of $57.9^{\circ}$ in the MARA group and $61.4^{\circ}$ in the Edgewise-only group. Girls, averaged an U1 posttreatment angle of $58.3^{\circ}$ in the MARA group and $69.9^{\circ}$ in the Edgewise-only group (Table C-25).

While not strictly statistically significant, it is of interest to note the difference in U1 movement (Figure 33). Edgewise-only subjects on average experienced greater $\mathrm{U} 1$ movement than the MARA group. Although this change is given a positive value, the positive change equates to a less protrusive, upright incisor. Boys on average had an U1 movement of $0.4 \mathrm{~mm}$ in the MARA group and $2.5 \mathrm{~mm}$ in the Edgewise-only group. Girls, on average had an U1 movement of $0.4 \mathrm{~mm}$ in the MARA group and $4.3 \mathrm{~mm}$ in the Edgewise-only group (Table C-27). In addition, Figure 11 illustrates the large difference in U1 movement between treatment groups. The Edgewise-only group experienced significantly greater U1 movement compared to the MARA group. The MARA group had 


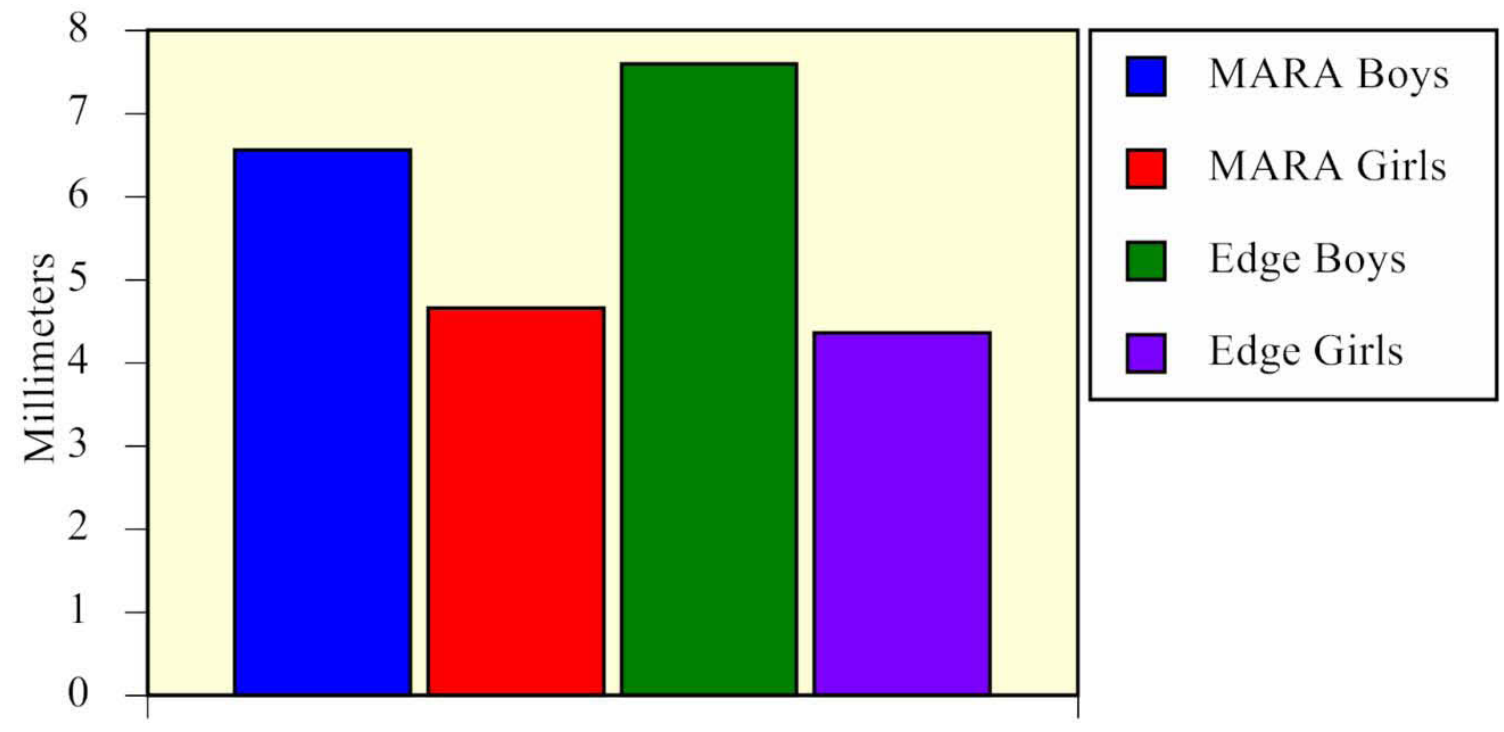

Figure 30. Barchart of total molar correction by treatment and sex.

Millimeters of change were significantly larger in boys than girls $(P=0.0076)$. Indeed, the average amounts of change are about twice as large (6 to $7 \mathrm{~mm}$ ) in boys than girls (4 to $5 \mathrm{~mm}$ ). 


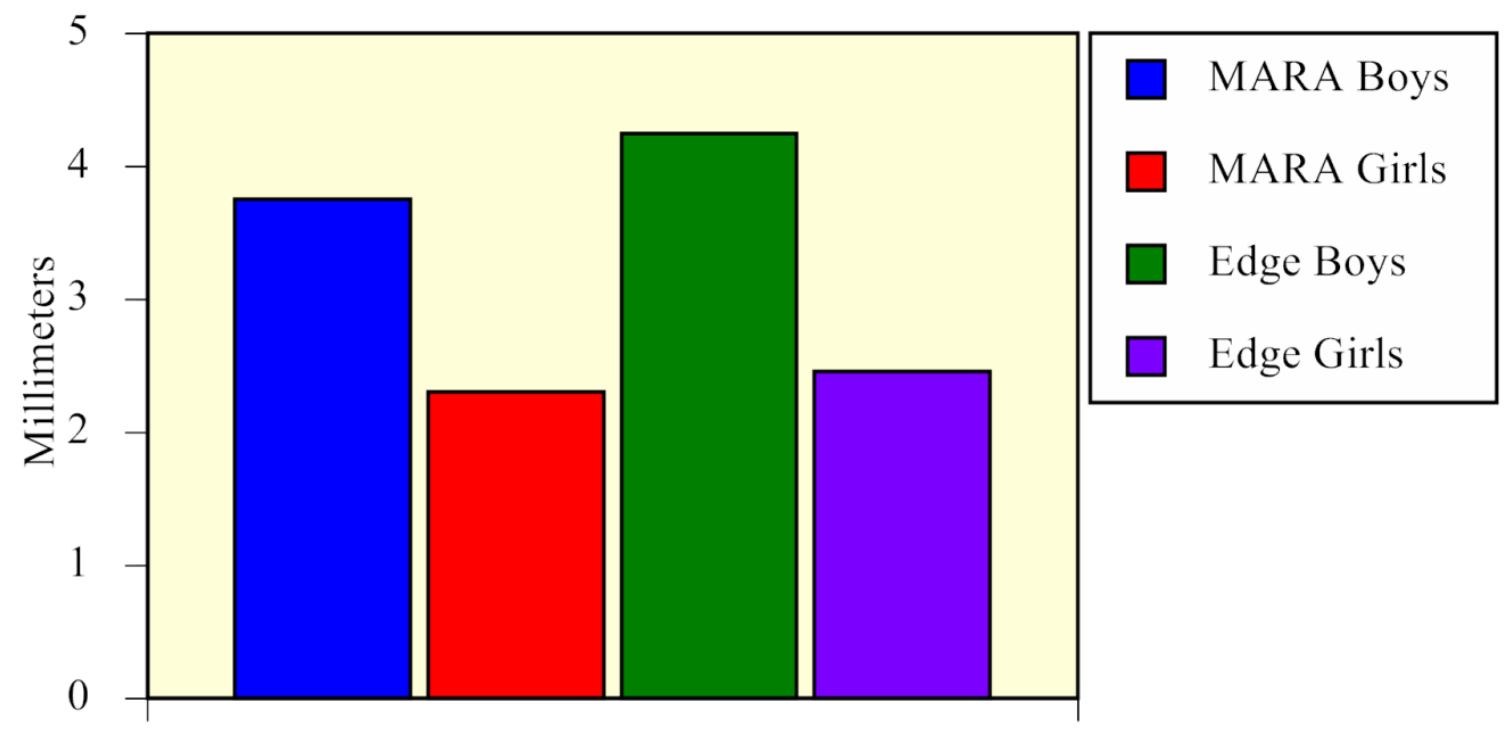

Figure 31. Barchart of the average changes in the apical base (ABCH), by treatment and sex.

The figure shows the significantly greater growth $(P=0.0061)$ in boys $(\mathrm{ca} .4 \mathrm{~mm})$ than girls (ca. $2 \mathrm{~mm}$ ). This essentially-ventral trajectory of growth increases facial depth. 


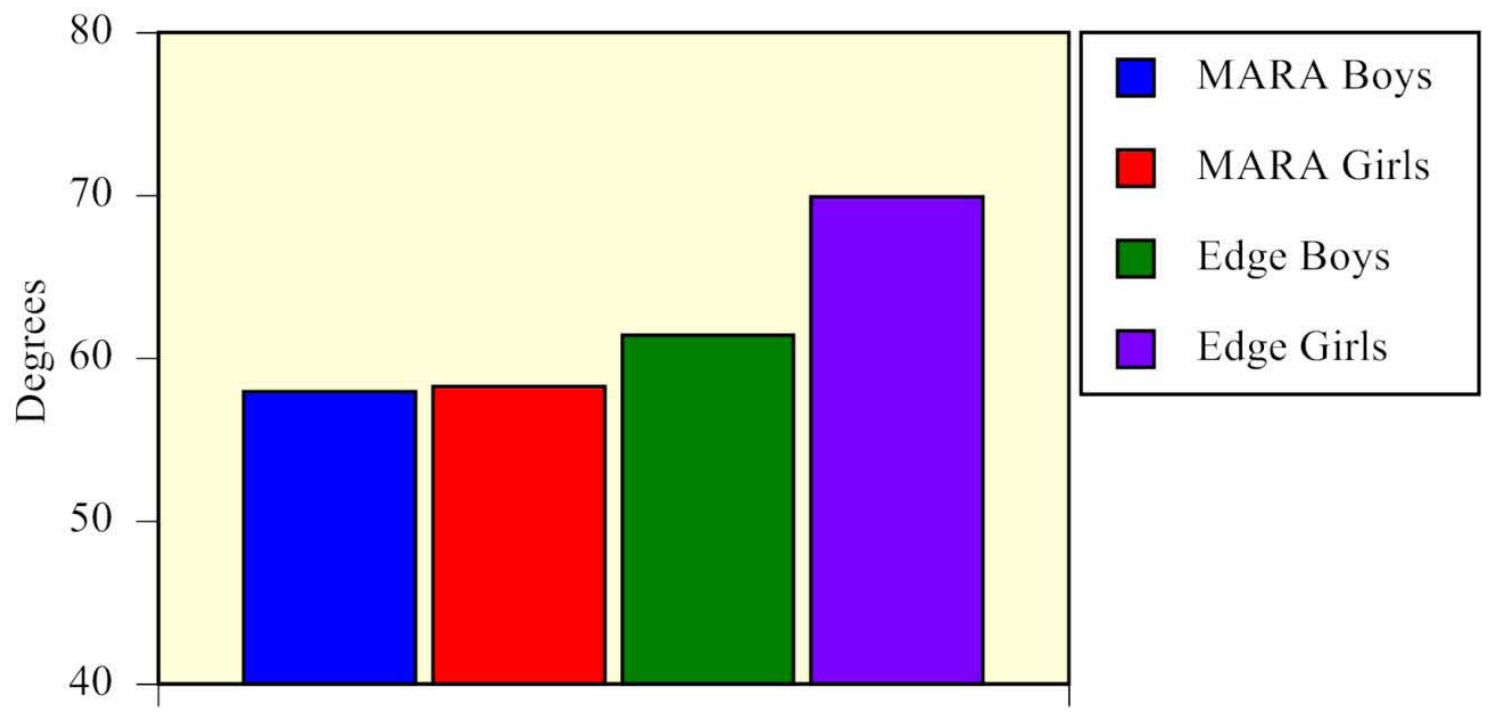

Figure 32. Barchart of the mean angulation of U1 at the end of treatment, showing a statistically significantly greater angle in boys.

As occasionally occurs with ANOVA, the difference is driven primarily by one group, here the disproportionately large angle of girls in the Edgewise-only group $(\mathrm{P}=0.0021)$. 


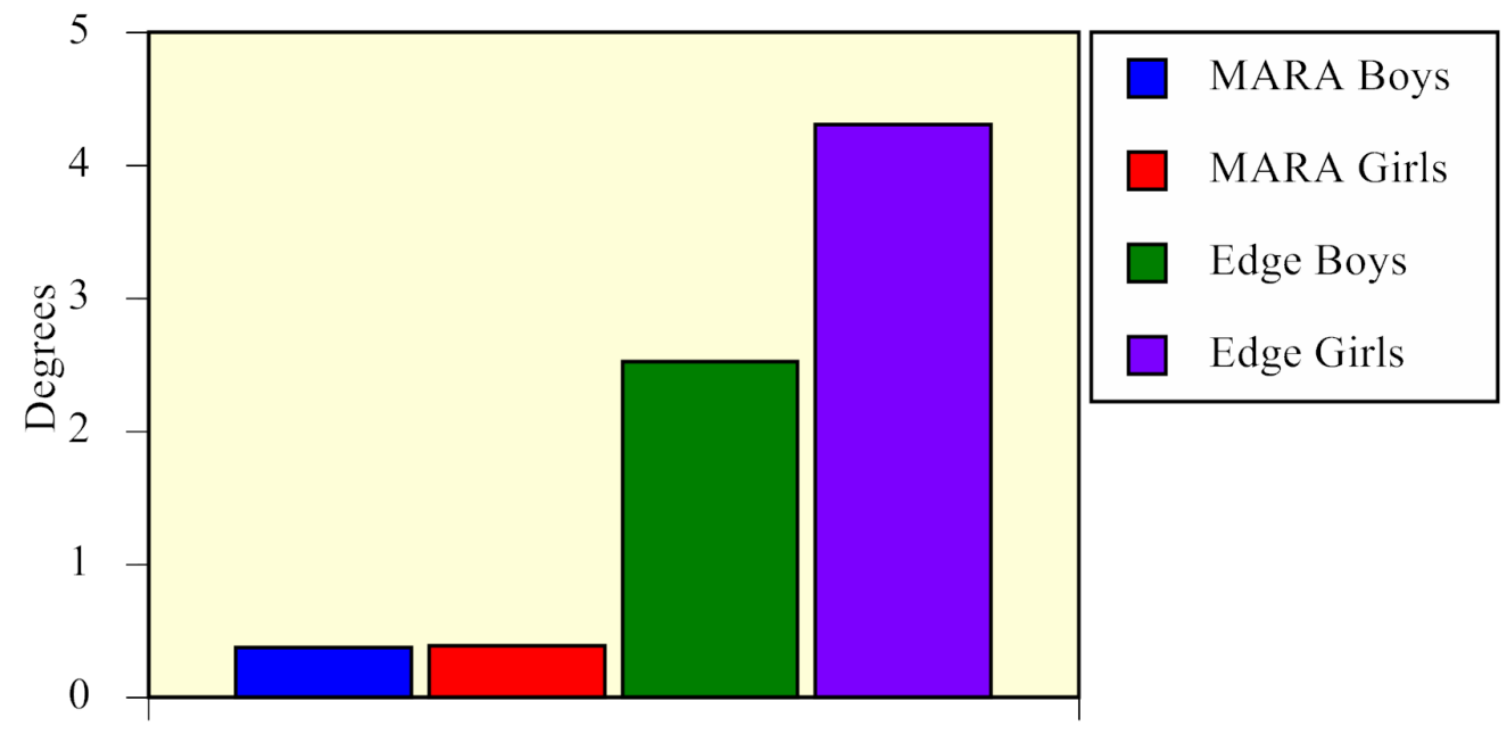

Figure 33. Barchart of the mean treatment change in U1 by treatment and sex.

While not strictly significant $(\mathrm{P}=0.0535)$, interesting features here are $(\mathrm{A})$ the large treatment difference with the much larger change in the Edgewise-only group and (B) the large change in Edgewise boys, while there is no apparent sex difference in the MARA group. 
almost no sex difference in U1 movement while the Edgewise-only group did have a significant sex difference in U1 movement.

Overjet was also found to differ significantly when accounting for sex (Figure 34). Boys were found to have, on average $2.3 \mathrm{~mm}$ and $1.7 \mathrm{~mm}$ of posttreatment overjet in the MARA and Edgewise-only groups, respectively. Girls had an average of $2.0 \mathrm{~mm}$ and $1.4 \mathrm{~mm}$ of posttreatment overjet in the MARA and Edgewise-only groups, respectively (Table C-29).

\section{Changes during Treatment}

This section describes the results of orthodontic treatment for each group without regard to the patients' sex. Descriptive statistics are provided in Appendix B.

A two-way mixed-model ANOVA was performed on the data to account for the sex and the treatment type. The results of the two-way mixed-model ANOVA are found in Appendix D Tables D1-D29. Although all data can be found in Appendix D only relevant findings will be discussed in this section.

\section{Treatment Differences}

Mean movements of the maxilla were $1.7 \mathrm{~mm}$ and $0.7 \mathrm{~mm}$ in the MARA and Standard Edgewise groups respectively (Figure 35). Both appliances had a restraining effect, but it was greater with the MARA group than the Edgewiseonly group. However, comparisons of maxillary growth between the subjects in the 2 groups showed no statistically significant differences $(P=0.0516)$ however the difference warrants mention (Figure 35).

The mean mandibular translatory growth was $1.5 \mathrm{~mm}$ in the MARA group and $2.8 \mathrm{~mm}$ in the Standard Edgewise group (Table B-23). The difference between these groups was statistically significant (Figure 36).

The U6 M-D movement relative to the functional plane varied significantly between treatment groups. Forward movement of the maxillary molars is given a negative value, therefore loss of posterior anchorage or mesial drifting of maxillary molars would result in a larger negative value. Figure 37 shows that the Standard Edgewise group changed almost twice as much as the 


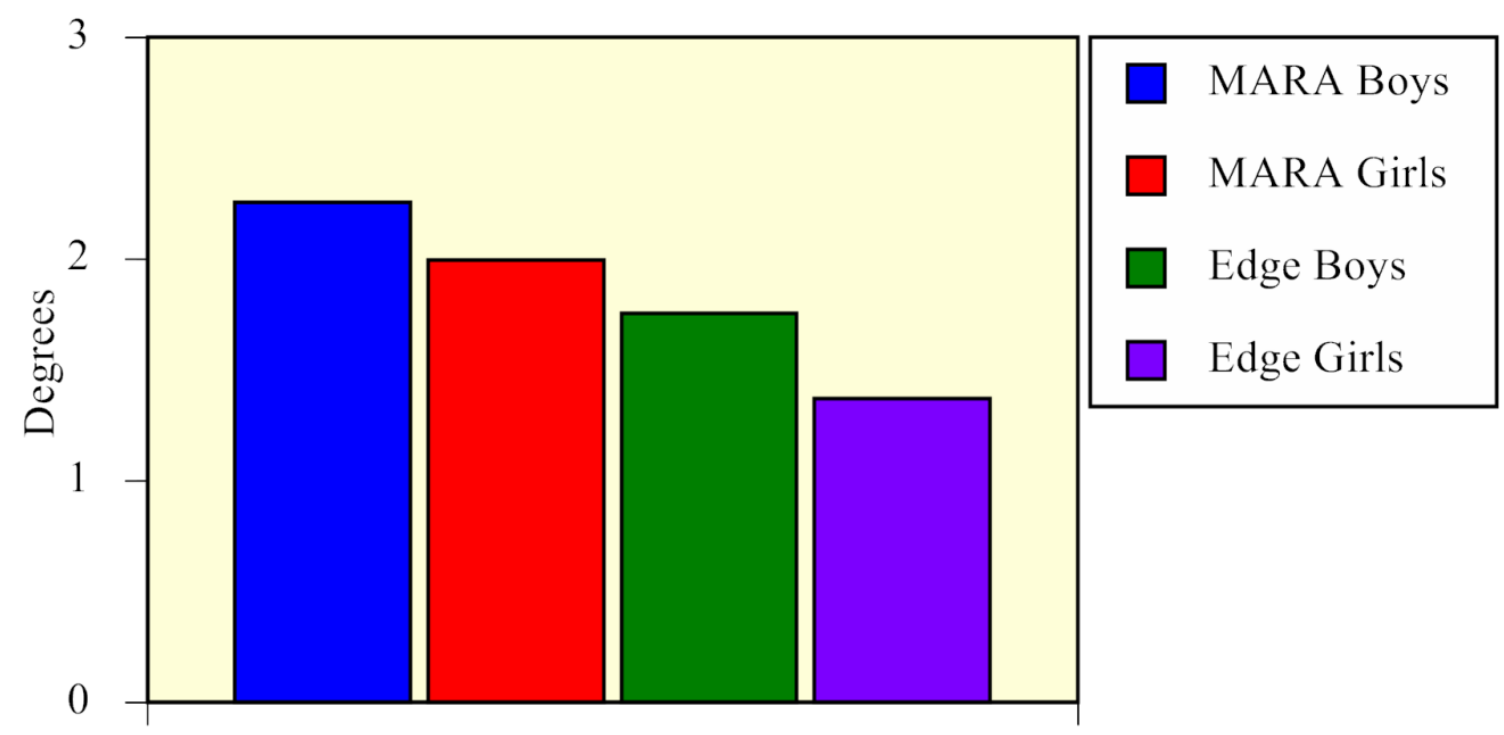

Figure 34. Barchart of the average amounts of overjet at the posttreatment examination.

While the treatment difference is obvious, the point of this graph is to show the marginally significant difference between the sexes $(P=0.0487)$. While changes are larger in the MARA groups, boys have greater overjet than girls within both treatments. 


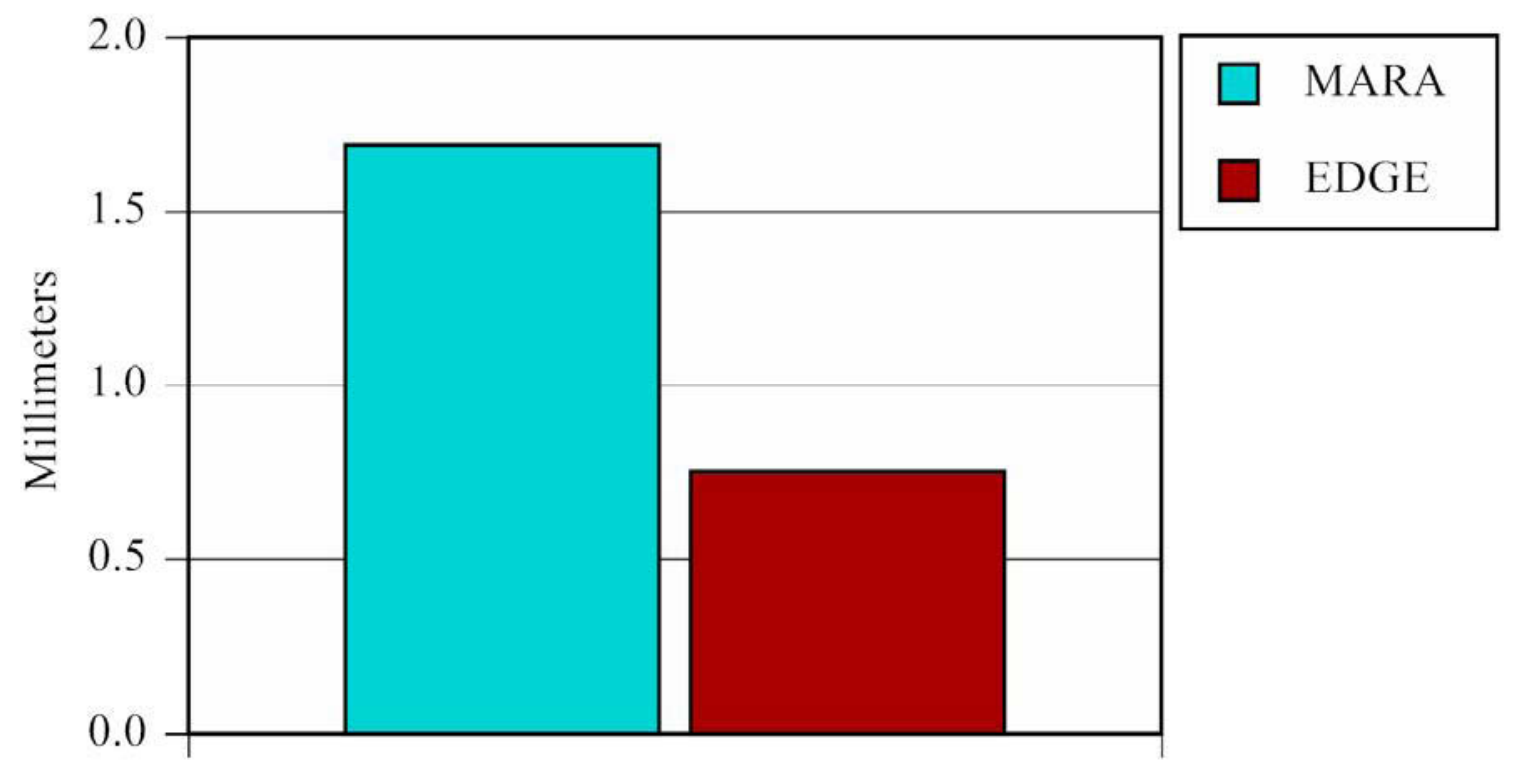

Figure 35. Barchart of the maxillary translative growth in the two treatments.

Notably, this difference is close to statistical significance, but does not truly attain it $(\mathrm{P}=0.0516)$. 


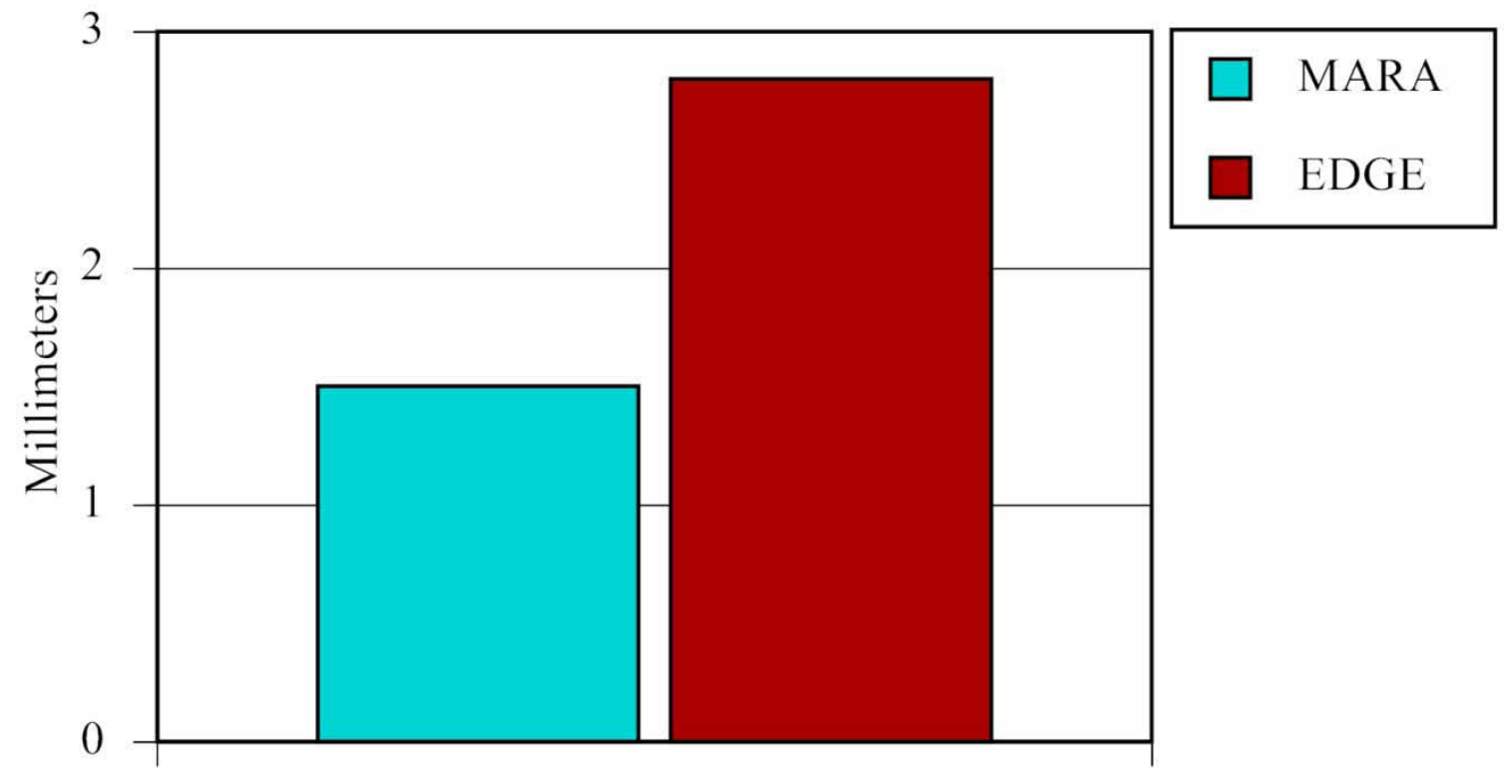

Figure 36. Barchart of average mandibular translative growth showing the significantly larger treatment effect in the Edgewise-only group $(P=0.0317)$. While small, the change is nearly twice as large in the Edgewise sample. 


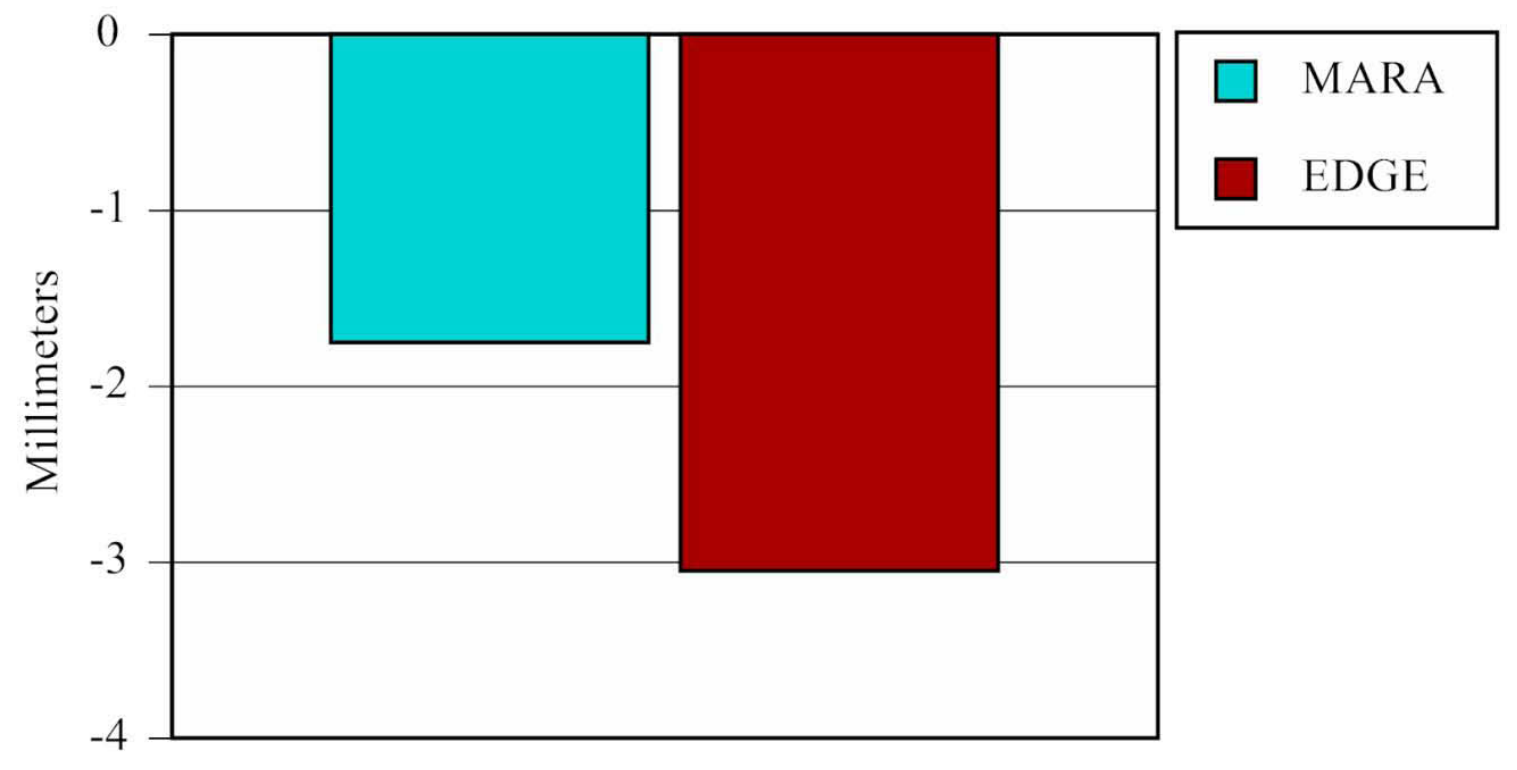

Figure 37. Barchart of the treatment effects for U6 M-D movement relative to the MFOP.

The graph shows that movement in the Edgewise-only group changed almost twice as much as in the MARA+Edgewise group $(\mathrm{P}=0.0152)$. 
MARA group. The MARA group had $-1.75 \mathrm{~mm}$ of mesial movement of maxillary molars while the Standard Edgewise only group had $-3.05 \mathrm{~mm}$ of forward movement (Table B-5).

The mean change in distance of L6-D in the MARA group was $1.1 \mathrm{~mm}$. In the Standard Edgewise group, this distance was found to be $2.2 \mathrm{~mm}$ (Figure 38). L6 movement of the MARA was less than in the Standard Edgewise group and was statistically significant $(P=0.0297)$ (Table D-15).

Pretreatment L6-D distance was found to differ significantly by about 1 $\mathrm{mm}$. The MARA group had a pretreatment L6-D distance of $16.8 \mathrm{~mm}$. The Edgewise-only group had a pretreatment L6-D distance of $17.7 \mathrm{~mm}$ (Figure 39). This one millimeter difference although small, was found to be statistically significant $(\mathrm{P}=0.0243)$ (Figure 39).

The SE change is the change in location of the SE point parallel to the MFOP from pre- to posttreatment. This change represents the maxillary anteroposterior change relative to the cranial base. Anterior movement of the SE point is given a negative value to reflect a worsening of the Class II condition. The MARA group had a mean SE change of $1.7 \mathrm{~mm}$ and the Edgewise-only group had a mean SE change of $0.7 \mathrm{~mm}$ (Figure 40). Although this difference did not reach statistical significance $(P=0.0516)$, the difference is worth noting. The MARA group experienced an average about twice the amount of change in SE (Figure 40).

The mean Post U1 Angle for the MARA group was $58^{\circ}$ while the mean Post U1 Angle of the Edgewise only group was $65^{\circ}$, meaning that the Edgewise only group had more upright maxillary incisors after treatment compared to that of the MARA group (Figure 41) (Table B-25). This difference is both statistically $(\mathrm{P}<0.0001)$ and clinically significant. Clinically, the MARA group had greater labial torque in the maxillary incisors after treatment compared to the Edgewiseonly group.

In addition, the mean change U1 Angle of the MARA group was $-2.1^{\circ}$, while the mean change U1 Angle of the Edgewise-only group was $5.5^{\circ}$ (Table B-26). This indicates that during treatment, on average, the MARA group's maxillary incisors became slightly more proclined while the Edgewise group's maxillary incisors on average uprighted about $5.5^{\circ}$. This difference is significant $(P=0.0002)$ (Table D-25), and it is illustrated in Figure 42. 


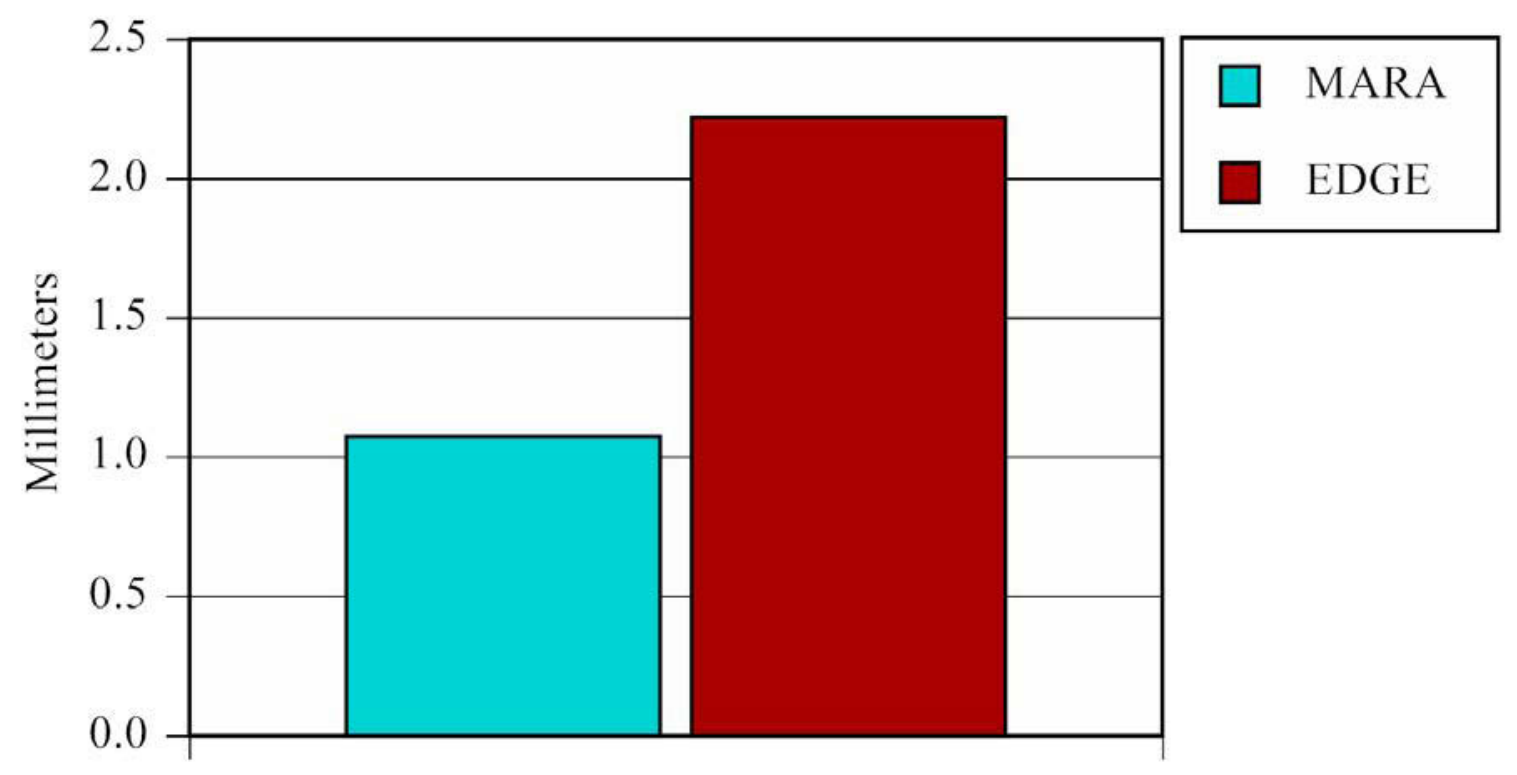

Figure 38. Barchart of the treatment difference in L6 M-D movement/MFOP. The average movement was more than twice as large in the Edgewise sample $(\mathrm{P}=0.0297)$ compared to the MARA sample. 


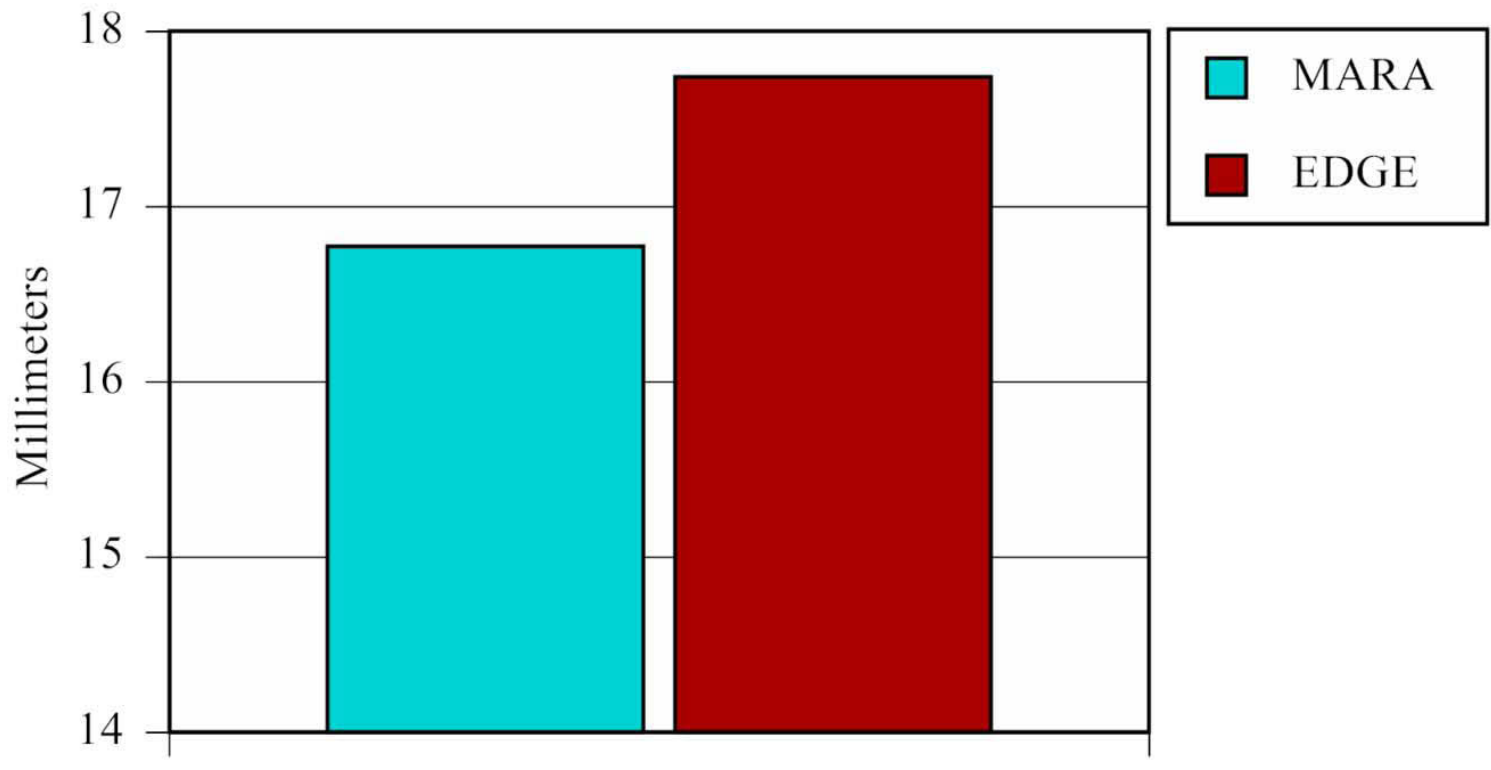

Figure 39. Barchart showing mean sizes for the L6-D distance at the start of treatment. 


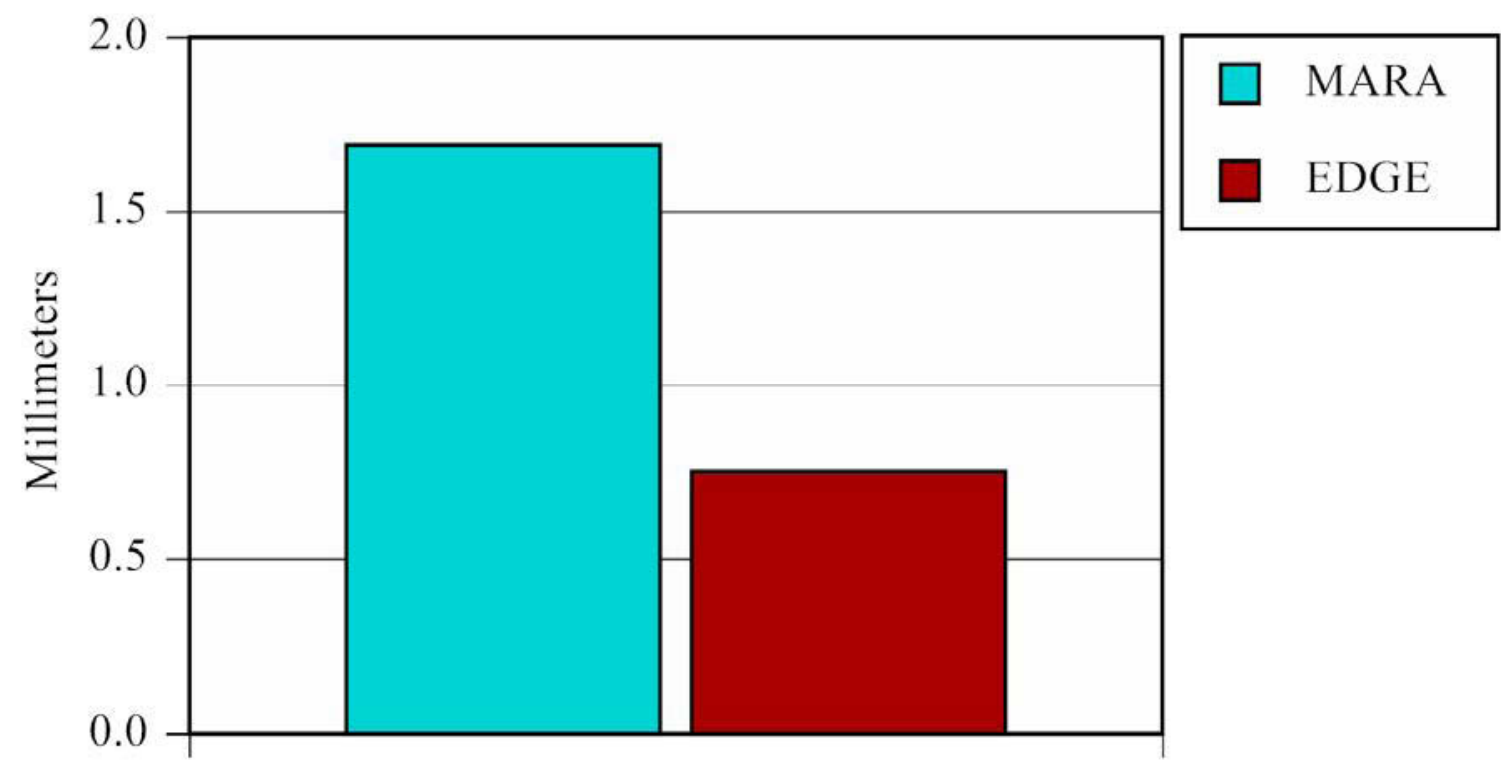

Figure 40. Barchart of the treatment differences in the amount of SE growth. The difference is about twice as large in the MARA sample $(\mathrm{P}=0.0516)$; while not strictly significant, the probability is low enough to warrant comment. 


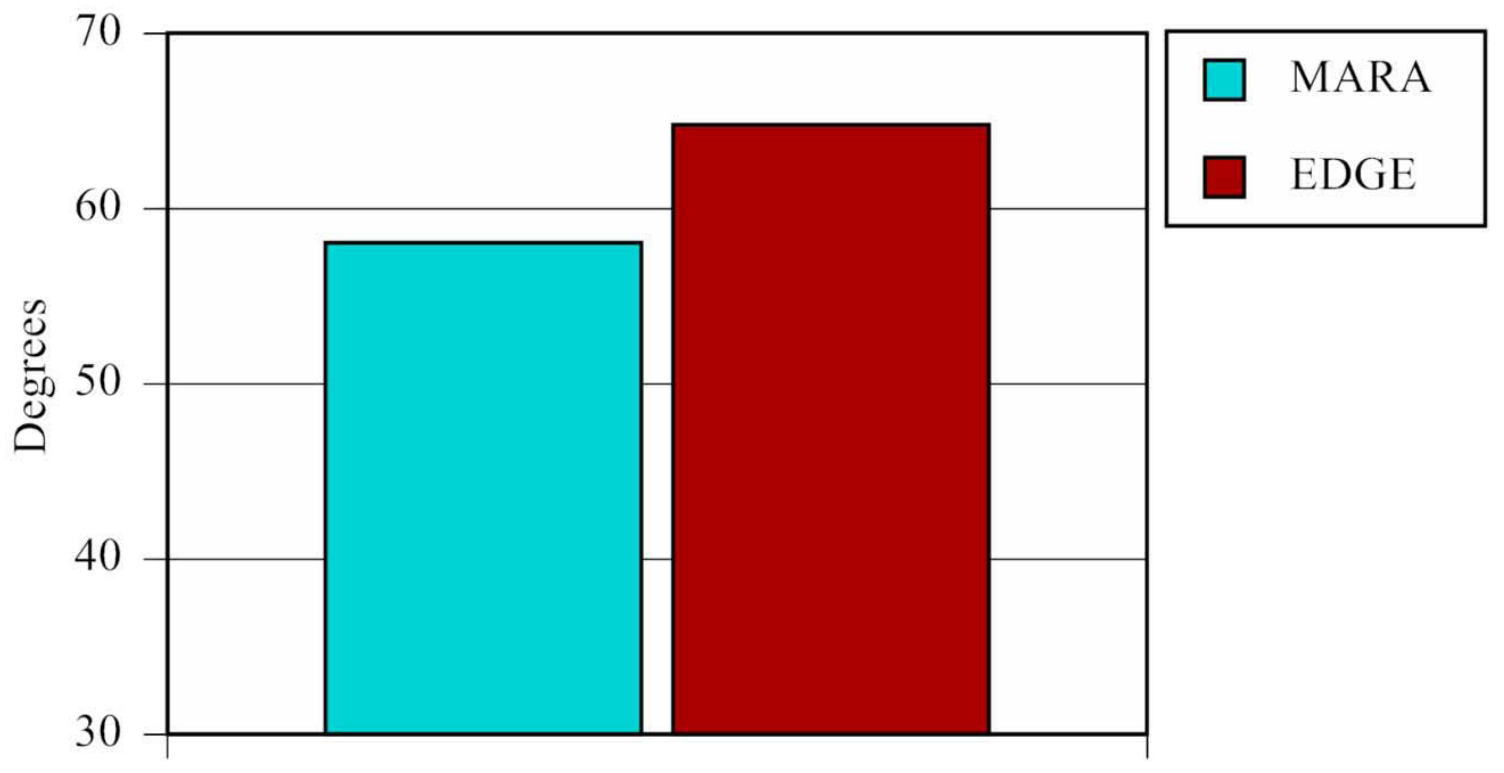

Figure 41. Barchart of the means of U1 angle at the end of treatment, by treatment sample $(P<0.0001)$.

The graph shows that the Edgewise group ended up with significantly more proclined maxillary incisors. 


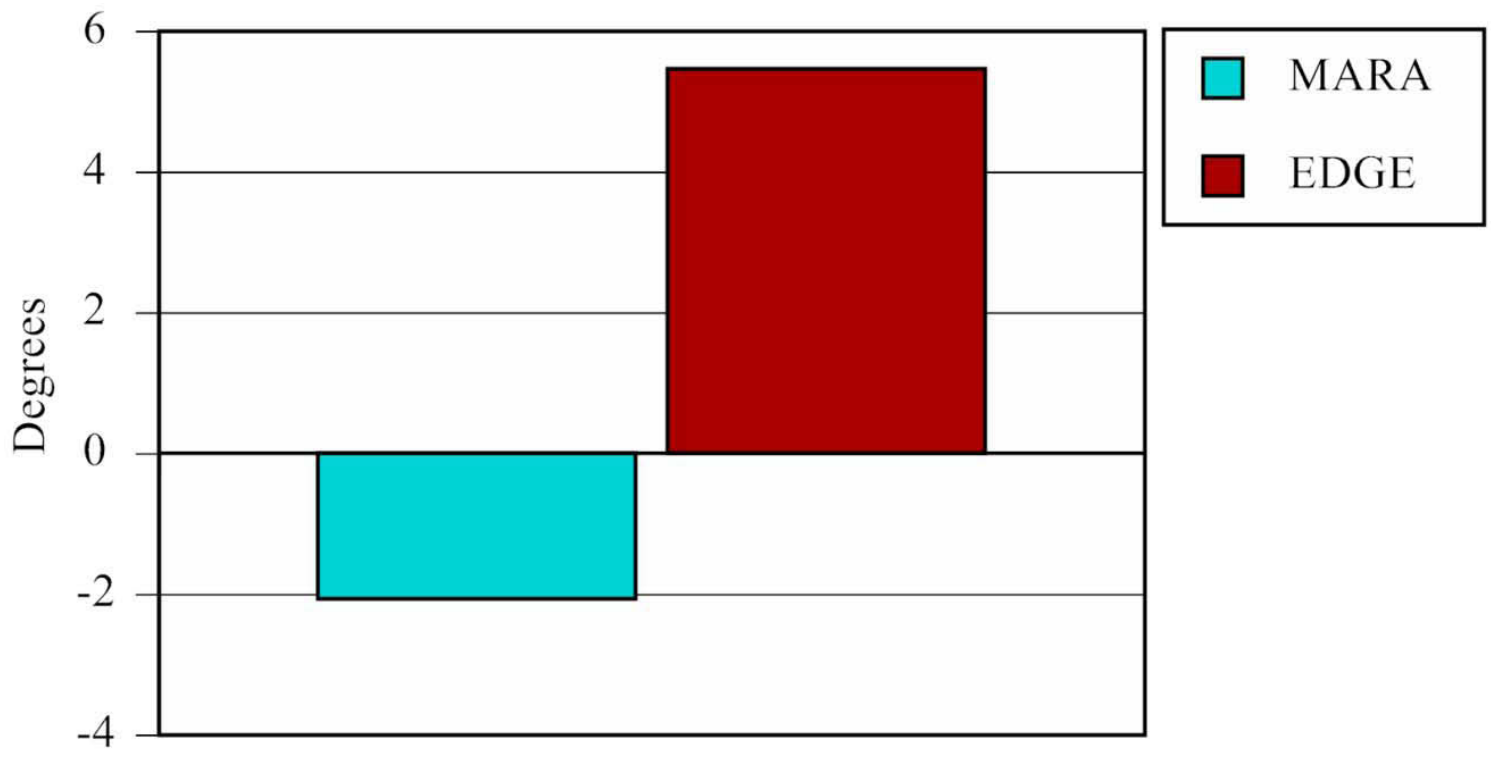

Figure 42. Barchart showing the average treatment changes in U1 between groups.

The difference is highly significant statistically $(P=0.0002)$ because of the complementary changes: the MARA sample flared somewhat, while the Edgewise group uprighted about 5 degrees. 
$\mathrm{U} 1$ movement is a measure of the movement of the maxillary incisor edge during treatment parallel to the MFOP. A negative sign indicates anterior movement of the incisor. The mean U1 movement of the MARA group was found to be $0.4 \mathrm{~mm}$ while the Edgewise-only group had a mean U1 Movement of $3.2 \mathrm{~mm}$ (Table B-27). Because both groups had positive U1 movement, this indicates that both groups on average experienced some amount of posterior movement of maxillary incisors, with the Edgewise group having a statistically greater amount of posterior movement $(\mathrm{P}<0.0001)$. The Edgewise group experienced more posterior movement, and the MARA group experienced very little change (Figure 43).

The mean pretreatment overjet for the MARA group was $4.9 \mathrm{~mm}$ and the Edgewise group was $6.4 \mathrm{~mm}$ (Table B-28). This difference was statistically significant $(\mathrm{P}=0.0056)$ and may account for differences found in the $\mathrm{U} 1$ movement and changes in angulation of the maxillary incisors (Figure 44).

In addition, the mean posttreatment overjet for the MARA group was 2.2 $\mathrm{mm}$ while the Edgewise group had a mean posttreatment overjet of $1.6 \mathrm{~mm}$ (Table B-29). Although both groups reduced overjet during treatment, the MARA group had a statistically $(\mathrm{P}=0.0030)$ more overjet at posttreatment compared to the Edgewise-only group (Figure 45).

The mean change in OJ for the MARA group was $2.8 \mathrm{~mm}$ while the mean change in OJ of the Edgewise group was $4.8 \mathrm{~mm}$ (Figure 46). This difference was statistically and clinically significant $(\mathrm{P}=0.0001)$. Overall, the Edgewise group had greater pretreatment overjet, greater changes in overjet, and less overjet at the end of treatment. 


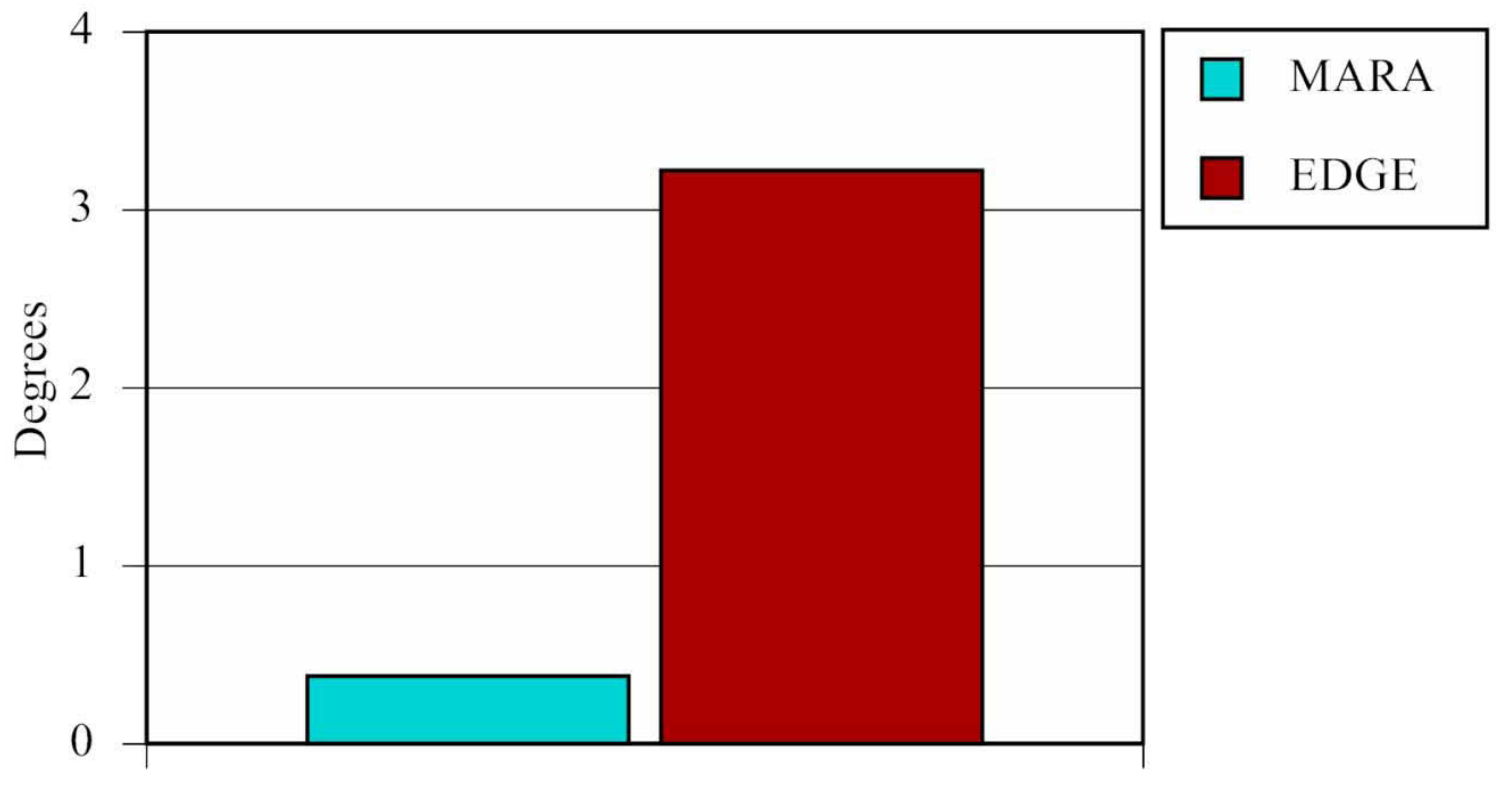

Figure 43. Barchart of the U1 movement parallel to the MFOP in the two treatment groups.

The difference is highly significant $(\mathrm{P}<0.0001)$, with comparative more uprighting in the Edgewise sample. The MARA sample changed very little. 


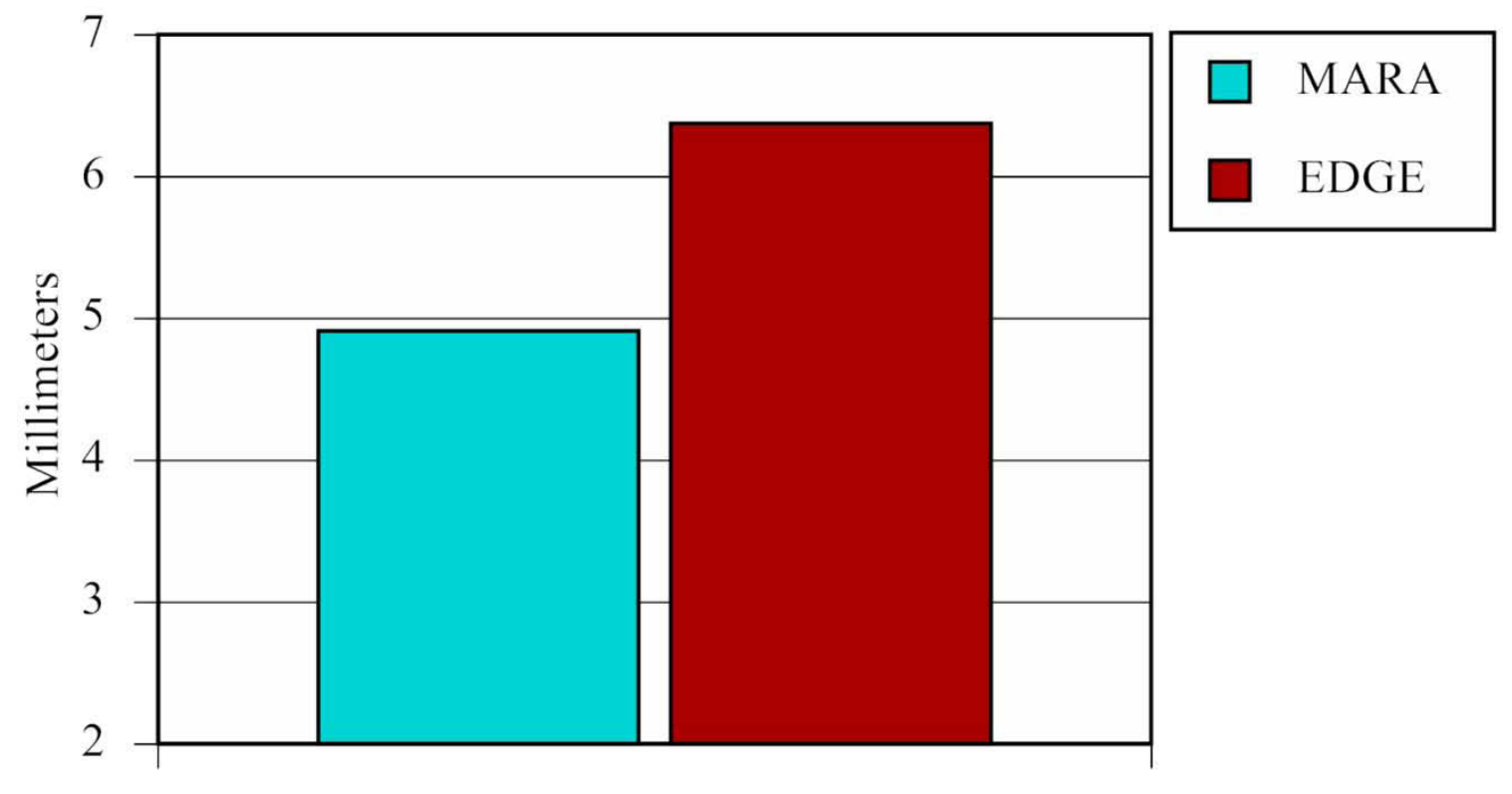

Figure 44. Barchart of the millimeters of overjet at the start of treatment. The Edgewise group had a significantly greater overjet at the start of treatment $(\mathrm{P}=0.0056)$. 


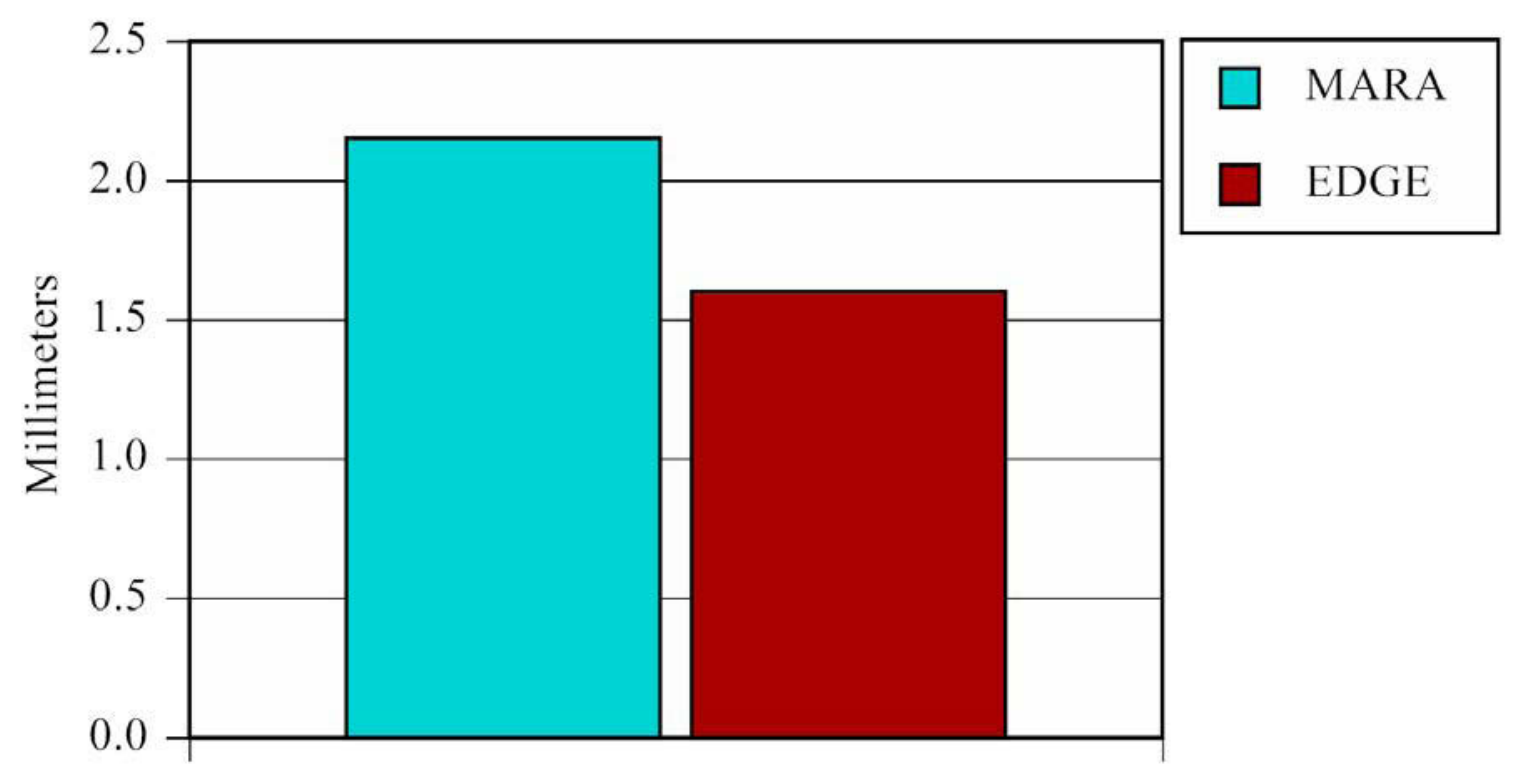

Figure 45. Barchart of the millimeters of overjet at the end of treatment. Overjet was reduced some millimeters in each treatments during treatment, but with no intergroup difference. The Edgewise group had a significantly less overjet at the end of treatment $(\mathrm{P}=0.0030)$. 


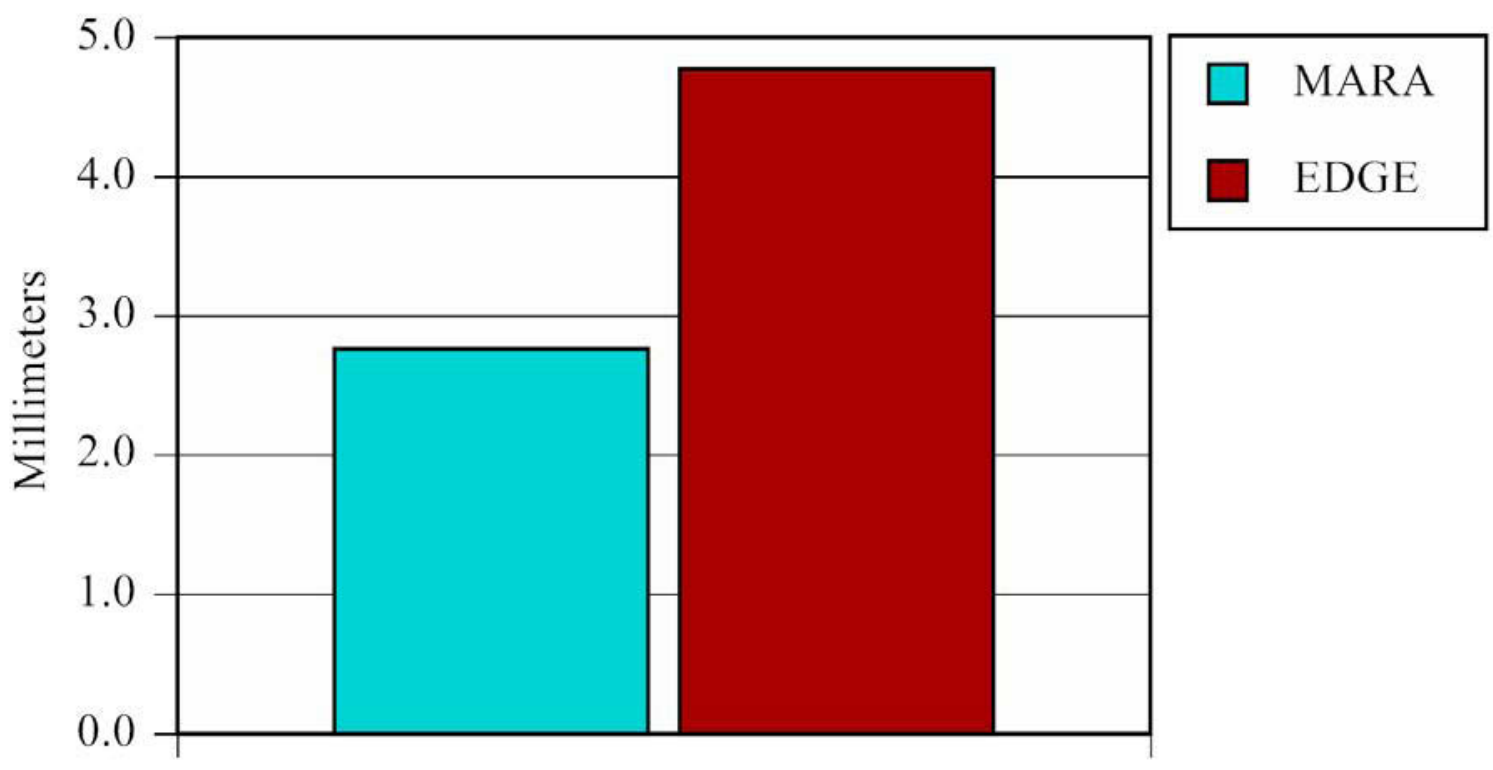

Figure 46. Barchart of the average in-treatment changes in overjet.

Given that there was greater overjet in the Edgewise group at the start of treatment, but significantly less at the end of treatment, makes it intuitive that this amount of change exceeds that of the MARA sample $(\mathrm{P}=0.0001)$. 


\section{CHAPTER 5. DISCUSSION}

The effect of functional appliance therapy on mandibular growth is a major controversy. Some researchers have claimed that extra mandibular growth occurs with the MARA appliance (Pangrazio-Kulbersh et al. 2003; Siara-

Olds et al. 2010; Ghislanzoni et al. 2011). In this study, the Edgewise-only group had a statistically significant greater amount of mandibular growth compared to the MARA group $(\mathrm{P}=0.0317)$. We observed $1.5 \mathrm{~mm}$ and $2.8 \mathrm{~mm}$ of mandibular growth in the MARA and Standard Edgewise groups, respectively. PangrazioKulbersh found that a MARA group, compared with a control group experienced $2.0 \mathrm{~mm}$ of mandibular growth. Ghislanzoni et al. also found an increase in mandibular length (Co-Gn) of $2.0 \mathrm{~mm}$ in subjects treated with the MARA. Both the MARA and Edgewise-only groups are within a one millimeter range of the previous MARA studies.

Some authors claim that the mandible does not experience additional growth with functional appliances, as found in the present study (Harvold et al. 1971; Weislander et al. 1979). In the present study, mandibular change was significantly different between the MARA and Standard Edgewise groups with the Edgewise-only group experiencing greater mandibular growth. Because the present study does not have a control, it is not possible to explain if the difference is because the MARA appliance does not increase mandibular length or because both groups simply experienced similar changes. This is a confounding variable of the study design.

The $\mathrm{ABCH}$ value is the maxillomandibular differential, or the movement of the mandible relative to the maxilla. A positive value indicates that the mandible grew more than the maxilla, and a negative value means that the maxilla outgrew the mandible. $\mathrm{ABCH}$ was $3.2 \mathrm{~mm}$ in the MARA group and 3.6 $\mathrm{mm}$ in the Standard Edgewise group. Although the Edgewise-only group had a larger $\mathrm{ABCH}$, the difference did not reach statistical significance $(\mathrm{P}=0.4150)$. Rushforth et al. (1999) found an $\mathrm{ABCH}$ of $1.9 \mathrm{~mm}$ in 17 months in Class II division 1 control subjects. In the present study, both groups had a greater $\mathrm{ABCH}$ than reported by Rushorth et al. This could be because the Class II rubber bands used for Class II correction in the Edgewise group are similar in effect to the mandibular propulsion of the MARA appliance, both of which result in a greater $\mathrm{ABCH}$ than was found in the control group by Rushforth et al. Whether the force is pushing the mandible forward as with the MARA, or pulling 
anteriorly as with Class II elastics, the result is similar compared to a control group from a previous study.

Mesial movement of the mandibular molars and the distal movement of the maxillary molars or restraint of the maxillary molars as the maxilla moves anteriorly are ideal movements for the correction of a Class II molar relationship. Dentoalveolar changes with tooth-borne functional appliances have been widely discussed. In our study, the maxillary first molars moved anteriorly $1.7 \mathrm{~mm}$ in the MARA group and $3.1 \mathrm{~mm}$ in the Standard Edgewise group. This large difference in molar restraint could be partially due to the minimum-to-no compliance required with the MARA. Any maxillary restraining forces in the Edgewise-only group would be very compliance-dependent and therefore result in a decreased mean molar restraint. Headgear and/or Class II elastics could help restrain forward movement of maxillary molars, however, the MARA is superior in restraining maxillary molar movement.

The mean forward movement of the mandibular first molars was $1.1 \mathrm{~mm}$ in the MARA group and $2.2 \mathrm{~mm}$ in the Standard Edgewise group. Lund and Sandler reported only $0.1 \mathrm{~mm}$ mesial movement of the mandibular first molars in their Twin-block control subjects, and Toth and McNamara (1999) found $0.5 \mathrm{~mm}$ mesial movement. Although is would seem that a constant, anterior force on the mandibular molars would result in greater anterior molar movement, this was not observed. The MARA is constructed with a lower-lingual arch to inhibit dentoalveolar movement and to encourage orthopaedic correction. The lowerlingual arch could be part of the reason that the MARA group experienced less anterior molar movement. Most likely, the difference is largely accounted by the fact that the Edgewise-only group had significantly more premolar extractions. As part of the mechanics for extraction cases, posterior teeth are used as anchorage to relieve crowding, retract canines, and upright protrusive incisors. All of these movements will result in anchorage loss. This different rate of extractions could account for the significant difference in L6 movement.

Maxillary incisors were more proclined during treatment in the MARA group when compared to the Edgewise-only group. This could be caused in part by the use of prescription brackets in the MARA patients. Standard Edgewise brackets have no torque or tip manufactured into the bracket design. In contrast, the prescription brackets used by the MARA clinician have $12^{\circ}$ of torque engineered in the maxillary incisor brackets and $8^{\circ}$ of torque in the lateral incisors. This bracket design difference as well as treatment mechanic 
differences could account for the statistical differences found between the groups. 


\section{CHAPTER 6. CONCLUSIONS}

The present study compared dental and skeletal changes in two groups, a MARA treatment group and a Standard Edgewise group. Both groups were Class II Division 1 pretreatment and were corrected to Class I dental relationships. While it is expected that the amounts of skeletal and dental movements differ among individuals; the present study identified trends in these differences between sexes and different treatment modalities. Although all individuals in each group were treated to Class I occlusion, the amount of skeletal and dental movement that contributed to this correction differed in each group.

The orthodontic treatment modalities were the MARA, followed by fixed Edgewise appliances and Standard Edgewise only appliances. The nature of the Class II correction was partitioned into skeletal and dental changes using the Johnston analysis. The following findings were obtained:

1. The Standard Edgewise group had greater mesial movement on the maxillary molars during treatment compared to the MARA group.

2. The Standard Edgewise group had a greater amount of mesial movement of the mandibular molars as measured from $\mathrm{D}$ point compared to the MARA group.

3. The MARA and Standard Edgewise groups did not experience a significant difference in the amounts of apical base change $(\mathrm{ABCH})$.

4. The MARA group had a greater amount of headgear effect than did the Standard Edgewise group.

5. The Standard Edgewise group had significantly greater mandibular translative growth than did the MARA group.

6. The MARA group had greater posttreatment maxillary incisor proclination (lingual root torque) compared to the Standard Edgewise group.

7. The amount of maxillary incisor movement found during treatment differed significantly with the Standard Edgewise group experiencing a greater amount of posterior movement compared to the MARA group.

8. Overjet also varied significantly between the two groups. The MARA group had significantly greater overjet measurements in both pretreatment and posttreatment radiographs. This also resulted in a significant difference in the change in overjet with the MARA group 
having a significantly smaller change in overjet compared to the Standard Edgewise group. 


\section{LIST OF REFERENCES}

Allen-Noble PS. A manual for orthodontists and staff: Clinical management of the MARA. http://www.ormco.com/index/cms-filesystemaction?file=AOALab-Education-PDF/clinicalmanagementmara2002manuals.pdf. February 2002. Accessed 10/19/2009.

Baccetti, T Franchi L, McNamara JA Jr. An improved version of the cervical vertebral maturation (CVM) method for the assessment of mandibular growth. Angle Orthod 2002;72:316-23.

Bland JM, Altman DG. Statistical methods for assessing agreement between two methods of clinical measurement. Lancet 1986; i:307-10.

Bland JM, Altman DG. Statistical notes: measurement error. BMJ 1996a; 313:744.

Bland JM, Altman DG. Statistical notes: measurement error and correlation coefficients. BMJ 1996b; $313: 41-42$.

Bland JM, Altman DG. Agreement between methods of measurement with multiple observations per individual. J Biopharmaceutical Stat 2007:17:571-82.

Braždžionytė J, Macas A. Bland-Altman analysis as an alternative approach for statistical evaluation of agreement between two methods for measuring hemodynamics during acute myocardial infarction. Medicina (Kaunas) 2007;43:208-14.

Brunelle JA, Bhat M, Lipton JA. Prevalence and distribution of selected occlusal characteristics in the US population, 1988-1991. J Dent Res 1996;75:706-13.

Collet AR. Current concepts on functional appliances and mandibular growth stimulation. Aust Dent J 2000;45(3):173-8.

Cozza P, Baccetti T, Franchi L, Toffol LD, McNamara Jr JA. Mandibular changes produced by functional appliances in Class II malocclusion: a systematic review. Am J Orthod Dentofacial Orthop 2006;129:599.el-12. 
English JD. Treatment of class II malocclusions. In: English JD, Peltomaki T, Pham-Litschel K, editors. Mosby's orthodontic review. St. Louis: CV Mosby; 2009. p. 152-177.

Feldmann I, Lundström F, Peck S. Occlusal changes from adolescence to adulthood in untreated patients with Class II division 1 deepbite malocclusion. Angle Orthod 1999;69:33-8.

Franchi L, Baccetti T. Prediction of individual mandibular changes induced by functional jaw orthopedics followed by fixed appliances in Class II patients. Angle Orthod 2006;76:950-4.

Ghislanzoni L, Toll DE, Defraia E, Baccetti T, Franchi L. Treatment and posttreatment outcomes induced by the Mandibular Advancement Repositioning Appliance; A controlled clinical study. Angle Orthod 2011;81:684-91.

Gönner U, Özkan V, Jahn E, Toll DE. Effect of the MARA appliance on the position of the lower anteriors in children, adolescents, and adults with Class II malocclusion. J Orofac Orthop 2007;68:397-412.

Graber TM. Treatment of patients in the mixed dentition. In: Graber TM, Vanarsdall RL, Vig KWL, editors. Orthodontics: current principles and techniques, 4th edition. St. Louis: CV Mosby; 2005. p. 543-77.

Graber TM. Treatment options for sagittal corrections in noncompliant patients. In: Graber TM, Vanarsdall RL, Vig KWL, editors. Orthodontics: current principles and techniques, 4th edition. St. Louis: CV Mosby; 2005. p. 879900.

Harris EF, Smith RN. Accounting for measurement error: A critical but often overlooked process. Arch Oral Biol 2009;54, Supplement 1, p. S107-S117.

Herbst E. Atlas und Grundriss der Zahnärztlichen Orthopädie. München: J.F. Lehmann Verlag; 1910.

Houston WJ. The analysis of errors in orthodontic measurements. Am J Orthod 1983;83:382-90. 
Johnston LE Jr. A comparative study of Class II treatments. In: Vig PS, Ribbens KA, editors. Science and clinical judgement in orthodontics. Craniofacial Growth Series, Monograph 19. Ann Arbor: Center for Human Growth and Development; University of Michigan, 1986: 103-48.

Johnston LE Jr. Balancing the books on orthodontic treatment: an integrated analysis of change. Br J Orthod 1996;23:93-102.

Kingsley, NW. A treatise on oral deformities as a branch of mechanical surgery. London: H.K. Lewis; 1880. p. 83-6.

Lund DL, Sandler PJ. The effects of Twin-blocks: a prospective controlled study. Am J Orthod Dentofacial Orthop. 1998;113:104-110.

McClaran TR, Harris EF. Cephalometric evaluation of MARA therapy in the treatment of class II malocclusions. Master of Dental Science Thesis, University of Tennessee, Memphis, 2010.

McKinney JR Harris EF. Influences of sex and orthodontic technique on correction of class II malocclusion. Am J Orthod Dentofacial Orthop 2001;120:530-41.

McNamara JA Jr. Components of Class II malocclusion in children 8-10 years of age. Angle Orthod 1981;51:177-202.

McNamara JA, Jr., Brudon WL. Orthodontic and orthopedic treatment in the mixed dentition. Needham Press; 1993.

McNamara JA, Jr., Brudon WL. Orthodontics and dentofacial orthopedics. Ann Arbor: Needham Press; 2001. p. 67-80.

Moyers RE, Riolo ML, Guire KE, Wainright RL, Bookstein FL. Differential diagnosis of Class II malocclusions. Part 1. Facial types associated with Class II malocclusions. Am J Orthod 1980;78;477-94.

Pancherz H. Treatment of class II malcocclusions by jumping the bite with the herbst appliance. A cephalometric investigation. Am J Orthod 1979;76:42342. 
Pancherz H, Fischer S. Amount and direction of temporomandibular joint growth changes in herbst treatment: a cephalometric long-term investigation. Angle Orthod 2003;73;493-501.

Pangrazio-Kulbersh V, Berger JL, Chermak DS, Kaczynski R, Simon ES, Haerian A. Treatment effects of the mandibular anterior repositioning appliance on patients with Class II malocclusion. Am J Orthod Dentofacial Orthop 2003;123:286-95.

Proffit WR. Orthodontic treatment planning: limitations, controversies, and special problems. In: Proffit WR, Fields HW, Sarver DM, editors.

Contemporary orthodontics, fourth edition. St. Louis: CV Mosby; 2007. p. 287-300.

Rushforth CDJ, Gordon PH, Aird JC. Skeletal and dental changes following the use of the Fränkel functional regulator. Br J Orthod 1999;26:127-134.

Siara-Olds NJ, Pangrazio-Kulbersh V, Berger J, Bayirli B. Long-term dentoskeletal changes with the bionator, herbst, twin block, and MARA functional appliances. Angle Orthod 2010;80:18-29.

Sokal RR, Rohlf FJ. Biometry: the principles and practice of statistics in biological research, 3rd ed. San Francisco: WH Freeman and Company, 1995.

Stahl, F. , T. Baccetti , L. Franchi, and J. A. McNamara Jr . Longitudinal growth changes in untreated subjects with Class II division 1 malocclusion. Am J Orthod Dentofacial Orthop 2008;134:125-137.

Toth LR, McNamara JA Jr. Treatment effects produced by the twin block appliance and the FR-2 appliance of Fränkel compared with an untreated Class II sample. Am J Orthod Dentofacial Orthop 1999;116:597-609.

Tukey JW. Exploratory data analysis. Reading, Mass: Addision-Wesley, 1977.

Tumer N, Gultan S. Comparison off the effects of monobloc and Twin-block appliances on the skeletal and dentoalveolar structures. Am J Orthod Dentofacial Orthop 1999; 116:460-8.

Wahl N. Orthodontics in 3 millenia: Functional appliances to midcentury. Am J Orthod Dentofacial Orthop 2006; 129: 829-33. 
Wieslander L, Lagerstrom L. The effects of activator treatment on Class II malocclusions. Am J Orthod 1979;75:20-6.

Woolf CM. Principles of biometry. Princeton, NJ: D Van Nostrand Company, Inc., 1968. 


\section{APPENDIX A. RESULTS OF THE TECHNICAL ERROR OF MEASUREMENT}

The following figures and tables represent the results of a Bland-Altman analysis for intraobserver measurement reliability. 


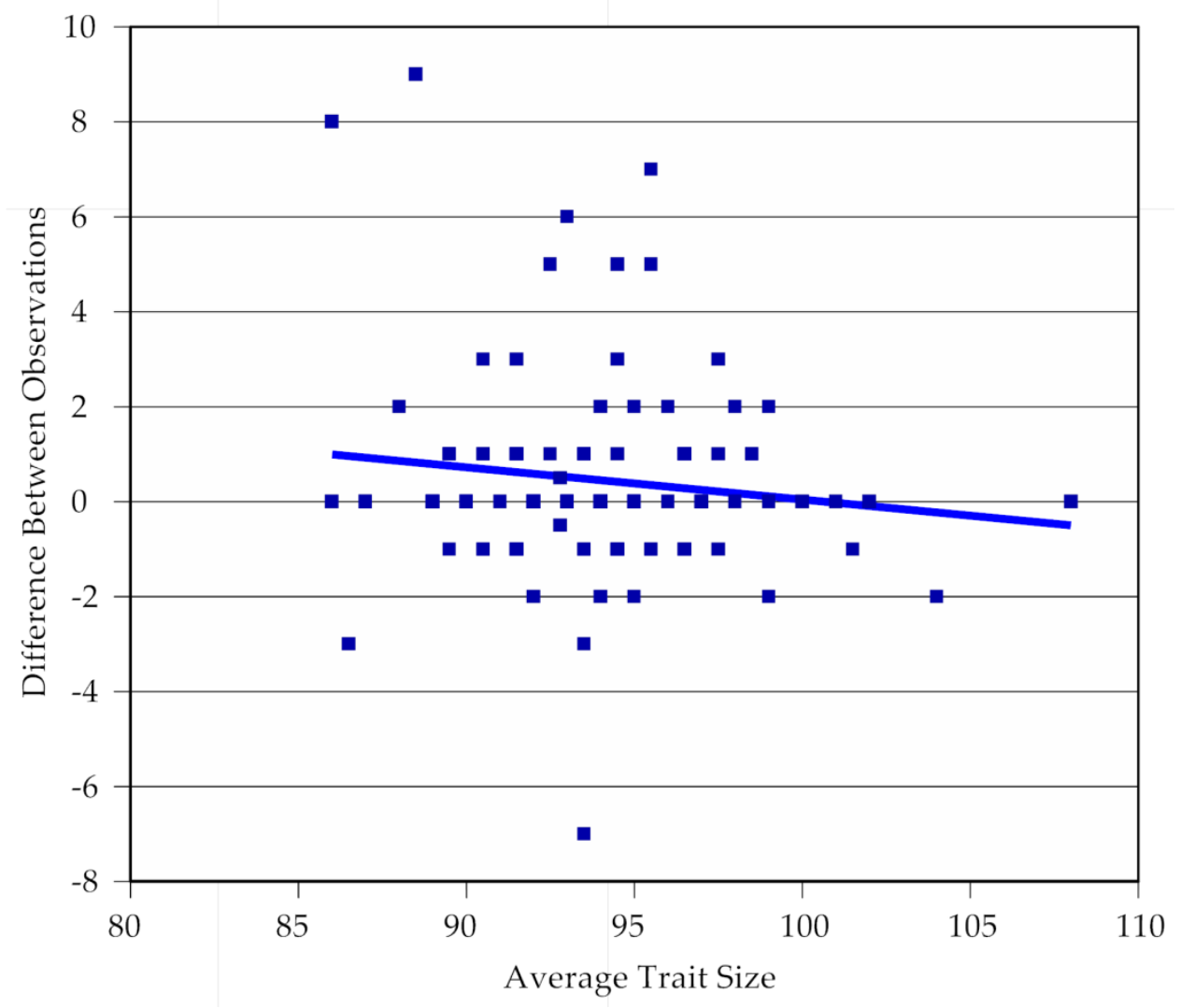

Figure A-1. Bland-Altman plot for intraobserver observations for U6 angle at pretreatment.

Table A-1. Results for Bland-Altman analysis of for U6 angle at pretreatment.

\begin{tabular}{lclc}
\hline Statistic & Result & Statistic & Result \\
\hline U6 Angle Pre 2 & 93.50 & t-ratio & -2.21 \\
U6 Angle Pre 1 & 93.97 & df & 101 \\
Mean Difference & -0.47 & Probability $>|\mathrm{t}|$ & 0.0292 \\
Standard Error & 0.21 & Probability $>\mathrm{t}$ & 0.9854 \\
Upper 95\% & -0.05 & Probability $<\mathrm{t}$ & 0.0146 \\
Lower 95\% & -0.89 & & \\
Sample Size & 102 & & \\
Correlation & 0.85 & & \\
\hline
\end{tabular}




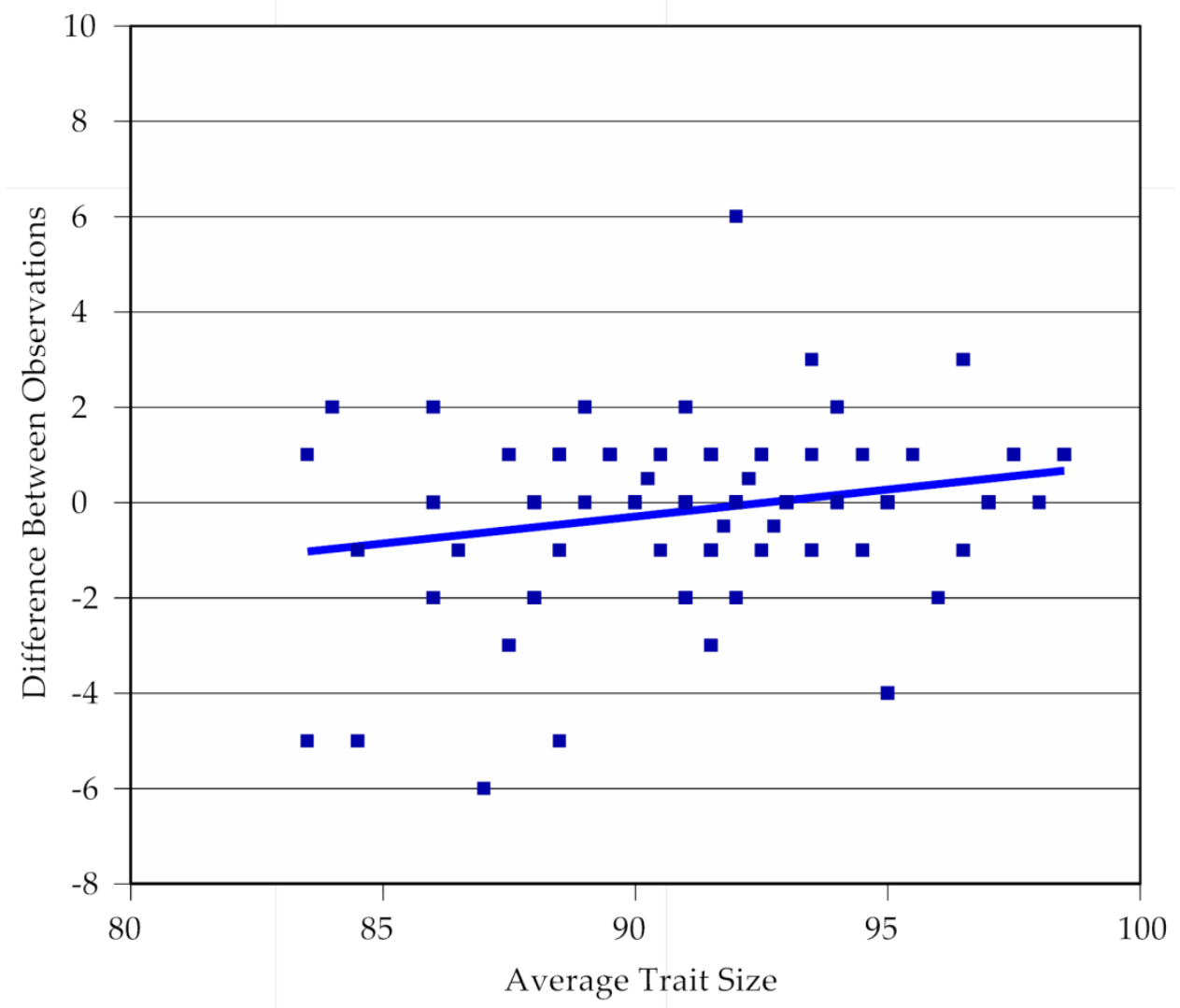

Figure A-2. Bland-Altman plot for intraobserver observations for U6 angle at posttreatment.

Table A-2. Results for Bland-Altman analysis of U6 angle at posttreatment.

\begin{tabular}{lclc}
\hline Statistic & Result & Statistic & Result \\
\hline U6 Angle Post 2 & 91.51 & t-ratio & 0.74 \\
U6 Angle Post 1 & 91.38 & df & 101 \\
Mean Difference & 0.13 & Probability $>|\mathrm{t}|$ & 0.46 \\
Standard Error & 0.17 & Probability $>\mathrm{t}$ & 0.2293 \\
Upper 95\% & 0.47 & Probability $<\mathrm{t}$ & 0.7707 \\
Lower 95\% & -0.21 & & \\
Sample Size & 102 & & \\
Correlation & 0.89 & & \\
\hline
\end{tabular}




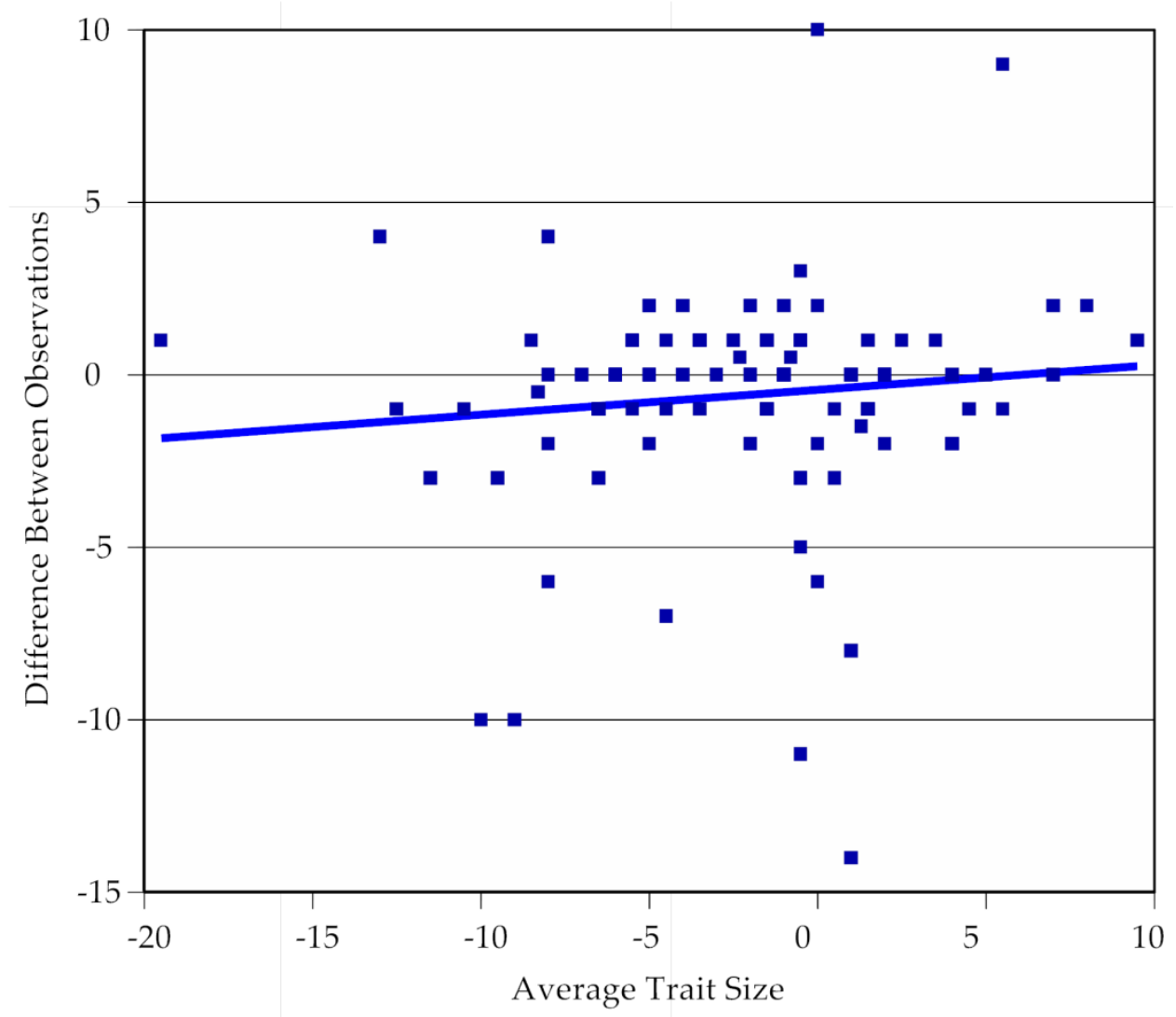

Figure A-3. Bland-Altman plot for intraobserver observations for change in U6 angle.

Table A-3. Results for Bland-Altman analysis of change in U6 angle.

\begin{tabular}{lclc}
\hline Statistic & Result & Statistic & Result \\
\hline Change U6 Angle 2 & -1.99 & t-ratio & 1.85 \\
Change U6 Angle 1 & -2.58 & df & 101 \\
Mean Difference & 0.60 & Probability $>|\mathrm{t}|$ & 0.0672 \\
Standard Error & 0.32 & Probability $>\mathrm{t}$ & 0.0336 \\
Upper 95\% & 1.24 & Probability $<\mathrm{t}$ & 0.9664 \\
Lower 95\% & -0.04 & & \\
Sample Size & 102 & & \\
Correlation & 0.80 & & \\
\hline
\end{tabular}




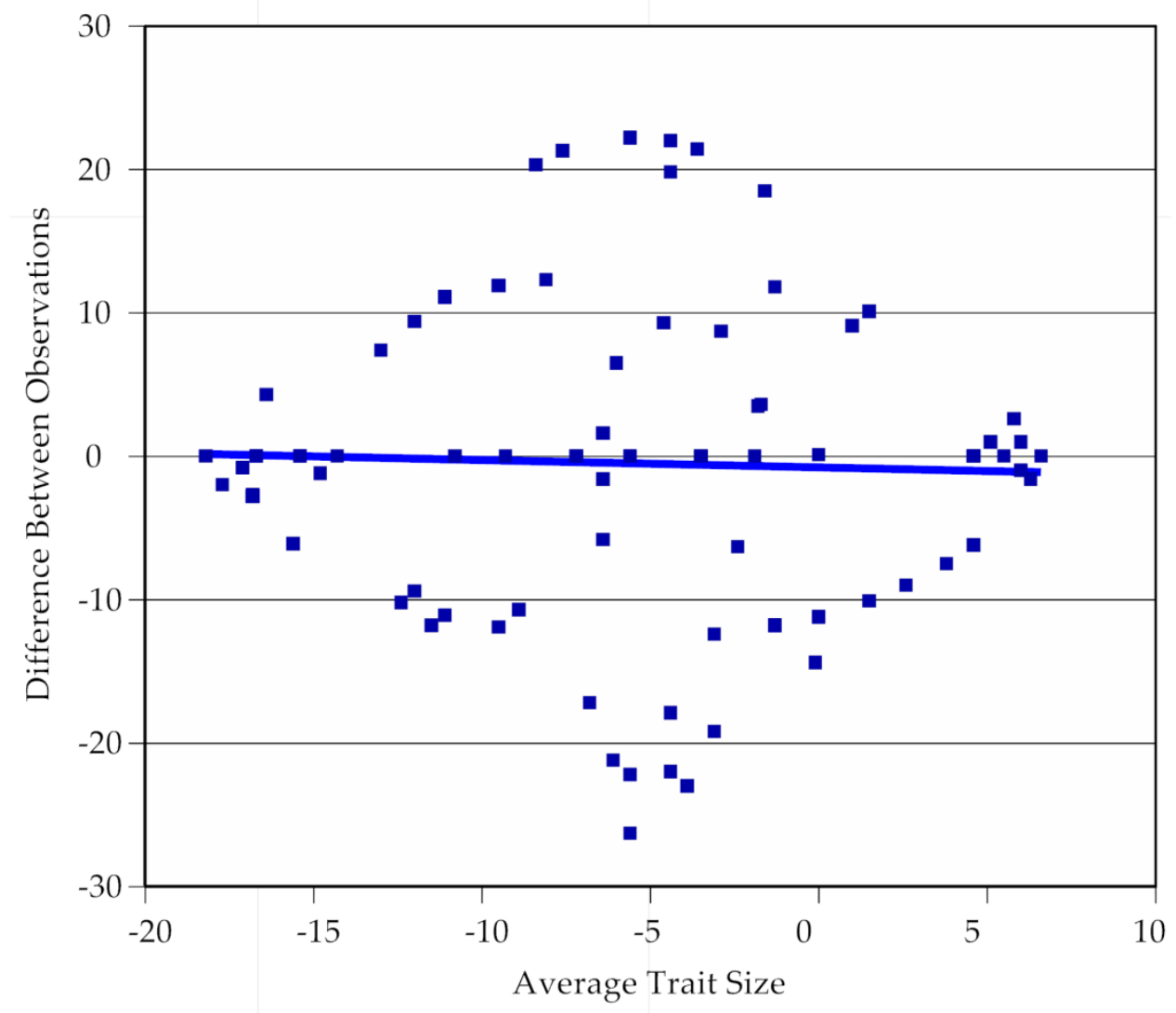

Figure A-4. Bland-Altman plot for intraobserver observations for linear conversion of $\mathrm{U} 6$ tip angle.

Table A-4. Results for Bland-Altman analysis of conversion of U6 tip angle.

\begin{tabular}{lclc}
\hline Statistic & Result & Statistic & Result \\
\hline LinCon U6 Tip 2 & -6.02 & t-ratio & 0.41 \\
LinCon U6 Tip 1 & -6.48 & df & 101 \\
Mean Difference & 0.45 & Probability $>|\mathrm{t}|$ & 0.6813 \\
Standard Error & 1.10 & Probability $>\mathrm{t}$ & 0.3406 \\
Upper 95\% & 2.64 & Probability $<\mathrm{t}$ & 0.6594 \\
Lower 95\% & -1.74 & & \\
Sample Size & 102 & & \\
Correlation & 0.25 & & \\
\hline
\end{tabular}




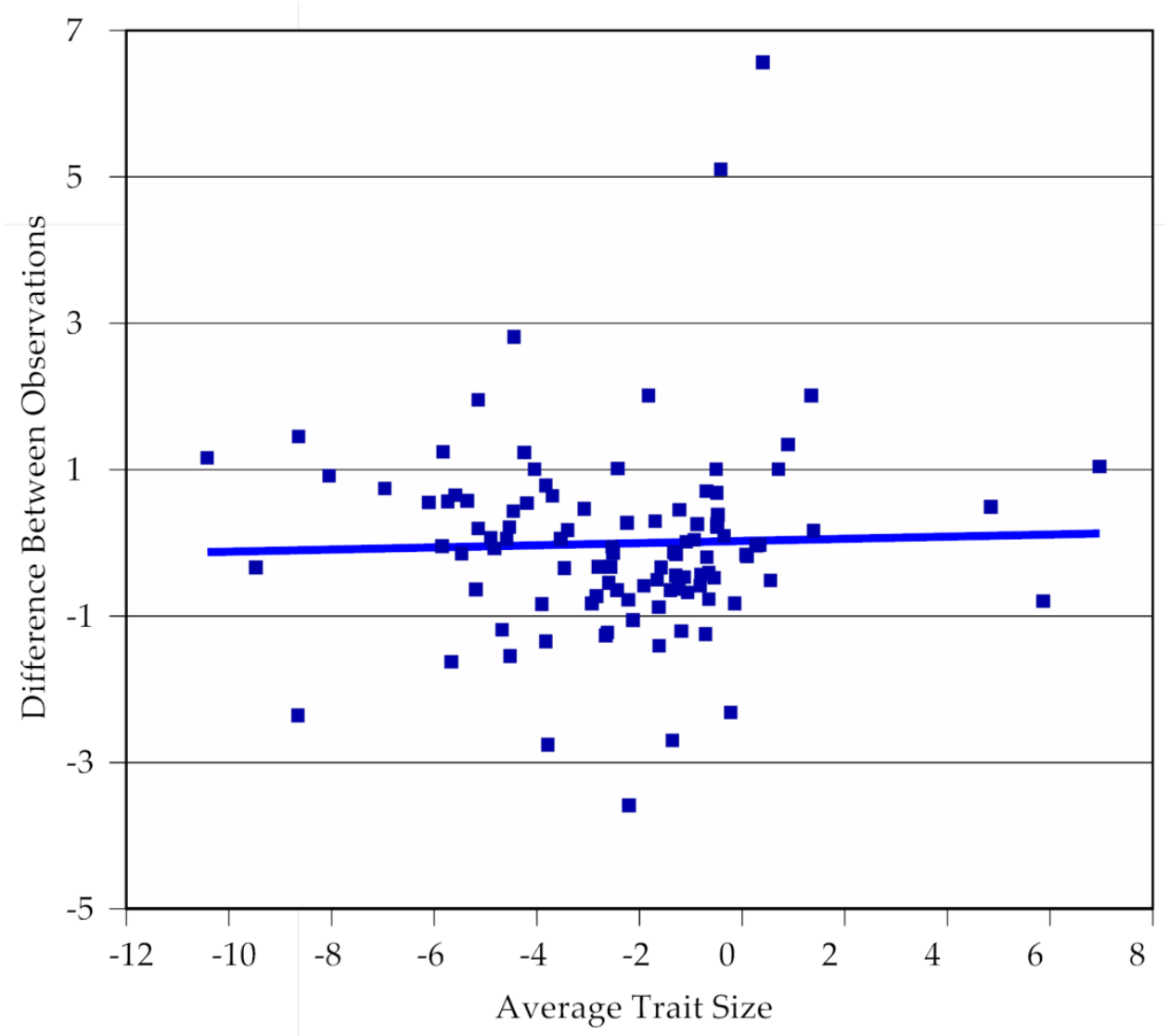

Figure A-5. Bland-Altman plot for intraobserver observations for U6 mesiodistal movement/MFOP.

Table A-5. Results for Bland-Altman analysis of U6 mesiodistal movement/MFOP.

\begin{tabular}{lclc}
\hline Statistic & Result & Statistic & Result \\
\hline U6 M-D/MFOP 2 & -2.53 & t-ratio & -0.83 \\
U6 M-D/MFOP 1 & -2.27 & df & 101 \\
Mean Difference & -0.25 & Probability $>|\mathrm{t}|$ & 0.4104 \\
Standard Error & 0.30 & Probability $>\mathrm{t}$ & 0.7948 \\
Upper 95\% & 0.35 & Probability $<\mathrm{t}$ & 0.2052 \\
Lower 95\% & -0.85 & & \\
Sample Size & 102 & & \\
Correlation & 0.54 & & \\
\hline
\end{tabular}




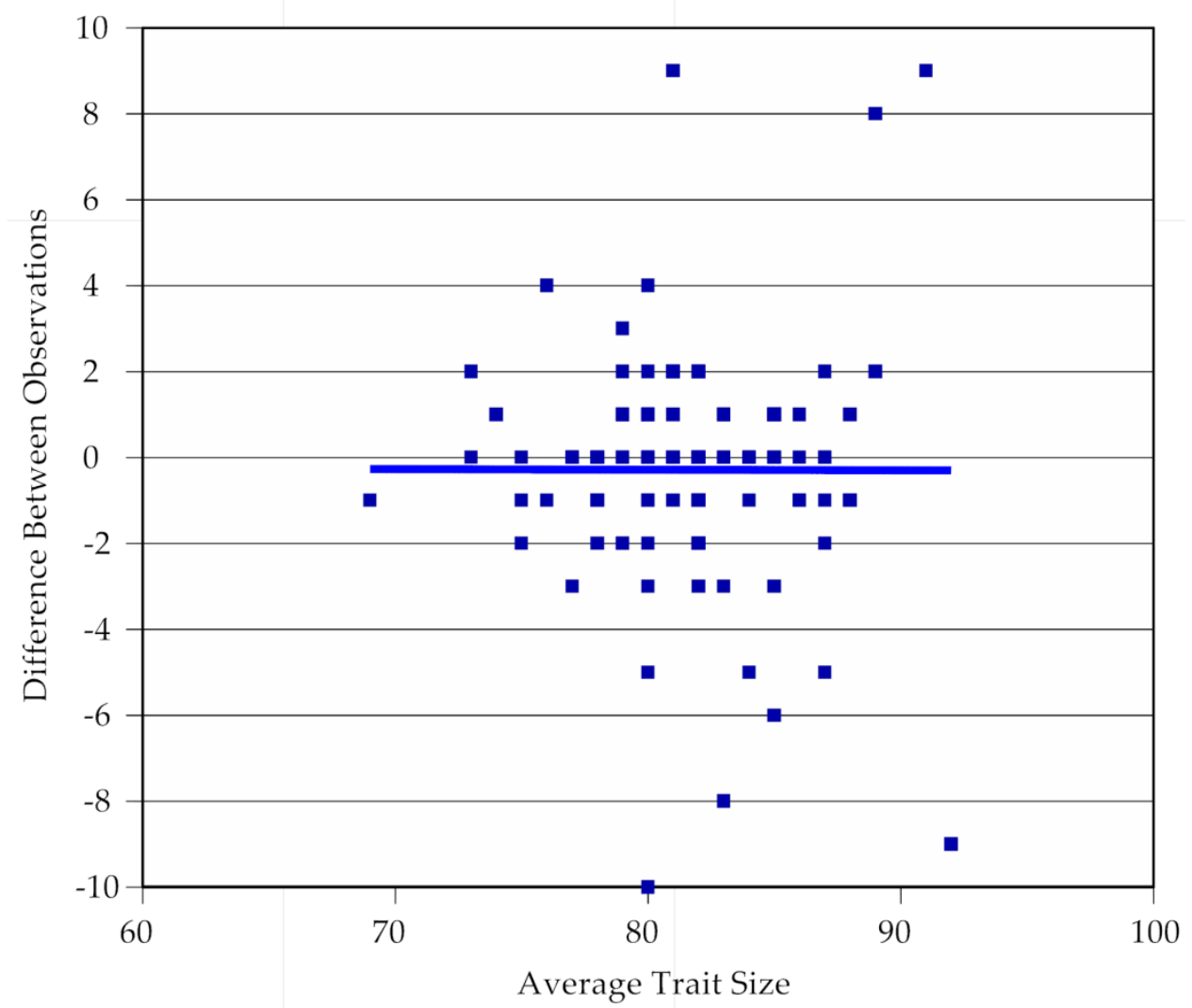

Figure A-6. Bland-Altman plot for intraobserver observations for L6 angle at pretreatment.

Table A-6. Results for Bland-Altman analysis of for L6 angle at pretreatment.

\begin{tabular}{lrlc}
\hline Statistic & Result & \multicolumn{1}{c}{ Statistic } & Result \\
\hline L6 Angle Pre 2 & 81.42 & t-ratio & 0.24 \\
L6 Angle Pre 1 & 81.33 & df & 101 \\
Mean Difference & 0.09 & Probability $>|\mathrm{t}|$ & 0.8137 \\
Standard Error & 0.37 & Probability $>\mathrm{t}$ & 0.4068 \\
Upper 95\% & 0.83 & Probability $<\mathrm{t}$ & 0.5932 \\
Lower 95\% & -0.65 & & \\
Sample Size & 102 & & \\
Correlation & 0.64 & & \\
\hline
\end{tabular}




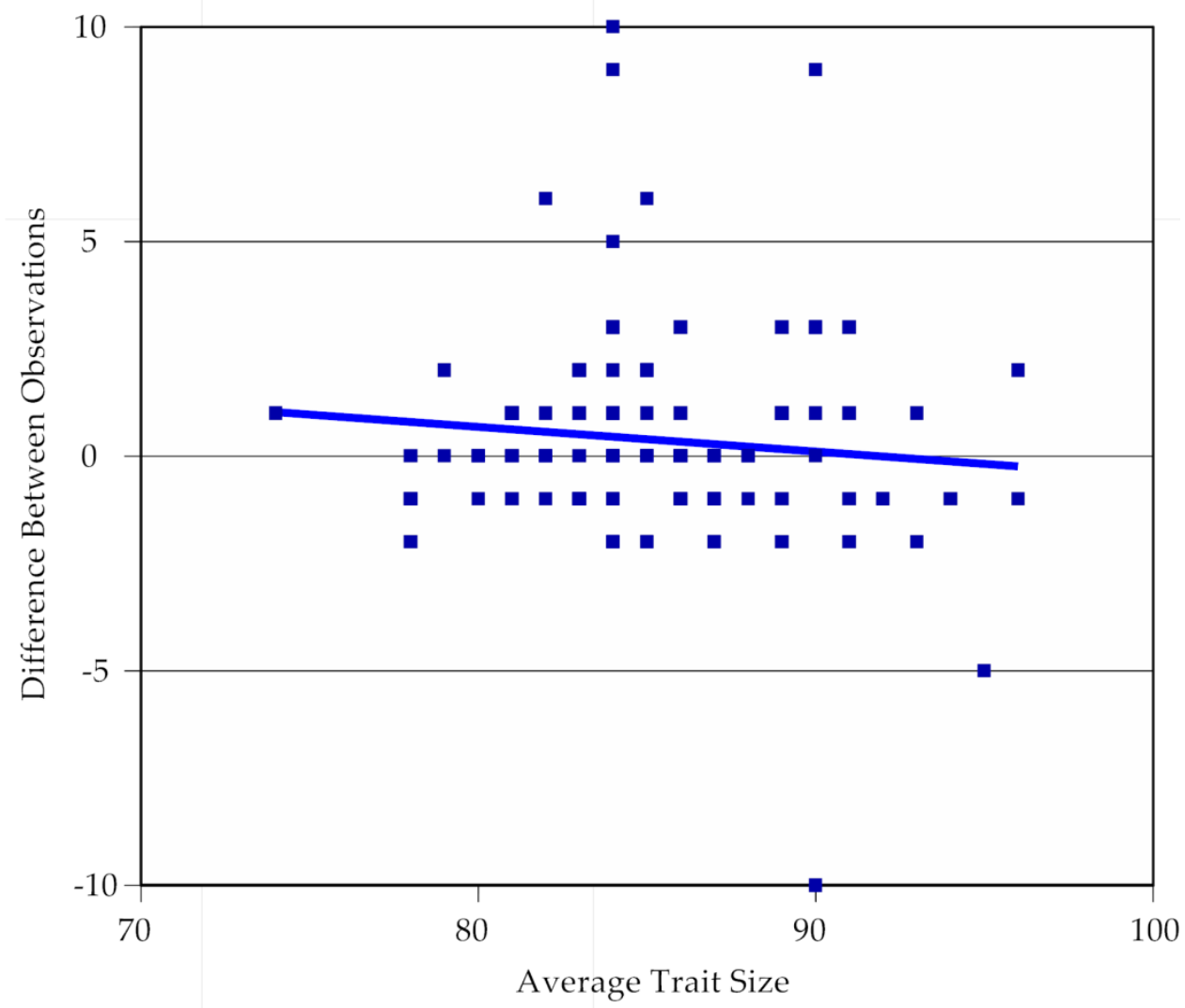

Figure A-7. Bland-Altman plot for intraobserver observations for L6 angle at posttreatment.

Table A-7. Results for Bland-Altman analysis of L6 angle at posttreatment.

\begin{tabular}{lclc}
\hline Statistic & Result & Statistic & Result \\
\hline U6 Angle Post 2 & 91.51 & t-ratio & 0.74 \\
U6 Angle Post 1 & 91.38 & df & 101 \\
Mean Difference & 0.13 & Probability $>|\mathrm{t}|$ & 0.4586 \\
Standard Error & 0.17 & Probability $>\mathrm{t}$ & 0.2293 \\
Upper 95\% & 0.47 & Probability $<\mathrm{t}$ & 0.7707 \\
Lower 95\% & -0.21 & & \\
Sample Size & 102 & & \\
Correlation & 0.89 & & \\
Correlation & 0.83 & & \\
\hline
\end{tabular}




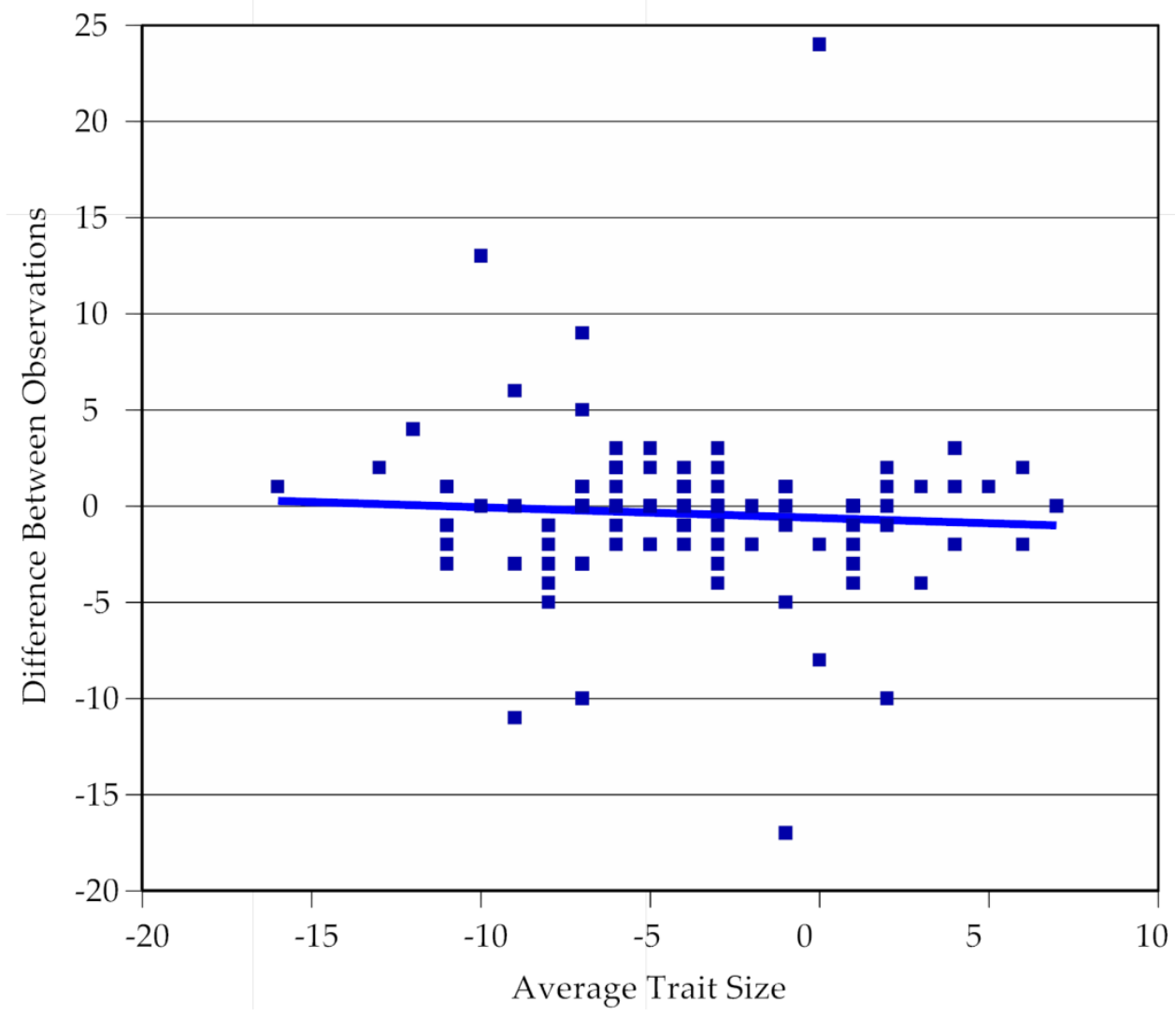

Figure A-8. Bland-Altman plot for intraobserver observations for change in L6 angle.

Table A-8. Results for Bland-Altman analysis of change in L6 angle.

\begin{tabular}{lclc}
\hline Statistic & Result & Statistic & Result \\
\hline Change U6 Angle 2 & -1.99 & t-ratio & 1.85 \\
Change U6 Angle 1 & -2.58 & df & 101 \\
Mean Difference & 0.60 & Probability $>|\mathrm{t}|$ & 0.0672 \\
Standard Error & 0.32 & Probability $>\mathrm{t}$ & 0.0336 \\
Upper 95\% & 1.24 & Probability $<\mathrm{t}$ & 0.9664 \\
Lower 95\% & -0.04 & & \\
Sample Size & 102 & & \\
Correlation & 0.80 & & \\
\hline
\end{tabular}




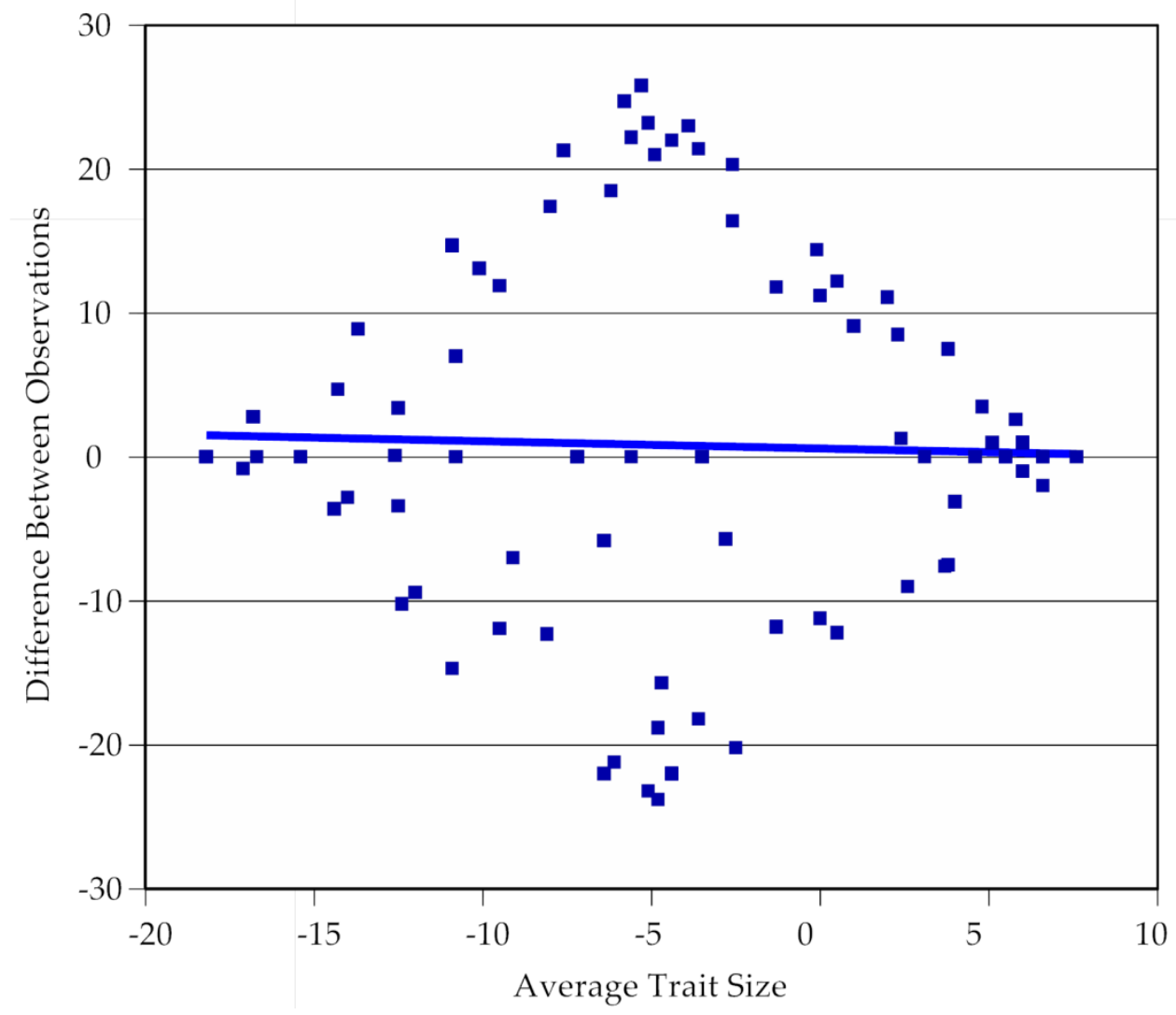

Figure A-9. Bland-Altman plot for intraobserver observations for linear conversion of L6 tip angle.

Table A-9. Results for Bland-Altman analysis of L6 tip angle.

\begin{tabular}{lclc}
\hline Statistic & Result & \multicolumn{1}{c}{ Statistic } & Result \\
\hline LinCon L6 Tip 2 & -4.80 & t-ratio & -0.68 \\
LinCon L6 Tip 1 & -3.99 & df & 101 \\
Mean Difference & -0.82 & Probability $>|\mathrm{t}|$ & 0.4985 \\
Standard Error & 1.20 & Probability $>\mathrm{t}$ & 0.7507 \\
Upper 95\% & 1.57 & Probability $<\mathrm{t}$ & 0.2493 \\
Lower 95\% & -3.21 & & \\
Sample Size & 102 & & \\
Correlation & 0.19 & & \\
\hline
\end{tabular}




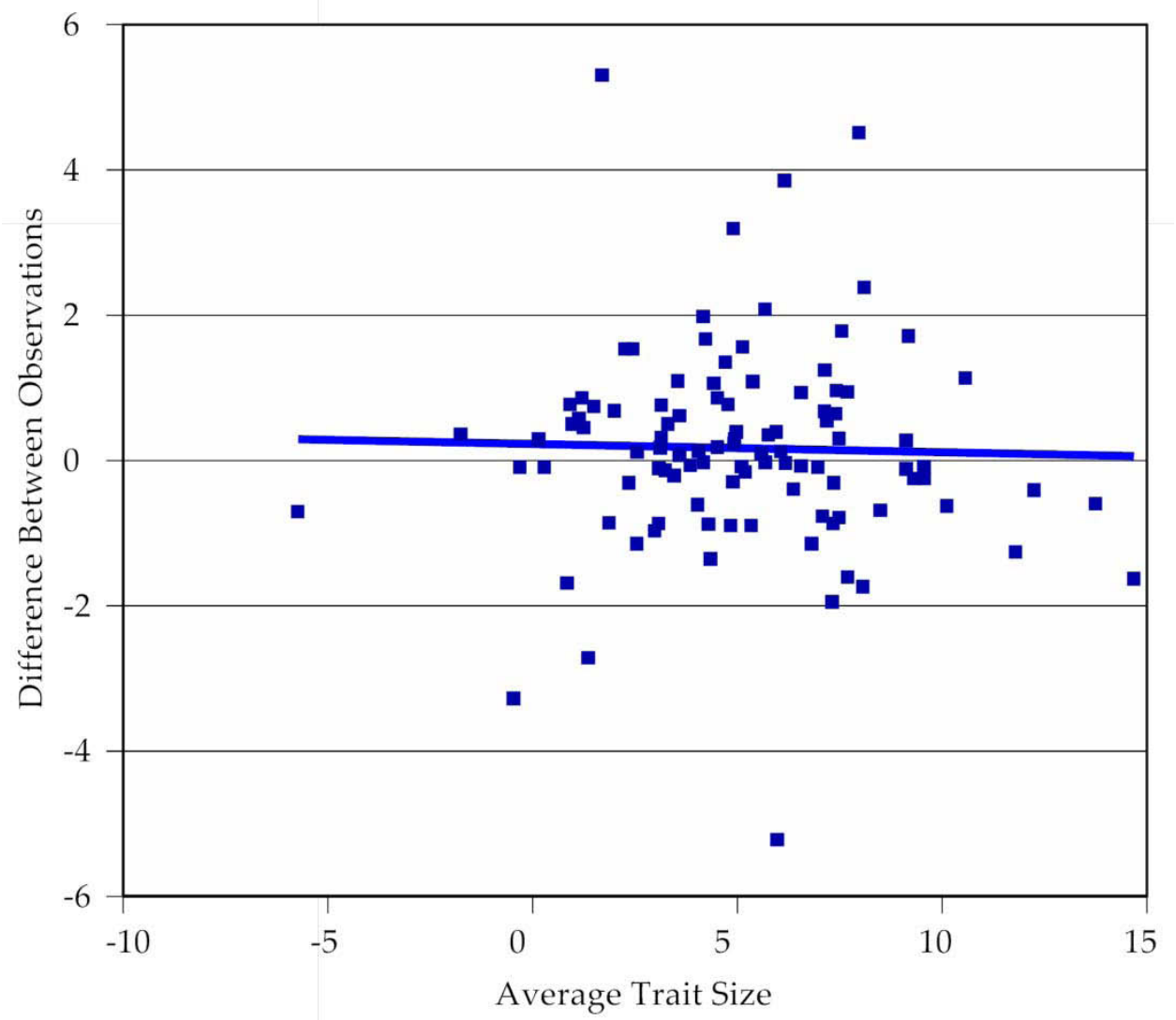

Figure A-10. Bland-Altman plot for intraobserver observations for L6 mesiodistal movement/MFOP.

Table A-10. Results for Bland-Altman analysis of for L6 mesiodistal movement/MFOP.

\begin{tabular}{lllc}
\hline Statistic & Result & Statistic & Result \\
\hline U6 M-D Movement/MFOP 2 & -2.53 & t-ratio & -0.83 \\
U6 M-D Movement/MFOP 1 & -2.27 & $\mathrm{df}$ & 101 \\
Mean Difference & -0.25 & Probability $>|\mathrm{t}|$ & 0.4104 \\
Standard Error & 0.30 & Probability $>\mathrm{t}$ & 0.7948 \\
Upper 95\% & 0.35 & Probability $<\mathrm{t}$ & 0.2052 \\
Lower 95\% & -0.85 & & \\
Sample Size & 102 & & \\
Correlation & 0.54 & & \\
\hline
\end{tabular}




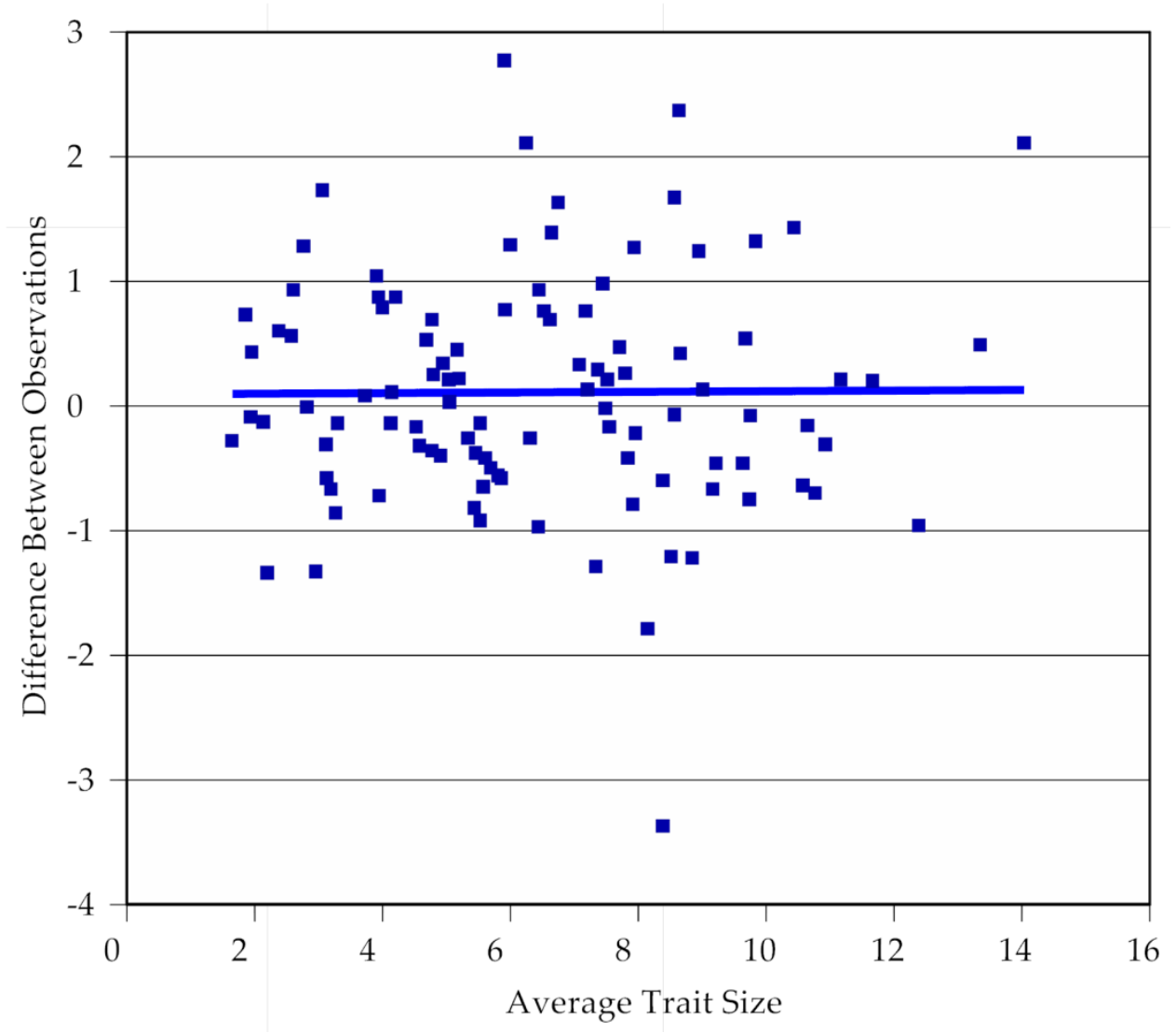

Figure A-11. Bland-Altman plot for intraobserver observations for change in D-D'.

Table A-11. Results for Bland-Altman analysis of change in D-D'.

\begin{tabular}{lclcc}
\hline Statistic & Result & Statistic & Result \\
\hline Linear Change D-D' 2 & 6.36 & & t-ratio & -1.19 \\
Linear Change D-D' 1 & 6.47 & & df & 101 \\
Mean Difference & -0.11 & & Probability $>|t|$ & 0.24 \\
Standard Error & 0.09 & & Probability $>\mathrm{t}$ & 0.88 \\
Upper 95\% & 0.07 & & Probability $<\mathrm{t}$ & 0.12 \\
Lower 95\% & -0.29 & & \\
Sample Size & 102 & & \\
Correlation & 0.94 & & \\
\hline
\end{tabular}




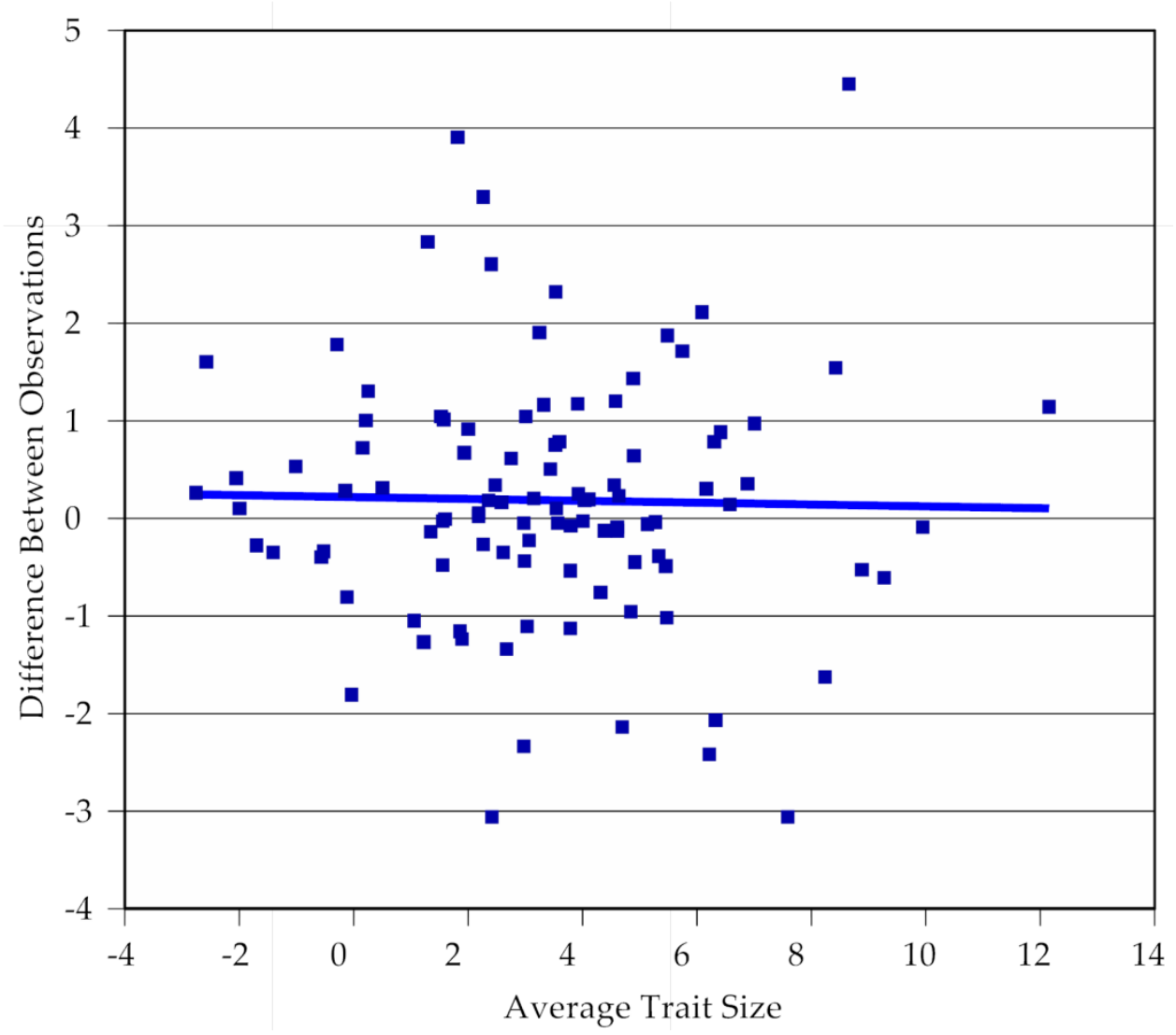

Figure A-12. Bland-Altman plot for intraobserver observations for horizontal change D-D'/MFOP.

Table A-12. Results for Bland-Altman analysis of for horizontal change D$\mathrm{D}^{\prime} / \mathrm{MFOP}$.

\begin{tabular}{lclc}
\hline Statistic & Result & Statistic & Result \\
\hline Horiz Change D-D' /MFOP 23.27 & t-ratio & -1.47 \\
Horiz Change D-D' & /MFOP 13.46 & df & 101 \\
Mean Difference & -0.19 & Probability $>$ |t $\mid$ & 0.1452 \\
Standard Error & 0.13 & Probability $>\mathrm{t}$ & 0.9274 \\
Upper 95\% & 0.07 & Probability $<\mathrm{t}$ & 0.0726 \\
Lower 95\% & -0.44 & & \\
Sample Size & 102 & & \\
Correlation & 0.90 & & \\
\hline
\end{tabular}




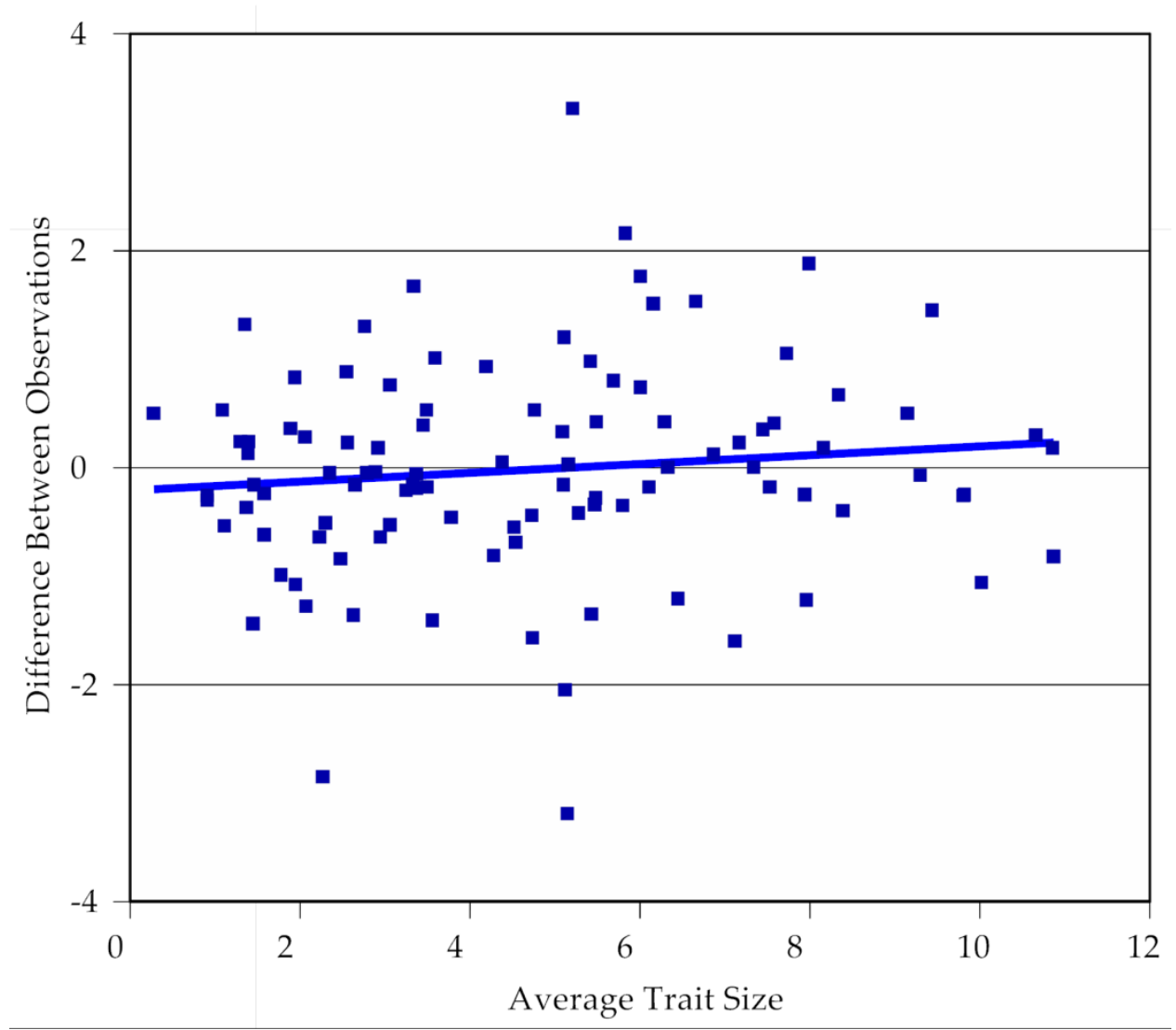

Figure A-13. Bland-Altman plot for intraobserver observations for vertical change in D-D'/MFOP.

Table A-13. Results for Bland-Altman analysis of vertical change in D-D'/MFOP.

\begin{tabular}{lclr}
\hline Statistic & Result & Statistic & Result \\
\hline Vert Change D-D'/MFOP 2 & 4.75 & t-ratio & 0.85 \\
Vert Change D-D'/MFOP 1 & 4.64 & df & 101.00 \\
Mean Difference & 0.11 & Probability $>|\mathrm{t}|$ & 0.4000 \\
Standard Error & 0.13 & Probability $>\mathrm{t}$ & 0.2000 \\
Upper 95\% & 0.37 & Probability $<\mathrm{t}$ & 0.8000 \\
Lower 95\% & -0.15 & & \\
Sample Size & 102 & & \\
Correlation & 0.89 & & \\
\hline
\end{tabular}




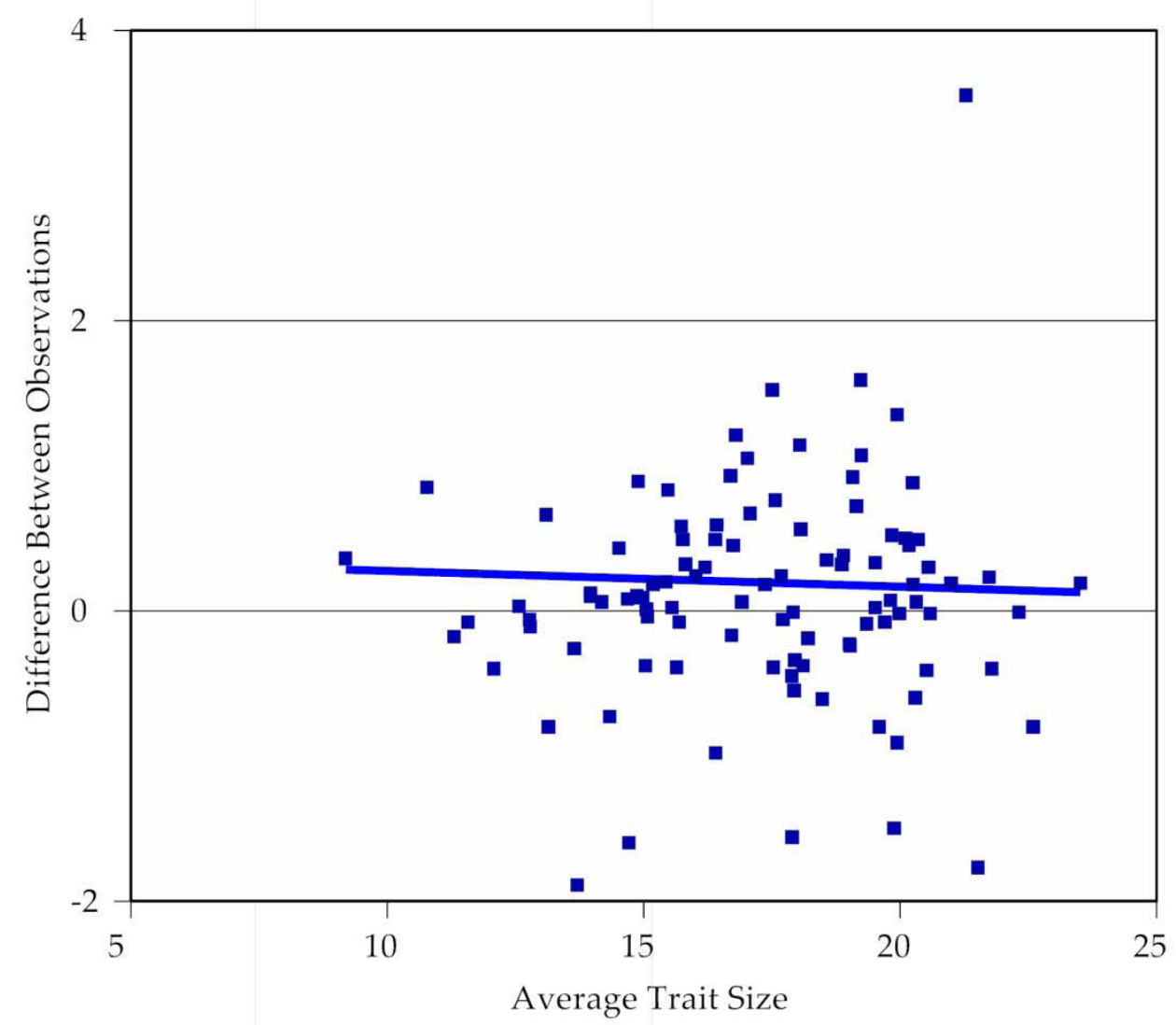

Figure A-14. Bland-Altman plot for intraobserver observations for pre L6 distance.

Table A-14. Results for Bland-Altman analysis of pre L6 distance.

\begin{tabular}{lclr}
\hline Statistic & Result & Statistic & Result \\
\hline Pretreatment L6-D Distance 217.15 & t-ratio & -1.72 \\
Pretreatment L6-D Distance 117.35 & df & 101.00 \\
Mean Difference & -0.20 & Probability $>|\mathrm{t}|$ & 0.0887 \\
Standard Error & 0.11 & Probability $>\mathrm{t}$ & 0.9556 \\
Upper 95\% & 0.03 & Probability $<\mathrm{t}$ & 0.0444 \\
Lower 95\% & -0.42 & & \\
Sample Size & 102 & & \\
Correlation & 0.92 & & \\
\hline
\end{tabular}




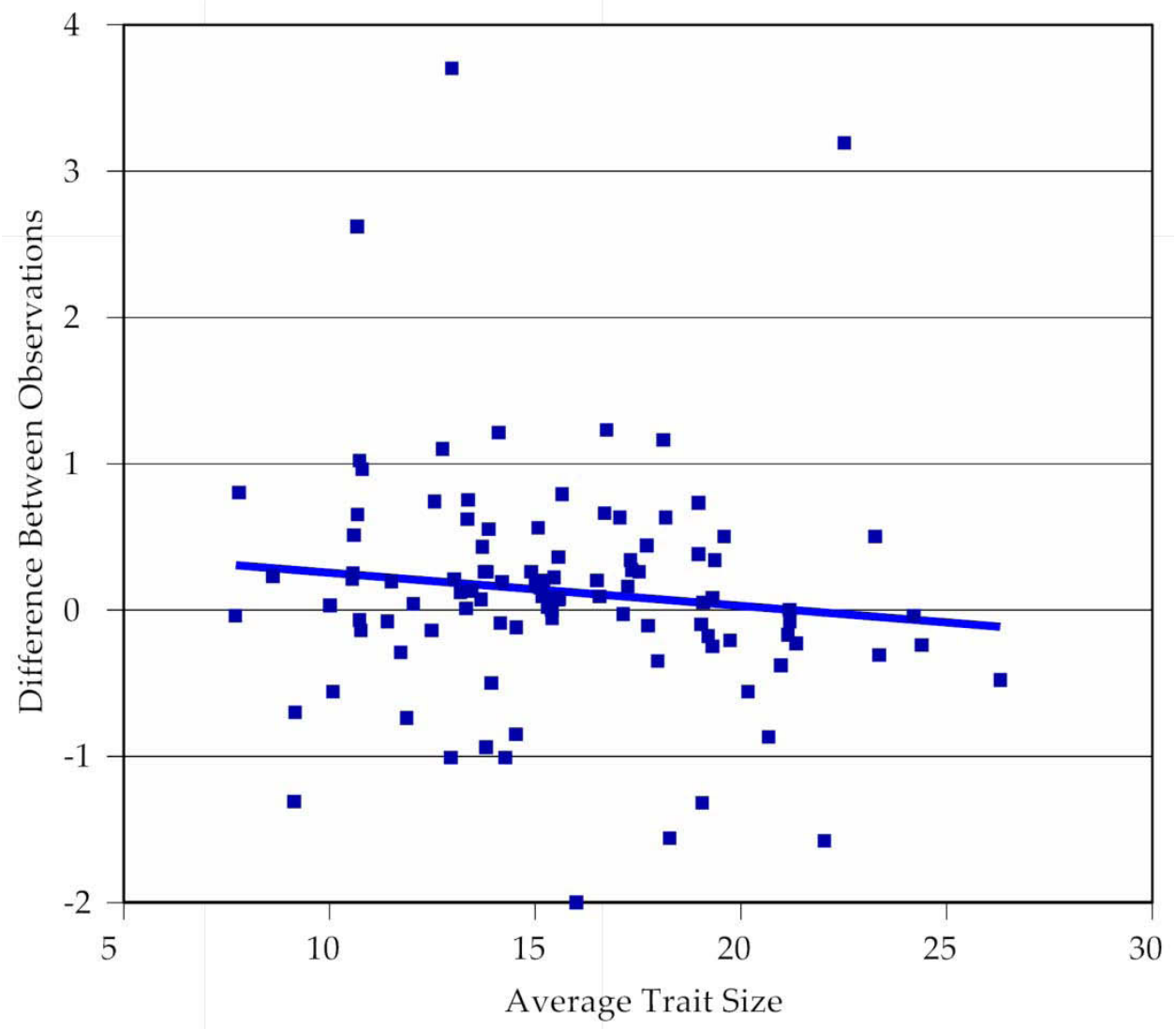

Figure A-15. Bland-Altman plot for intraobserver observations for post L6 distance.

Table A-15. Results for Bland-Altman analysis of post L6 distance.

\begin{tabular}{lclc}
\hline Statistic & Result & Statistic & Result \\
\hline Post L6-D Distance 2 & 15.54 & t-ratio & -1.62 \\
Post L6-D Distance 1 & 15.67 & df & 101 \\
Mean Difference & -0.13 & Probability $>|\mathrm{t}|$ & 0.11 \\
Standard Error & 0.08 & Probability $>\mathrm{t}$ & 0.95 \\
Upper 95\% & 0.03 & Probability $<\mathrm{t}$ & 0.05 \\
Lower 95\% & -0.28 & & \\
Sample Size & 102 & & \\
Correlation & 0.98 & & \\
\hline
\end{tabular}




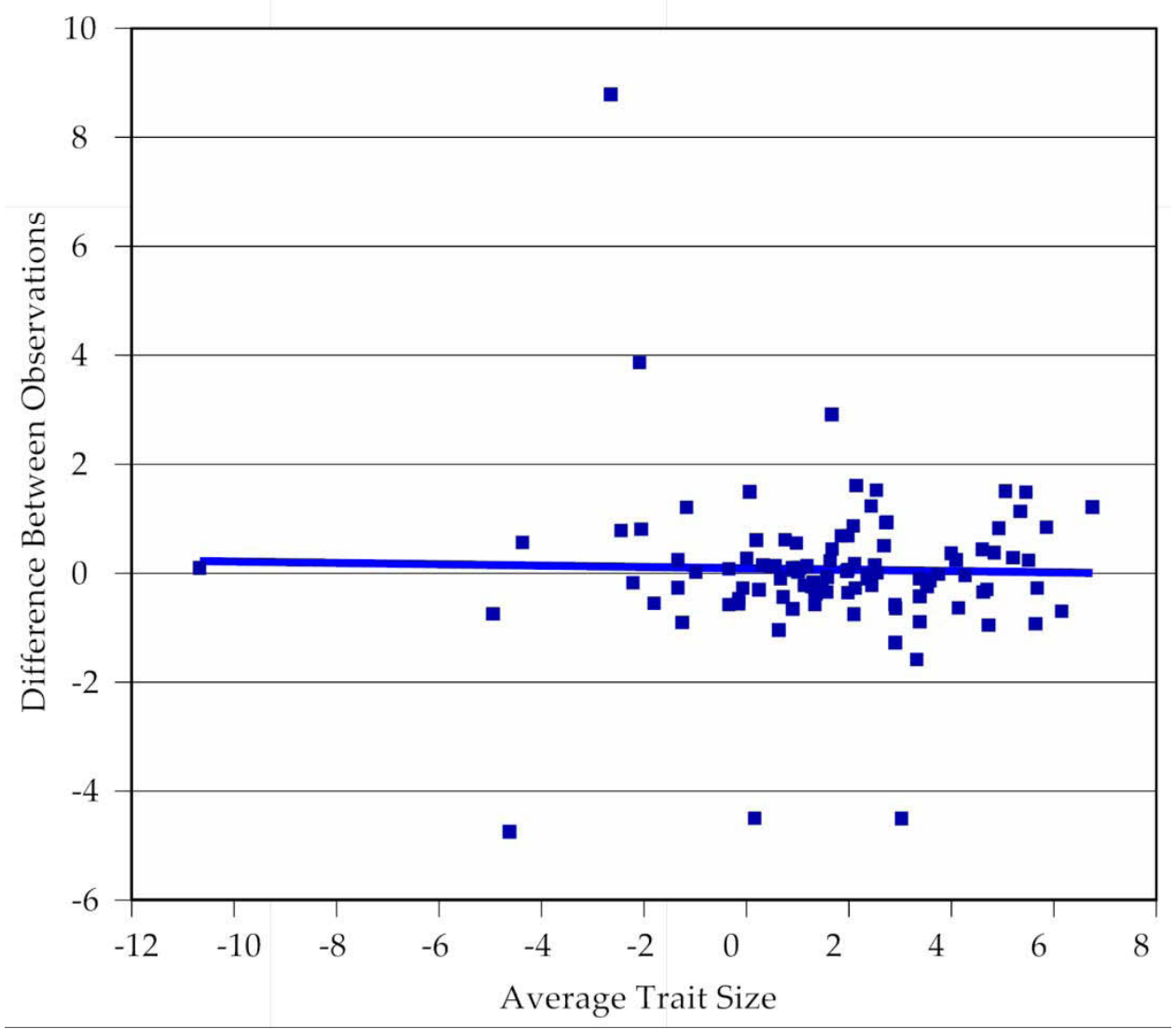

Figure A-16. Bland-Altman plot for intraobserver observations for L6 M-D Movement.

Table A-16. Results for Bland-Altman analysis of L6 M-D Movement.

\begin{tabular}{lrlr}
\hline Statistic & Result & Statistic & Result \\
\hline L6 M-D Movement/D 2 & 1.61 & t-ratio & -0.49 \\
L6 M-D Movement/D 1 & 1.68 & df & 101.00 \\
Mean Difference & -0.07 & Probability $>|\mathrm{t}|$ & 0.6253 \\
Standard Error & 0.14 & Probability $>\mathrm{t}$ & 0.6874 \\
Upper 95\% & 0.21 & Probability $<\mathrm{t}$ & 0.3126 \\
Lower 95\% & -0.35 & & \\
Sample Size & 102 & & \\
Correlation & 0.87 & & \\
\hline
\end{tabular}




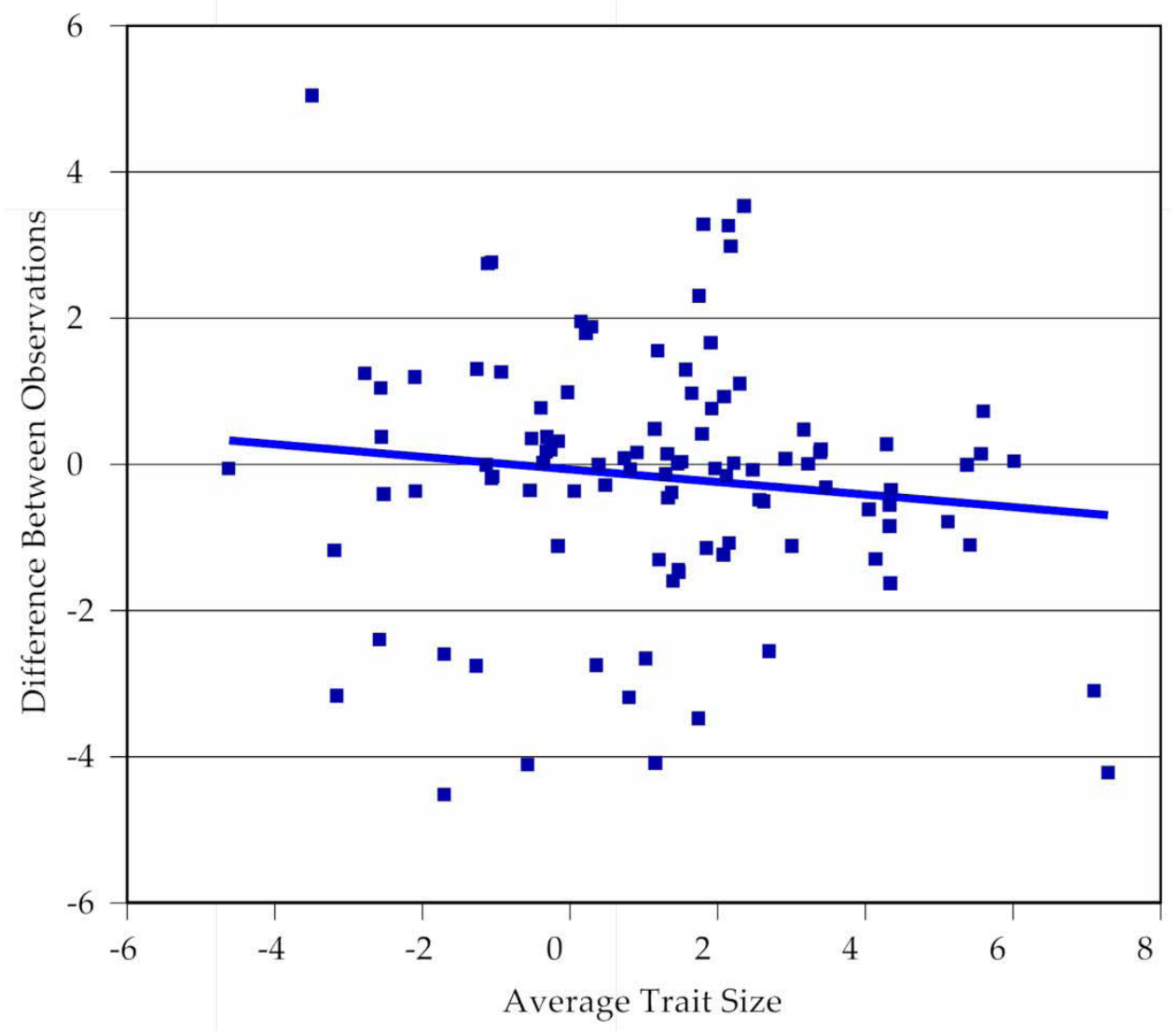

Figure A-17. Bland-Altman plot for intraobserver observations for change in SE.

Table A-17. Results for Bland-Altman analysis of change in SE.

\begin{tabular}{lrlc}
\hline Statistic & Result & Statistic & Result \\
\hline Change SE 2 & 1.25 & t-ratio & 0.34 \\
Change SE 1 & 1.18 & df & 101 \\
Mean Difference & 0.07 & Probability $>|\mathrm{t}|$ & 0.7377 \\
Standard Error & 0.20 & Probability $>\mathrm{t}$ & 0.3688 \\
Upper 95\% & 0.47 & Probability $<\mathrm{t}$ & 0.6312 \\
Lower 95\% & -0.33 & & \\
Sample Size & 102 & & \\
Correlation & 0.70 & & \\
\hline
\end{tabular}




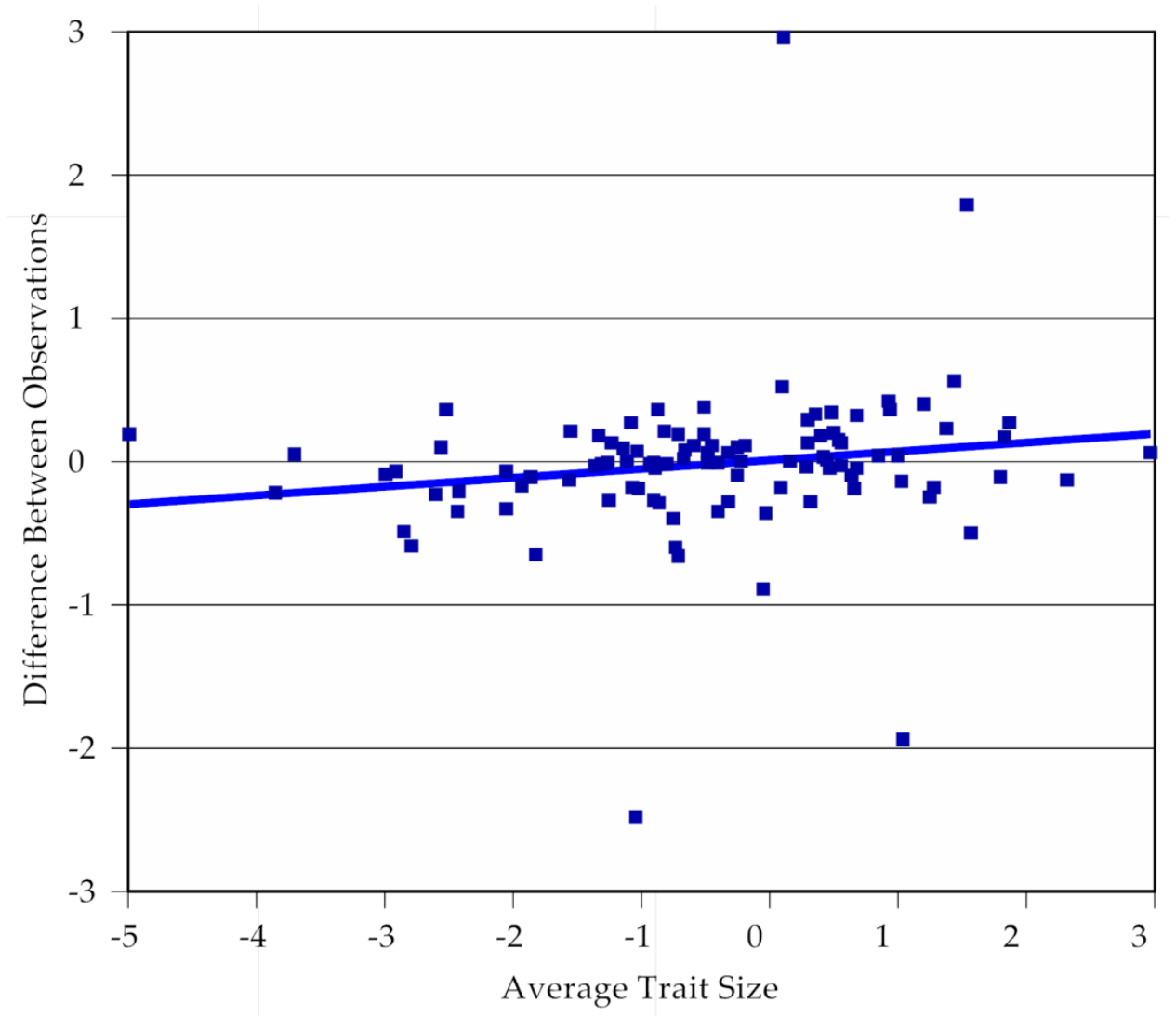

Figure A-18. Bland-Altman plot for intraobserver observations for pretreatment U6-L6 distance.

Table A-18. Results for Bland-Altman analysis of change in pretreatment U6L6 distance.

\begin{tabular}{lrlr}
\hline Statistic & Result & Statistic & Result \\
\hline Pre U6-L6 Distance 2 & -0.42 & t-ratio & 0.75 \\
Pre U6-L6 Distance 1 & -0.48 & df & 101 \\
Mean Difference & 0.06 & Probability $>|\mathrm{t}|$ & 0.4572 \\
Standard Error & 0.08 & Probability $>\mathrm{t}$ & 0.2286 \\
Upper 95\% & 0.21 & Probability $<\mathrm{t}$ & 0.7714 \\
Lower 95\% & -0.09 & & \\
Sample Size & 102 & & \\
Correlation & 0.86 & & \\
\hline
\end{tabular}




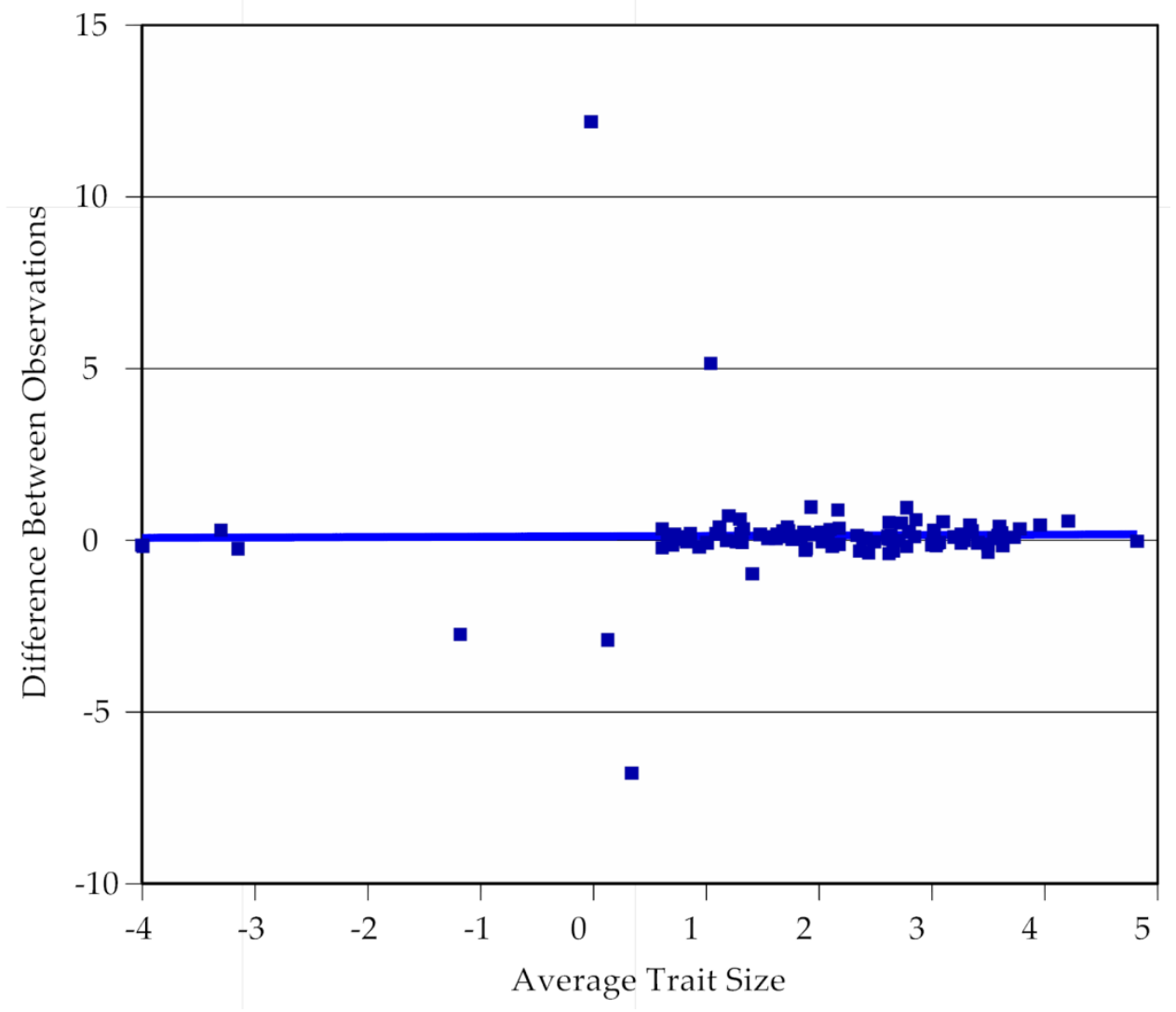

Figure A-19. Bland-Altman plot for intraobserver observations for posttreatment U6-L6 distance.

Table A-19. Results for Bland-Altman analysis of change in posttreatment U6L6 distance.

\begin{tabular}{lrlc}
\hline Statistic & Result & Statistic & Result \\
\hline Post U6-L6 Distance 2 & 1.86 & t-ratio & -0.91 \\
Post U6-L6 Distance 1 & 2.00 & df & 101 \\
Mean Difference & -0.14 & Probability $>|\mathrm{t}|$ & 0.3634 \\
Standard Error & 0.15 & Probability $>\mathrm{t}$ & 0.8183 \\
Upper 95\% & 0.16 & Probability $<\mathrm{t}$ & 0.1817 \\
Lower 95\% & -0.45 & & \\
Sample Size & 102 & & \\
Correlation & 0.59 & & \\
\hline
\end{tabular}




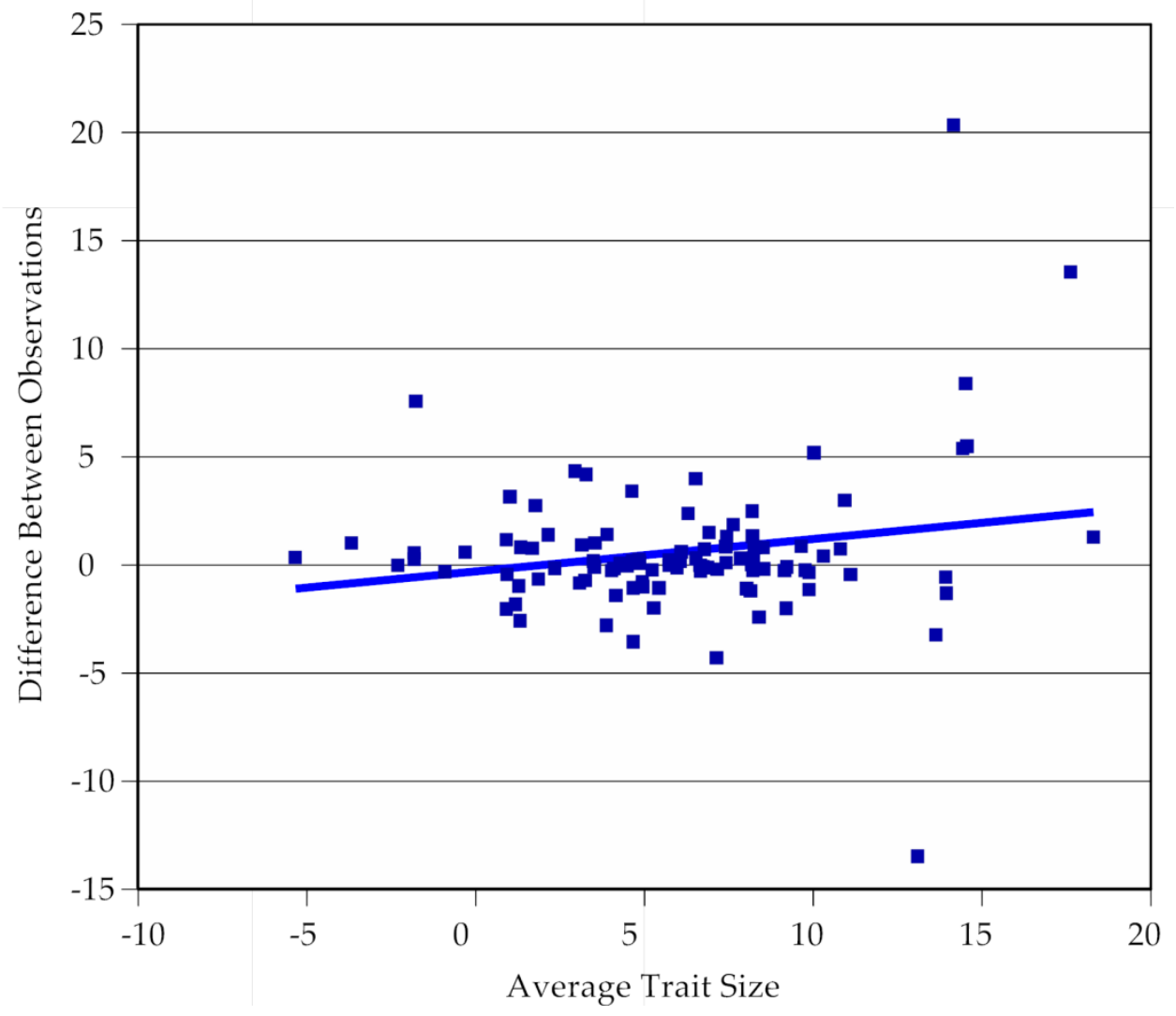

Figure A-20. Bland-Altman plot for intraobserver observations for total molar correction.

Table A-20. Results for Bland-Altman analysis of total molar correction.

\begin{tabular}{lclc}
\hline Statistic & Result & Statistic & Result \\
\hline Total Molar Correction 2 & 5.76 & t-ratio & -1.81 \\
Total Molar Correction 1 & 6.38 & df & 101 \\
Mean Difference & -0.61 & Probability $>|\mathrm{t}|$ & 0.0727 \\
Standard Error & 0.34 & Probability $>\mathrm{t}$ & 0.9637 \\
Upper 95\% & 0.06 & Probability $<\mathrm{t}$ & 0.0363 \\
Lower 95\% & -1.28 & & \\
Sample Size & 102 & & \\
Correlation & 0.75 & & \\
\hline
\end{tabular}




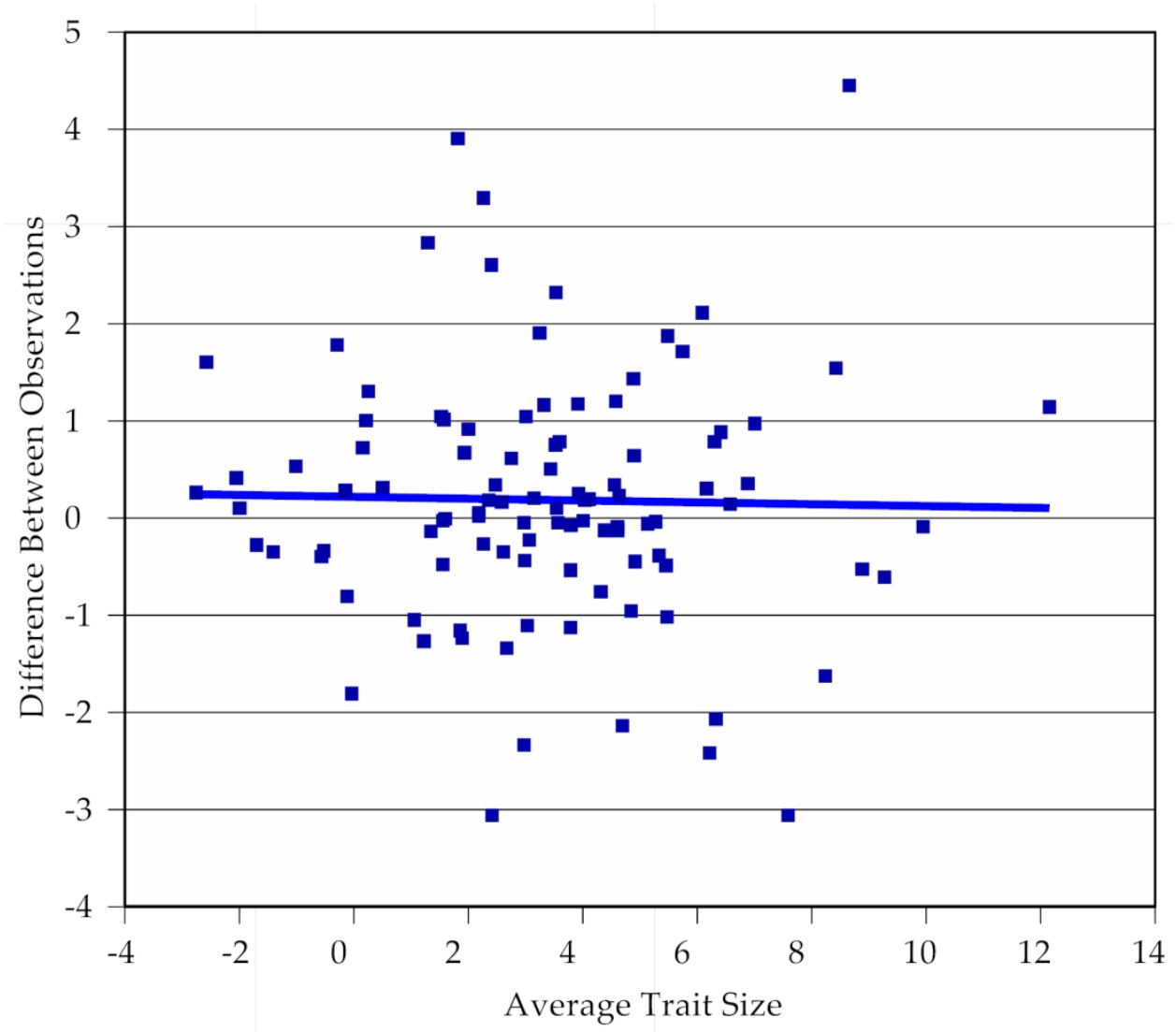

Figure A-21. Bland-Altman plot for intraobserver observations for $\mathrm{ABCH}$.

Table A-21. Results for Bland-Altman analysis of $\mathrm{ABCH}$.

\begin{tabular}{lcllr}
\hline Statistic & Result & & Statistic & Result \\
\hline ABCH 2 & 1.25 & t-ratio & -7.26 \\
ABCH 1 & 3.41 & & df & 101 \\
Mean Difference & -2.16 & & Probability $>$ & $|\mathrm{t}|<0.0001$ \\
Standard Error & 0.30 & & Probability $>\mathrm{t}$ & 1.00 \\
Upper 95\% & -1.57 & & Probability $<\mathrm{t}$ & $<0.0001$ \\
Lower 95\% & -2.75 & & \\
Sample Size & 102 & & \\
Correlation & 0.33 & & \\
\hline
\end{tabular}




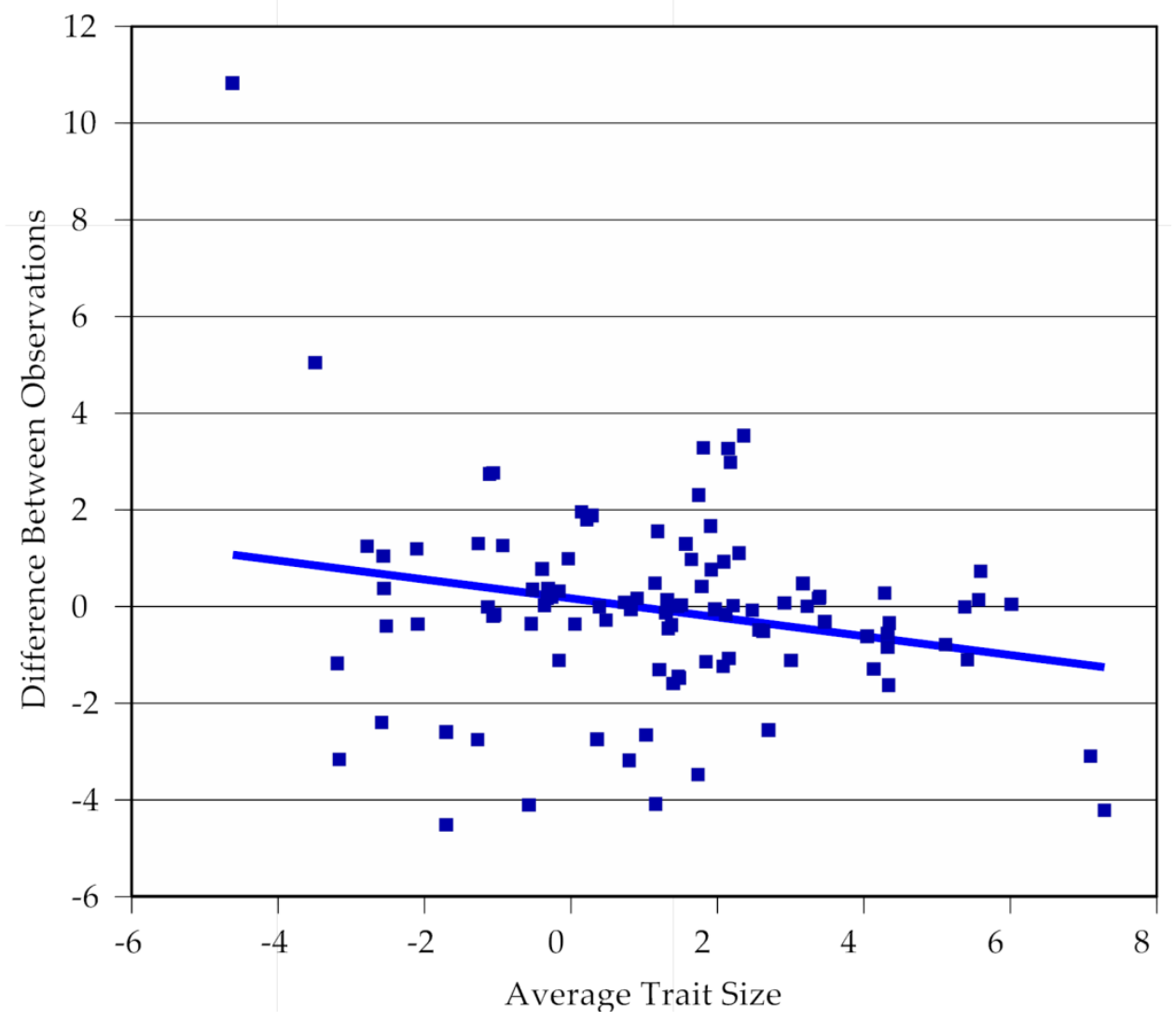

Figure A-22. Bland-Altman plot for intraobserver observations for maxillary translative growth.

Table A-22. Results for Bland-Altman analysis of maxillary translative growth.

\begin{tabular}{lclrr}
\hline Statistic & Result & & Statistic & Result \\
\hline Max Trans Growth 2 & -0.29 & t-ratio & -10.45 \\
Max Trans Growth 1 & 2.16 & & df & 101 \\
Mean Difference & -2.46 & & Probability $>$ & $|\mathrm{t}|<0.0001$ \\
Standard Error & 0.24 & & Probability $>\mathrm{t}$ & 1.00 \\
Upper 95\% & -1.99 & & Probability $<\mathrm{t}$ & $<0.0001$ \\
Lower 95\% & -2.92 & & \\
Sample Size & 102 & & \\
Correlation & 0.72 & & \\
\hline
\end{tabular}




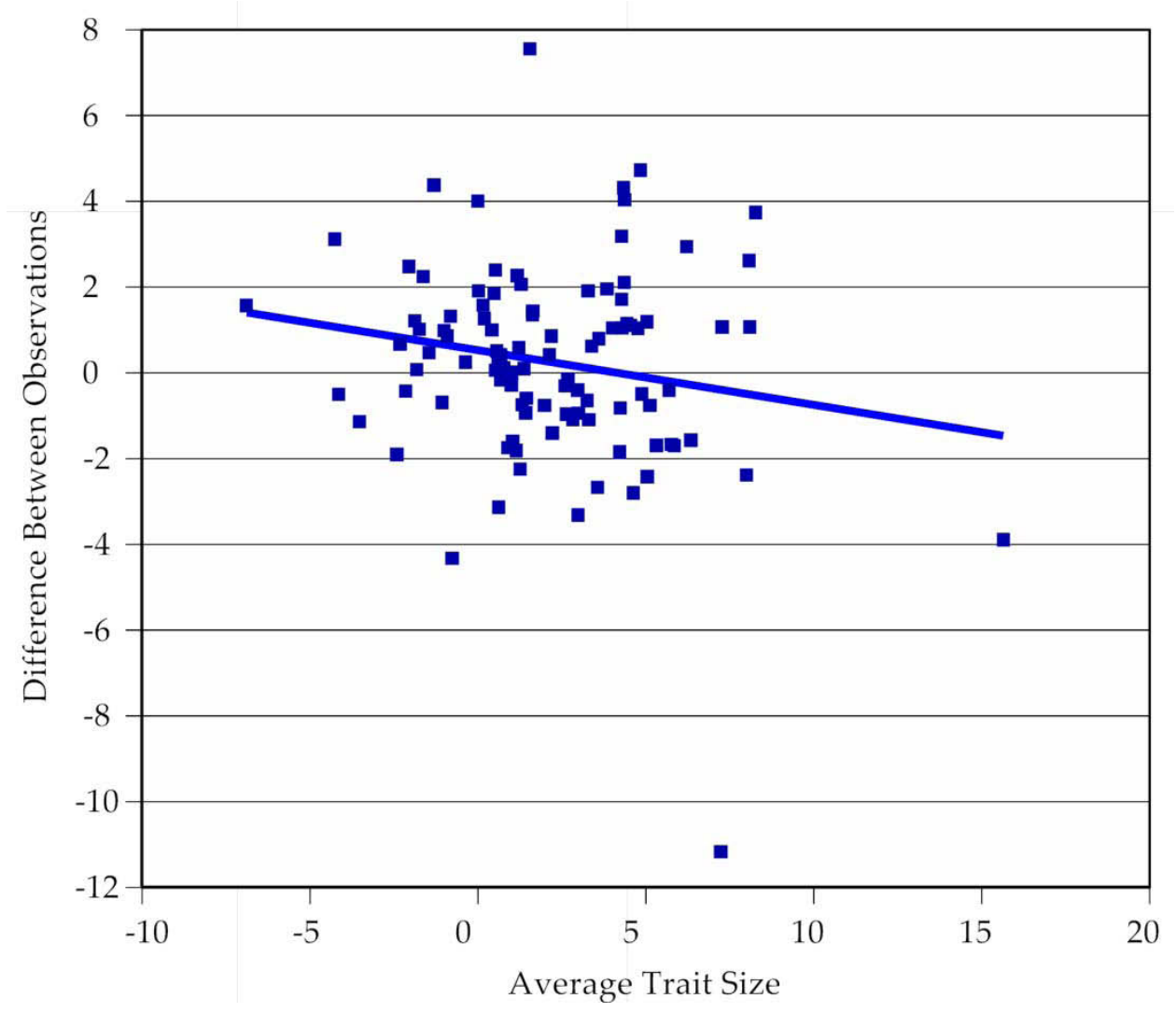

Figure A-23. Bland-Altman plot for intraobserver observations for mandibular translative growth.

Table A-23. Results for Bland-Altman analysis of mandibular translative growth.

\begin{tabular}{lclc}
\hline Statistic & Result & Statistic & Result \\
\hline Mand Trans Growth 2 & 2.02 & t-ratio & -1.13 \\
Mand Trans Growth 1 & 2.27 & df & 101 \\
Mean Difference & -0.25 & Probability $>|t|$ & 0.2608 \\
Standard Error & 0.23 & Probability $>$ t & 0.8696 \\
Upper 95\% & 0.19 & Probability $<\mathrm{t}$ & 0.1304 \\
Lower 95\% & -0.70 & & \\
Sample Size & 102 & & \\
Correlation & 0.78 & & \\
\hline
\end{tabular}




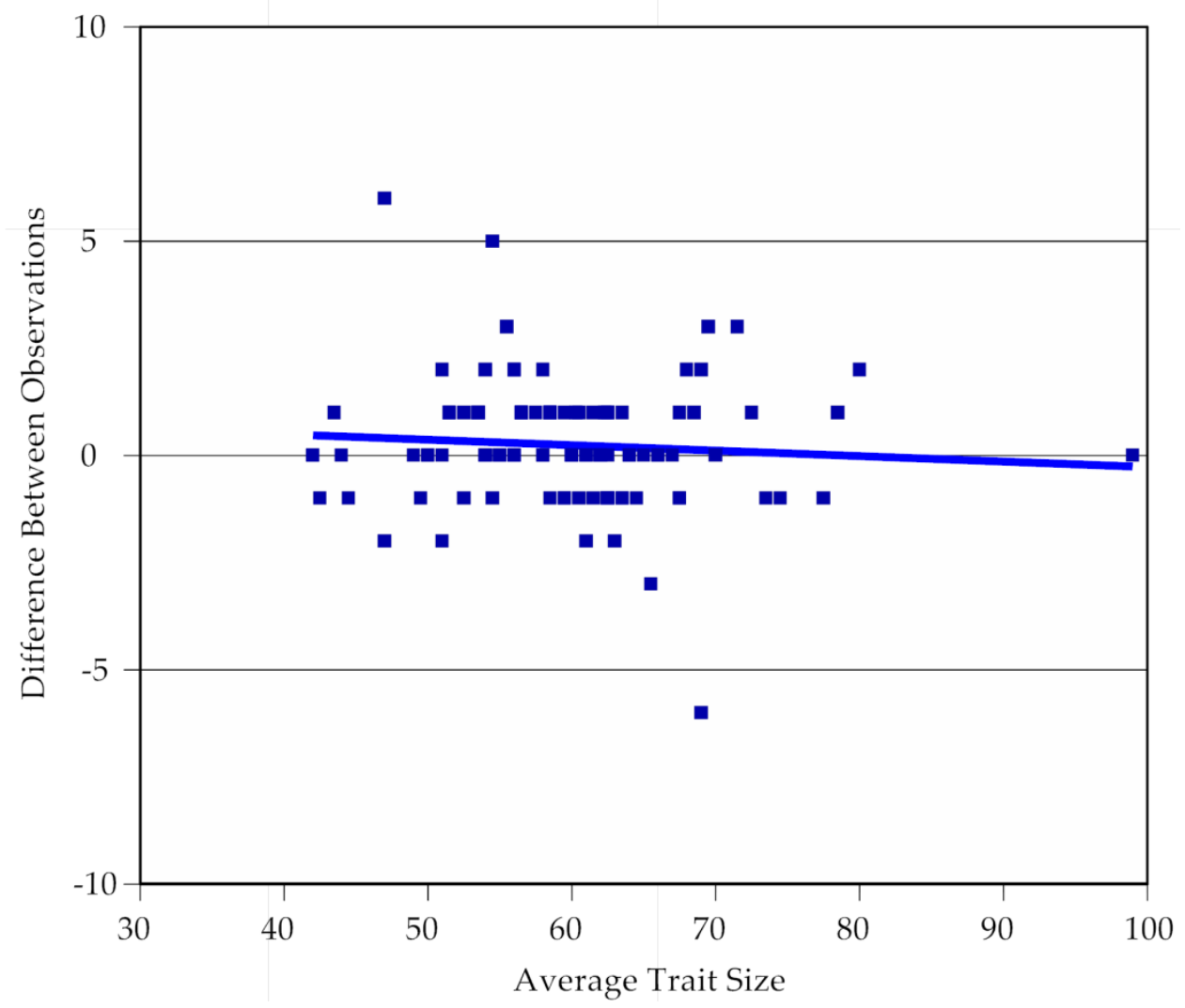

Figure A-24. Bland-Altman plot for intraobserver observations for pretreatment $\mathrm{U} 1$ angle.

Table A-24. Results for Bland-Altman analysis of pretreatment U1 angle.

\begin{tabular}{lclc}
\hline Statistic & Result & Statistic & Result \\
\hline Pretreatment U1 Angle 2 & 59.51 & t-ratio & -1.90 \\
Pretreatment U1 Angle 1 & 59.90 & df & 101 \\
Mean Difference & -0.39 & Probability $>|\mathrm{t}|$ & 0.0601 \\
Standard Error & 0.21 & Probability $>\mathrm{t}$ & 0.9699 \\
Upper 95\% & 0.02 & Probability $<\mathrm{t}$ & 0.0301 \\
Lower 95\% & -0.80 & & \\
Sample Size & 102 & & \\
Correlation & 0.97 & & \\
\hline
\end{tabular}




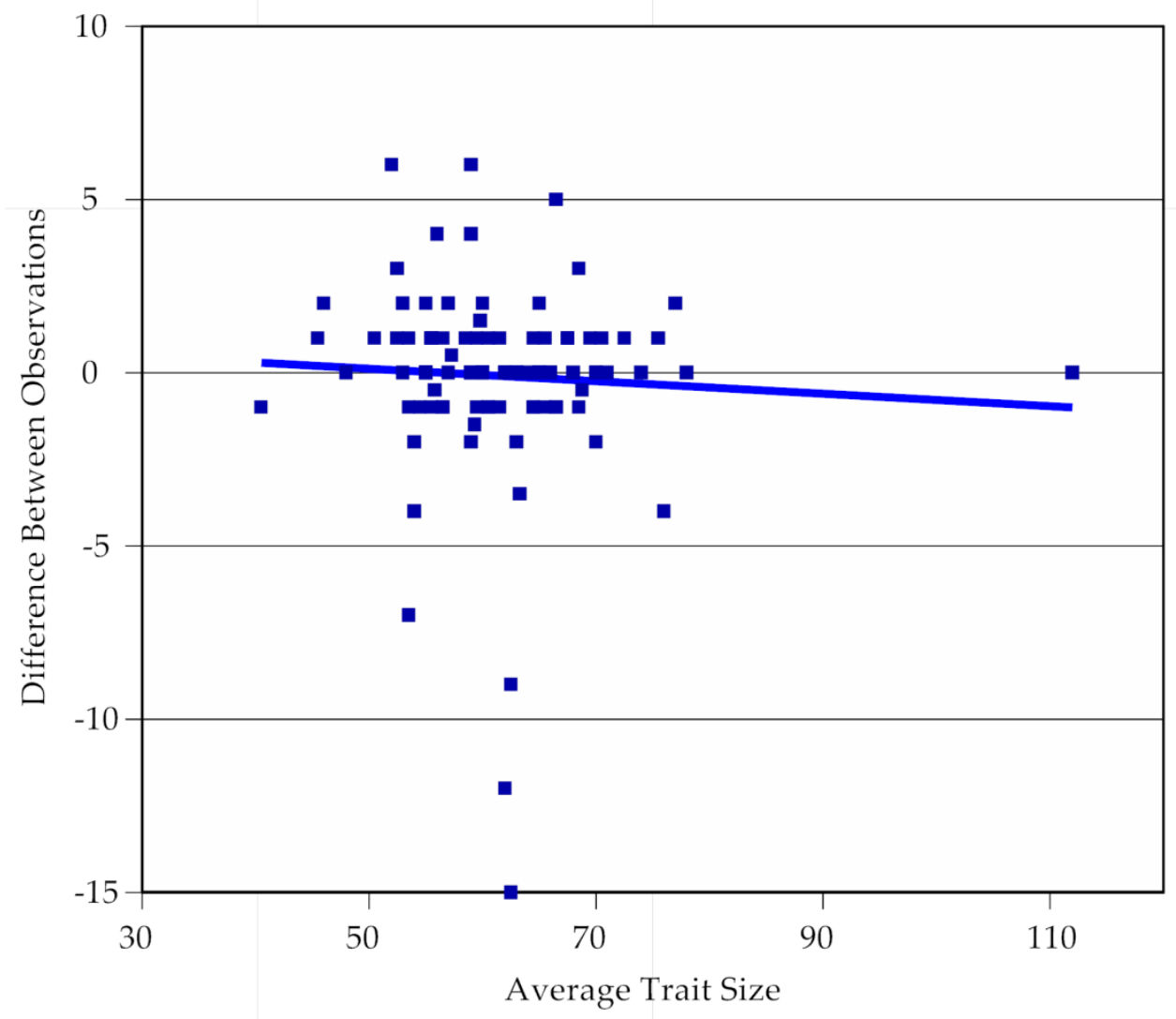

Figure A-25. Bland-Altman plot for intraobserver observations for posttreatment $\mathrm{U} 1$ angle.

Table A-25. Results for Bland-Altman analysis of posttreatment U1 angle.

\begin{tabular}{|c|c|c|c|}
\hline Statistic & Result & Statistic & Result \\
\hline Post U1 Angle 2 & 61.44 & t-ratio & 0.32 \\
\hline Post U1 Angle 1 & 61.35 & $\mathrm{df}$ & 101 \\
\hline Mean Difference & 0.09 & Probability $>|t|$ & 0.7497 \\
\hline Standard Error & 0.28 & Probability $>t$ & 0.3748 \\
\hline Upper 95\% & 0.64 & Probability $<\mathrm{t}$ & 0.6252 \\
\hline Lower 95\% & -0.46 & & \\
\hline Sample Size & 102 & & \\
\hline Correlation & 0.95 & & \\
\hline
\end{tabular}




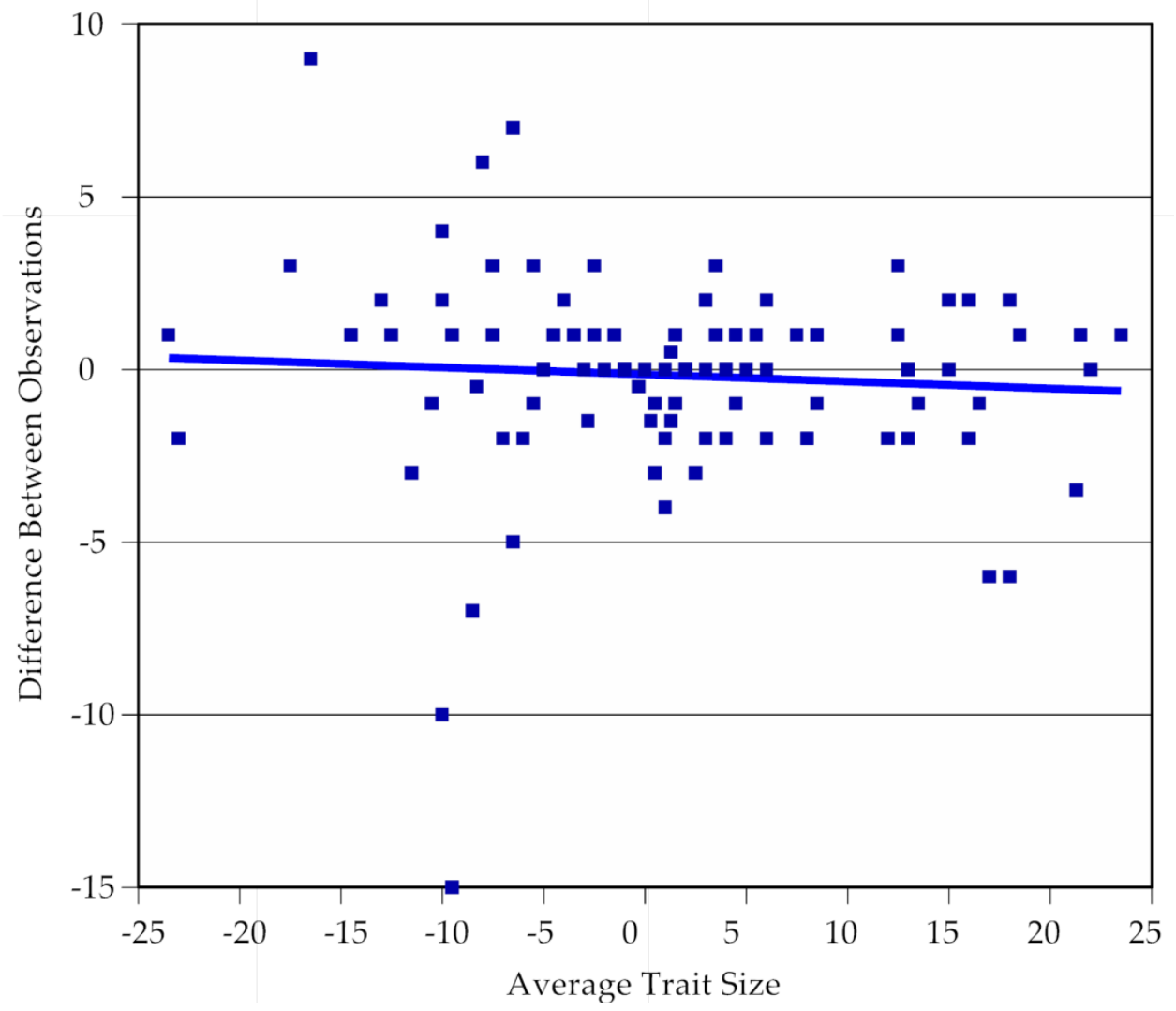

Figure A-26. Bland-Altman plot for intraobserver observations for change in U1 angle.

Table A-26. Results for Bland-Altman analysis of change in U1 angle.

\begin{tabular}{lclc}
\hline Statistic & Result & Statistic & Result \\
\hline Change U1 Angle 2 & 1.93 & t-ratio & 1.14 \\
Change U1 Angle 1 & 1.46 & df & 101 \\
Mean Difference & 0.47 & Probability $>$ |t $\mid$ & 0.2580 \\
Standard Error & 0.41 & Probability $>\mathrm{t}$ & 0.1290 \\
Upper 95\% & 1.29 & Probability $<\mathrm{t}$ & 0.8710 \\
Lower 95\% & -0.35 & & \\
Sample Size & 102 & & \\
Correlation & 0.92 & & \\
\hline
\end{tabular}




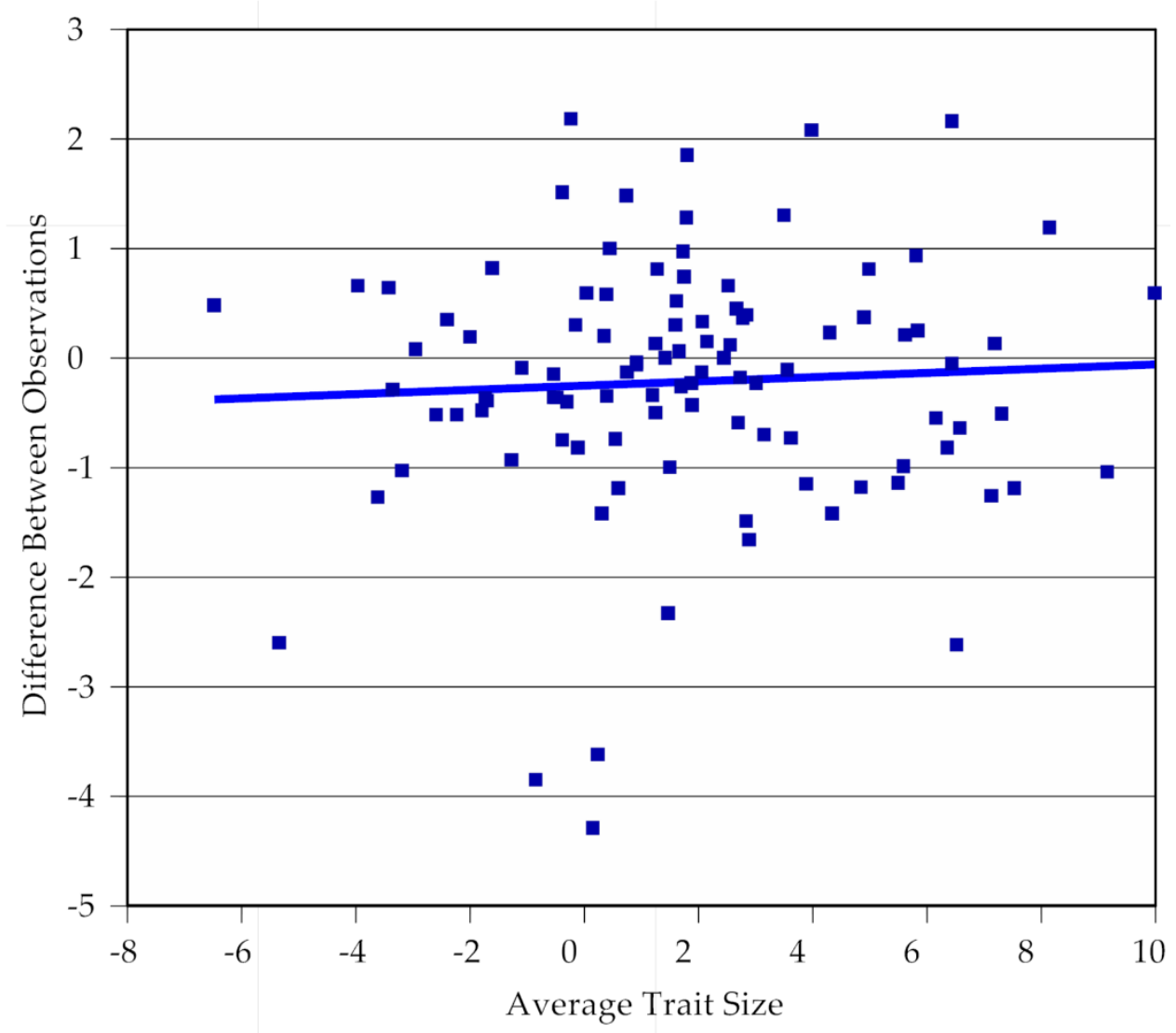

Figure A-27. Bland-Altman plot for intraobserver observations for change in U1 movement.

Table A-27. Results for Bland-Altman analysis of change in U1 movement.

\begin{tabular}{lclc}
\hline Statistic & Result & Statistic & Result \\
\hline U1 Movement 2 & 1.86 & t-ratio & 0.71 \\
U1 Movement 1 & 1.74 & df & 101 \\
Mean Difference & 0.11 & Probability $>|t|$ & 0.4817 \\
Standard Error & 0.16 & Probability $>\mathrm{t}$ & 0.2409 \\
Upper 95\% & 0.43 & Probability $<\mathrm{t}$ & 0.7591 \\
Lower 95\% & -0.21 & & \\
Sample Size & 102 & & \\
Correlation & 0.88 & & \\
\hline
\end{tabular}




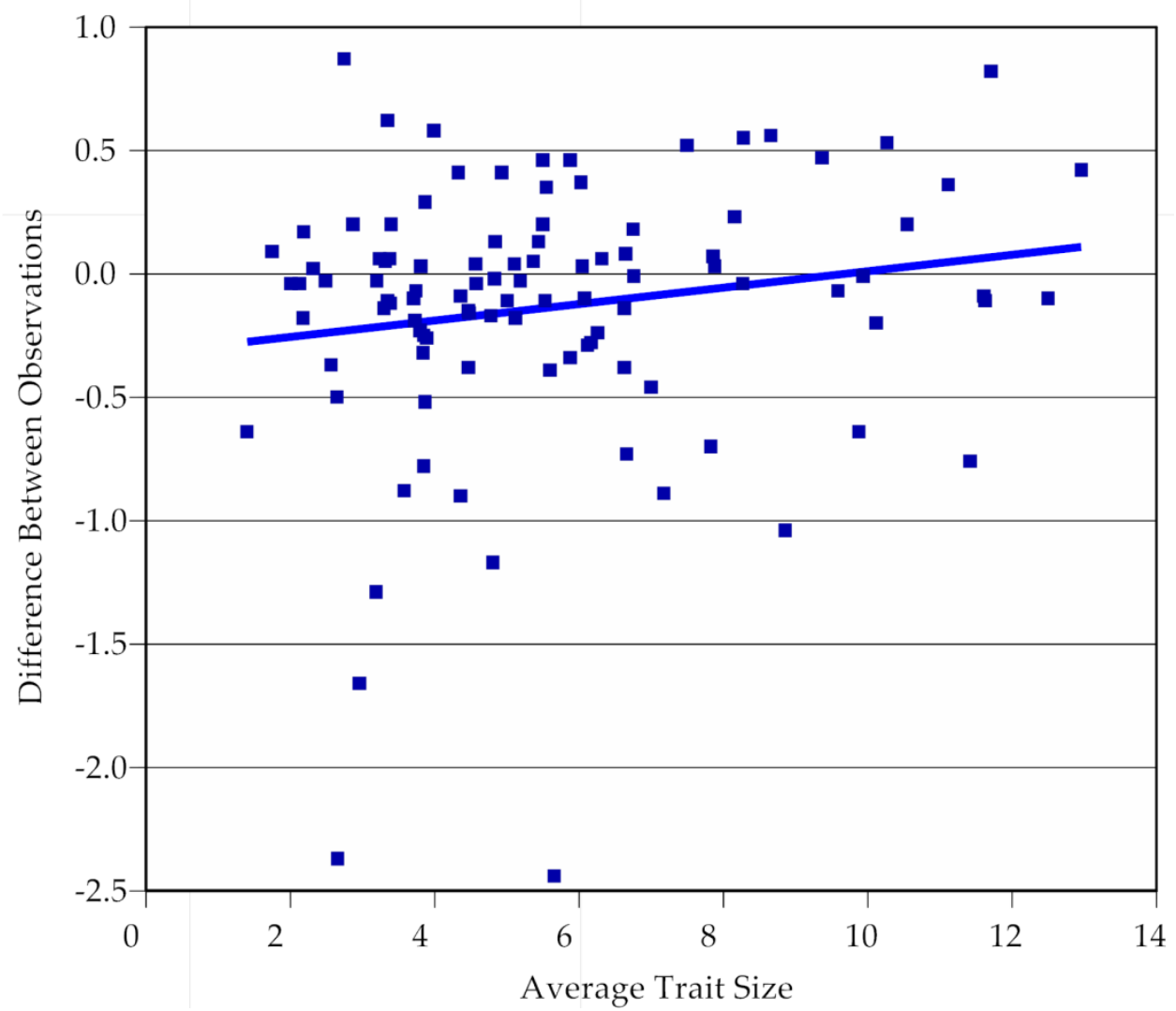

Figure A-28. Bland-Altman plot for intraobserver observations for pretreatment overjet.

Table A-28. Results for Bland-Altman analysis of pretreatment overjet.

\begin{tabular}{lclc}
\hline Statistic & Result & Statistic & Result \\
\hline Pretreatment OJ 2 & 5.70 & t-ratio & 2.50 \\
Pretreatment OJ 1 & 5.57 & df & 101 \\
Mean Difference & 0.13 & Probability $>|\mathrm{t}|$ & 0.0140 \\
Standard Error & 0.05 & Probability $>\mathrm{t}$ & 0.0070 \\
Upper 95\% & 0.24 & Probability $<\mathrm{t}$ & 0.9930 \\
Lower 95\% & 0.03 & & \\
Sample Size & 102 & & \\
Correlation & 0.98 & & \\
\hline
\end{tabular}




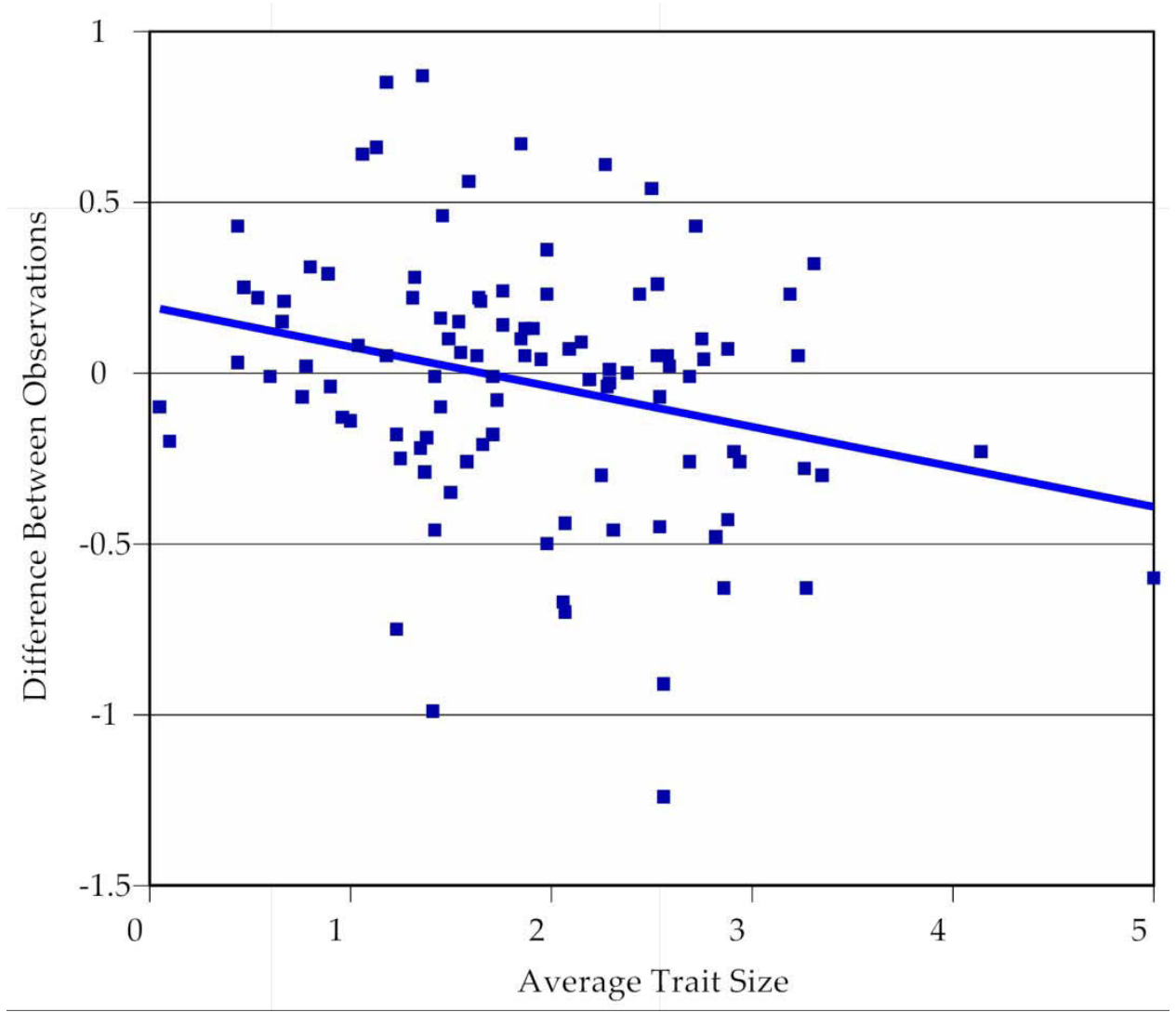

Figure A-29. Bland-Altman plot for intraobserver observations for posttreatment overjet.

Table A-29. Results for Bland-Altman analysis of posttreatment overjet.

\begin{tabular}{lclc}
\hline Statistic & Result & Statistic & Result \\
\hline Posttreatment OJ 2 & 1.89 & t-ratio & 0.69 \\
Posttreatment OJ 1 & 1.86 & df & 101 \\
Mean Difference & 0.03 & Probability $>|\mathrm{t}|$ & 0.4935 \\
Standard Error & 0.04 & Probability $>\mathrm{t}$ & 0.2467 \\
Upper 95\% & 0.10 & Probability $<\mathrm{t}$ & 0.7533 \\
Lower 95\% & -0.05 & & \\
Sample Size & 102 & & \\
Correlation & 0.92 & & \\
\hline
\end{tabular}




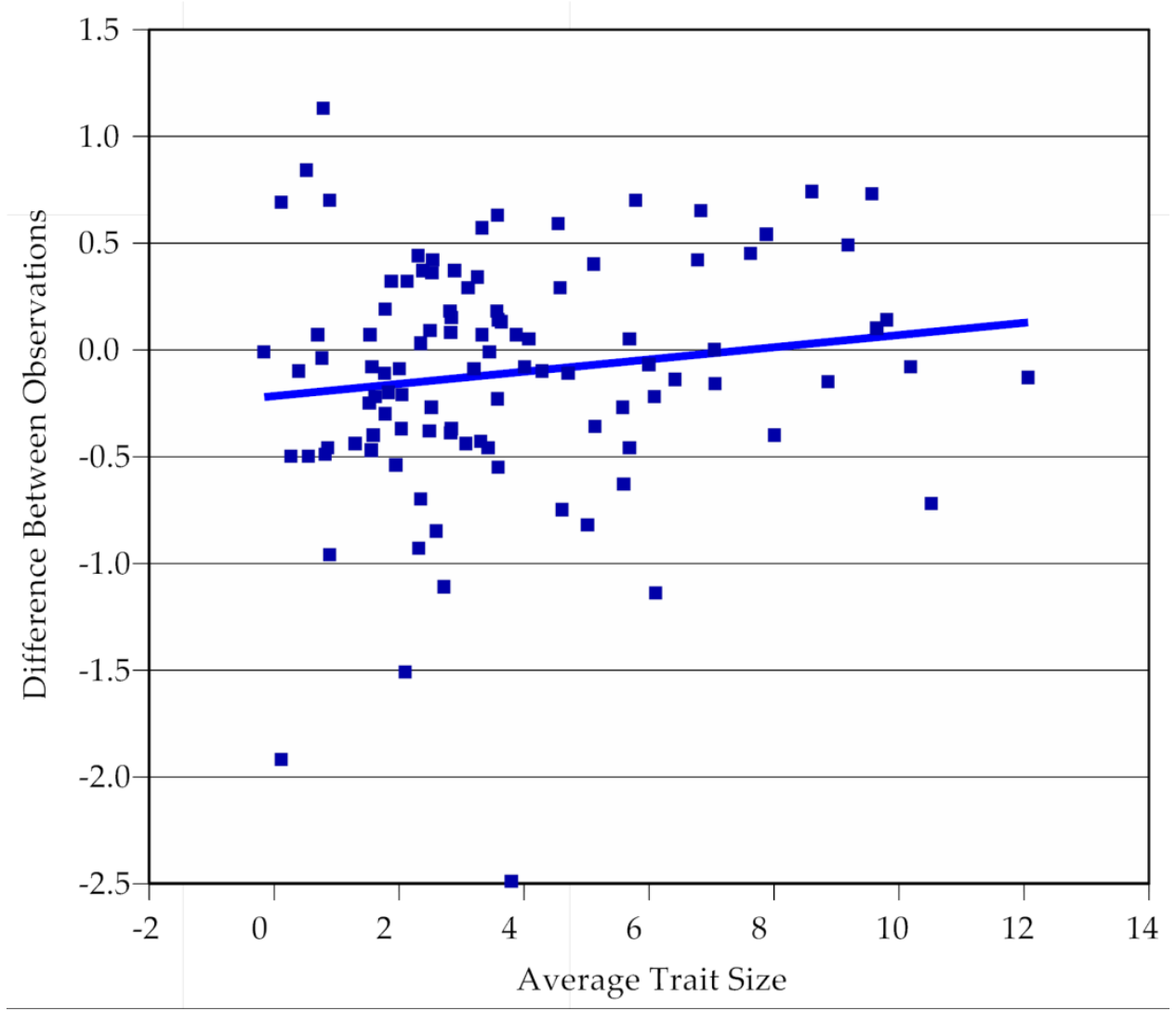

Figure A-30. Bland-Altman plot for intraobserver observations for change in overjet.

Table A-30. Results for Bland-Altman analysis of change in overjet.

\begin{tabular}{lclc}
\hline Statistic & Result & Statistic & Result \\
\hline Change OJ 2 & 3.81 & t-Ratio & 1.54 \\
Change OJ 1 & 3.74 & df & 101 \\
Mean Difference & 0.08 & Probability $>|\mathrm{t}|$ & 0.13 \\
Standard Error & 0.05 & Probability $>\mathrm{t}$ & 0.06 \\
Upper 95\% & 0.18 & Probability $<\mathrm{t}$ & 0.94 \\
Lower 95\% & -0.02 & & \\
Sample Size & 102 & & \\
Correlation & 0.98 & & \\
\hline
\end{tabular}


APPENDIX B. DESCRIPTIVE STATISTICS BY TREATMENT GROUP, WITH SEXES COMBINED 
Table B-1. Descriptive statistics for the MARA and Edgewise groups, sexes pooled, for averaged $\mathrm{U} 6$ angle at pretreatment.

\begin{tabular}{lcc}
\hline Statistic & MARA & Edgewise \\
\hline Mean & 94.473 & 92.990 \\
Standard Deviation & 3.782 & 3.713 \\
Standard Error & 0.530 & 0.520 \\
Upper 95\% & 95.536 & 94.034 \\
Lower 95\% & 93.409 & 91.946 \\
Sample size & 51 & 51 \\
Variance & 14.305 & 13.785 \\
Skewness & 1.082 & 0.268 \\
Kurtosis & 2.308 & 0.321 \\
CV & 4.003 & 3.993 \\
\hline
\end{tabular}

Table B-2. Descriptive statistics for the MARA and Edgewise groups, sexes pooled, for averaged $\mathrm{U} 6$ angle at posttretament.

\begin{tabular}{lcc}
\hline Statistic & MARA & Edgewise \\
\hline Mean & 91.740 & 91.152 \\
Standard Deviation & 3.447 & 3.494 \\
Standard Error & 0.483 & 0.489 \\
Upper 95\% & 92.710 & 92.135 \\
Lower 95\% & 90.771 & 90.169 \\
Sample size & 51 & 51 \\
Variance & 11.880 & 12.208 \\
Skewness & -0.107 & -0.118 \\
Kurtosis & -0.382 & -0.089 \\
CV & 3.757 & 3.833 \\
\hline
\end{tabular}


Table B-3. Descriptive statistics for the MARA and Edgewise groups, sexes pooled, for averaged change in U6 angle.

\begin{tabular}{lcc}
\hline Statistic & MARA & Edgewise \\
\hline Mean & -2.733 & -1.837 \\
Standard Deviation & 4.660 & 5.016 \\
Standard Error & 0.653 & 0.702 \\
Upper 95\% & -1.423 & -0.426 \\
Lower 95\% & -4.044 & -3.248 \\
Sample size & 51 & 51 \\
Variance & 21.716 & 25.161 \\
Skewness & -1.140 & 0.200 \\
Kurtosis & 2.160 & -0.240 \\
CV & -170.489 & -273.019 \\
\hline
\end{tabular}

Table B-4. Descriptive statistics for the MARA and Edgewise groups, sexes pooled, for the averaged linear conversion of the U6 tip.

\begin{tabular}{lcc}
\hline Statistic & MARA & Edgewise \\
\hline Mean & -7.933 & -4.571 \\
Standard Deviation & 7.354 & 6.629 \\
Standard Error & 1.030 & 0.928 \\
Upper 95\% & -5.865 & -2.706 \\
Lower 95\% & -10.002 & -6.435 \\
Sample size & 51 & 51 \\
Variance & 54.086 & 43.944 \\
Skewness & 0.177 & 0.062 \\
Kurtosis & -1.108 & -0.801 \\
CV & -92.701 & -145.037 \\
\hline
\end{tabular}


Table B-5. Descriptive statistics for the MARA and Edgewise groups, sexes pooled, for averaged U6 M-D movement/MFOP.

\begin{tabular}{lcc}
\hline Statistic & MARA & Edgewise \\
\hline Mean & -1.75 & -3.05 \\
Standard Dev & 2.55 & 2.95 \\
Standard Err Mean & 0.36 & 0.41 \\
Upper 95\% Mean & -1.04 & -2.22 \\
Lower 95\% Mean & -2.47 & -3.88 \\
Sample size & 51.00 & 51.00 \\
Variance & 6.51 & 8.69 \\
Skewness & -0.12 & 0.34 \\
Kurtosis & 2.91 & 1.82 \\
CV & -145.42 & -96.65 \\
\hline
\end{tabular}

Table B-6. Descriptive statistics for the MARA and Edgewise groups, sexes pooled, for averaged $\mathrm{L} 6$ angle at pretreatment.

\begin{tabular}{lcc}
\hline Statistic & MARA & Edgewise \\
\hline Mean & 82.02 & 81.14 \\
Standard Dev & 4.04 & 4.03 \\
Standard Err Mean & 0.57 & 0.57 \\
Upper 95\% Mean & 83.16 & 82.27 \\
Lower 95\% Mean & 80.88 & 80.00 \\
Sample size & 51.00 & 51.00 \\
Variance & 16.34 & 16.28 \\
Skewness & 0.15 & -0.32 \\
Kurtosis & -0.17 & 0.98 \\
CV & 4.93 & 4.97 \\
\hline
\end{tabular}


Table B-7. Descriptive statistics for the MARA and Edgewise groups, sexes pooled, for averaged L6 angle at posttreatment.

\begin{tabular}{lcc}
\hline Statistic & MARA & Edgewise \\
\hline Mean & 85.39 & 85.39 \\
Standard Dev & 4.08 & 4.34 \\
Standard Err Mean & 0.57 & 0.61 \\
Upper 95\% Mean & 86.54 & 86.61 \\
Lower 95\% Mean & 84.24 & 84.17 \\
Sample size & 51 & 51 \\
Variance & 16.64 & 18.84 \\
Skewness & 0.78 & -0.17 \\
Kurtosis & 0.50 & 0.06 \\
CV & 4.78 & 5.08 \\
\hline
\end{tabular}

Table B-8. Descriptive statistics for the MARA and Edgewise groups, sexes pooled, for averaged change in L6 angle.

\begin{tabular}{lcc}
\hline Statistic & MARA & Edgewise \\
\hline Mean & -3.47 & -4.39 \\
Standard Dev & 4.38 & 5.02 \\
Standard Err Mean & 0.61 & 0.70 \\
Upper 95\% Mean & -2.24 & -2.98 \\
Lower 95\% Mean & -4.70 & -5.80 \\
Sample size & 51 & 51 \\
Skewness & -0.01 & 0.30 \\
Kurtosis & 0.63 & -0.87 \\
CV & -126.30 & -114.21 \\
\hline
\end{tabular}


Table B-9. Descriptive statistics for the MARA and Edgewise groups, sexes pooled, for averaged linear conversion of L6 tip.

\begin{tabular}{lcc}
\hline Statistic & MARA & Edgewise \\
\hline Mean & -5.02 & -3.78 \\
Standard Dev & 8.19 & 6.39 \\
Standard Err Mean & 1.15 & 0.89 \\
Upper 95\% Mean & -2.72 & -1.98 \\
Lower 95\% Mean & -7.32 & -5.58 \\
Sample size & 51 & 51 \\
Variance & 67.06 & 40.78 \\
Skewness & -0.12 & -0.01 \\
Kurtosis & -1.26 & -0.96 \\
CV & -163.14 & -168.92 \\
\hline
\end{tabular}

Table B-10. Descriptive statistics for the MARA and Edgewise groups, sexes pooled, for averaged L6 M-D movement/MFOP.

\begin{tabular}{lcc}
\hline Statistic & MARA & Edgewise \\
\hline Mean & 4.40 & 5.83 \\
Standard Deviation & 2.97 & 3.39 \\
Standard Error & 0.42 & 0.47 \\
Upper 95\% & 5.23 & 6.79 \\
Lower 95\% & 3.56 & 4.880 \\
Sample size & 51 & 51 \\
Variance & 8.83 & 11.47 \\
Skewness & -0.39 & 0.26 \\
Kurtosis & 1.94 & 0.38 \\
CV & 67.61 & 58.07 \\
\hline
\end{tabular}


Table B-11. Descriptive statistics for the MARA and Edgewise groups, sexes pooled, for averaged linear change in D-D'.

\begin{tabular}{lcc}
\hline Statistic & MARA & Edgewise \\
\hline Mean & 6.521 & 6.307 \\
Standard Deviation & 2.423 & 3.108 \\
Standard Error & 0.339 & 0.435 \\
Upper 95\% & 7.202 & 7.182 \\
Lower 95\% & 5.839 & 5.433 \\
Sample size & 51 & 51 \\
Variance & 5.869 & 9.658 \\
Skewness & 0.234 & 0.478 \\
Kurtosis & -0.496 & -0.388 \\
CV & 37.151 & 49.271 \\
\hline
\end{tabular}

Table B-12. Descriptive statistics for the MARA and Edgewise groups, sexes pooled, for averaged horizontal change in D-D'/MFOP.

\begin{tabular}{lcc}
\hline Statistic & MARA & Edgewise \\
\hline Mean & 3.18 & 3.55 \\
Standard Dev & 2.66 & 2.95 \\
Standard Err Mean & 0.37 & 0.41 \\
Upper 95\% Mean & 3.93 & 4.38 \\
Lower 95\% Mean & 2.43 & 2.72 \\
Sample size & 51 & 51 \\
Variance & 7.08 & 8.72 \\
Skewness & -0.20 & 0.59 \\
Kurtosis & 0.14 & 0.56 \\
CV & 83.64 & 83.26 \\
\hline
\end{tabular}


Table B-13. Descriptive statistics for the MARA and Edgewise groups, sexes pooled, for averaged vertical change in D-D'/MFOP.

\begin{tabular}{lcc}
\hline Statistic & MARA & Edgewise \\
\hline Mean & 4.96 & 4.43 \\
Standard Dev & 2.55 & 2.76 \\
Standard Err Mean & 0.36 & 0.39 \\
Upper 95\% Mean & 5.68 & 5.21 \\
Lower 95\% Mean & 4.24 & 3.65 \\
Sample size & 51 & 51 \\
Variance & 6.50 & 7.61 \\
Skewness & 0.45 & 0.63 \\
Kurtosis & -0.52 & -0.52 \\
CV & 51.42 & 62.26 \\
\hline
\end{tabular}

Table B-14. Descriptive statistics for the MARA and Edgewise groups, sexes pooled, for averaged pretreatment L6-D distance.

\begin{tabular}{lcc}
\hline Statistic & MARA & Edgewise \\
\hline Mean & 16.77 & 17.74 \\
Standard Dev & 2.80 & 2.91 \\
Standard Err Mean & 0.39 & 0.41 \\
Upper 95\% Mean & 17.55 & 18.56 \\
Lower 95\% Mean & 15.98 & 16.92 \\
Sample size & 51 & 51 \\
Variance & 7.84 & 8.47 \\
Skewness & -0.34 & -0.35 \\
Kurtosis & -0.30 & -0.29 \\
CV & 16.70 & 16.40 \\
\hline
\end{tabular}


Table B-15. Descriptive statistics for the MARA and Edgewise groups, sexes pooled, for averaged posttreatment L6-D distance.

\begin{tabular}{lcc}
\hline Statistic & MARA & Edgewise \\
\hline Mean & 15.696 & 15.521 \\
Standard Deviation & 4.161 & 3.822 \\
Standard Error & 0.583 & 0.535 \\
Upper 95\% & 16.867 & 16.596 \\
Lower 95\% & 14.526 & 14.446 \\
Sample size & 51 & 51 \\
Variance & 17.314 & 14.607 \\
Skewness & 0.219 & 0.447 \\
Kurtosis & -0.219 & -0.359 \\
CV & 26.509 & 24.625 \\
\hline
\end{tabular}

Table B-16. Descriptive statistics for the MARA and Edgewise groups, sexes pooled, for averaged L6 movement/D.

\begin{tabular}{lcc}
\hline Statistic & MARA & Edgewise \\
\hline Mean & 1.07 & 2.22 \\
Standard Deviation & 2.74 & 2.53 \\
Standard Err Mean & 0.38 & 0.35 \\
Upper 95\% Mean & 1.84 & 2.93 \\
Lower 95\% Mean & 0.30 & 1.51 \\
Sample size & 51 & 51 \\
Variance & 7.49 & 6.39 \\
Skewness & -1.63 & -0.59 \\
Kurtosis & 6.18 & 0.06 \\
CV & 255.45 & 113.91 \\
\hline
\end{tabular}


Table B-17. Descriptive statistics for the MARA and Edgewise groups, sexes pooled, for averaged change in SE point.

\begin{tabular}{lcc}
\hline Statistic & MARA & Edgewise \\
\hline Mean & 1.69 & 0.75 \\
Standard Dev & 2.17 & 2.54 \\
Standard Err Mean & 0.30 & 0.36 \\
Upper 95\% Mean & 2.30 & 1.46 \\
Lower 95\% Mean & 1.08 & 0.03 \\
Sample size & 51 & 51 \\
Variance & 4.70 & 6.45 \\
Skewness & 0.12 & 0.30 \\
Kurtosis & -0.62 & 0.41 \\
CV & 128.55 & 340.65 \\
\hline
\end{tabular}

Table B-18. Descriptive statistics for the MARA and Edgewise groups, sexes pooled, for averaged pretreatment U6-L6 distance.

\begin{tabular}{lcc}
\hline Statistic & MARA & Edgewise \\
\hline Mean & -0.26 & -0.65 \\
Standard Dev & 1.14 & 1.61 \\
Standard Err Mean & 0.16 & 0.23 \\
Upper 95\% Mean & 0.06 & -0.19 \\
Lower 95\% Mean & -0.58 & -1.10 \\
Sample size & 51.00 & 51.00 \\
Variance & 1.29 & 2.60 \\
Skewness & -0.08 & -0.38 \\
Kurtosis & 1.51 & -0.23 \\
CV & -445.50 & -249.21 \\
\hline
\end{tabular}


Table B-19. Descriptive statistics for the MARA and Edgewise groups, sexes pooled, for averaged posttreatment U6-L6 distance.

\begin{tabular}{lcc}
\hline Statistic & MARA & Edgewise \\
\hline Mean & 2.039 & 1.823 \\
Standard Deviation & 1.042 & 1.919 \\
Standard Error & 0.146 & 0.269 \\
Upper 95\% & 2.332 & 2.363 \\
Lower 95\% & 1.746 & 1.283 \\
Sample size & 51 & 51 \\
Variance & 1.085 & 3.682 \\
Skewness & -0.309 & -1.705 \\
Kurtosis & 0.540 & 3.142 \\
CV & 51.077 & 105.257 \\
\hline
\end{tabular}

Table B-20. Descriptive statistics for the MARA and Edgewise groups, sexes pooled, for averaged total molar correction.

\begin{tabular}{lcc}
\hline Statistic & MARA & Edgewise \\
\hline Mean & 5.81 & 6.33 \\
Standard Dev & 3.93 & 4.97 \\
Standard Err Mean & 0.55 & 0.70 \\
Upper 95\% Mean & 6.92 & 7.73 \\
Lower 95\% Mean & 4.71 & 4.93 \\
Sample size & 51 & 51 \\
Variance & 15.44 & 24.72 \\
Skewness & 0.34 & 0.07 \\
Kurtosis & 1.23 & -0.12 \\
CV & 67.60 & 78.56 \\
\hline
\end{tabular}


Table B-21. Descriptive statistics for the MARA and Edgewise groups, sexes pooled, for averaged apical base change $(\mathrm{ABCH})$.

\begin{tabular}{lcc}
\hline Statistic & MARA & Edgewise \\
\hline Mean & 3.18 & 3.55 \\
Standard Dev & 2.66 & 2.95 \\
Standard Err Mean & 0.37 & 0.41 \\
Upper 95\% Mean & 3.93 & 4.38 \\
Lower 95\% Mean & 2.43 & 2.72 \\
Sample size & 51 & 51 \\
Variance & 7.08 & 8.72 \\
Skewness & -0.20 & 0.59 \\
Kurtosis & 0.14 & 0.56 \\
CV & 83.64 & 83.26 \\
\hline
\end{tabular}

Table B-22. Descriptive statistics for the MARA and Edgewise groups, sexes pooled, for averaged maxillary translative growth.

\begin{tabular}{lcc}
\hline Statistic & MARA & Edgewise \\
\hline Mean & 1.69 & 0.75 \\
Standard Dev & 2.17 & 2.54 \\
Standard Err Mean & 0.30 & 0.36 \\
Upper 95\% Mean & 2.30 & 1.46 \\
Lower 95\% Mean & 1.08 & 0.03 \\
Sample size & 51.00 & 51.00 \\
Variance & 4.70 & 6.45 \\
Skewness & 0.12 & 0.30 \\
Kurtosis & -0.62 & 0.41 \\
CV & 128.55 & 340.65 \\
\hline
\end{tabular}


Table B-23. Descriptive statistics for the MARA and Edgewise groups, sexes pooled, for averaged mandibular translative gowth.

\begin{tabular}{lcc}
\hline Statistic & MARA & Edgewise \\
\hline Mean & 1.50 & 2.80 \\
Standard Dev & 2.69 & 3.59 \\
Standard Err Mean & 0.38 & 0.50 \\
Upper 95\% Mean & 2.25 & 3.81 \\
Lower 95\% Mean & 0.74 & 1.79 \\
Sample size & 51.00 & 51.00 \\
Variance & 7.23 & 12.92 \\
Skewness & -0.33 & 0.71 \\
Kurtosis & 1.17 & 1.98 \\
CV & 179.66 & 128.31 \\
\hline
\end{tabular}

Table B-24. Descriptive statistics for the MARA and Edgewise groups, sexes pooled, for averaged pretreatment $\mathrm{U} 1$ angle.

\begin{tabular}{lcc}
\hline Statistic & MARA & Edgewise \\
\hline Mean & 60.13 & 59.27 \\
Standard Dev & 8.18 & 9.34 \\
Standard Err Mean & 1.14 & 1.31 \\
Upper 95\% Mean & 62.43 & 61.90 \\
Lower 95\% Mean & 57.83 & 56.65 \\
Sample size & 51.00 & 51.00 \\
Variance & 66.84 & 87.31 \\
Skewness & -0.21 & 1.63 \\
Kurtosis & 0.39 & 5.63 \\
CV & 13.60 & 15.76 \\
\hline
\end{tabular}


Table B-25. Descriptive statistics for the MARA and Edgewise groups, sexes pooled, for averaged posttreatment $\mathrm{U} 1$ angle.

\begin{tabular}{lcc}
\hline Statistic & MARA & Edgewise \\
\hline Mean & 58.06 & 64.74 \\
Standard Dev & 5.61 & 9.74 \\
Standard Err Mean & 0.79 & 1.36 \\
Upper 95\% Mean & 59.64 & 67.48 \\
Lower 95\% Mean & 56.48 & 62.00 \\
Sample size & 51.00 & 51.00 \\
Variance & 31.48 & 94.81 \\
Skewness & -0.52 & 2.18 \\
Kurtosis & 1.06 & 10.18 \\
CV & 9.66 & 15.04 \\
\hline
\end{tabular}

Table B-26. Descriptive statistics for the MARA and Edgewise groups, sexes pooled, for averaged change in $\mathrm{U} 1$ angle.

\begin{tabular}{lcc}
\hline Statistic & MARA & Edgewise \\
\hline Mean & -2.07 & 5.46 \\
Standard Dev & 8.41 & 10.39 \\
Standard Err Mean & 1.18 & 1.45 \\
Upper 95\% Mean & 0.30 & 8.38 \\
Lower 95\% Mean & -4.43 & 2.54 \\
Sample size & 51.00 & 51.00 \\
Variance & 70.75 & 107.89 \\
Skewness & -0.33 & -0.13 \\
Kurtosis & 0.57 & -0.77 \\
CV & -406.62 & 190.14 \\
\hline
\end{tabular}


Table B-27. Descriptive statistics for the MARA and Edgewise groups, sexes pooled, for averaged U1 movement.

\begin{tabular}{lcc}
\hline Statistic & MARA & Edgewise \\
\hline Mean & 0.38 & 3.22 \\
Standard Dev & 2.48 & 3.28 \\
Standard Err Mean & 0.35 & 0.46 \\
Upper 95\% Mean & 1.08 & 4.14 \\
Lower 95\% Mean & -0.32 & 2.30 \\
Sample size & 51.00 & 51.00 \\
Variance & 6.16 & 10.73 \\
Skewness & -0.24 & -0.19 \\
Kurtosis & 0.41 & -0.22 \\
CV & 655.82 & 101.64 \\
\hline
\end{tabular}

Table B-28. Descriptive statistics for the MARA and Edgewise groups, sexes pooled, for averaged pretreatment overjet.

\begin{tabular}{lcc}
\hline Statistic & MARA & Edgewise \\
\hline Mean & 4.91 & 6.37 \\
Standard Dev & 1.93 & 3.17 \\
Standard Err Mean & 0.27 & 0.44 \\
Upper 95\% Mean & 5.45 & 7.26 \\
Lower 95\% Mean & 4.36 & 5.48 \\
Sample size & 51 & 51 \\
Variance & 3.73 & 10.03 \\
Skewness & 0.97 & 0.46 \\
Kurtosis & 0.76 & -0.82 \\
CV & 39.34 & 49.74 \\
\hline
\end{tabular}


Table B-29. Descriptive statistics for the MARA and Edgewise groups, sexes pooled, for averaged posttreatment overjet.

\begin{tabular}{lcc}
\hline Statistic & MARA & Edgewise \\
\hline Mean & 2.153 & 1.603 \\
Standard Deviation & 0.673 & 0.958 \\
Standard Error & 0.094 & 0.134 \\
Upper 95\% & 2.342 & 1.872 \\
Lower 95\% & 1.963 & 1.333 \\
Sample size & 51 & 51 \\
Variance & 0.452 & 0.918 \\
Skewness & 0.316 & 1.062 \\
Kurtosis & 0.341 & 1.890 \\
CV & 31.248 & 59.772 \\
\hline
\end{tabular}

Table B-30. Descriptive statistics for the MARA and Edgewise groups, sexes pooled, for averaged change in overjet.

\begin{tabular}{lcc}
\hline Statistic & MARA & Edgewise \\
\hline Mean & 2.76 & 4.77 \\
Standard Dev & 1.76 & 3.06 \\
Standard Err Mean & 0.25 & 0.43 \\
Upper 95\% Mean & 3.25 & 5.63 \\
Lower 95\% Mean & 2.26 & 3.91 \\
Sample size & 51 & 51 \\
Variance & 3.10 & 9.37 \\
Skewness & 0.96 & 0.54 \\
Kurtosis & 0.91 & -0.59 \\
CV & 63.85 & 64.20 \\
\hline
\end{tabular}


APPENDIX C. DESCRIPTIVE STATISTICS BY TREATMENT GROUP AND SEX 
Table C-1. Descriptive statistics, by treatment and sex, for averaged U6 angle at pretreatment.

\begin{tabular}{lcccc}
\hline Statistic & $\begin{array}{c}\text { MARA } \\
\text { Boys }\end{array}$ & $\begin{array}{c}\text { MARA } \\
\text { Girls }\end{array}$ & $\begin{array}{c}\text { Edge } \\
\text { Boys }\end{array}$ & $\begin{array}{c}\text { Edge } \\
\text { Girls }\end{array}$ \\
\hline Mean & 94.777 & 94.000 & 93.371 & 92.400 \\
Standard Dev & 3.951 & 3.550 & 3.509 & 4.028 \\
Standard Err Mean & 0.710 & 0.794 & 0.630 & 0.901 \\
Upper 95\% Mean & 96.227 & 95.662 & 94.658 & 94.285 \\
Lower 95\% Mean & 93.328 & 92.338 & 92.084 & 90.515 \\
Sample size & 31 & 20 & 31 & 20 \\
Variance & 15.613 & 12.605 & 12.316 & 16.226 \\
Skewness & 1.434 & 0.315 & -0.518 & 1.266 \\
Kurtosis & 2.898 & 0.766 & -0.466 & 2.567 \\
CV & 4.169 & 3.777 & 3.759 & 4.360 \\
\hline
\end{tabular}

Table C-2. Descriptive statistics, by treatment and sex, for averaged U6 angle posttreatment.

\begin{tabular}{lcccc}
\hline Statistic & $\begin{array}{c}\text { MARA } \\
\text { Boys }\end{array}$ & $\begin{array}{c}\text { MARA } \\
\text { Girls }\end{array}$ & $\begin{array}{c}\text { Edge } \\
\text { Boys }\end{array}$ & $\begin{array}{c}\text { Edge } \\
\text { Girls }\end{array}$ \\
\hline Mean & 91.081 & 92.763 & 91.629 & 90.413 \\
Standard Dev & 3.333 & 3.452 & 3.235 & 3.828 \\
Standard Err Mean & 0.599 & 0.772 & 0.581 & 0.856 \\
Upper 95\% Mean & 92.303 & 94.378 & 92.816 & 92.204 \\
Lower 95\% Mean & 89.858 & 91.147 & 90.442 & 88.621 \\
Sample Size & 31 & 20 & 31 & 20 \\
Variance & 11.106 & 11.918 & 10.466 & 14.653 \\
Skewness & -0.096 & -0.226 & -0.168 & 0.094 \\
Kurtosis & 0.051 & -0.787 & 0.058 & 0.028 \\
CV & 3.659 & 3.722 & 3.531 & 4.234 \\
\hline
\end{tabular}


Table C-3. Descriptive statistics, by treatment and sex, for averaged change in U6 angle.

\begin{tabular}{lcccc}
\hline Statistic & $\begin{array}{c}\text { MARA } \\
\text { Boys }\end{array}$ & $\begin{array}{c}\text { MARA } \\
\text { Girls }\end{array}$ & $\begin{array}{c}\text { Edge } \\
\text { Boys }\end{array}$ & $\begin{array}{c}\text { Edge } \\
\text { Girls }\end{array}$ \\
\hline Mean & -3.697 & -1.240 & -1.742 & -1.985 \\
Standard Dev & 5.086 & 3.527 & 5.091 & 5.026 \\
Standard Err Mean & 0.913 & 0.789 & 0.914 & 1.124 \\
Upper 95\% Mean & -1.831 & 0.411 & 0.125 & 0.367 \\
Lower 95\% Mean & -5.562 & -2.891 & -3.609 & -4.337 \\
Sample size & 31 & 20 & 31 & 20 \\
Variance & 25.868 & 12.441 & 25.915 & 25.257 \\
Skewness & -1.048 & -0.700 & 0.464 & -0.239 \\
Kurtosis & 1.826 & 0.112 & -0.323 & 0.107 \\
CV & -137.580 & -284.455 & -292.240 & -253.181 \\
\hline
\end{tabular}

Table C-4. Descriptive statistics, by treatment and sex, for averaged linear conversion of $\mathrm{U} 6$ tip.

\begin{tabular}{lcccc}
\hline Statistic & $\begin{array}{c}\text { MARA } \\
\text { Boys }\end{array}$ & $\begin{array}{c}\text { MARA } \\
\text { Girls }\end{array}$ & $\begin{array}{c}\text { Edge } \\
\text { Boys }\end{array}$ & $\begin{array}{c}\text { Edge } \\
\text { Girls }\end{array}$ \\
\hline Mean & -9.281 & -5.845 & -4.761 & -4.275 \\
Standard Dev & 7.390 & 6.968 & 7.755 & 4.531 \\
Standard Err Mean & 1.327 & 1.558 & 1.393 & 1.013 \\
Upper 95\% Mean & -6.570 & -2.584 & -1.917 & -2.155 \\
Lower 95\% Mean & -11.991 & -9.106 & -7.606 & -6.395 \\
Sample size & 31 & 20 & 31 & 20 \\
Variance & 54.606 & 48.558 & 60.144 & 20.527 \\
Skewness & 0.307 & 0.111 & 0.053 & 0.541 \\
Kurtosis & -1.314 & -0.676 & -1.320 & 0.783 \\
CV & -79.624 & -119.220 & -162.881 & -105.981 \\
\hline
\end{tabular}


Table C-5. Descriptive statistics, by treatment and sex, for averaged U6 M-D movement/MFOP.

\begin{tabular}{lcccc}
\hline MARA & $\begin{array}{c}\text { MARA } \\
\text { Boys }\end{array}$ & $\begin{array}{c}\text { Edge } \\
\text { Girls }\end{array}$ & $\begin{array}{c}\text { Edge } \\
\text { Boys }\end{array}$ & $\begin{array}{c}\text { Edge } \\
\text { Girls }\end{array}$ \\
\hline Mean & -1.979 & -1.406 & -2.801 & -3.437 \\
Standard Dev & 2.511 & 2.639 & 3.338 & 2.241 \\
Standard Err Mean & 0.451 & 0.590 & 0.600 & 0.501 \\
Upper 95\% Mean & -1.058 & -0.170 & -1.577 & -2.388 \\
Lower 95\% Mean & -2.900 & -2.641 & -4.025 & -4.486 \\
Sample size & 31 & 20 & 31 & 20 \\
Variance & 6.303 & 6.964 & 11.142 & 5.023 \\
Skewness & -1.159 & 1.295 & 0.530 & -1.450 \\
Kurtosis & 1.417 & 4.873 & 0.901 & 4.205 \\
CV & -126.839 & -187.763 & -119.170 & -65.211 \\
\hline
\end{tabular}

Table C-6. Descriptive statistics, by treatment and sex, for averaged L6 angle at pretreatment.

\begin{tabular}{lcccc}
\hline Statistics & $\begin{array}{c}\text { MARA } \\
\text { Boys }\end{array}$ & $\begin{array}{c}\text { MARA } \\
\text { Girls }\end{array}$ & $\begin{array}{c}\text { Edge } \\
\text { Boys }\end{array}$ & $\begin{array}{c}\text { Edge } \\
\text { Girls }\end{array}$ \\
\hline Mean & 82.419 & 81.400 & 80.516 & 82.100 \\
Standard Dev & 4.129 & 3.926 & 3.325 & 4.876 \\
Standard Err Mean & 0.742 & 0.878 & 0.597 & 1.090 \\
Upper 95\% Mean & 83.934 & 83.237 & 81.736 & 84.382 \\
Lower 95\% Mean & 80.905 & 79.563 & 79.296 & 79.818 \\
Sample size & 31 & 20 & 31 & 20 \\
Variance & 17.052 & 15.411 & 11.058 & 23.779 \\
Skewness & 0.190 & 0.026 & -0.969 & -0.361 \\
Kurtosis & -0.260 & 0.146 & 3.888 & -0.439 \\
CV & 5.010 & 4.823 & 4.130 & 5.940 \\
\hline
\end{tabular}


Table C-7. Descriptive statistics, by treatment and sex, for averaged L6 angle at posttreatment.

\begin{tabular}{lcccc}
\hline Statistic & $\begin{array}{c}\text { MARA } \\
\text { Boys }\end{array}$ & $\begin{array}{c}\text { MARA } \\
\text { Girls }\end{array}$ & $\begin{array}{c}\text { Edge } \\
\text { Boys }\end{array}$ & $\begin{array}{c}\text { Edge } \\
\text { Girls }\end{array}$ \\
\hline Mean & 86.387 & 83.850 & 85.806 & 84.750 \\
Standard Dev & 4.402 & 3.014 & 4.415 & 4.253 \\
Standard Err Mean & 0.791 & 0.674 & 0.793 & 0.951 \\
Upper 95\% Mean & 88.002 & 85.260 & 87.426 & 86.741 \\
Lower 95\% Mean & 84.772 & 82.440 & 84.187 & 82.759 \\
Sample size & 31 & 20 & 31 & 20 \\
Variance & 19.378 & 9.082 & 19.495 & 18.092 \\
Skewness & 0.459 & 1.198 & -0.490 & 0.343 \\
Kurtosis & 0.102 & 2.405 & 0.435 & 0.355 \\
CV & 5.096 & 3.594 & 5.146 & 5.019 \\
\hline
\end{tabular}

Table C-8. Descriptive statistics, by treatment and sex, for averaged change in L6 angle.

\begin{tabular}{lcccc}
\hline Statistic & $\begin{array}{c}\text { MARA } \\
\text { Boys }\end{array}$ & $\begin{array}{c}\text { MARA } \\
\text { Girls }\end{array}$ & $\begin{array}{c}\text { Edge } \\
\text { Boys }\end{array}$ & $\begin{array}{c}\text { Edge } \\
\text { Girls }\end{array}$ \\
\hline Mean & -4.065 & -2.550 & -5.419 & -2.800 \\
Standard Dev & 4.389 & 4.322 & 4.724 & 5.156 \\
Standard Err Mean & 0.788 & 0.966 & 0.848 & 1.153 \\
Upper 95\% Mean & -2.455 & -0.527 & -3.686 & -0.387 \\
Lower 95\% Mean & -5.674 & -4.573 & -7.152 & -5.213 \\
Sample size & 31 & 20 & 31 & 20 \\
Variance & 19.262 & 18.682 & 22.318 & 26.589 \\
Skewness & -0.368 & 0.618 & 0.423 & 0.072 \\
Kurtosis & 0.442 & 0.586 & -0.807 & -0.841 \\
CV & -107.981 & -169.499 & -87.173 & -184.161 \\
\hline
\end{tabular}


Table C-9. Descriptive statistics, by treatment and sex, for averaged linear conversion of L6 tip.

\begin{tabular}{lcccc}
\hline Statistic & $\begin{array}{c}\text { MARA } \\
\text { Boys }\end{array}$ & $\begin{array}{c}\text { MARA } \\
\text { Girls }\end{array}$ & $\begin{array}{c}\text { Edge } \\
\text { Boys }\end{array}$ & $\begin{array}{l}\text { Edge } \\
\text { Girls }\end{array}$ \\
\hline Mean & -5.590 & -4.135 & -5.258 & -1.490 \\
Standard Dev & 8.015 & 8.585 & 6.179 & 6.161 \\
Standard Err Mean & 1.439 & 1.920 & 1.110 & 1.378 \\
Upper 95\% Mean & -2.651 & -0.117 & -2.992 & 1.393 \\
Lower 95\% Mean & -8.530 & -8.153 & -7.524 & -4.373 \\
Sample size & 31 & 20 & 31 & 20 \\
Variance & 64.232 & 73.703 & 38.177 & 37.954 \\
Skewness & -0.108 & -0.190 & 0.071 & -0.142 \\
Kurtosis & -1.255 & -1.290 & -0.846 & -1.283 \\
CV & -143.364 & -207.620 & -117.510 & -413.466 \\
\hline
\end{tabular}

Table C-10. Descriptive statistics, by treatment and sex, for averaged L6 M-D movement/MFOP.

\begin{tabular}{lcccc}
\hline Statistic & $\begin{array}{c}\text { MARA } \\
\text { Boys }\end{array}$ & $\begin{array}{c}\text { MARA } \\
\text { Girls }\end{array}$ & $\begin{array}{c}\text { Edge } \\
\text { Boys }\end{array}$ & $\begin{array}{c}\text { Edge } \\
\text { Girls }\end{array}$ \\
\hline Mean & 4.791 & 3.782 & 6.151 & 5.341 \\
Standard Dev & 2.888 & 3.069 & 3.908 & 2.378 \\
Standard Err Mean & 0.519 & 0.686 & 0.702 & 0.532 \\
Upper 95\% Mean & 5.850 & 5.218 & 7.584 & 6.453 \\
Lower 95\% Mean & 3.732 & 2.345 & 4.717 & 4.228 \\
Sample size & 31 & 20 & 31 & 20 \\
Variance & 8.338 & 9.419 & 15.275 & 5.654 \\
Skewness & 0.500 & -1.619 & 0.309 & -1.362 \\
Kurtosis & -0.036 & 3.761 & -0.491 & 2.933 \\
CV & 60.267 & 81.159 & 63.544 & 44.526 \\
\hline
\end{tabular}


Table C-11. Descriptive statistics, by treatment and sex, for averaged linear change in D-D'.

\begin{tabular}{lcccc}
\hline Statistic & $\begin{array}{c}\text { MARA } \\
\text { Boys }\end{array}$ & $\begin{array}{c}\text { MARA } \\
\text { Girls }\end{array}$ & $\begin{array}{c}\text { Edge } \\
\text { Boys }\end{array}$ & $\begin{array}{l}\text { Edge } \\
\text { Girls }\end{array}$ \\
\hline Mean & 7.390 & 5.173 & 7.088 & 5.098 \\
Standard Dev & 2.339 & 1.913 & 3.227 & 2.538 \\
Standard Err Mean & 0.420 & 0.428 & 0.580 & 0.568 \\
Upper 95\% Mean & 8.248 & 6.068 & 8.271 & 6.286 \\
Lower 95\% Mean & 6.532 & 4.278 & 5.904 & 3.910 \\
Sample size & 31 & 20 & 31 & 20 \\
Variance & 5.470 & 3.661 & 10.412 & 6.442 \\
Skewness & -0.092 & 0.625 & 0.123 & 1.096 \\
Kurtosis & -0.142 & 0.268 & -0.393 & 1.037 \\
CV & 31.648 & 36.988 & 45.527 & 49.787 \\
\hline
\end{tabular}

Table C-12. Descriptive statistics, by treatment and sex, for averaged horizontal change in D-D'/MFOP.

\begin{tabular}{lcccc}
\hline Statistic & $\begin{array}{c}\text { MARA } \\
\text { Boys }\end{array}$ & $\begin{array}{c}\text { MARA } \\
\text { Girls }\end{array}$ & $\begin{array}{c}\text { Edge } \\
\text { Boys }\end{array}$ & $\begin{array}{c}\text { Edge } \\
\text { Girls }\end{array}$ \\
\hline Mean & 3.749 & 2.304 & 4.248 & 2.459 \\
Standard Dev & 2.634 & 2.520 & 3.171 & 2.241 \\
Standard Err Mean & 0.473 & 0.563 & 0.569 & 0.501 \\
Upper 95\% Mean & 4.715 & 3.483 & 5.411 & 3.508 \\
Lower 95\% Mean & 2.783 & 1.124 & 3.085 & 1.410 \\
Sample size & 31 & 20 & 31 & 20 \\
Variance & 6.939 & 6.349 & 10.053 & 5.021 \\
Skewness & -0.045 & -0.667 & 0.435 & 0.188 \\
Kurtosis & 0.307 & -0.778 & 0.386 & -1.032 \\
CV & 70.262 & 109.386 & 74.642 & 91.125 \\
\hline
\end{tabular}


Table C-13. Descriptive statistics, by treatment and sex, for averaged vertical change in D-D'/MFOP.

\begin{tabular}{lcccc}
\hline Statistic & $\begin{array}{c}\text { MARA } \\
\text { Boys }\end{array}$ & $\begin{array}{c}\text { MARA } \\
\text { Girls }\end{array}$ & $\begin{array}{c}\text { Edge } \\
\text { Boys }\end{array}$ & $\begin{array}{c}\text { Edge } \\
\text { Girls }\end{array}$ \\
\hline Mean & 5.810 & 3.641 & 4.913 & 3.682 \\
Standard Dev & 2.305 & 2.391 & 2.836 & 2.520 \\
Standard Err Mean & 0.414 & 0.535 & 0.509 & 0.564 \\
Upper 95\% Mean & 6.655 & 4.760 & 5.953 & 4.861 \\
Lower 95\% Mean & 4.964 & 2.522 & 3.873 & 2.502 \\
Sample size & 31 & 20 & 31 & 20 \\
Variance & 5.313 & 5.716 & 8.040 & 6.353 \\
Skewness & 0.496 & 1.002 & 0.360 & 1.194 \\
Kurtosis & -0.309 & 0.144 & -0.721 & 0.928 \\
CV & 39.674 & 65.666 & 57.720 & 68.463 \\
\hline
\end{tabular}

Table C-14. Descriptive statistics, by treatment and sex, for averaged pretreatment L6-D distance.

\begin{tabular}{lcccc}
\hline Statistic & $\begin{array}{c}\text { MARA } \\
\text { Boys }\end{array}$ & $\begin{array}{c}\text { MARA } \\
\text { Girls }\end{array}$ & $\begin{array}{c}\text { Edge } \\
\text { Boys }\end{array}$ & $\begin{array}{c}\text { Edge } \\
\text { Girls }\end{array}$ \\
\hline Mean & 16.854 & 16.632 & 18.293 & 16.881 \\
Standard Dev & 2.575 & 3.181 & 3.302 & 1.948 \\
Standard Err Mean & 0.463 & 0.711 & 0.593 & 0.435 \\
Upper 95\% Mean & 17.799 & 18.120 & 19.504 & 17.792 \\
Lower 95\% Mean & 15.910 & 15.143 & 17.081 & 15.970 \\
Sample size & 31 & 20 & 31 & 20 \\
Variance & 6.632 & 10.120 & 10.903 & 3.793 \\
Skewness & 0.013 & -0.612 & -0.741 & -0.156 \\
Kurtosis & -0.825 & -0.055 & -0.112 & -1.042 \\
CV & 15.279 & 19.128 & 18.051 & 11.537 \\
\hline
\end{tabular}


Table C-15. Descriptive statistics, by treatment and sex, for averaged posttreatment L6-D distance.

\begin{tabular}{|c|c|c|c|c|}
\hline Statistic & $\begin{array}{c}\text { MARA } \\
\text { Boys }\end{array}$ & $\begin{array}{c}\text { MARA } \\
\text { Girls }\end{array}$ & $\begin{array}{l}\text { Edge } \\
\text { Boys }\end{array}$ & $\begin{array}{l}\text { Edge } \\
\text { Girls }\end{array}$ \\
\hline Mean & 15.989 & 15.243 & 16.462 & 14.062 \\
\hline Standard Dev & 3.854 & 4.664 & 4.125 & 2.809 \\
\hline Standard Err Mean & 0.692 & 1.043 & 0.741 & 0.628 \\
\hline Upper 95\% Mean & 17.403 & 17.425 & 17.975 & 15.377 \\
\hline Lower 95\% Mean & 14.575 & 13.060 & 14.949 & 12.747 \\
\hline Sample size & 31 & 20 & 31 & 20 \\
\hline Variance & 14.852 & 21.754 & 17.015 & 7.889 \\
\hline Skewness & 0.149 & 0.398 & 0.117 & 0.578 \\
\hline Kurtosis & -0.511 & 0.195 & -0.490 & -0.887 \\
\hline $\mathrm{CV}$ & 24.103 & 30.600 & 25.057 & 19.974 \\
\hline
\end{tabular}

Table C-16. Descriptive statistics, by treatment and sex, for averaged L6 M-D Movement/D.

\begin{tabular}{lcccc}
\hline Statistic & $\begin{array}{c}\text { MARA } \\
\text { Boys }\end{array}$ & $\begin{array}{c}\text { MARA } \\
\text { Girls }\end{array}$ & $\begin{array}{c}\text { Edge } \\
\text { Boys }\end{array}$ & $\begin{array}{c}\text { Edge } \\
\text { Girls }\end{array}$ \\
\hline Mean & 0.866 & 1.390 & 1.831 & 2.819 \\
Standard Dev & 2.339 & 3.302 & 2.853 & 1.824 \\
Standard Err Mean & 0.420 & 0.738 & 0.512 & 0.408 \\
Upper 95\% Mean & 1.724 & 2.935 & 2.878 & 3.673 \\
Lower 95\% Mean & 0.008 & -0.155 & 0.785 & 1.965 \\
Sample size & 31 & 20 & 31 & 20 \\
Variance & 5.469 & 10.900 & 8.141 & 3.327 \\
Skewness & -0.290 & -2.599 & -0.371 & -0.488 \\
Kurtosis & 0.970 & 9.794 & -0.419 & -0.086 \\
CV & 270.106 & 237.523 & 155.810 & 64.709 \\
\hline
\end{tabular}


Table C-17. Descriptive statistics, by treatment and sex, for averaged change in SE point.

\begin{tabular}{lcccc}
\hline Statistic & $\begin{array}{c}\text { MARA } \\
\text { Boys }\end{array}$ & $\begin{array}{c}\text { MARA } \\
\text { Girls }\end{array}$ & $\begin{array}{c}\text { Edge } \\
\text { Boys }\end{array}$ & $\begin{array}{c}\text { Edge } \\
\text { Girls }\end{array}$ \\
\hline Mean & 2.015 & 1.177 & 0.890 & 0.521 \\
Standard Dev & 2.330 & 1.827 & 2.739 & 2.244 \\
Standard Err Mean & 0.419 & 0.409 & 0.492 & 0.502 \\
Upper 95\% Mean & 2.870 & 2.032 & 1.895 & 1.571 \\
Lower 95\% Mean & 1.160 & 0.321 & -0.115 & -0.529 \\
Sample size & 31 & 20 & 31 & 20 \\
Variance & 5.430 & 3.339 & 7.504 & 5.035 \\
Skewness & 0.185 & -0.674 & 0.340 & 0.025 \\
Kurtosis & -1.205 & 0.009 & 0.539 & -0.325 \\
CV & 115.653 & 155.322 & 307.690 & 430.690 \\
\hline
\end{tabular}

Table C-18. Descriptive statistics, by treatment and sex, for averaged pretreatment U6-L6 distance.

\begin{tabular}{lcccc}
\hline MARA & $\begin{array}{c}\text { MARA } \\
\text { Soys }\end{array}$ & $\begin{array}{c}\text { Edge } \\
\text { Girls }\end{array}$ & $\begin{array}{c}\text { Edge } \\
\text { Boys }\end{array}$ & $\begin{array}{c}\text { Edge } \\
\text { Girls }\end{array}$ \\
\hline Mean & -0.236 & -0.285 & -0.815 & -0.385 \\
Standard Dev & 1.175 & 1.105 & 1.787 & 1.292 \\
Standard Err Mean & 0.211 & 0.247 & 0.321 & 0.289 \\
Upper 95\% Mean & 0.195 & 0.232 & -0.160 & 0.220 \\
Lower 95\% Mean & -0.667 & -0.802 & -1.471 & -0.989 \\
Sample size & 31 & 20 & 31 & 20 \\
Variance & 1.381 & 1.222 & 3.194 & 1.668 \\
Skewness & -0.212 & 0.160 & -0.282 & -0.198 \\
Kurtosis & 2.666 & -0.218 & -0.476 & -0.487 \\
CV & -497.697 & -387.842 & -219.159 & -335.935 \\
\hline
\end{tabular}


Table C-19. Descriptive statistics, by treatment and sex, for averaged posttreatment U6-L6 distance.

\begin{tabular}{lcccc}
\hline Statistic & $\begin{array}{c}\text { MARA } \\
\text { Boys }\end{array}$ & $\begin{array}{c}\text { MARA } \\
\text { Girls }\end{array}$ & $\begin{array}{c}\text { Edge } \\
\text { Boys }\end{array}$ & $\begin{array}{c}\text { Edge } \\
\text { Girls }\end{array}$ \\
\hline Mean & 2.122 & 1.911 & 1.864 & 1.760 \\
Standard Dev & 1.121 & 0.918 & 2.126 & 1.596 \\
Standard Err Mean & 0.201 & 0.205 & 0.382 & 0.357 \\
Upper 95\% Mean & 2.533 & 2.340 & 2.643 & 2.507 \\
Lower 95\% Mean & 1.711 & 1.481 & 1.084 & 1.013 \\
Sample size & 31 & 20 & 31 & 20 \\
Variance & 1.256 & 0.843 & 4.519 & 2.546 \\
Skewness & -0.617 & 0.335 & -1.506 & -2.587 \\
Kurtosis & 1.252 & -1.048 & 2.043 & 9.067 \\
CV & 52.811 & 48.053 & 114.078 & 90.657 \\
\hline
\end{tabular}

Table C-20. Descriptive statistics, by treatment and sex, for averaged total molar correction.

\begin{tabular}{lcccc}
\hline Statistic & $\begin{array}{c}\text { MARA } \\
\text { Boys }\end{array}$ & $\begin{array}{c}\text { MARA } \\
\text { Girls }\end{array}$ & $\begin{array}{c}\text { Edge } \\
\text { Boys }\end{array}$ & $\begin{array}{c}\text { Edge } \\
\text { Girls }\end{array}$ \\
\hline Mean & 6.560 & 4.657 & 7.598 & 4.362 \\
Standard Dev & 3.964 & 3.675 & 5.221 & 3.912 \\
Standard Err Mean & 0.712 & 0.822 & 0.938 & 0.875 \\
Upper 95\% Mean & 8.014 & 6.377 & 9.513 & 6.193 \\
Lower 95\% Mean & 5.106 & 2.937 & 5.683 & 2.531 \\
Sample size & 31 & 20 & 31 & 20 \\
Variance & 15.716 & 13.509 & 27.259 & 15.307 \\
Skewness & 0.745 & -0.549 & -0.110 & -0.440 \\
Kurtosis & 1.571 & -0.640 & -0.372 & 0.459 \\
CV & 60.434 & 78.922 & 68.718 & 89.693 \\
\hline
\end{tabular}


Table C-21. Descriptive statistics, by treatment and sex, for averaged ABCH.

\begin{tabular}{lcccc}
\hline Statistic & $\begin{array}{c}\text { MARA } \\
\text { Boys }\end{array}$ & $\begin{array}{c}\text { MARA } \\
\text { Girls }\end{array}$ & $\begin{array}{c}\text { Edge } \\
\text { Boys }\end{array}$ & $\begin{array}{c}\text { Edge } \\
\text { Girls }\end{array}$ \\
\hline Mean & 3.749 & 2.304 & 4.248 & 2.459 \\
Standard Dev & 2.634 & 2.520 & 3.171 & 2.241 \\
Standard Err Mean & 0.473 & 0.563 & 0.569 & 0.501 \\
Upper 95\% Mean & 4.715 & 3.483 & 5.411 & 3.508 \\
Lower 95\% Mean & 2.783 & 1.124 & 3.085 & 1.410 \\
Sample size & 31 & 20 & 31 & 20 \\
Variance & 6.939 & 6.349 & 10.053 & 5.021 \\
Skewness & -0.045 & -0.667 & 0.435 & 0.188 \\
Kurtosis & 0.307 & -0.778 & 0.386 & -1.032 \\
CV & 70.262 & 109.386 & 74.642 & 91.125 \\
\hline
\end{tabular}

Table C-22. Descriptive statistics, by treatment and sex, for averaged maxillary translative growth.

\begin{tabular}{lcccc}
\hline Statistic & $\begin{array}{c}\text { MARA } \\
\text { Boys }\end{array}$ & $\begin{array}{c}\text { MARA } \\
\text { Girls }\end{array}$ & $\begin{array}{c}\text { Edge } \\
\text { Boys }\end{array}$ & $\begin{array}{c}\text { Edge } \\
\text { Girls }\end{array}$ \\
\hline Mean & 2.015 & 1.177 & 0.890 & 0.521 \\
Standard Dev & 2.330 & 1.827 & 2.739 & 2.244 \\
Standard Err Mean & 0.419 & 0.409 & 0.492 & 0.502 \\
Upper 95\% Mean & 2.870 & 2.032 & 1.895 & 1.571 \\
Lower 95\% Mean & 1.160 & 0.321 & -0.115 & -0.529 \\
Sample size & 31 & 20 & 31 & 20 \\
Variance & 5.430 & 3.339 & 7.504 & 5.035 \\
Skewness & 0.185 & -0.674 & 0.340 & 0.025 \\
Kurtosis & -1.205 & 0.009 & 0.539 & -0.325 \\
CV & 115.653 & 155.322 & 307.690 & 430.690 \\
\hline
\end{tabular}


Table C-23. Descriptive statistics, by treatment and sex, for averaged mandibular translative growth.

\begin{tabular}{lcccc}
\hline Statistic & $\begin{array}{c}\text { MARA } \\
\text { Boys }\end{array}$ & $\begin{array}{c}\text { MARA } \\
\text { Girls }\end{array}$ & $\begin{array}{c}\text { Edge } \\
\text { Boys }\end{array}$ & $\begin{array}{l}\text { Edge } \\
\text { Girls }\end{array}$ \\
\hline Mean & 1.735 & 1.129 & 3.358 & 1.938 \\
Standard Dev & 2.832 & 2.477 & 3.842 & 3.064 \\
Standard Err Mean & 0.509 & 0.554 & 0.690 & 0.685 \\
Upper 95\% Mean & 2.773 & 2.288 & 4.767 & 3.372 \\
Lower 95\% Mean & 0.696 & -0.031 & 1.949 & 0.503 \\
Sample size & 31 & 20 & 31 & 20 \\
Variance & 8.021 & 6.133 & 14.764 & 9.390 \\
Skewness & -0.528 & -0.060 & 0.802 & 0.072 \\
Kurtosis & 1.877 & 0.334 & 2.348 & -0.664 \\
CV & 163.278 & 219.457 & 114.423 & 158.159 \\
\hline
\end{tabular}

Table C-24. Descriptive statistics, by treatment and sex, for averaged pretreatment $\mathrm{U} 1$ angle.

\begin{tabular}{lccrc}
\hline Statistic & $\begin{array}{c}\text { MARA } \\
\text { Boys }\end{array}$ & $\begin{array}{c}\text { MARA } \\
\text { Girls }\end{array}$ & $\begin{array}{c}\text { Edge } \\
\text { Boys }\end{array}$ & $\begin{array}{c}\text { Edge } \\
\text { Girls }\end{array}$ \\
\hline Mean & 60.632 & 59.350 & 58.597 & 60.325 \\
Standard Dev & 7.891 & 8.748 & 8.196 & 11.036 \\
Standard Err Mean & 1.417 & 1.956 & 1.472 & 2.468 \\
Upper 95\% Mean & 63.527 & 63.444 & 61.603 & 65.490 \\
Lower 95\% Mean & 57.738 & 55.256 & 55.590 & 55.160 \\
Sample size & 31 & 20 & 31 & 20 \\
Variance & 62.266 & 76.529 & 67.174 & 121.797 \\
Skewness & -0.346 & -0.010 & 0.402 & 2.376 \\
Kurtosis & 0.917 & 0.240 & 0.572 & 7.743 \\
CV & 13.014 & 14.740 & 13.987 & 18.294 \\
\hline
\end{tabular}


Table C-25. Descriptive statistics, by treatment and sex, for averaged posttreatment $\mathrm{U} 1$ angle.

\begin{tabular}{lrrrr}
\hline Statistic & $\begin{array}{c}\text { MARA } \\
\text { Boys }\end{array}$ & $\begin{array}{c}\text { MARA } \\
\text { Girls }\end{array}$ & $\begin{array}{c}\text { Edge } \\
\text { Boys }\end{array}$ & $\begin{array}{c}\text { Edge } \\
\text { Girls }\end{array}$ \\
\hline Mean & 57.932 & 58.265 & 61.413 & 69.890 \\
Standard Dev & 5.629 & 5.722 & 6.763 & 11.459 \\
Standard Err Mean & 1.011 & 1.279 & 1.215 & 2.562 \\
Upper 95\% Mean & 59.997 & 60.943 & 63.894 & 75.253 \\
Lower 95\% Mean & 55.867 & 55.587 & 58.932 & 64.527 \\
Sample size & 31 & 20 & 31 & 20 \\
Variance & 31.688 & 32.741 & 45.742 & 131.300 \\
Skewness & -0.723 & -0.250 & 0.055 & 2.712 \\
Kurtosis & 1.521 & 0.891 & 0.185 & 9.920 \\
CV & 9.717 & 9.821 & 11.013 & 16.395 \\
\hline
\end{tabular}

Table C-26. Descriptive statistics, by treatment and sex, for averaged change in U1 angle.

\begin{tabular}{lcccc}
\hline Statistic & $\begin{array}{c}\text { MARA } \\
\text { Boys }\end{array}$ & $\begin{array}{c}\text { MARA } \\
\text { Girls }\end{array}$ & $\begin{array}{c}\text { Edge } \\
\text { Boys }\end{array}$ & $\begin{array}{c}\text { Edge } \\
\text { Girls }\end{array}$ \\
\hline Mean & -2.700 & -1.090 & 2.816 & 9.565 \\
Standard Dev & 8.938 & 7.642 & 10.783 & 8.436 \\
Standard Err Mean & 1.605 & 1.709 & 1.937 & 1.886 \\
Upper 95\% Mean & 0.578 & 2.487 & 6.771 & 13.513 \\
Lower 95\% Mean & -5.978 & -4.667 & -1.139 & 5.617 \\
Sample size & 31 & 20 & 31 & 20 \\
Variance & 79.885 & 58.399 & 116.278 & 71.174 \\
Skewness & -0.396 & -0.023 & 0.206 & -0.374 \\
Kurtosis & 0.663 & 0.230 & -0.717 & -0.209 \\
CV & -331.032 & -701.093 & 382.910 & 88.201 \\
\hline
\end{tabular}


Table C-27. Descriptive statistics, by treatment and sex, for averaged U1 change in angulation.

\begin{tabular}{lcccc}
\hline Statistic & $\begin{array}{c}\text { MARA } \\
\text { Boys }\end{array}$ & $\begin{array}{c}\text { MARA } \\
\text { Girls }\end{array}$ & $\begin{array}{c}\text { Edge } \\
\text { Boys }\end{array}$ & $\begin{array}{l}\text { Edge } \\
\text { Girls }\end{array}$ \\
\hline Mean & 0.372 & 0.389 & 2.525 & 4.303 \\
Standard Dev & 2.592 & 2.367 & 3.260 & 3.071 \\
Standard Err Mean & 0.466 & 0.529 & 0.585 & 0.687 \\
Upper 95\% Mean & 1.323 & 1.496 & 3.721 & 5.740 \\
Lower 95\% Mean & -0.579 & -0.719 & 1.329 & 2.865 \\
Sample size & 31 & 20 & 31 & 20 \\
Variance & 6.717 & 5.603 & 10.626 & 9.429 \\
Skewness & 0.004 & -0.796 & -0.103 & -0.291 \\
Kurtosis & 1.062 & -0.773 & 0.496 & -1.373 \\
CV & 696.841 & 609.265 & 129.089 & 71.368 \\
\hline
\end{tabular}

Table C-28. Descriptive statistics, by treatment and sex, for averaged pretreatment overjet.

\begin{tabular}{lcccc}
\hline Statistic & $\begin{array}{c}\text { MARA } \\
\text { Boys }\end{array}$ & $\begin{array}{c}\text { MARA } \\
\text { Girls }\end{array}$ & $\begin{array}{c}\text { Edge } \\
\text { Boys }\end{array}$ & $\begin{array}{c}\text { Edge } \\
\text { Girls }\end{array}$ \\
\hline Mean & 4.904 & 4.911 & 6.570 & 6.054 \\
Standard Dev & 1.770 & 2.205 & 3.402 & 2.821 \\
Standard Err Mean & 0.318 & 0.493 & 0.611 & 0.631 \\
Upper 95\% Mean & 5.553 & 5.942 & 7.818 & 7.374 \\
Lower 95\% Mean & 4.255 & 3.879 & 5.322 & 4.734 \\
Sample size & 31 & 20 & 31 & 20 \\
Variance & 3.133 & 4.862 & 11.572 & 7.958 \\
Skewness & 0.878 & 1.078 & 0.388 & 0.532 \\
Kurtosis & 1.112 & 0.617 & -1.144 & 0.011 \\
CV & 36.089 & 44.902 & 51.777 & 46.598 \\
\hline
\end{tabular}


Table C-29. Descriptive statistics, by treatment and sex, for averaged posttreatment overjet.

\begin{tabular}{lcccc}
\hline Statistic & $\begin{array}{c}\text { MARA } \\
\text { Boys }\end{array}$ & $\begin{array}{c}\text { MARA } \\
\text { Girls }\end{array}$ & $\begin{array}{c}\text { Edge } \\
\text { Boys }\end{array}$ & $\begin{array}{l}\text { Edge } \\
\text { Girls }\end{array}$ \\
\hline Mean & 2.256 & 1.993 & 1.754 & 1.369 \\
Standard Dev & 0.669 & 0.663 & 1.052 & 0.756 \\
Standard Err Mean & 0.120 & 0.148 & 0.189 & 0.169 \\
Upper 95\% Mean & 2.501 & 2.303 & 2.140 & 1.722 \\
Lower 95\% Mean & 2.010 & 1.682 & 1.368 & 1.015 \\
Sample size & 31 & 20 & 31 & 20 \\
Variance & 0.448 & 0.439 & 1.107 & 0.572 \\
Skewness & 0.207 & 0.558 & 0.932 & 0.958 \\
Kurtosis & 1.166 & -0.236 & 1.770 & 0.049 \\
CV & 29.670 & 33.252 & 60.001 & 55.244 \\
\hline
\end{tabular}

Table C-30. Descriptive statistics, by treatment and sex, for averaged change in overjet.

\begin{tabular}{lcccc}
\hline Statistic & $\begin{array}{c}\text { MARA } \\
\text { Boys }\end{array}$ & $\begin{array}{c}\text { MARA } \\
\text { Girls }\end{array}$ & $\begin{array}{c}\text { Edge } \\
\text { Boys }\end{array}$ & $\begin{array}{c}\text { Edge } \\
\text { Girls }\end{array}$ \\
\hline Mean & 2.652 & 2.918 & 4.819 & 4.689 \\
Standard Dev & 1.654 & 1.946 & 3.100 & 3.079 \\
Standard Err Mean & 0.297 & 0.435 & 0.557 & 0.688 \\
Upper 95\% Mean & 3.259 & 3.829 & 5.956 & 6.129 \\
Lower 95\% Mean & 2.046 & 2.007 & 3.682 & 3.248 \\
Sample size & 31 & 20 & 31 & 20 \\
Variance & 2.736 & 3.786 & 9.610 & 9.478 \\
Skewness & 0.640 & 1.270 & 0.524 & 0.620 \\
Kurtosis & 0.707 & 1.082 & -0.923 & 0.207 \\
CV & 62.368 & 66.682 & 64.323 & 65.662 \\
\hline
\end{tabular}


APPENDIX D. ANOVA RESULTS FOR DIFFERENCES BETWEEN TREATMENTS, CONTROLLING FOR SEX AND INITIAL AGE 
Table D-1. Results of three-way factorial ANOVA for averaged U6 angle at pretreatment.

\begin{tabular}{lcrrc}
\hline Source & df & SSQ & F Ratio & P Value \\
\hline Group & 1 & 26.62 & 1.93 & 0.1676 \\
Sex & 1 & 38.19 & 2.78 & 0.0990 \\
ChronologicalAge & 1 & 37.70 & 2.74 & 0.1012 \\
Group-x-Sex & 1 & 0.19 & 0.01 & 0.9065 \\
Group-x-ChronologicalAge & 1 & 0.88 & 0.06 & 0.8009 \\
ChronologicalAge-x-Sex & 1 & 5.18 & 0.38 & 0.5411 \\
Group-x-Sex-x-ChronologicalAge & 1 & 31.03 & 2.26 & 0.1365 \\
\hline
\end{tabular}

Table D-2. Results of three-way factorial ANOVA for averaged U6 angle at posttreatment.

\begin{tabular}{lcrcc}
\hline Source & df & SSQ & F Ratio & P Value \\
\hline Group & 1 & 5.11 & 0.44 & 0.5109 \\
Sex & 1 & 1.45 & 0.12 & 0.7257 \\
ChronologicalAge & 1 & 14.38 & 1.23 & 0.2709 \\
Group-x-Sex & 1 & 38.96 & 3.32 & 0.0715 \\
Group-x-ChronologicalAge & 1 & 32.52 & 2.77 & 0.0992 \\
ChronologicalAge-x-Sex & 1 & 0.01 & 0.00 & 0.9825 \\
Group-x-Sex-x-ChronologicalAge & 1 & 6.67 & 0.57 & 0.4526 \\
\hline
\end{tabular}

Table D-3. Results of three-way factorial ANOVA for averaged change in U6 angle.

\begin{tabular}{lcrcc}
\hline Source & df & SSQ & F Ratio & P Value \\
\hline Group & 1 & 8.47 & 0.38 & 0.5386 \\
Sex & 1 & 54.57 & 2.45 & 0.1206 \\
ChronologicalAge & 1 & 5.43 & 0.24 & 0.6223 \\
Group-x-Sex & 1 & 44.46 & 2.00 & 0.1608 \\
Group-x-ChronologicalAge & 1 & 44.20 & 1.99 & 0.1619 \\
ChronologicalAge-x-Sex & 1 & 4.86 & 0.22 & 0.6413 \\
Group-x-Sex-x-ChronologicalAge & 1 & 66.72 & 3.00 & 0.0866 \\
\hline
\end{tabular}


Table D-4. Results of three-way factorial ANOVA for averaged linear conversion of $\mathrm{U} 6$ angle.

\begin{tabular}{lcrcc}
\hline Source & df & SSQ & F Ratio & P Value \\
\hline Group & 1 & 5.06 & 0.04 & 0.8450 \\
Sex & 1 & 4.55 & 0.03 & 0.8528 \\
ChronologicalAge & 1 & 108.35 & 0.82 & 0.3664 \\
Group-x-Sex & 1 & 1.63 & 0.01 & 0.9115 \\
Group-x-ChronologicalAge & 1 & 4.00 & 0.03 & 0.8619 \\
ChronologicalAge-x-Sex & 1 & 0.18 & 0.00 & 0.9707 \\
Group-x-Sex-x-ChronologicalAge & 1 & 11.88 & 0.09 & 0.7645 \\
\hline
\end{tabular}

Table D-5. Results of three-way factorial ANOVA for averaged U6 M-D movement/MFOP.

\begin{tabular}{lcrrc}
\hline Source & df & SSQ & F Ratio & P Value \\
\hline Group & 1 & 48.25 & 6.11 & 0.0152 \\
Sex & 1 & 0.09 & 0.01 & 0.9151 \\
ChronologicalAge & 1 & 6.41 & 0.81 & 0.3698 \\
Group-x-Sex & 1 & 8.81 & 1.12 & 0.2936 \\
Group-x-ChronologicalAge & 1 & 2.86 & 0.36 & 0.5489 \\
ChronologicalAge-x-Sex & 1 & 0.32 & 0.04 & 0.8401 \\
Group-x-Sex-x-ChronologicalAge & 1 & 0.50 & 0.06 & 0.8012 \\
\hline
\end{tabular}

Table D-6. Results of three-way factorial ANOVA for averaged L6 angle at pretreatment.

\begin{tabular}{lcrcc}
\hline Source & df & SSQ & F Ratio & P Value \\
\hline Group & 1 & 15.16 & 0.92 & 0.3388 \\
Sex & 1 & 0.00 & 0.00 & 0.9982 \\
ChronologicalAge & 1 & 1.26 & 0.08 & 0.7823 \\
Group-x-Sex & 1 & 44.50 & 2.71 & 0.1028 \\
Group-x-ChronologicalAge & 1 & 7.21 & 0.44 & 0.5090 \\
ChronologicalAge-x-Sex & 1 & 5.68 & 0.35 & 0.5574 \\
Group-x-Sex-x-ChronologicalAge & 1 & 32.06 & 1.96 & 0.1653 \\
\hline
\end{tabular}


Table D-7. Results of three-way factorial ANOVA for averaged L6 angle at posttreatment.

\begin{tabular}{lcrcc}
\hline Source & df & SSQ & F Ratio & P Value \\
\hline Group & 1 & 1.15 & 0.07 & 0.7978 \\
Sex & 1 & 83.09 & 4.78 & 0.0314 \\
ChronologicalAge & 1 & 15.89 & 0.91 & 0.3418 \\
Group-x-Sex & 1 & 12.50 & 0.72 & 0.3988 \\
Group-x-ChronologicalAge & 1 & 8.83 & 0.51 & 0.4780 \\
ChronologicalAge-x-Sex & 1 & 0.56 & 0.03 & 0.8586 \\
Group-x-Sex-x-ChronologicalAge & 1 & 1.70 & 0.10 & 0.7553 \\
\hline
\end{tabular}

Table D-8. Results of three-way factorial ANOVA for averaged change in L6 angle.

\begin{tabular}{lcccc}
\hline Source & df & SSQ & F Ratio & P Value \\
\hline Group & 1 & 28.05 & 1.29 & 0.2588 \\
Sex & 1 & 81.54 & 3.75 & 0.0557 \\
ChronologicalAge & 1 & 35.02 & 1.61 & 0.2074 \\
Group-x-Sex & 1 & 9.52 & 0.44 & 0.5097 \\
Group-x-ChronologicalAge & 1 & 0.00 & 0.00 & 0.9924 \\
ChronologicalAge-x-Sex & 1 & 2.93 & 0.13 & 0.7144 \\
Group-x-Sex-x-ChronologicalAge & 1 & 22.75 & 1.05 & 0.3088 \\
\hline
\end{tabular}

Table D-9. Results of three-way factorial ANOVA for averaged linear conversion of L6 tip.

\begin{tabular}{lcccc}
\hline Source & df & SSQ & F Ratio & P Value \\
\hline Group & 1 & 34.99 & 0.66 & 0.4173 \\
Sex & 1 & 96.76 & 1.84 & 0.1787 \\
ChronologicalAge & 1 & 45.83 & 0.87 & 0.3535 \\
Group-x-Sex & 1 & 57.08 & 1.08 & 0.3008 \\
Group-x-ChronologicalAge & 1 & 23.43 & 0.44 & 0.5066 \\
ChronologicalAge-x-Sex & 1 & 82.85 & 1.57 & 0.2131 \\
Group-x-Sex-x-ChronologicalAge & 1 & 128.12 & 2.43 & 0.1224 \\
\hline
\end{tabular}


Table D-10. Results of three-way factorial ANOVA for averaged linear change in D-D'.

\begin{tabular}{lcrrr}
\hline Source & df & SSQ & F Ratio & P Value \\
\hline Group & 1 & 0.98 & 0.17 & 0.6832 \\
Sex & 1 & 118.49 & 20.19 & $<0.0001$ \\
ChronologicalAge & 1 & 70.97 & 12.09 & 0.0008 \\
Group-x-Sex & 1 & 0.43 & 0.07 & 0.7869 \\
Group-x-ChronologicalAge & 1 & 4.46 & 0.76 & 0.3856 \\
ChronologicalAge-x-Sex & 1 & 0.07 & 0.01 & 0.9113 \\
Group-x-Sex-x-ChronologicalAge & 1 & 0.73 & 0.12 & 0.7252 \\
\hline
\end{tabular}

Table D-11. Results of three-way factorial ANOVA for averaged horizontal change in D-D'/MFOP.

\begin{tabular}{lcrcc}
\hline Source & df & SSQ & F Ratio & P Value \\
\hline Group & 1 & 4.94 & 0.67 & 0.4150 \\
Sex & 1 & 58.11 & 7.88 & 0.0061 \\
ChronologicalAge & 1 & 5.74 & 0.78 & 0.3798 \\
Group-x-Sex & 1 & 2.85 & 0.39 & 0.5358 \\
Group-x-ChronologicalAge & 1 & 2.76 & 0.37 & 0.5426 \\
ChronologicalAge-x-Sex & 1 & 9.74 & 1.32 & 0.2535 \\
Group-x-Sex-x-ChronologicalAge & 1 & 0.01 & 0.00 & 0.9706 \\
\hline
\end{tabular}

Table D-12. Results of three-way factorial ANOVA for averaged vertical change in D-D'/MFOP.

\begin{tabular}{lcrrc}
\hline Source & df & SSQ & F Ratio & P Value \\
\hline Group & 1 & 0.45 & 0.08 & 0.7772 \\
Sex & 1 & 74.22 & 13.24 & 0.0004 \\
ChronologicalAge & 1 & 72.30 & 12.90 & 0.0005 \\
Group-x-Sex & 1 & 9.08 & 1.62 & 0.2061 \\
Group-x-ChronologicalAge & 1 & 1.69 & 0.30 & 0.5838 \\
ChronologicalAge-x-Sex & 1 & 9.61 & 1.71 & 0.1936 \\
Group-x-Sex-x-ChronologicalAge & 1 & 1.65 & 0.29 & 0.5891 \\
\hline
\end{tabular}


Table D-13. Results of three-way factorial ANOVA for averaged L6-D distance at pretreatment.

\begin{tabular}{lcrrc}
\hline Source & df & SSQ & F Ratio & P Value \\
\hline Group & 1 & 38.67 & 5.24 & 0.0243 \\
Sex & 1 & 27.02 & 3.66 & 0.0588 \\
ChronologicalAge & 1 & 22.08 & 2.99 & 0.0870 \\
Group-x-Sex & 1 & 8.53 & 1.16 & 0.2851 \\
Group-x-ChronologicalAge & 1 & 11.60 & 1.57 & 0.2131 \\
ChronologicalAge-x-Sex & 1 & 0.16 & 0.02 & 0.8827 \\
Group-x-Sex-x-ChronologicalAge & 1 & 16.24 & 2.20 & 0.1413 \\
\hline
\end{tabular}

Table D-14. Results of three-way factorial ANOVA for averaged L6-D distance at posttreatment.

\begin{tabular}{lcrcc}
\hline Source & df & SSQ & F Ratio & P Value \\
\hline Group & 1 & 0.10 & 0.01 & 0.9334 \\
Sex & 1 & 72.71 & 4.93 & 0.0289 \\
ChronologicalAge & 1 & 11.74 & 0.80 & 0.3747 \\
Group-x-Sex & 1 & 20.29 & 1.37 & 0.2441 \\
Group-x-ChronologicalAge & 1 & 35.57 & 2.41 & 0.1240 \\
ChronologicalAge-x-Sex & 1 & 1.52 & 0.10 & 0.7491 \\
Group-x-Sex-x-ChronologicalAge & 1 & 16.53 & 1.12 & 0.2927 \\
\hline
\end{tabular}

Table D-15. Results of three-way factorial ANOVA for averaged L6 M-D movement/D.

\begin{tabular}{lcccc}
\hline Source & df & SSQ & F Ratio & P Value \\
\hline Group & 1 & 34.77 & 4.87 & 0.0297 \\
Sex & 1 & 11.07 & 1.55 & 0.2161 \\
ChronologicalAge & 1 & 1.64 & 0.23 & 0.6333 \\
Group-x-Sex & 1 & 2.50 & 0.35 & 0.5551 \\
Group-x-ChronologicalAge & 1 & 6.61 & 0.93 & 0.3384 \\
ChronologicalAge-x-Sex & 1 & 0.68 & 0.10 & 0.7574 \\
Group-x-Sex-x-ChronologicalAge & 1 & 0.00 & 0.00 & 0.9905 \\
\hline
\end{tabular}


Table D-16. Results of three-way factorial ANOVA for averaged change in SE point.

\begin{tabular}{lcrrc}
\hline Source & df & SSQ & F Ratio & P Value \\
\hline Group & 1 & 22.23 & 3.89 & 0.0516 \\
Sex & 1 & 5.12 & 0.90 & 0.3465 \\
ChronologicalAge & 1 & 0.20 & 0.03 & 0.8529 \\
Group-x-Sex & 1 & 0.50 & 0.09 & 0.7682 \\
Group-x-ChronologicalAge & 1 & 4.59 & 0.80 & 0.3727 \\
ChronologicalAge-x-Sex & 1 & 0.15 & 0.03 & 0.8734 \\
Group-x-Sex-x-ChronologicalAge & 1 & 4.78 & 0.84 & 0.3630 \\
\hline
\end{tabular}

Table D-17. Results of three-way factorial ANOVA for averaged pretreatment U6-L6 distance.

\begin{tabular}{lcccc}
\hline Source & $\mathrm{df}$ & SSQ & F Ratio & P Value \\
\hline Group & 1 & 3.18 & 1.61 & 0.2077 \\
Sex & 1 & 0.12 & 0.06 & 0.8036 \\
ChronologicalAge & 1 & 0.34 & 0.17 & 0.6801 \\
Group-x-Sex & 1 & 1.69 & 0.85 & 0.3575 \\
Group-x-ChronologicalAge & 1 & 0.03 & 0.01 & 0.9036 \\
ChronologicalAge-x-Sex & 1 & 0.06 & 0.03 & 0.8568 \\
Group-x-Sex-x-ChronologicalAge & 1 & 5.59 & 2.83 & 0.0960 \\
\hline
\end{tabular}

Table D-18. Results of three-way factorial ANOVA for averaged posttreatment U6-L6 distance.

\begin{tabular}{lcccc}
\hline Source & df & SSQ & F Ratio & P Value \\
\hline Group & 1 & 1.26 & 0.50 & 0.4803 \\
Sex & 1 & 0.95 & 0.38 & 0.5383 \\
ChronologicalAge & 1 & 0.87 & 0.35 & 0.5560 \\
Group-x-Sex & 1 & 0.12 & 0.05 & 0.8242 \\
Group-x-ChronologicalAge & 1 & 0.19 & 0.08 & 0.7843 \\
ChronologicalAge-x-Sex & 1 & 0.19 & 0.07 & 0.7858 \\
Group-x-Sex-x-ChronologicalAge & 1 & 1.66 & 0.66 & 0.4178 \\
\hline
\end{tabular}


Table D-19. Results of three-way factorial ANOVA for averaged total molar correction

\begin{tabular}{lcrcc}
\hline Source & df & SSQ & F Ratio & P Value \\
\hline Group & 1 & 10.02 & 0.53 & 0.4677 \\
Sex & 1 & 140.35 & 7.45 & 0.0076 \\
ChronologicalAge & 1 & 16.86 & 0.89 & 0.3466 \\
Group-x-Sex & 1 & 19.42 & 1.03 & 0.3127 \\
Group-x-ChronologicalAge & 1 & 3.50 & 0.19 & 0.6674 \\
ChronologicalAge-x-Sex & 1 & 20.67 & 1.10 & 0.2977 \\
Group-x-Sex-x-ChronologicalAge & 1 & 2.24 & 0.12 & 0.7310 \\
\hline
\end{tabular}

Table D-20. Results of three-way factorial ANOVA for averaged ABCH.

\begin{tabular}{lcrcc}
\hline Source & df & SSQ & F Ratio & P Value \\
\hline Group & 1 & 4.94 & 0.67 & 0.4150 \\
Sex & 1 & 58.11 & 7.88 & 0.0061 \\
ChronologicalAge & 1 & 5.74 & 0.78 & 0.3798 \\
Group-x-Sex & 1 & 2.85 & 0.39 & 0.5358 \\
Group-x-ChronologicalAge & 1 & 2.76 & 0.37 & 0.5426 \\
ChronologicalAge-x-Sex & 1 & 9.74 & 1.32 & 0.2535 \\
Group-x-Sex-x-ChronologicalAge & 1 & 0.01 & 0.00 & 0.9706 \\
\hline
\end{tabular}

Table D-21. Results of three-way factorial ANOVA for averaged maxillary translative growth.

\begin{tabular}{lcrrc}
\hline Source & df & SSQ & F Ratio & P Value \\
\hline Group & 1 & 22.23 & 3.89 & 0.0516 \\
Sex & 1 & 5.12 & 0.90 & 0.3465 \\
ChronologicalAge & 1 & 0.20 & 0.03 & 0.8529 \\
Group-x-Sex & 1 & 0.50 & 0.09 & 0.7682 \\
Group-x-ChronologicalAge & 1 & 4.59 & 0.80 & 0.3727 \\
ChronologicalAge-x-Sex & 1 & 0.15 & 0.03 & 0.8734 \\
Group-x-Sex-x-ChronologicalAge & 1 & 4.78 & 0.84 & 0.3630 \\
\hline
\end{tabular}


Table D-22. Results of three-way factorial ANOVA for averaged mandibular translative growth.

\begin{tabular}{lcccc}
\hline Source & df & SSQ & F Ratio & P Value \\
\hline Group & 1 & 48.09 & 4.76 & 0.0317 \\
Sex & 1 & 28.73 & 2.84 & 0.0952 \\
ChronologicalAge & 1 & 3.81 & 0.38 & 0.5409 \\
Group-x-Sex & 1 & 5.77 & 0.57 & 0.4521 \\
Group-x-ChronologicalAge & 1 & 0.23 & 0.02 & 0.8812 \\
ChronologicalAge-x-Sex & 1 & 7.51 & 0.74 & 0.3911 \\
Group-x-Sex-x-ChronologicalAge & 1 & 4.33 & 0.43 & 0.5143 \\
\hline
\end{tabular}

Table D-23. Results of three-way factorial ANOVA for averaged U1 angle at pretreatment.

\begin{tabular}{lcrcc}
\hline Source & df & SSQ & F Ratio & P Value \\
\hline Group & 1 & 25.58 & 0.34 & 0.5609 \\
Sex & 1 & 18.31 & 0.24 & 0.6226 \\
ChronologicalAge & 1 & 1.73 & 0.02 & 0.8798 \\
Group-x-Sex & 1 & 67.95 & 0.90 & 0.3439 \\
Group-x-ChronologicalAge & 1 & 97.95 & 1.30 & 0.2563 \\
ChronologicalAge-x-Sex & 1 & 124.44 & 1.66 & 0.2011 \\
Group-x-Sex-x-ChronologicalAge & 1 & 209.87 & 2.79 & 0.0979 \\
\hline
\end{tabular}

Table D-24. Results of three-way factorial ANOVA for averaged U1 angle at posttreatment.

\begin{tabular}{lcrrr}
\hline Source & df & SSQ & F Ratio & P Value \\
\hline Group & 1 & 990.51 & 19.35 & $<0.0001$ \\
Sex & 1 & 512.34 & 10.01 & 0.0021 \\
ChronologicalAge & 1 & 5.05 & 0.10 & 0.7542 \\
Group-x-Sex & 1 & 492.96 & 9.63 & 0.0025 \\
Group-x-ChronologicalAge & 1 & 43.81 & 0.86 & 0.3573 \\
ChronologicalAge-x-Sex & 1 & 286.07 & 5.59 & 0.0201 \\
Group-x-Sex-x-ChronologicalAge & 1 & 86.30 & 1.69 & 0.1973 \\
\hline
\end{tabular}


Table D-25. Results of three-way factorial ANOVA for averaged change U1 angle.

\begin{tabular}{lcrrc}
\hline Source & df & SSQ & F Ratio & P Value \\
\hline Group & 1 & 1335.75 & 15.21 & 0.0002 \\
Sex & 1 & 335.94 & 3.82 & 0.0535 \\
ChronologicalAge & 1 & 12.61 & 0.14 & 0.7057 \\
Group-x-Sex & 1 & 195.63 & 2.23 & 0.1390 \\
Group-x-ChronologicalAge & 1 & 10.81 & 0.12 & 0.7265 \\
ChronologicalAge-x-Sex & 1 & 33.72 & 0.38 & 0.5371 \\
Group-x-Sex-x-ChronologicalAge & 1 & 27.51 & 0.31 & 0.5771 \\
\hline
\end{tabular}

Table D-26. Results of three-way factorial ANOVA for averaged U1 movement.

\begin{tabular}{lcrrr}
\hline Source & df & SSQ & F Ratio & P Value \\
\hline Group & 1 & 154.80 & 20.21 & $<0.0001$ \\
Sex & 1 & 18.52 & 2.42 & 0.1233 \\
ChronologicalAge & 1 & 50.40 & 6.58 & 0.0119 \\
Group-x-Sex & 1 & 18.29 & 2.39 & 0.1256 \\
Group-x-ChronologicalAge & 1 & 5.16 & 0.67 & 0.4137 \\
ChronologicalAge-x-Sex & 1 & 0.00 & 0.00 & 0.9954 \\
Group-x-Sex-x-ChronologicalAge & 1 & 4.91 & 0.64 & 0.4252 \\
\hline
\end{tabular}

Table D-27. Results of three-way factorial ANOVA for averaged overjet at pretreatment.

\begin{tabular}{lcccc}
\hline Source & df & SSQ & F Ratio & P Value \\
\hline Group & 1 & 57.08 & 8.06 & 0.0056 \\
Sex & 1 & 3.99 & 0.56 & 0.4551 \\
ChronologicalAge & 1 & 0.55 & 0.08 & 0.7816 \\
Group-x-Sex & 1 & 1.64 & 0.23 & 0.6320 \\
Group-x-ChronologicalAge & 1 & 2.14 & 0.30 & 0.5835 \\
ChronologicalAge-x-Sex & 1 & 2.03 & 0.29 & 0.5940 \\
Group-x-Sex-x-ChronologicalAge & 1 & 9.12 & 1.29 & 0.2594 \\
\hline
\end{tabular}


Table D-28. Results of three-way factorial ANOVA for averaged overjet at postttreatment.

\begin{tabular}{lcccc}
\hline Source & df & SSQ & F Ratio & P Value \\
\hline Group & 1 & 6.40 & 9.28 & 0.0030 \\
Sex & 1 & 2.75 & 3.99 & 0.0487 \\
ChronologicalAge & 1 & 0.30 & 0.43 & 0.5134 \\
Group-x-Sex & 1 & 0.04 & 0.05 & 0.8158 \\
Group-x-ChronologicalAge & 1 & 0.99 & 1.43 & 0.2345 \\
ChronologicalAge-x-Sex & 1 & 0.02 & 0.02 & 0.8813 \\
Group-x-Sex-x-ChronologicalAge & 1 & 0.06 & 0.08 & 0.7744 \\
\hline
\end{tabular}

Table D-29. Results of three-way factorial ANOVA for averaged change in overjet.

\begin{tabular}{lcrrc}
\hline Source & df & SSQ & F Ratio & P Value \\
\hline Group & 1 & 101.77 & 15.75 & 0.0001 \\
Sex & 1 & 0.12 & 0.02 & 0.8913 \\
ChronologicalAge & 1 & 0.04 & 0.01 & 0.9388 \\
Group-x-Sex & 1 & 1.16 & 0.18 & 0.6731 \\
Group-x-ChronologicalAge & 1 & 0.22 & 0.03 & 0.8554 \\
ChronologicalAge-x-Sex & 1 & 1.68 & 0.26 & 0.6116 \\
Group-x-Sex-x-ChronologicalAge & 1 & 7.74 & 1.20 & 0.2765 \\
\hline
\end{tabular}




\section{VITA}

Born in Ogden, Utah in 1980, Zachary is the fourth of five children. After attending Weber State University for one year, Zachary took a leave from his education to serve for two years as a missionary in the Amazon River Basin area of Northern Brazil. Upon returning to the United States, he continued his education, receiving his B.S. in Neuroscience from Brigham Young University in 2005. Upon graduation, he continued his academic pursuits at the University of Pittsburgh where he was awarded a Doctor of Dental Medicine degree in May 2009. Postgraduate studies then lead him to the University of Tennessee in Memphis where he received his Master of Dental Science degree in May 2012. 